\title{
Revision of the New World Species of Oedichirus (Coleoptera: Staphylinidae: Paederinae: Pinophilini: PROCIRRINA)
}

\author{
Author(s): Lee H. Herman \\ 2013. \\ Published By: American Museum of Natural History \\ DOI: http://dx.doi.org/10.1206/816.1 \\ URL: http://www.bioone.org/doi/full/10.1206/816.1
}

Source: Bulletin of the American Museum of Natural History, 375(1):1-137.

BioOne (www.bioone.org) is a nonprofit, online aggregation of core research in the biological, ecological, and environmental sciences. BioOne provides a sustainable online platform for over 170 journals and books published by nonprofit societies, associations, museums, institutions, and presses.

Your use of this PDF, the BioOne Web site, and all posted and associated content indicates your acceptance of BioOne's Terms of Use, available at www.bioone.org/page/ terms of use.

Usage of BioOne content is strictly limited to personal, educational, and non-commercial use. Commercial inquiries or rights and permissions requests should be directed to the individual publisher as copyright holder. 


\title{
REVISION OF THE NEW WORLD SPECIES OF OEDICHIRUS (COLEOPTERA: STAPHYLINIDAE: PAEDERINAE: PINOPHILINI: PROCIRRINA)
}

\author{
LEE H. HERMAN \\ Division of Invertebrate Zoology \\ American Museum of Natural History
}

BULLETIN OF THE AMERICAN MUSEUM OF NATURAL HISTORY

Number 375, 137 pp., 224 figures

Issued March 15, 2013 


\section{CONTENTS}

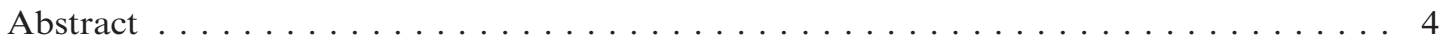

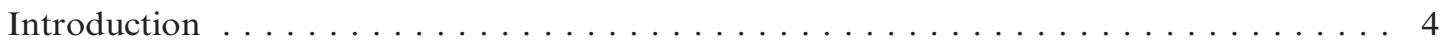

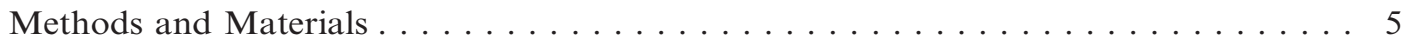

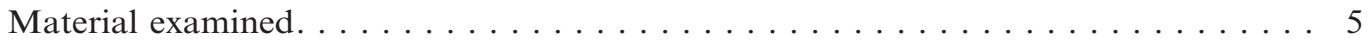

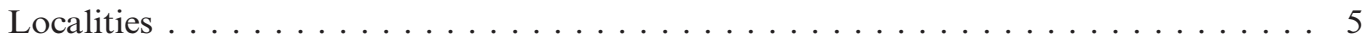

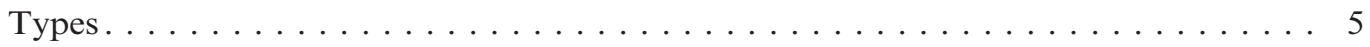

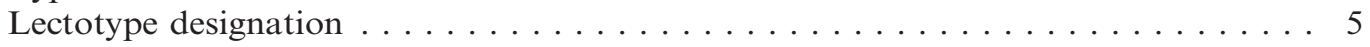

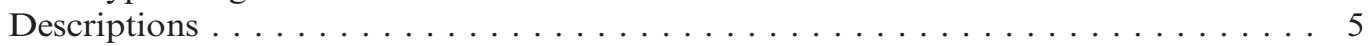

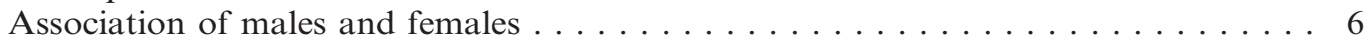

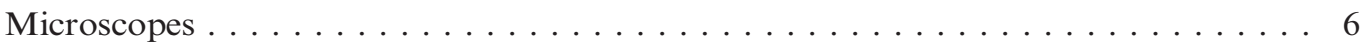

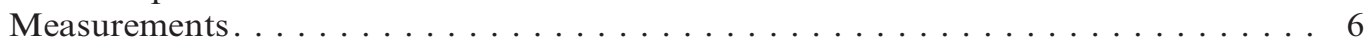

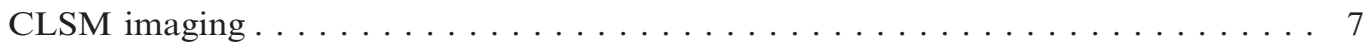

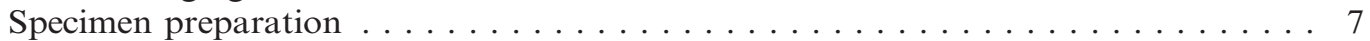

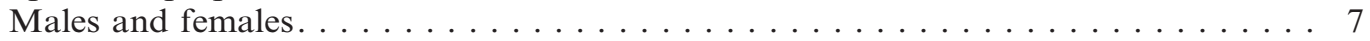

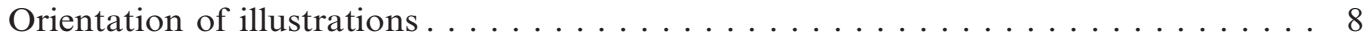

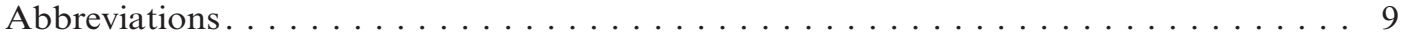

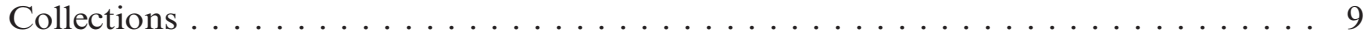

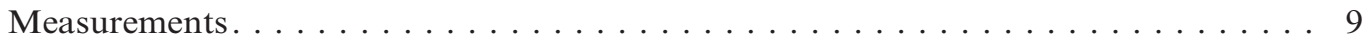

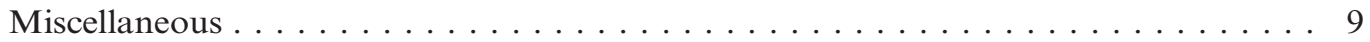

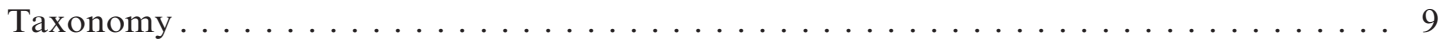

Key to the New World genera of the Procirrina . . . . . . . . . . . . . 9

Diagnostic features of and notes on New World genera of the Procirrina . . . . . . . 9

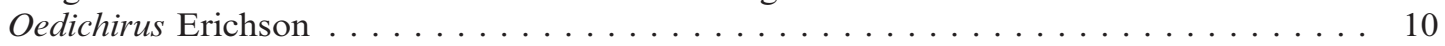

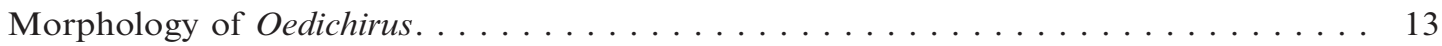

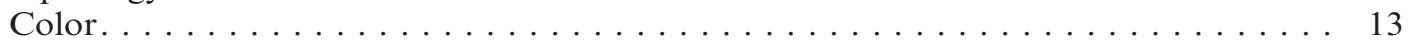

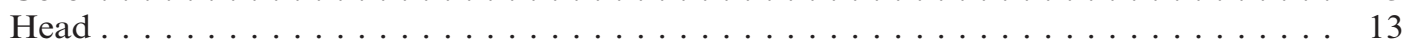

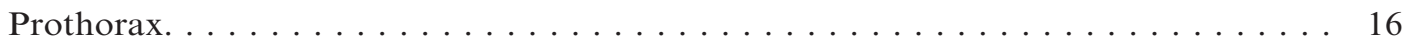

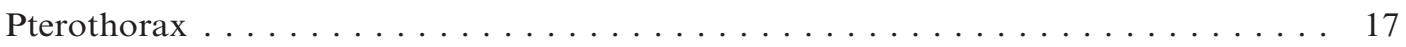

Hypotheses of origin of lateral and ventral sclerites $\ldots \ldots \ldots \ldots \ldots \ldots$

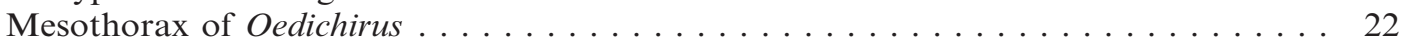

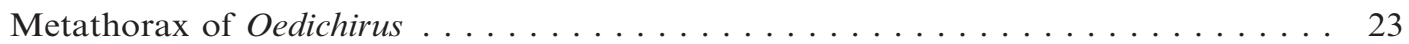

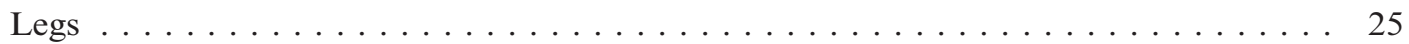

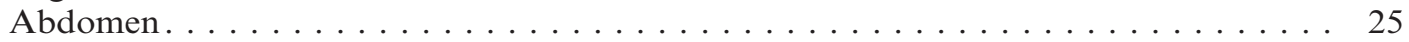

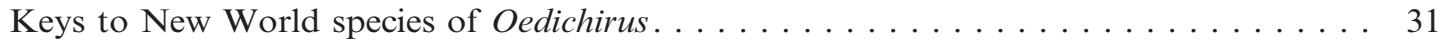

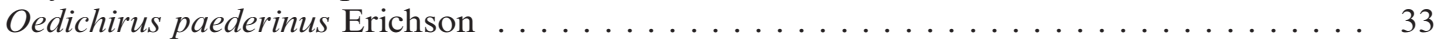

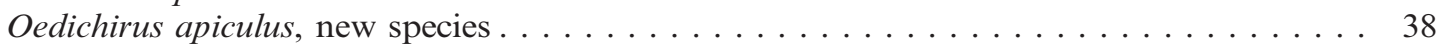

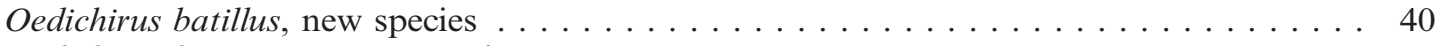

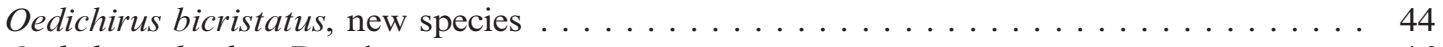

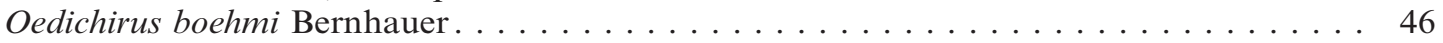

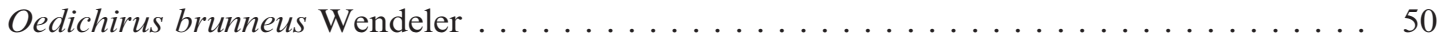

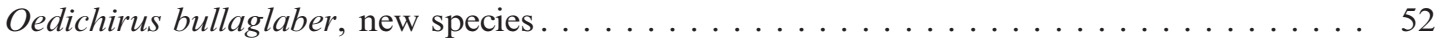

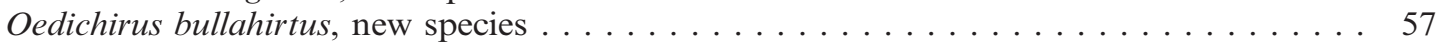

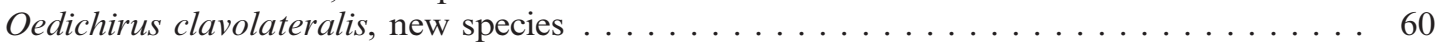

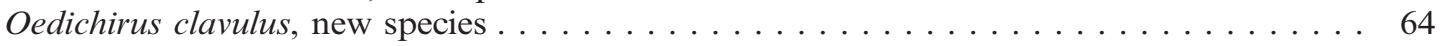

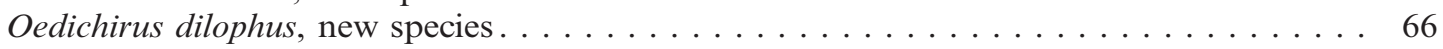

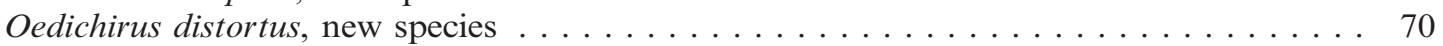

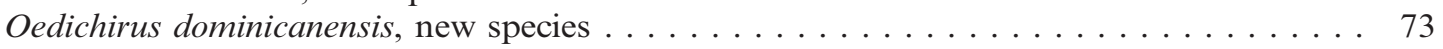

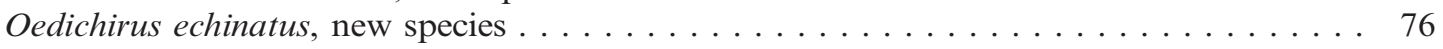

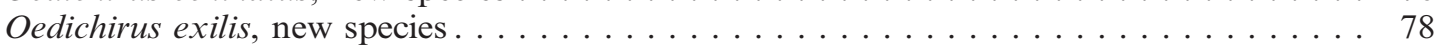

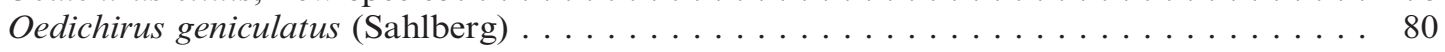

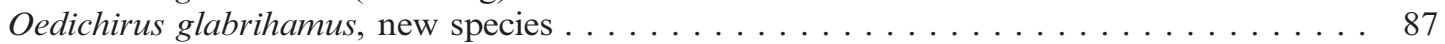




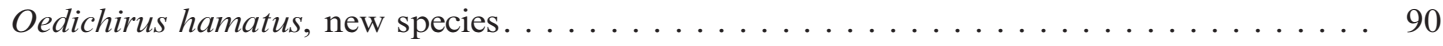

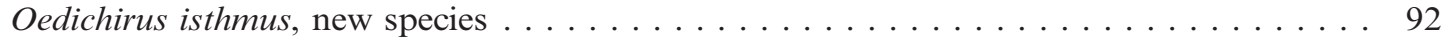

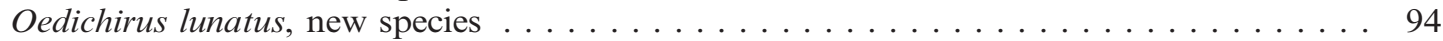

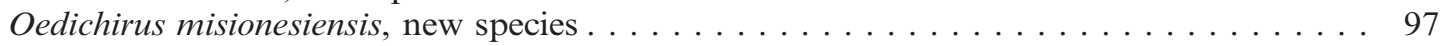

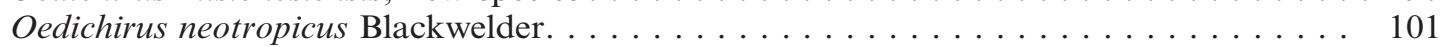

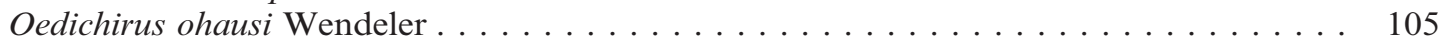

Oedichirus optatus Sharp . . . . . . . . . . . . . . . . . . . . . . . . 107

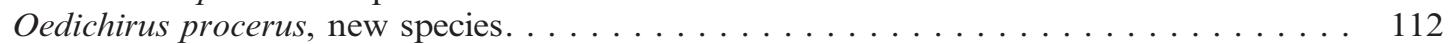

Oedichirus sinuosus, new species . . . . . . . . . . . . . . . . . . . . . . . . . 114

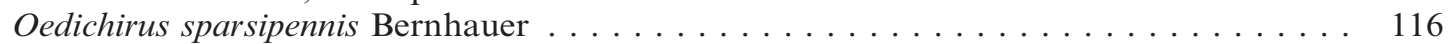

Oedichirus speculifrons Bernhauer. . . . . . . . . . . . . . . . . . . . . . . . 119

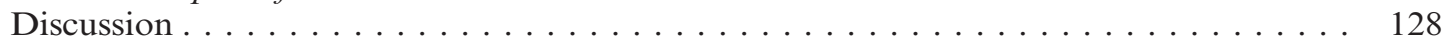

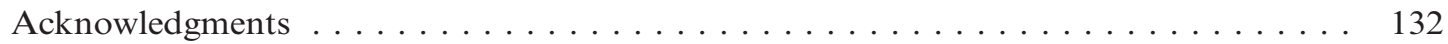

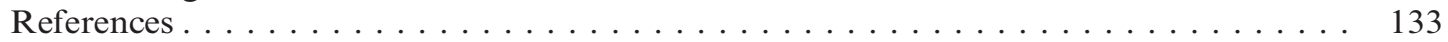

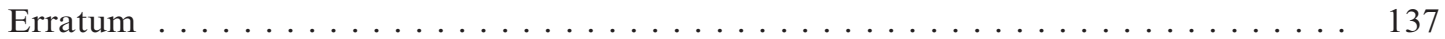




\begin{abstract}
The New World species of Oedichirus Erichson, 1839, are revised, redescribed, or newly described, illustrated, and included in keys for identification. The morphology of the ventral pterothoracic sclerites is examined and Matsuda's (1970) interpretation is largely adopted over that of Ferris (1940b). Newly discovered characters of the median gonocoxal plate and associated vulvar plate, including its microstructures, are discussed. Prior to the present paper New World species were known in Brazil and Costa Rica, but are herein newly reported for the Dominican Republic, Mexico, Ecuador, Peru, Bolivia, and Argentina; a specimen intercepted at a port in the United States was said to have come from Nicaragua. Eight species were previously described; 19 new ones are added herein, 12 from Brazil (O. apiculus, O. batillus, O. bicristatus, O. bullaglaber, $O$. bullahirtus, $O$. clavolateralis, $O$. clavulus, $O$. echinatus, O. exilis, $O$. glabrihamus, $O$. lunatus, and $O$. procerus), two from Mexico $(O$. isthmus and $O$. sinuosus), and one each from Argentina (O. misionesiensis), Bolivia (O. dilophus), Ecuador $(O$. distortus), Peru (O. hamatus), and Dominican Republic $(O$. dominicanensis). A neotype is designated for $O$. geniculatus and lectotypes are designated for O. brunneus Wendeler, O. pictipes Bierig, O. ohausi Wendeler, O. optatus Sharp, O. sparsipennis Bernhauer, and O. speculifrons Bernhauer. Some species are included in species groups.
\end{abstract}

\section{INTRODUCTION}

My interest in the New World species of Oedichirus was piqued while examining the generic classification of the Procirrina and I noted that, although the genus included 303 species worldwide, only eight were known for the New World. That observation seemed counterintuitive for a largely tropical genus and for which even arid Australia, with only 11 species, at that time had more than the New World. Prior to the present study, about $84 \%$ of the species are found throughout Africa and Madagascar. The four European species also occur in North Africa. About 40, or $13 \%$ of known species, are scattered across Asia to Japan and Australia and have been reported from Turkey, Cyprus, Lebanon, Israel, Jordan, Iraq, Tajikistan, Afghanistan, India, Myanmar, Malaysia, Singapore, Vietnam, Indonesia, Philippines, Papua New Guinea, Australia, New Caledonia, China, Korea, and Japan. Except for the Levant countries and one Afghan record, the genus is unknown in southwestern and central Asia. However, only $2.6 \%$ of the named species are found in the New World before the present work and all but one of those is from Brazil.

Oedichirus was founded by Erichson (1839: 29) for one subsequently included species, Oedichirus paederinus Erichson (1840: 685), from Sicily. The oldest species in the genus is Paederus senegalensis Laporte, 1835. It was transferred to Oedichirus in 1867 (Wollaston, 1867: 249), but is deemed a nomen dubium because Fagel (1958: 454) could neither identify the species nor find its type (Fagel, 1971: 388). By 1899 only 31 species had been named; four of those are now junior synonyms and one is a nomen dubium. Even by the end of the 1940s only 72 species had been described and that included all of the known New World species. Since 1955 the number of species has more than quadrupled with most of the species resulting from the work of three authors. This explosion began with Fagel's $(1955,1958,1961,1971)$ publications on the African species. By 1971 he had added 128 names including 9 subspecies; 94 more were described from Madagascar, 63 by Lecoq (1986, 1987, 1990, 1991, 1996) and 31 by Janák (1995, 1996, 1998, 2003).

At about the time the genus was established the first New World species was collected (in 1839 or 1840) and later described by R.F. Sahlberg (1847: 801). He placed it in his new genus, Elytrobaeus, which was synonymized with Oedichirus independently by Fauvel (1875a: xvii [= 1875b: 219]) and Sharp (1876: 338). Sharp briefly discussed his reasons for the synonymy, Fauvel did not. The second New World species was collected by H.W. Bates (Sharp, 1876: 338) in 1852 and described in 1876 (Sharp, 1876: 339). Between 1876 and 1940 five other species were added by Bernhauer (1927, 1939) and Wendeler (1930); Bierig (1940: 604) added the eighth. Until the present work the eight New World species of Oedichirus 
were known only from Brazil, with seven species, and Costa Rica, with the eighth.

For the present work only about 260 specimens were available for study and nearly two thirds represented two species. The scarcity of new material made this work unsatisfying and incomplete. However, despite the limited number of specimens, this work serves as an introduction to Oedichirus in the New World and may stimulate further collection and study.

\section{Methods And Materials}

Material examined: About a third of the specimens are in the American Museum, the others are from the eight collections listed below under Collections.

Localities: Insofar as possible, the longitude and latitude are cited for each locality and the source for each is cited. Coordinates taken from locality labels are cited without parentheses or brackets, but enclosed with one or the other if the coordinates are from other sources. If the locality label included coordinates, those were used despite discrepancies in the coordinates as cited in other references. For example, Nova Teutonia, Brazil, is cited with different coordinates on the labels than stated by Paynter and Traylor (1991: 414). In lieu of label data, the coordinates were taken from, in no particular order, the Times Atlas of the World (Times Books, 1999), Google Earth, Ornithological Gazetteers for Brazil and Ecuador (Paynter and Traylor, 1991; Paynter, 1993), Falling Rain Genomics (www.fallingrain.com/world/ index.html), and the online botanical gazetteer from the Missouri Botanical Garden, cited herein and in the references cited as "MoBot," along with other atlases and websites cited with the particular locality. The use of the gazetteer of Falling Rain Genomics was a problem. After recording the latitude/longitude from that website, subsequent visits to the site revealed that a few localities had been deleted.

Types: I was able to see the primary types for seven of the eight previously described New World species. The type for the eighth species, Oedichirus geniculatus (Sahlberg), was not found; the problem is discussed in the account for the species. Bernhauer designated a holotype for Oedichirus boehmi. For the remaining six species no holotype was designated, but for five of them a specimen of the type series is labeled as "type" or "holotype"; that selection was not published in the original publication, so the specimens of the original series of each species are syntypes. Lectotypes are designated for each of those six names. Discussions of the designations are found with the account of the relevant species.

The label data for name-bearing specimens, holotypes, neotypes, and lectotypes are enclosed in quotation marks and presented in the sequence on the label. Multiple labels are cited in the same order as on the pin and the data of one label are separated from those of the next by a slash (/). Annotations about the specimen or the data are included in parentheses. Label data for non-name-bearing specimens, including paratypes and paralectotypes, are not delimited by quotation marks or slashes and the data may be rearranged or punctuated and some abbreviated words spelled out to present the data more efficiently and comprehensibly; data are presented in the language on the label.

Lectotype designation: Because among the species of Oedichirus there are clusters of externally similar species distinguished only by details of the genitalia, to stabilize the names lectotypes are selected herein for all previously described species for which no holotype was designated. When I began this project I had not intended to designate lectotypes for species represented only by female syntypes because females could not be reliably identified nor could they be associated with males. However, for reasons provided in the next section, I decided to designate lectotypes for species represented by only female syntypes.

Descriptions: As must be the case, the descriptions of the genus and species herein are a compromise between massive detail that is overwhelming and burdensome and a brief diagnosis that will separate a species from one or a few others. The attempt is to present features that are diagonostic within the genus or that vary among species and might be important to separate currently unknown species and that are more or less consistent within a species. Because these animals are 
bilaterally symmetrical, the descriptions throughout describe only one side of the body unless that structure differs one side to the other. So the description refers to proleg, not prolegs, or abdominal paratergite I, not abdominal paratergites I.

Association of males and females: Eight species were named prior to the present work; six of those names had no holotype designation, but the syntypes of three of them are females. Moreover, three species newly described herein are represented only by females. As reported for the first time in the present work, females of some species of Oedichirus can be identified by gender specific characters of segment IX that are discussed in the section on the morphology and described in the species accounts. In most instances the males and females of the same species are linked by having been collected together at the same locality, on the same date, by the same person and some also share unique characters. Male and female conspecificity by the aforementioned collecting site/date/collector method needs corroboration and that might be accomplished by collecting both sexes of the species at other sites. A more direct method of linking males and females might be DNA barcoding.

To extract and analyze DNA from museum specimens of Oedichirus, I collaborated with Susan Perkins, a fellow curator at the AMNH. We used specimens of $O$. geniculatus, which is one of only two species represented by a sufficiently large number of specimens that destructive sampling could be risked. However, the specimens of both species had been collected 40 to 55 years ago and neither the method of killing nor means of preserving them prior to being pinned and stored in museum collections were known. The specimens of $O$. geniculatus have been dry and pinned in museum drawers and cabinets for about 40 years. The legs and the terminal segments of the abdomen of a male and female were removed and an entire specimen of each sex was crushed. Although several primers were tried, N2353 and "Jerry" yielded the best product, but fragments of DNA were recovered for only the crushed female and none of the other samples yielded any usable DNA. We began developing primers specific for Oedichirus when my collaborator took an extended, temporary leave of absence from the AMNH. Upon realizing it was going to be impossible to get newly collected specimens, the search for DNA was halted.

Despite some success it was clear that acquiring satisfactory DNA from old specimens and from unique specimens was going to be a challenge. However, since there appear to be female-specific diagnostic characters and since in the long run barcoding will permit association of males and females, I decided to designate lectotypes for the three species represented by only female syntypes. Although extracting adequate DNA nondestructively from any of the three 85- to 125year-old lectotypes may be improbable, by collecting new females of the three lectotypes at or near their respective type localities, selecting females that match the characters published herein for the lectotype, extracting DNA from a female, and seeking males collected at that type locality that match the DNA of the female, the conspecificity of the males and females can be determined, and the identity of both males and females of the species fixed. The same procedures can be applied to discover the males of the three species described herein from females. Furthermore, even hypotheses of male/female association proposed herein for the other species can be corroborated or refuted by DNA barcoding techniques using newly collected specimens.

Microscopes: Specimens were studied and illustrated using a Leitz stereoscopic microscope with a camera lucida, Wild M20 compound microscope with a drawing tube, scanning electron microscope, and confocal laser scanning microscope.

Measurements: Measurements were made using an ocular grid in the Leitz stereoscopic microscope. The end points of the measurements are given below in the section Abbreviations and Measurements. The end points for the length of the animal are from the anterior edge of the labrum to the tip of the abdomen; the antennae are excluded. For species represented by only one to four specimens, all of them were measured. For those represented by more, only a few examples of the largest and smallest specimens were measured. 
CLSM imaging: The confocal images were produced with the use of a Zeiss confocal laser scanning microscope LSM 710 equipped with a Zeiss Axio Obeserver.Z1 inverted microscope. Each image is a computer-generated composite comprised of stacks of between 90 to 185 optical sections, depending on object thickness, image resolution, and space between slices. Completed images were produced by stitching the stacks of single-focal plane sections in sequence with Zeiss Zen software. A $20 \times$ dry objective and, to cut out out-of-focus bleed-through, a pinhole set at 1 Airy unit were used. Cuticular autoflourescence was induced by three, simultaneously collected, laser spectra: DAPI (range 410-556 nanometers [nm]) excited by $405 \mathrm{~nm}$ wavelength, Texas Red (range 563-630 nm) excited by $561 \mathrm{~nm}$ wavelength, and Cy5 (range 638-759 nm) excited by $633 \mathrm{~nm}$ wavelength. Image resolution varied from $1024 \times 1024$ to $4096 \times$ 4096 pixels and pixel dwell time varied from 7.12 to 3.56 microseconds across the data collected in this paper. Scan speed was optimized qualitatively with assistance from Zen software and depended on the resolution and objective selected. Scan time varied from 5 to 15 hours per specimen depending on the thickness of the specimen, the level of resolution selected, and the image quality desired.

Specimen preparation: Specimens dissected for study were relaxed in hot water and the structure of interest removed, cleared in warm $\mathrm{KOH}$ for a few minutes to about 3 hours or in cold $\mathrm{KOH}$ overnight. Alternatively, the structure was cleared in warm lactic acid for a few hours to a day or in cold lactic acid for as many days as needed. The muscle tissue of some dissected specimens is hard and unyielding and is not even slightly softened by $\mathrm{KOH}$ or lactic acid alone. However, if the specimen is placed in one warm solvent for a few hours, then in the other for a few more hours the tissue begins dissolving; continuing the alternation of solvents helps to dissolve most of the tissue. Specimens can remain in lactic acid far longer with far less damage or distortion than is the case for $\mathrm{KOH}$, so when alternating solvents specimens can remain in lactic acid longer than in $\mathrm{KOH}$. The specimen was removed from lactic acid, washed in water, transferred to alcohol, then to glycerin. When removed from $\mathrm{KOH}$, the specimen was placed in warm lactic acid for a short time, then treated as described in the previous sentence.

For both line illustrations using a bright field compound microscope and imaging with the CLSM, after the specimen was cleared, washed, and placed in glycerin, it was embedded on a depression slide in glycerin jelly melted over a warm hot plate, and oriented with the surface to be examined facing upward. The specimen could be reoriented to reveal a different surface as needed by melting the glycerin jelly. If the surface of the mounting medium was maintained flat and level, use of the recommended coverslip (see Klaus and Schawaroch, 2006) could be avoided and the orientation of the specimen adjusted quickly and easily.

Males and Females: The males of Oedichirus have excellent diagnostic characters associated with the aedeagus, sternum VIII, and, for some species, sternum VII. By contrast, heretofore no characters specific to females have been found that permit their identification. Three, O. brunneus Wendeler, $O$. ohausi Wendeler, and $O$. sparsipennis Bernhauer, of the eight previously described New World species are based only on females and have been impossible to reliably distinguish from the other species. Since most females are associated with males by collecting site rather than by morphology, it appeared that these three species were going to remain unidentifiable, or marginally identifiable, until males and females of the three were collected together at their respective type localities and even then only the newly associated males, not the females, would be reliably and usefully characterized. Furthermore, association of males and females by collecting site would continue to be suspect and most females not collected with males would be forever unidentified. With the foregoing thoughts guiding the study, I ignored females that were not collected at the same site and time with males and had all but finished the revision over a year ago when, in the course of dissecting the terminal segments of females, which up to that time had yielded no notable and observable diagnostic characters, I suddenly found a 
female that exhibited extraordinary variation of the median gonocoxal plate and variation of the vulvar plate (fig. 110). This discovery led me to begin the revision again to assess and use, if possible, these newly discovered characters and attempt to associate males and females and incorporate the latter into the study. However, although I discovered the character complex with a bright field compound microscope, it was quickly clear that this microscope would provide insufficient resolution to see and interprete the structures and create illustrations. Furthermore, the ornamentation of the vulvar plate was too complex to render in adequate detail with line drawings. As in earlier studies (Herman, 1970, 1972, 1986, 2003, 2010), I could have used the scanning electron microscope (SEM), but the material in this case presented special problems. To use the SEM a specimen is attached with an adhesive to a stub from which the specimen is difficult or impossible to remove, coated with a permanent conductive coating, and placed in a vacuum where it dehydrates. In earlier studies I used specimens that were expendable because they were one of many with the same collecting data. Furthermore, in the vacuum of the SEM membranous structures frequently collapse thereby distorting or otherwise making parts of the structure unobservable. Retaining and storing the SEM prepared and examined structures with the specimen from which it was extracted was awkward at best. Obtaining SEM images for unique or rare specimens was impossible. The structures I wanted to study for females of Oedichirus, although surrounded by sclerites, the features of interest were largely membranous with an overlay of minute cuticular structures. More importantly, the females of nearly all of the species I wanted to examine were represented by one or a few specimens.

The dilemma of finding a gentle method of examining delicate structures of the genital segment of the females of rarely collected species was resolved by use of a confocal laser scanning microscope (CLSM). The CLSM produces images of nearly SEM quality and resolution. The computer driven CLSM, making use of the autoflorescent properties of insect cuticle, optically sections a specimen to produce a stack of 2-dimensional images that can be assembled as a 3-dimensional image and rotated using the relevant computer software programs (see Klaus et al., 2003; Schawaroch et al., 2005; and Klaus and Schawaroch, 2006, for details of the functioning, techniques, and specimen preparation for use of the CLSM). For purposes of the present work, shallow 3-dimensional images, not unlike SEM images, suffice as the structures are small, thin, and relatively flat. The structure to be examined was dissected from a specimen, treated and placed on a slide as described above under Specimen Preparation.

Despite the preceding discussion of characters of the female genitalia, caution should be the watchword when reporting distributonal records, particularly if new. It is with that caveat that the localities known for females are noted in the diagnoses and discussions. Most species herein are known from one or only a few nearby localities. The species are all flightless and we have no idea whether their distributions are wide or restricted.

Orientation of illustrations: In the present work, as is general and traditional practice for most morphological illustrations, the anterior end of the structure is directed to the top of the page (or to the left), whether the illustration depicts a dorsal, ventral, or lateral view and regardless of the part of the body illustrated. The principal and common exception are aedeagal (and female genitalic segments in some works) illustrations which are often presented upside down, that is, with the posterior end directed to the top of the page. Herein, illustrations of the aedeagus and female genital segment conform to standard practice and the anterior end is directed to the top of the page.

The rationale for reversed page orientation is puzzling, but perhaps was chosen originally because when specimens are studied with a stereoscopic microscope they are usually placed with the anterior end at the top of the field of view and the specimens are normally illuminated from the anterior end. However, to afford a better view of the aedeagus it is often studied and illustrated with the posterior end at the top of the field of view. As workers became accustomed to illustrating the aedeagus upside down, they then published their illustrations in the same 
orientation. In addition to deviating from standard practice for other illustrations, the reversed orientation of the aedeagus or female genital segments is sometimes confusing.

\section{AbBreviations}

\section{Collections}

$\begin{array}{ll}\text { AMNH } & \begin{array}{l}\text { American Museum of Natural } \\ \text { History, New York }\end{array} \\ \text { BMNH } & \begin{array}{l}\text { Natural History Museum, Lon- } \\ \text { don } \\ \text { Canadian National Collection, } \\ \text { Ottawa }\end{array} \\ \text { ENCI } & \begin{array}{l}\text { Essig Museum, University of } \\ \text { California, Berkeley, California }\end{array} \\ \text { FMNH } & \begin{array}{l}\text { Field Museum of Natural Histo- } \\ \text { ry, Chicago, Illinois }\end{array} \\ \text { KUSM } & \begin{array}{l}\text { Snow Museum, University of } \\ \text { Kansas, Lawrence, Kansas } \\ \text { Museo de La Plata, Argentina }\end{array} \\ \text { MLPA } & \begin{array}{l}\text { Museum für Naturkunde, Berlin } \\ \text { Senckenberg Deutsches Entomo- } \\ \text { MNHB }\end{array} \\ \text { SDEI } & \text { logisches Institut, Müncheberg }\end{array}$

\section{Measurements}

HL Head length, measured from a line across the frontoclypeal margin to a line across the juncture of the head and "neck"

HW Head width, measured from the outer margin of one eye across to the outer margin of the other

PW Pronotal width, measured across greatest width, usually at about the anterior third

PL Pronotal length, measured from a line across the anterior margin to a line across the posterior margin

EL Elytral length, measured from a line across the angles of the innermost humeral margin to a line across the apicolateral corners of the contiguous elytra (fig. 8)

EW Elytral width, measured across the greatest width of the contiguous elytra

L9 Tergum IX length, measured midlongitudinally from middle of anterior margin to middle of the margin separating tergum IX and $X$ (fig. 27)

LLaP Lateroapical process length, measured from the line across the posterior margin of IX to the apex of the process (fig. 27)

\section{Miscellaneous}

CLSM Confocal laser scanning microscope

SEM Scanning electron microscope

\section{TAXONOMY}

Key to the New World Genera of the Procirrina

(Distributions cited in this key are for the New World only.)

1. Abdominal segment VII with tergum and sternum fused from base to or to near apex (fig. 25) . . . . . . . . . . . . . 2

- Abdominal segment VII with tergum and sternum separated from base to apex ... . 3

2. Abdomen without imbricate macrosculpturing, surface strongly punctate (figs. 2, 23, 24); elytra without long, prominent seta on lateroapical angle (fig. 8); Mexico and Caribbean to Argentina and Brazil. ....... Oedichirus

- Abdomen with diamond-shaped, imbricate macrosculpturing, surface without noticeable punctation (fig. 31); elytra with long, prominent, coarse seta on lateroapical angle (fig. 30); Canada to Argentina. . . . . . . . . Palaminus

3. Protarsus with basal three tarsomeres enlarged; Mexico to Argentina and Chile...... ............. Oedodactylus

- Protarsus with basal four tarsomeres enlarged; Brazil . . . . ........ Stylokyrtus

DIAGNOSTIC FEATURES OF AND NOTES ON NEW WORLD GENERA OF THE PROCIRRINA

Oedichirus: Diagnostic features for the genus are attached to the description of the genus in the present work.

Oedodactylus: Most of the four species have been rarely collected. The type species, O. fuscobrunneus Fairmaire and Germain, 1861 , is the most commonly represented species in collections and the largest, most 
robust of the genus. The genus can be distinguished from other New World genera of the subtribe by the inflated basal three protarsomeres. Other diagnostic characters include the row of coarse setae on the posterior edge of the elytra, the presence of one paratergite III on each side of the segment, the separation of tergum and sternum VII, and the punctate surface of the abdomen.

Palaminus: This speciose genus is the most recognizable of the Procirrina and the subfamily. The four originally included species are from the New World. Most of the species are long, slender, and honey colored, but many are brown and black. They uniquely possess diamond-shaped, imbricate macrosculpturing on abdominal segments III to VI (fig. 31). Each unit of the imbrication has a seta arising from the apical corner. The abdomen lacks paratergites and segments III to VII are cylindrical with the tergum and sternum of each segment fused. The lateroapical processes of tergum IX are straight to slightly deflexed ventrally. The elytra have a long, coarse seta arising from near the apicolateral corner (fig. 30) and the posterior edge lacks a row of setae. The basal four protarsomeres are enlarged. Among the Procirrina, only Palaminus and Oedichirus have a pair of "windows" adjacent to the anterior margins of terga and sterna III to VII (fig. 24). In only Palaminus are terga and sterna VII fused for the entire length of the segment. In Oedichirus these sclerites are fused basally, but separated apically by an incision (fig. 25).

Stylokyrtus: This monotypic genus, known by only one specimen, was recognized for a species with four inflated protarsomeres that had been included in Oedodactylus for which now the included species have three swollen protarsomeres. The elytra have a row of coarse setae on the posterior edge, the abdomen is punctate rather than imbricate, tergum and sternum VII are separated, and tergum IX has long, strongly deflexed lateroapical processes.

\section{Oedichirus Erichson}

Oedichirus Erichson, 1839: 29 (published without included species; for first included species, see
Erichson, 1840: 685). Type species: Oedichirus paederinus Erichson, fixed by Erichson (1840: 685 ) by subsequent monotypy. (The following subsequent references for Oedichirus include only those pertaining to the New World fauna. For a more extensive list, see Herman, 2010: 36.) - Erichson, 1840: 684 (first included species: paederinus; characters). - Sharp, 1876: 338 (first two New World species described in Oedichirus). - Blackwelder, 1944: 131 (checklist of species of Latin America). - Blackwelder, 1952: 269 (type species). — Navarrete-Heredia et al., 2002: 293 (characters in key to genera for Mexico; general notes; unnamed species in Mexico). - Herman, 2010: 36 (characters; list of species included; phylogenetic position).

Elytrobaeus Sahlberg, 1847: 801. Type species: Elytrobaeus geniculatus Sahlberg, fixed by monotypy.

- Gemminger and Harold, 1868: 629 (catalog). - Fauvel, 1875a: xvii (=1875b: 219) (synonym of Oedichirus). — Sharp, 1876: 338 (synonym of Oedichirus). - Bernhauer and Schubert, 1912: 201 (synonym of Oedichirus). - Cameron, 1931: 25 (synonym of Oedichirus). - Blackwelder, 1952: 147 (type species).

Oedichiranus Reitter, 1906: 263, 264 (subgenus). Type species: Oedichirus (Oedichiranus) dimidiatus Reitter, fixed by monotypy.

- Herman, 2010: 38 (synonym of Oedichirus).

Diagnosis: Oedichirus can be separated from all other genera of the Procirrina by the apical, spiniform pencil of antennomere 11 (fig. 9) and the basal fusion of tergum and sternum VII (fig. 25). Only Oedichirus and Palaminus have windows near the anterior margins of terga and sterna III to VII (fig. 24) and a dense cluster of setae on the ventral surface of protarsomere 5 (fig. 7). Tergum and sternum VII are fused in Palaminus, but fused in Oedichirus from the base to near the apex then separated by a short incision (fig. 25). The surface of the abdomen of Oedichirus is punctate (figs. 23, 24) and lacks the imbricate macrosculpturing of Palaminus (fig. 31). The long, thick, lateroapical elytral seta found in Palaminus (fig. 30) is absent in Oedichirus (fig. 8). The posterior edge of the elytra lack a row of setae (figs. 1, 2, 8) and the basal four protarsomeres are inflated in Oedichirus (figs. 6,7). 
DESCRIPTION: Head broad; postocular lateral margin short and straight (figs. 1, 2); basal margin of head extending anterolaterally from neck and with ridge extending laterally from neck to near eye; ridge acutely angulate laterally. Eye length greater than postocular length of head. Dorsal surface of head with umbilicate punctation (Herman, 2010: fig. 15); frontoclypeus polished, impunctate, and with median impression. Antennomere 10 and 11 of subequal length; antennomere 11 with spiniform process apically (fig. 9). Labrum (fig. 3) with moderately deep median emargination of anterior margin; anterior margin with one, two (fig. 3), or three pairs of denticles. Mandible (figs. 2, 137) with one denticle near middle. Maxillary palpus (fig. 138) with fourth segment shorter to slightly longer than second and enlarged, robust, moderately compressed, and covered with fine, dense pubesence.

Pronotum longer than wide (figs. 1, 2, 10); widest near anterior third and with lateral margins strongly convergent anteriorly and gradually convergent posteriorly; punctation umbilicate, sparse to dense, absent from midline medially and posteriorly, present or absent from midline anteriorly, and confused, arranged in curved rows, or grouped in clusters. Pronotal marginal ridge present, complete, and well developed. Mesospiracular peritremal plate (fig. 10) large, strongly sclerotized, fused anteriorly to furcasternum and laterally to hypomeron. Procoxal cavity closed posteriorly by mesospiracular peritremal plate (fig. 10). Elytra (figs. 1, 2) shorter than pronotum; surface with uniform punctation; posterior margin without row of setae on edge; apicolateral corner without long prominent seta (fig. 8).

Protarsomeres (figs. 6, 7) 1 to 4 inflated and with crescent-shaped slit on ventral surface; slit bordered by setae; ventral surface without setose pad; tarsomere 4 not expanded beneath 5 and apical margin entire, not emarginate; tarsomere 5 densely setose ventrally (fig. 7). Mesotarsomeres and metatarsomeres (Herman, 2010: fig. 50) 1 to 4 slender and each with long first tarsomere; tarsomeres 1-3 pubescent ventrally, but without setose pad; tarsomere 4 extending beneath 5, apical margin entire to slightly emarginate, dorsal surface deeply impressed medially, and ventral surface with dense cluster of long setae.

Abdominal segments punctate and without imbricate macrosculpturing (cf. figs. 23 and 31). Abdomen with oval, membranous "window" (fig. 24) in intersegmental membrane at anterior margin of terga and sterna III-VII. Segment III with paratergite or paratergal carina (fig. 23); tergum and sternum separated by tergosternal suture and paratergite in some species or by paratergal carina and feeble groove or line (fig. 23) in others. Segments IV to VII without paratergites or paratergal carinae and with tergum and sternum on each segment fused. Segment VII with tergum and sternum fused basally, posterior margin with notch on midlateral side and with short incision extending anteriorly from notch (fig. 25). Sternum III with midlongitudinal carina; transverse basal ridge with sublateral carina extending posteriorly (Herman, 2010: fig. 22). Tergum III with two or three wedge-shaped points extending posteriorly from transverse basal ridge; sublateral point present (fig. 23), median point present (as shown for tergum or sternum VIII, figs. 26, 73) or absent. Tergum VIII with (figs. 26, 166) or without median point extending from transverse basal ridge. Tergum IX fused middorsally (fig. 27); posterior margin truncate and deeply emarginate medially; lateroapical process (fig. 27) long, slender, slightly (fig. 158) to strongly curved (fig. 168) ventrally, and extending beyond apex of tergum X. Sternum IX of male slightly (figs. 51, 86, 109) to strongly (fig. 117) asymmetrical; base wide (fig. 117) to narrow (fig. 144). Tergum X (fig. 140) present and nearly entirely exposed; apical margin curved to slightly produced medially.

Male with sterna VI and VII modified or unmodified; sternum VIII modified. Aedeagus with parameres present (figs. 103, 104, 161, 162); basal piece absent.

Female with sterna VI-VIII unmodified. Median gonocoxal plate undivided (fig. 29. Vulvar plate with two lobes (figs. 29, 111, 157, 196). Vulva embedded in posterior vulvar lobe and surrounded by membrane (figs. 29, 64, 196).

Distribution and Habitat: Most species of Oedichirus are found in tropical and subtropical regions of the world; a few are 


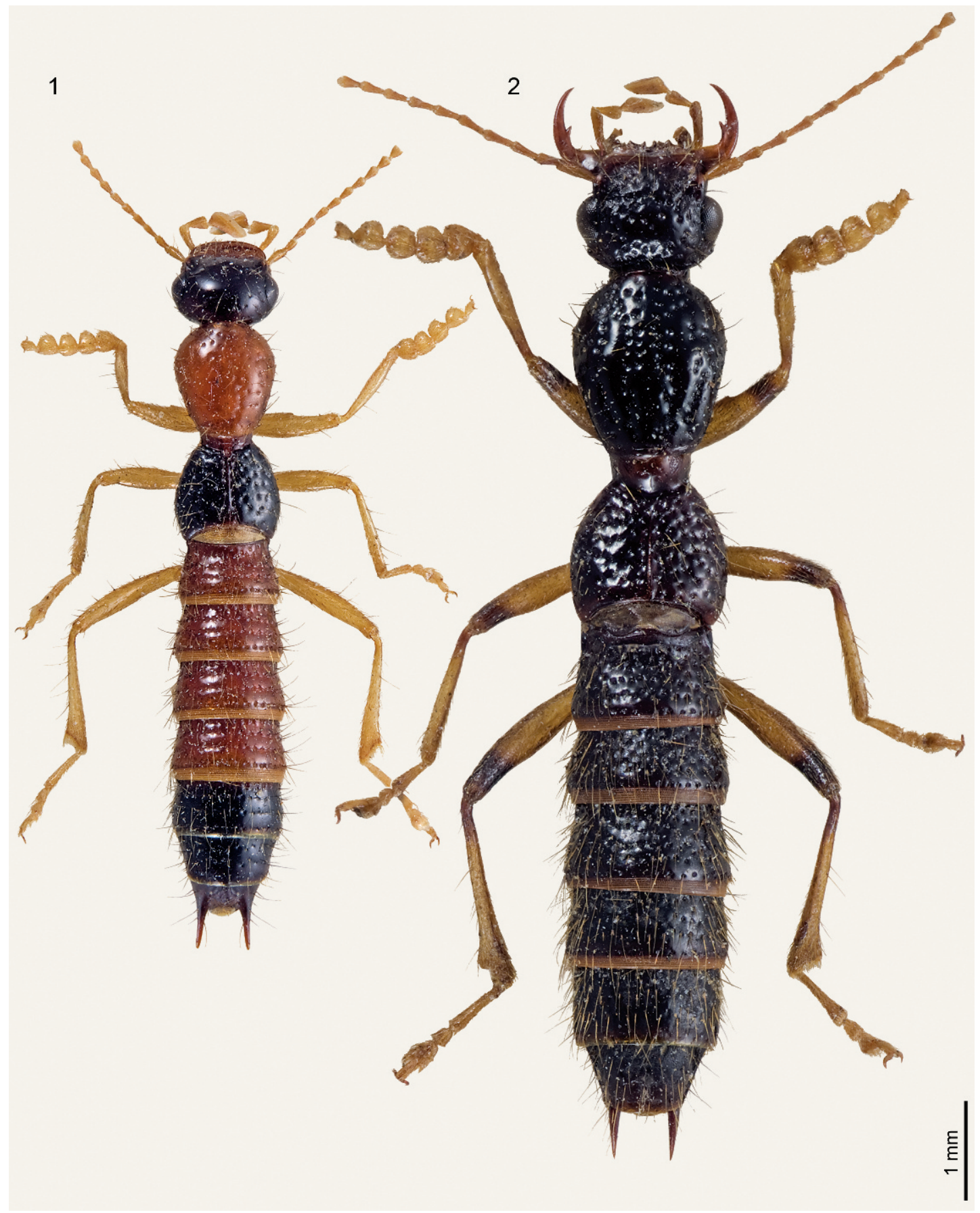

Figs. 1-2. Habitus. 1. Oedichirus paederinus Erichson, type species. 2. Oedichirus geniculatus (Sahlberg), first collected and described New World species. Specimens are to the same scale. 
known from temperate regions. The New World species are known from Mexico to southern Brazil, northern Argentina, and Bolivia, but have been captured in few countries and at few sites (figs. 39, 40). Most of the previously described species are found in Brazil and one is from Costa Rica, but herein species are reported from the Dominican Republic, Mexico, Ecuador, Peru, Bolivia, Argentina, and perhaps Nicaragua.

Little has been published and few data are on specimen labels that indicate the habitat of the New World species, but labels record specimens to have been collected from shrubs, trees, and leaf litter.

In the Old World, Oedichirus is widespread and represented by many species. Subsaharan Africa and Madagascar are densely populated by the genus. Four North African species occur along the southern edge of Europe in Spain, Italy, and Crete and two others have been reported from countries adjacent to the Mediterranean and from there the genus is found from India to Japan and through Indonesia to Australia. One species reaches Central Asia (Tajikistan and Afghanistan), one species is reported from Tasmania, and two are from New Caledonia. Old World species have been collected from leaf litter on the forest floor, moist ground litter, and in swamps, near streams and springs, and from vegetation by beating shrubs and branches of trees, and epiphytes and are found in lowland forests and in montane forests to as high as $3500 \mathrm{~m}$. At least 10 African species have been collected at or above $3000 \mathrm{~m}$ elevation (see Fagel, 1971: 194, 237, 241, 243-245, 252, 266, 287, 291).

\section{MORPHOLOGY OF OEDICHIRUS}

The following summary of the morphological variation of Oedichirus is based primarily on New World species, includes some speculation, and introduces a few new structures and terms. So the reader can better understand the rationale behind the terms used herein for the lateral and ventral pterothoracic sclerites of Oedichirus, a discussion of two hypotheses concerning the evolution of the pterothorax is provided.

COLOR: Most species of the genus are varying shades of reddish brown to reddish black to black, different segments of the body may be paler or darker and the legs of some species are bicolored. Like species in some other staphylinid genera, some species of Oedichirus mimic a color pattern common to many species of Paederus, one in which the head, elytra, and apical abdominal segments are black and the remaining regions are orange to reddish orange. Among the Old World Oedichirus at least 30 species have this color pattern, but there may be others among those I have not examined. All but four of the 30 species are African; the others are from Japan (2), India (1), and Central Asia (1). One of the Paederus-like African species, $O$. paederinus Erichson, is also from Europe and is the type species of the genus (fig. 1). All of these mimetic species, except $O$. paederinus, have fully developed elytra and probably wings and may be capable of flight; all of them lack the pronotal marginal ridge. Coiffait (1978: 330, 332) reported the same color pattern in $O$. simoni, which I've not seen, from the Mediterranean region. I have seen no Australian species so colored, but although MacLeay (1873: 147) reported the head and apical three abdominal segments for $O$. paederoides as black and the thorax and basal abdominal segments reddish, he did not describe the elytra. In the New World I have seen no species that as closely resemble the color pattern of Paederus as do the mimetic Old World species. Those with the closest resemblance are $O$. bullaglaber in which the head and prothorax are black and the remainder of the body is reddish brown and $O$. neotropicus in which the body is reddish brown and the apical abdominal segments are black. The legs of 12 New World species are bicolored.

HEAD: Excluding the eyes, the head is more or less quadrate in dorsal view in many species, the dorsal surface is densely to sparsely punctate, and the punctures are large and deep to relatively small and shallow (figs. 1, 2). Some species have almost no dorsal punctures and all have impunctate spots. The ventral punctation is sparse and shallow. Trichobothria are absent. The frontoclypeal region, usually polished and depressed medially, has a low frontoclypeal ridge extending medially from near the antennal insertion and is complete or incomplete. The basal margin of the head is broadly 


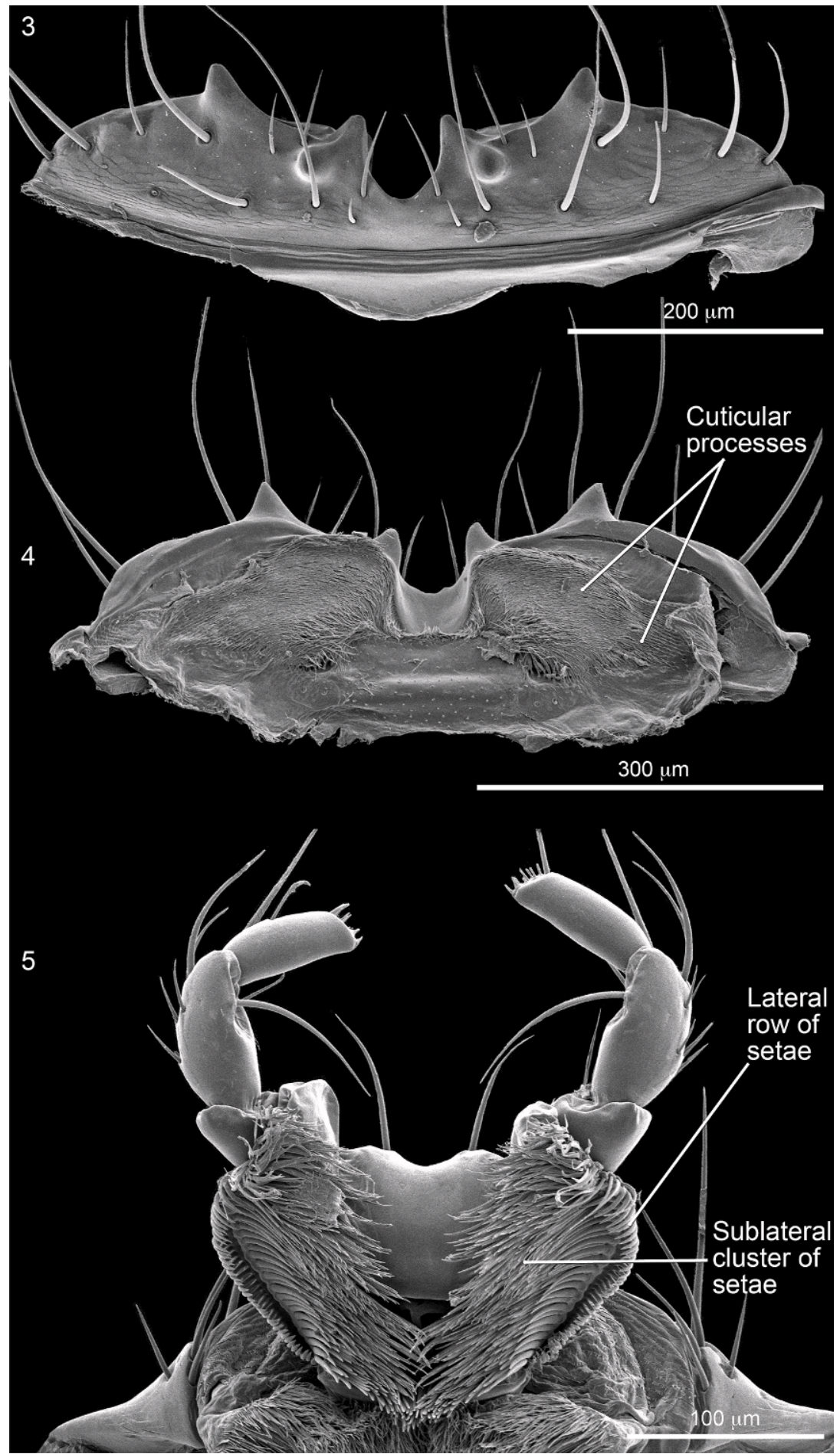

Figs. 3-5. Oedichirus geniculatus. 3. Labrum, dorsal (SEM). 4. Labrum, epipharynx (SEM). 5. Labium, hypopharynx (SEM). 


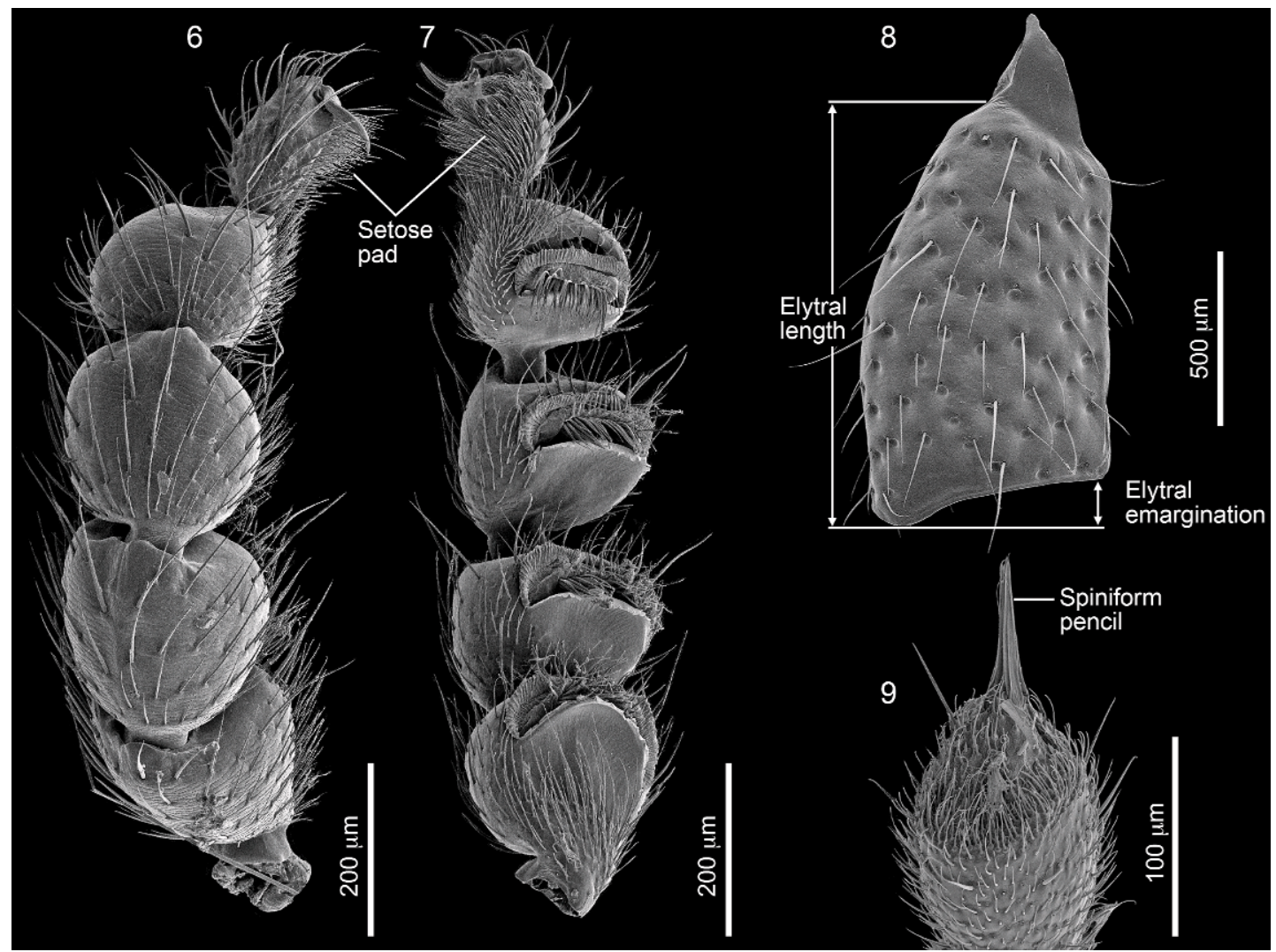

Figs. 6-9. Oedichirus geniculatus. 6. Protarsus, dorsal (SEM). 7. Protarsus, ventral (SEM). 8. Elytron, left, dorsal (SEM). 9. Antennomere 11, apex (SEM).

and gradually rounded from the eye to the neck (fig. 1) or has a carina extending from the neck laterally to near the base of the eye where the carina is strongly angulate (fig. 2). The neck is about half to two thirds as wide as the postocular width of the head. Separating the head and neck is a nuchal constriction, the dorsal portion of which is termed the nuchal groove, followed posteriorly by the nuchal ridge on the neck. The nuchal groove lacks longitudinal carinae. On the ventral surface of the neck the postoccipital suture is evident as a well-developed ridge, that extends anteriorly as the gular sutures, which are moderately to poorly developed or absent (see Herman, 2010: fig. 16). The gular sutures are separated, shallow grooves that when feebly developed are evident only as slight impressions and when absent leave no impressions on the surface, but are visible through the cuticle as dark lines. The eyes are more or less protuberant from the sides of the head and lack setae, each facet is nearly flat and only feebly raised, and the posterior margin of the eye is not emarginate.

Most antennomeres are not notably modified, but 11 has a long, spiniform apical pencil (fig. 9) that, with a light microscope, appears to be a spine or tightly packed cluster of setae. Unique to Oedichirus, the spiniform pencil was noted by Sahlberg (1847: 303), then by Sharp (1876: 338, 339), who was unsure of what it was. SEM images show a group of three wide, flattened processes that are apparently modified setae. Each seta is wider than thick, tapers apically, has longitudinal ridges extending for most of the length, and three apical cuticular processes. This spiniform pencil is partially withdrawn into the apex of the antennomere in some individuals because the apex is more or less 
membranous and collapses in dried specimens. The function is unknown, but the pencil may serve to wick chemicals produced by antennal glands to the surface for dispersal. Secretory glands have yet to be discovered.

While the anterior margin of the labrum of most New World species has four denticles, $O$. optatus has six, and $O$. echinatus, $O$. lunatus, and $O$. procerus have two. One species, O. geniculatus, has four denticles and a small, dentiform, subapical tubercle near the base of the submedial denticle in males (figs. 3,136 ) and $O$. echinatus has a minute tubercle at the edge of the anterior margin adjacent to the median emargination. The epipharynx lacks setae, has a deep median groove, and the median region has a dense, transverse mat of cuticular processes (fig. 4).

Typical of most staphylinids the labium has three, undistinguished palpomeres that are increasingly slender from the thick, basal article (fig. 135). The anterior margin of the hypopharynx has a pair of rounded to truncate lobes. The hypopharynx has, on the anterior margin, a pair of rounded to truncate lobes, but lacks clusters of spinelike setae; the lateromedial surface is densely covered with cuticular processes and bordered laterally by a row of setae (fig. 5).

The maxilla has four palpomeres (fig. 138). The basal palpomere is small and the second and third long, slender, and slightly expanded apically. The fourth palpomere is greatly enlarged and the sides are covered with fine pubescence while the apical surface is covered with sensory structures similar to sensilla basiconica (see Herman, 2010: fig. 30). This enlarged, pubescent palpomere is characteristic of species in the Procirrina and Pinophilina and SEM images may reveal significant variation of potential diagnostic or phylogenetic interest, but at present insufficient material exists for most species or genera to determine this.

The mandibles are long, slender, have only one simple, apically acute denticle near the middle (fig. 137), and the prostheca is a simple, basal cluster of cuticular processes.

PROTHORAX: The prothorax (figs. 1, 2) is tapered posteriorly from about the anterior third. The dorsal surface of the pronotum is moderately to strongly convex and coarsely punctate in most species. The punctures are unevenly distributed in most species, but among the New World ones, O. dilophus has smaller, shallower, marginally more uniformly arranged punctures than do the others. All of the species have scattered, polished, impunctate spots. Trichobothria are absent. The notosternal suture is present and short and separated from the marginal ridge (fig. 10). The basisternum has coarse, deep punctures, each bordered by a seta near its anterior margin (fig. 10; the seta of many punctures missing or broken). The postprocoxal lobe (fig. 10), the posteroventral part of the hypomeron, is long, tapered, and covered with dense, deep, coarse, asetate punctation.

The pronotal marginal ridge is present and complete in New World species. However, among Old World species the ridge is present and complete or divided or absent; based on the three states Fagel (1971: 129-130) arranged the African species into three groups. The marginal ridge is present in most staphylinids and most paederines and, as pointed out by Lecoq (1986: 9), its presence must be considered ancestral. Whether there is phylogenetic significance in variation of the ridge is yet to be tested. The ridge of most, perhaps all, species of Oedichirus is margined by a row of punctures along the dorsal edge.

Except for the procoxal cavities and spiracular openings, the entire ventral surface of the prothorax is covered by a large, undivided sclerite in Oedichirus. This compound, prosternal/mesotergal sclerite, which incorporates four strongly sclerotized plates, the basisternum, furcasternum, and two mesospiracular peritremes, was discussed in more detail previously (Herman, 2010: 16-17). The basisternum extends between the notosternal sutures and from the anteroventral prothoracic margin posteriorly to the two prosternal apophyseal pits, which mark the anterior edge of the furcasternum (= sternellum). The large sclerite behind the furcasternum, the mesospiracular peritremal plate, is formed by the enlarged, fused mesospiracular peritremes and covers the surface between the hypomera and the area from the procoxal cavities and furcasternal region to the posterior margin of the ventral surface (figs. 10, 139). Since spiracles are part of the dorsum (Snodgrass, 1935: 71- 


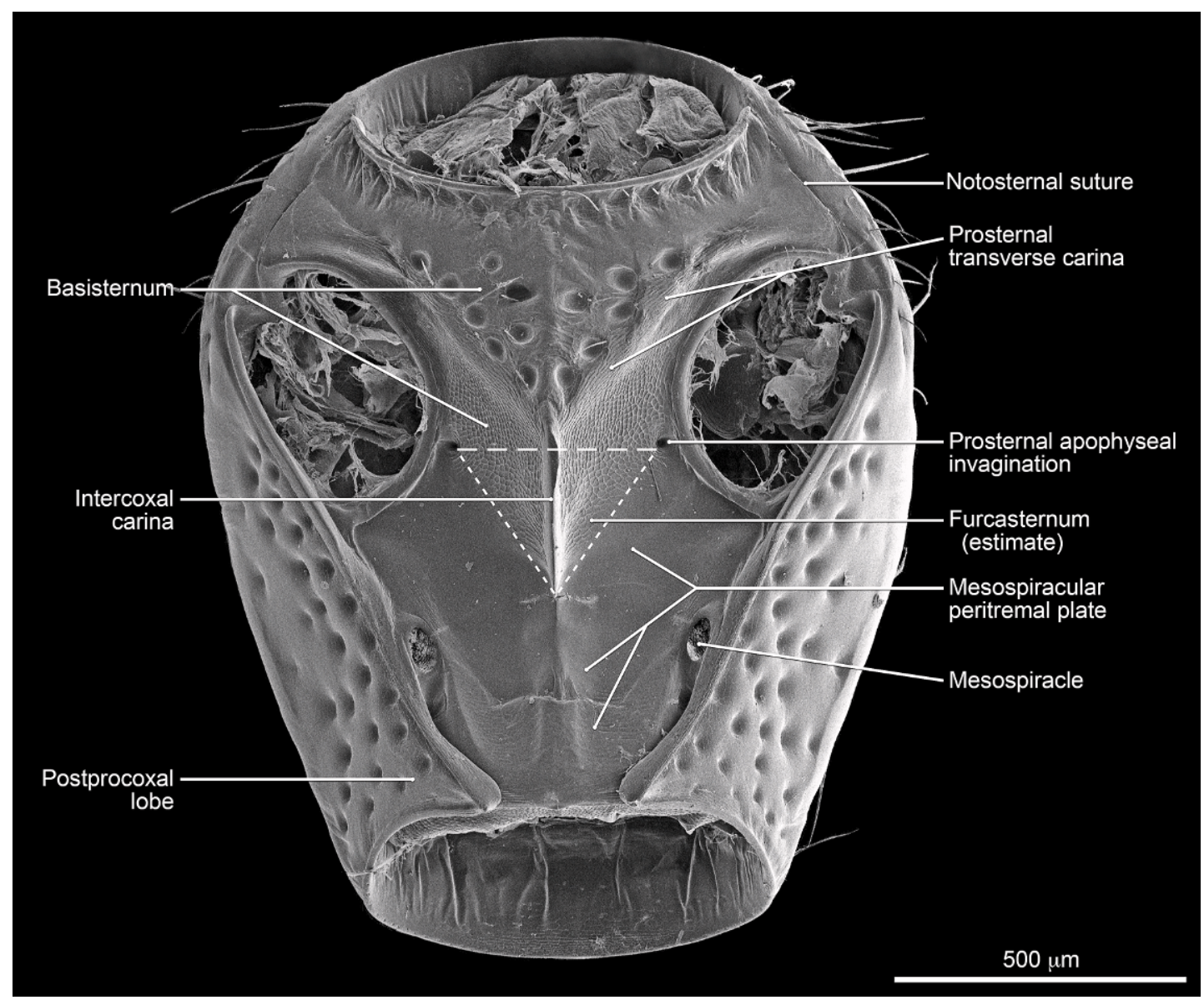

Fig. 10. Oedichirus geniculatus. Prothorax, ventral (SEM).

$72,249$ and figs. 35,137$)$ and the tergum is sclerotized dorsum, the spiracular peritremal plate is part of the mesotergum. Between the procoxae is a large, midlongitudinal intercoxal carina, extending posteriorly from the prosternal transverse carina and ending at the midposterior edge of the mesospiracular peritremal plate.

PTEROTHORAX: The elytra of most species of Oedichirus are densely and coarsely punctate. Each puncture has a seta near the anterior margin. The dorsal surface, the disc, of the elytra of most species of Oedichirus is slightly convex to flat. For three species, $O$. boehmi, O. ohausi, and O. procerus, most of the disc is moderately to strongly concave and the beetle has a swayback appearance. The elytral disc of three other species, O. brunneus, $O$. hamatus, and $O$. neotropicus, is weakly concave and the elytra of $O$. optatus are flat to slightly concave. The posterior margin of the conjoined elytra is emarginate (figs. 2,8 ) and lacks a row of setae on the edge (fig. 8). The elytra lack an epipleural ridge. Most species of Oedichirus, and all of the New World ones, are flightless with the concomitant reduction of the mesothorax and metathorax as well as further shortening of the elytra, reduction of the epipleuron, and loss of the humeral angles. The elytra of the flightless species are shorter than the prothorax. The flying species of Oedichirus have fully developed elytra that are longer than the prothorax and are scattered in Africa and Madagascar and across Asia to Indonesia and Japan.

Hypotheses of origin of lateral and ventral sclerites of pterothorax: The pterothoracic ventral and lateral sclerites of adult staphy- 


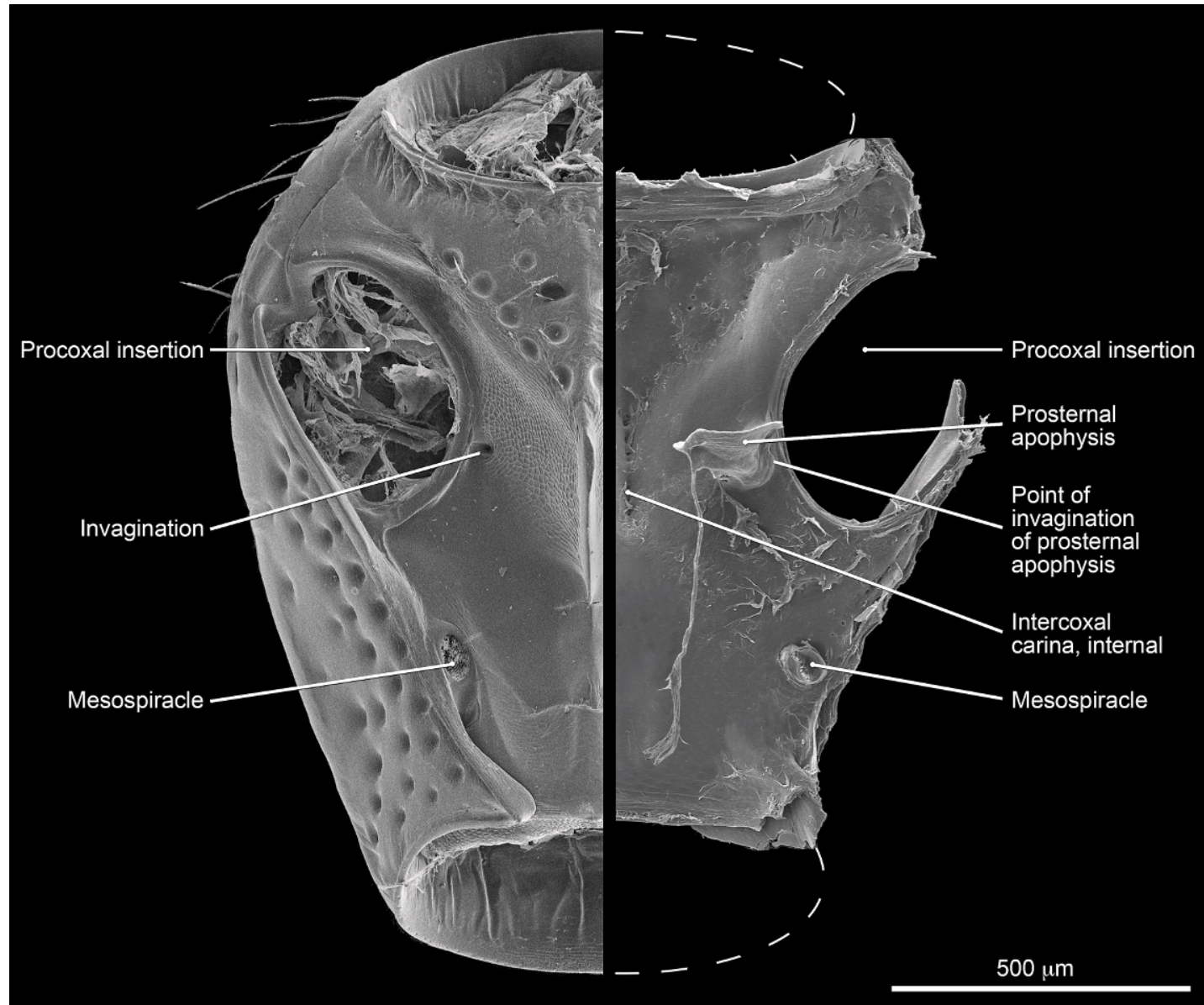

Fig. 11. Oedichirus geniculatus. Prosternum, left, external view; right, internal view (SEM).

linids were referred to as epimeron, episternum, and sternum for both segments by Blackwelder (1936) and most taxonomists have similarly referred to these sclerites. Naomi (1988) used epimeron, anepisternum, and basisternum + preepisternum, respectively, for the same sclerites. Thayer (2005) returned to the use of epimeron and episternum, but dispensed with sternum and basisternum + preepisternum and used instead ventrite for the large, median ventral sclerite. Lawrence et al. (2011: 33) briefly discussed the replacement of the term "sternum" and adopted the view that the external sterna of the pterothorax have been lost. Because of the revised interpretation of the pterothorax, the following paragraphs briefly summarize the infrequently discussed rationale for the changes of the pterothoracic vocabulary.
Snodgrass (1935: 161-166, fig. 88) considered the pleural sclerites to be derived from subcoxal sclerites (figs. 12-14) of limb bases and that three main sclerites comprised the eventual sclerotized pterygote pleuron, two above the coxa, the anapleurite and coxopleurite, and one below, the sternopleurite (fig. 12). In pterygotes, to strengthen the thoracic walls for flight (figs. 13-14), the anapleurite fused with part of the coxopleurite, enlarged to cover the dorsal, anterior and posterior pleural regions, and was divided by an invagination, the pleural suture, to form an internal apodeme, the pleural apophysis, thereby creating the episternum anteriorly and the epimeron posteriorly. The remainder of the coxopleurite became the trochantin. $\mathrm{He}$ also named two sclerotized "bridges" (figs. 14, $18)$, the precoxal bridge (= precoxale) and 

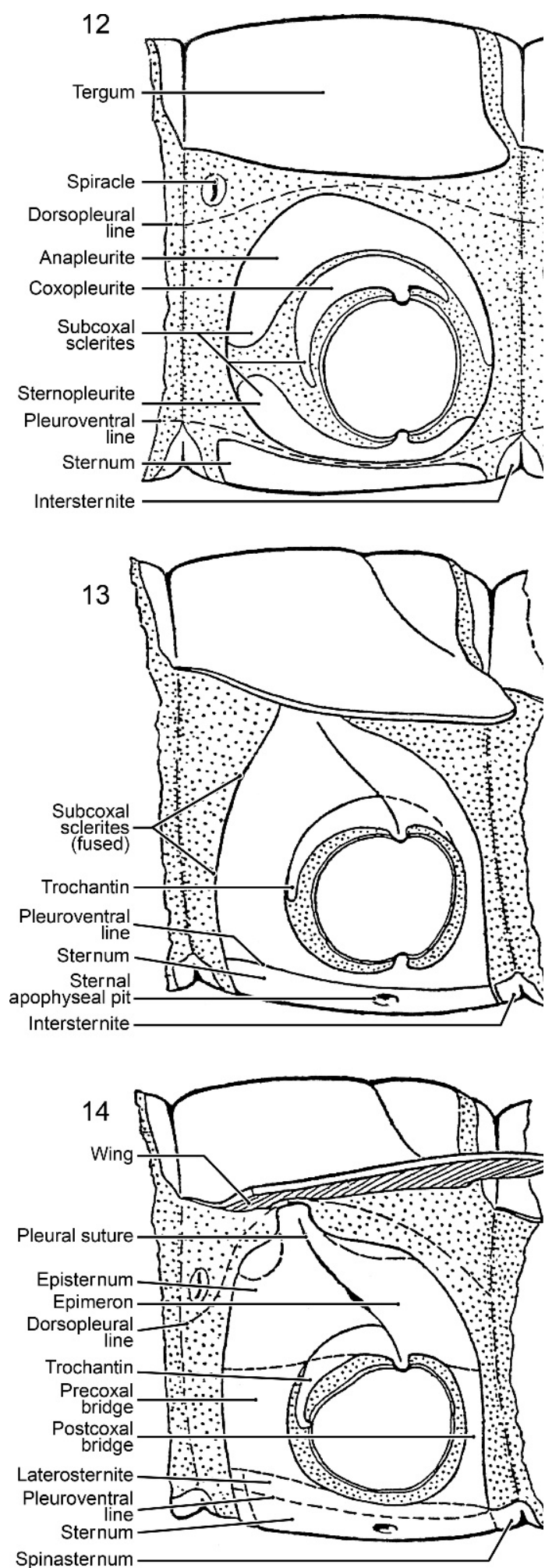

postcoxal bridge (= postcoxale), in front of and behind the coxa, that extend toward the sternal region from the episternum and epimeron, but he elaborated no further on them. The third subcoxal sclerite, the sternopleurite (= laterosternite) (figs. 14, 18), fused to the sternum (and the coxal bridges, according to his figure 91B (= fig. 14 herein), although Snodgrass did not state that). The laterosternite was little mentioned by Snodgrass or subsequent investigators. Finally, the episternum and epimeron each divided resulting in the dorsal anepisternum and anepimeron and the ventral katepisternum and katepimeron; the preepisternum is an anterior division of the anepisternum (Snodgrass, 1935: 184). Matsuda (1963: 62-67) supported Snodgrass's ideas, but suggested slight modifications concerning the articulating condyles.

Moving from the pleural to the ventral side, Snodgrass (1935: 77-78, 166-172) regarded the thoracic sternum or eusternum to be a composite sclerite that developed from sternal and pleural elements (figs. 15-18). Included among the sclerites are the primitive sternum medially, the intersegmental sclerite (spinasternum) posteriorly, and the sternopleurite laterally $(=$ his laterosternite $)$ (fig. 18). The primary sternal sclerite has a pair of invaginations, the sternal apophyseal pits, the origin of the sternal apophyses (figs. 16-18). The regions anterior and posterior to the sternal apophyses are the basisternum and furcasternum (= sternellum) (fig. 17), and along the anterior margin the presternum separated from the basisternum (fig. 18). Despite the composite nature of the ventral sclerite, Snodgrass (1935: 78) referred it as "sternum" and that designation has been followed by innumerable entomologists.

Weber (1928), studying species of Papilio, Zygaena, Sphinx, and Sialis, proposed that the external sterna of the pterothorax were

Figs. 12-14. Hypothetical evolution of pleural sclerites of pterothorax. 12. Primitive segment. 13. Intermediate development. 14. Wing-bearing segment (modified from Snodgrass, 1935). 

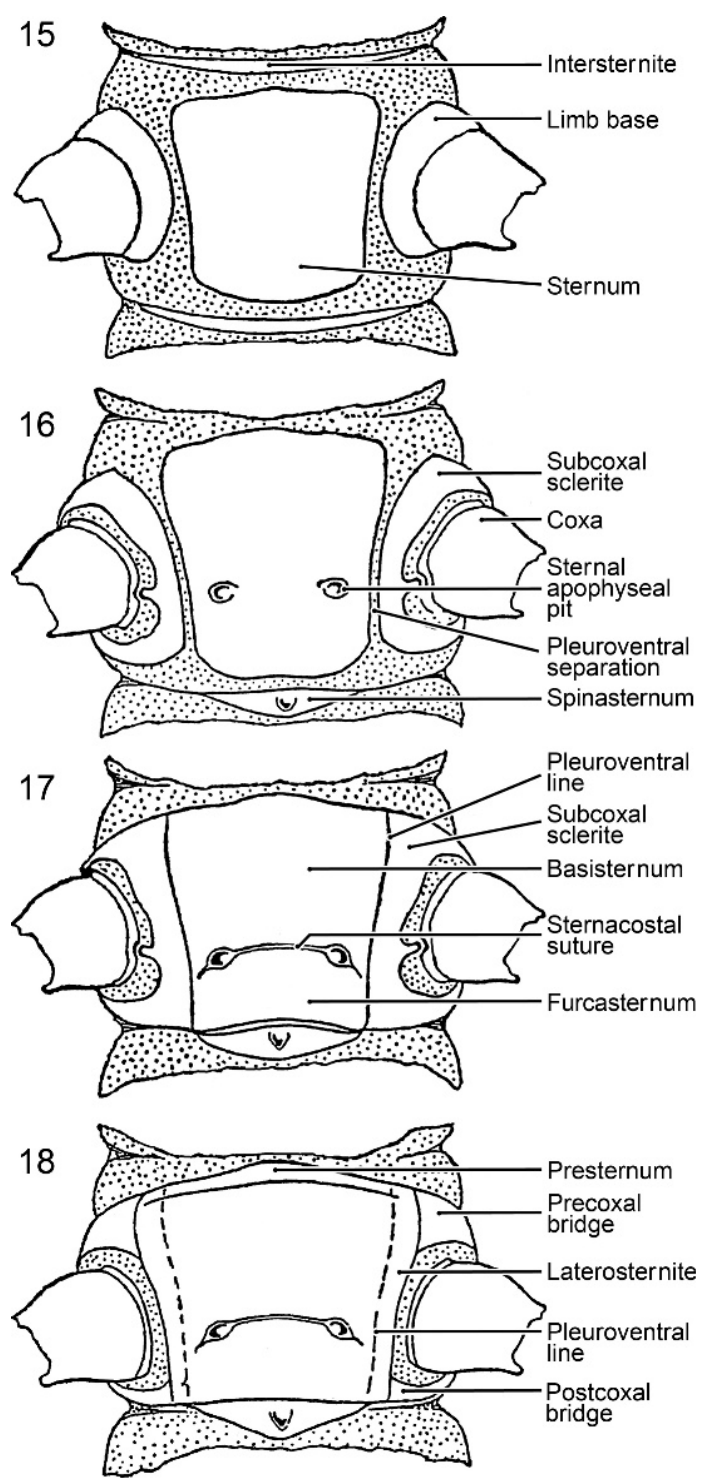

Figs. 15-18. Hypothetical evolution of sternum. 15. Primitive. 16, 17. Intermediate development. 18. Generalized thoracic sternum (modified from Snodgrass, 1935).

lost in holometabolous insects by invagination along a midlongitudinal line during postembryonic development and that the pterothoracic venter was comprised of pleural elements. Snodgrass (1935: 170) remarked only that Weber's hypothesis that the sternal apophyses were between the lateral edge of the primary sternum and the medial edge of the subcoxal laterosternite was not always true.

Ferris and his students (Ferris and Rees, 1939; Rees and Ferris, 1939; Ferris, 1940a), although not citing Weber, wrote that external pterothoracic sterna do not exist in Panorpa nuptialis Gerstaecker (Panorpidae), Tipula reesi Alexander (Tipulidae), and Plega signata (Hagen) (Mantispidae). Campau (1940), a student of Ferris, thought the metathorax of Chauliognathus pennsylvanicus (De Geer) (Cantharidae) lacked a sternum, but that mesosternal elements were present (fig. 19). The pterosternal apophyses of the four species are close together (except for those of the mesothorax of $C$. pennsylvanicus) and the ventral sclerite has a fold or furrow (discrimen) or median line (discriminal line [present only on the metaventral sclerite of $C$. pennsylvanicus]) that they interpreted as indicating the point of invagination of the entire basisternum and the meeting point of the subcoxal sclerites (fig. 19). The area on each side of the discrimen or discriminal line was referred to as the discriminal area (= preepisternum, fig. 19) and regarded to be of subcoxal origin (Ferris, 1940a: 36-37). Ferris (1940b: 88) extended this view to state that "in the vast majority of insects-probably 95 percent of them, ... the sternal apophyseal pits of the pterothoracic segments are set close together on the midline of the body." $\mathrm{He}$ considered close proximity to be the "primitive position" and that any more lateral position of the apophyses was correlated with the loss of "the ventral subcoxal arc" (= sternopleurite?; preepisternum?), in which case the resulting sclerite between the apophyses was truly sternal. In another article, Ferris (1940a: 36) stated that in Neuropteroid species the "only possible sternal element is the very narrow area between the sternal apophyseal pits and perhaps along the apex of the internal ridge formed by the meeting of the subcoxae" (= subcoxal sclerites). He interpreted a basisternal sclerite, an area between the sternal apophyseal pits, as a purely secondary development (Ferris, 1940b: 88). (However, see Matsuda, 1970, discussed below, who disagreed that the sternum was secondarily developed.) Ferris and his students regarded the sclerites on each side of the discrimen to be preepisternum (fig. 19). No 


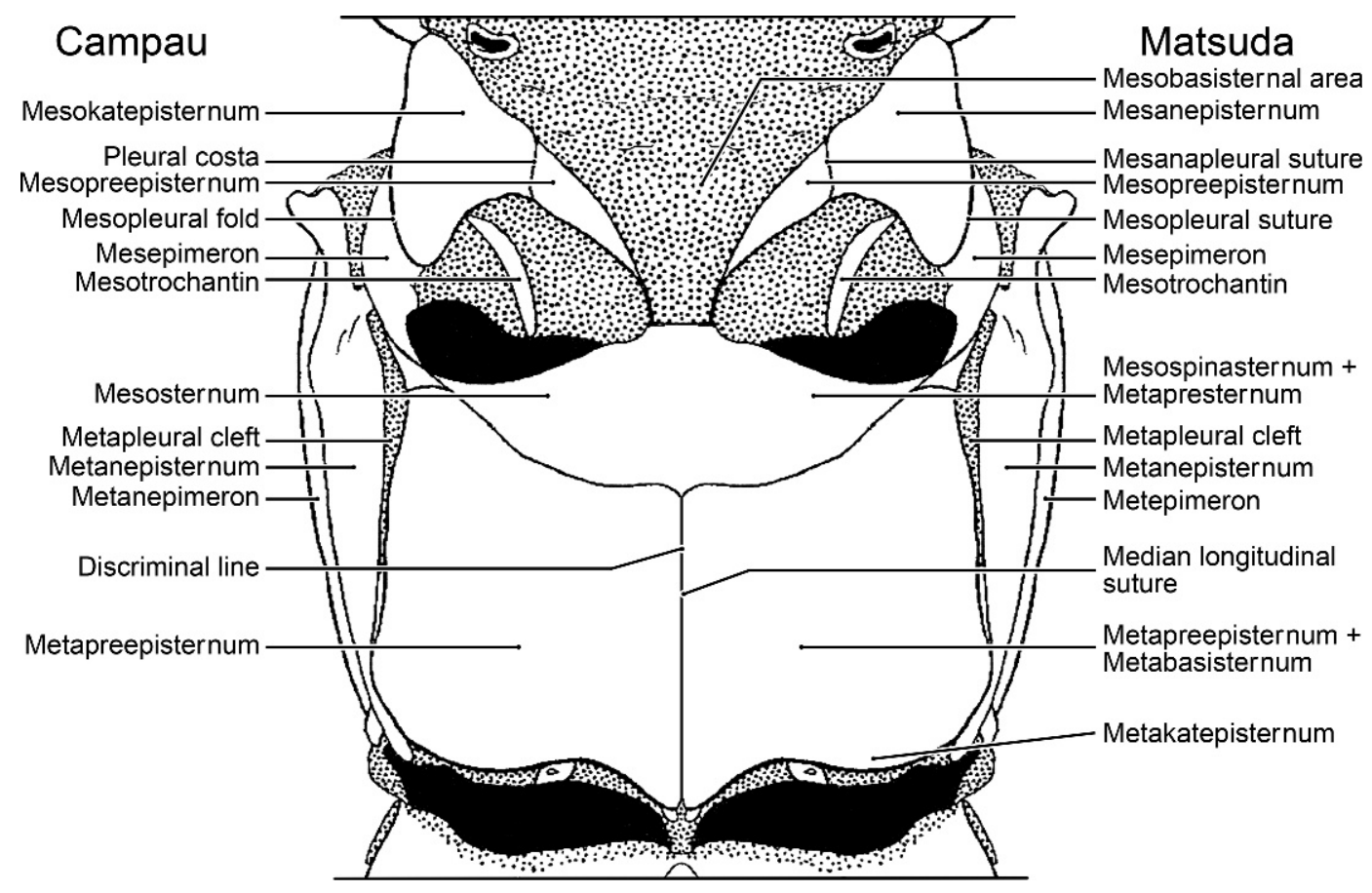

Fig. 19. Chauliognathus pennsylvanicus. Pterothorax, ventral, alternative terminology for sclerites and sutures proposed by Campau and Matsuda (modified from Campau, 1940, and Matsuda, 1970).

one discussed the fate of the laterosternite $(=$ sternopleurite of Snodgrass, 1935: 163, 192) (figs. 12, 14, 18) until Matsuda (1960: 713) renamed it "ventropleurite" and wrote that it was fused to either the basisternum or the preepisternum or lost. If the sternal apophyseal pits are near the lateral limit of the sternum, the ventropleurite would be laterad of the pits and, although unidentifiable, one wonders why the ventral sclerite is interpreted as only preepisternum rather than "preepisternum + ventropleurite." However, regardless of whether or not the sternal apophyseal pits mark the lateral edges of the sternum, any sclerites or membranes between them would be sternal because the endosternites are sternal elements. Saether (1980: 14) equated the sternopleurite with the preepisternum, but that interpretation is erroneous because they are separately derived sclerites according to morphologists cited in the preceding paragraphs.

Ferris's view that the ventral pterothoracic sclerites were of subcoxal origin was embraced by Michener (1944: 172-174) for bees and by Hansen and Cook (1976: 32) and Saether (1980: see preepisternum and mesosternum) for Chironomidae, and probably by other workers for other groups.

Matsuda (1960: 714; 1970) disputed the conclusions of Ferris that the presence of the basisternum was a secondary development by citing evidence that it is present in Thysanura, Ephemeroptera, and most hemimetabolous insects. Matsuda (1970: 21) further challenged the hypothesis of the loss by invagination of the pterosterna by citing a study on the postembryonic development of the thorax of a species of Apis that showed the median longitudinal ridge of the basisternum was "produced by the migration or proliferation of cells from a low midventral ridge... that suggest[s] that the basisternal median longitudinal elevation was not formed by invagination" (Matsuda, 1970: 21). He also cited Gnophomyia tristissima (Tipulidae) as having widely separated coxae and pleurosternal sutures, while at the same time having a median longitudinal suture $(=$ discriminal line) (Matsuda, 1960: 722, 723; 1970: 317, 
fig. 136b). In a dense, complex, demanding monograph, Matsuda (1970: 88-401) discussed or illustrated the thorax of species of 30 orders of insects and for nearly all he interpreted the presence of pterothoracic sterna. Some taxa with the sternal apophyses close together either lacked (Matsuda, 1970: figs. $118 \mathrm{~b}, 121$ ) or had reduced pterothoracic sterna: for example, Tipula, which had been regarded as lacking pterothoracic sterna by Rees and Ferris (1939), was considered to possess pterosternal sclerites by Matsuda (fig. 136a). Ferris's (1940a, 1940b) hypothesis was based on four pterygote orders of insects, but was challenged by Matsuda (1970) based on data for many more orders, both apterygote and pterygote. However, Matsuda's objections appear not to have been addressed.

For the Coleoptera, Matsuda (1970: 199218) regarded the pterothoracic pleural (subcoxal) sclerites to include an epimeron, anepisternum, katepisternum, preepisternum, and trochantin and the sternal sclerites to include a basisternum (including a presternum, an anterior part of the basisternum; fig. 19, also see fig. 18), and spinasternum (fig. 19); his ventral plate included both sternal and pleural elements. Matsuda (1970: 205-214) revisited Campau's (1940) study of Chauliognathus pennsylvanicus and renamed many of the structures according to a partial loss of the pterosterna and corrected some sclerites and sutures that Campau misunderstood (fig. 19, compare left and right sides). Naomi's (1988) study of the pterothorax of the Staphylinidae largely followed Matsuda's interpretation.

More recently, Lawrence et al. (2011: 33$34)$, without explanation, cited and endorsed Ferris's (1940b) hypothesis that the entire ventral and lateral surfaces of the metathorax were pleural sclerites, and adopted metaventrite for the ventral sclerite and, perhaps, so interpreted the mesoventrite, but that is unclear (see Lawrence et al., 2011: 30, char. 159). After the work of Ferris, Lawrence and associates were the next to apply this hypothesis broadly to the Coleoptera.

Matsuda's work $(1960,1963,1970)$ offers a far more complex and nuanced understanding of the pterothoracic ventral sclerites than do the views of Ferris. Matsuda agreed with Weber and Ferris that invagination occurred, but thought only part of the pterosternal sclerites were invaginated in most cases and that sternal loss was secondary. Based on the numerous examples in his 1970 work, insects have wide to narrow pterosterna, depending on the distance between the bases of the apophyses, and some may have no sternal elements at all. However, searching his 1970 monograph, one is hard-pressed to find examples of insects that have no sternal elements at all. His view might be summarized in a statement he made about beetles: "The degree of invagination of the basisternum and possibly of the preepisternum must vary in different beetles; in some beetles the original basisternal area is presumably present indistinguishably along the median longitudinal suture" (Matsuda, 1970: 214; fig. 19). Because Matsuda's ideas have not been refuted, the position adopted in the present work is his subtler perception of the evolution of the pterothoracic ventral sclerites. Despite the fact that "mesoventrite" and "metaventrite" were coined to refer to the pleural sclerites that replaced pterothoracic sterna lost through invagination, they are also useful terms to refer to the ventral sclerites that are a composite of sternal and pleural elements.

Mesothorax of Oedichirus: For the mesothorax of Oedichirus geniculatus (figs. 20, 21), the smaller and more posterior of the two lateral sclerites is the mesepimeron separated by the mesopleural suture from the larger mesanepisternum that is distinguished from the mesoventrite by a ridge, the mesanapleural suture. The mesanapleural suture terminates at the mesothoracic constriction near the anterior third of the segment. The mesoventrite lacks a discriminal line. The surface from the anterior margin to the mesothoracic constriction can be considered the mesobasisternum + mesopreepisternum + mesanepisternum, and behind the mesothoracic constriction the median surface is the mesobasisternum + mesopreepisternum. The mesoventrite between and posterior to the mesosternal apophyseal pits is the mesofurcasternum (= mesosternellum). The mesoventropleurite is theoretically indistinguishably fused between the mesobasisternum and mesopreepisternum, so a remnant of the ventropleurite may still be present. The 


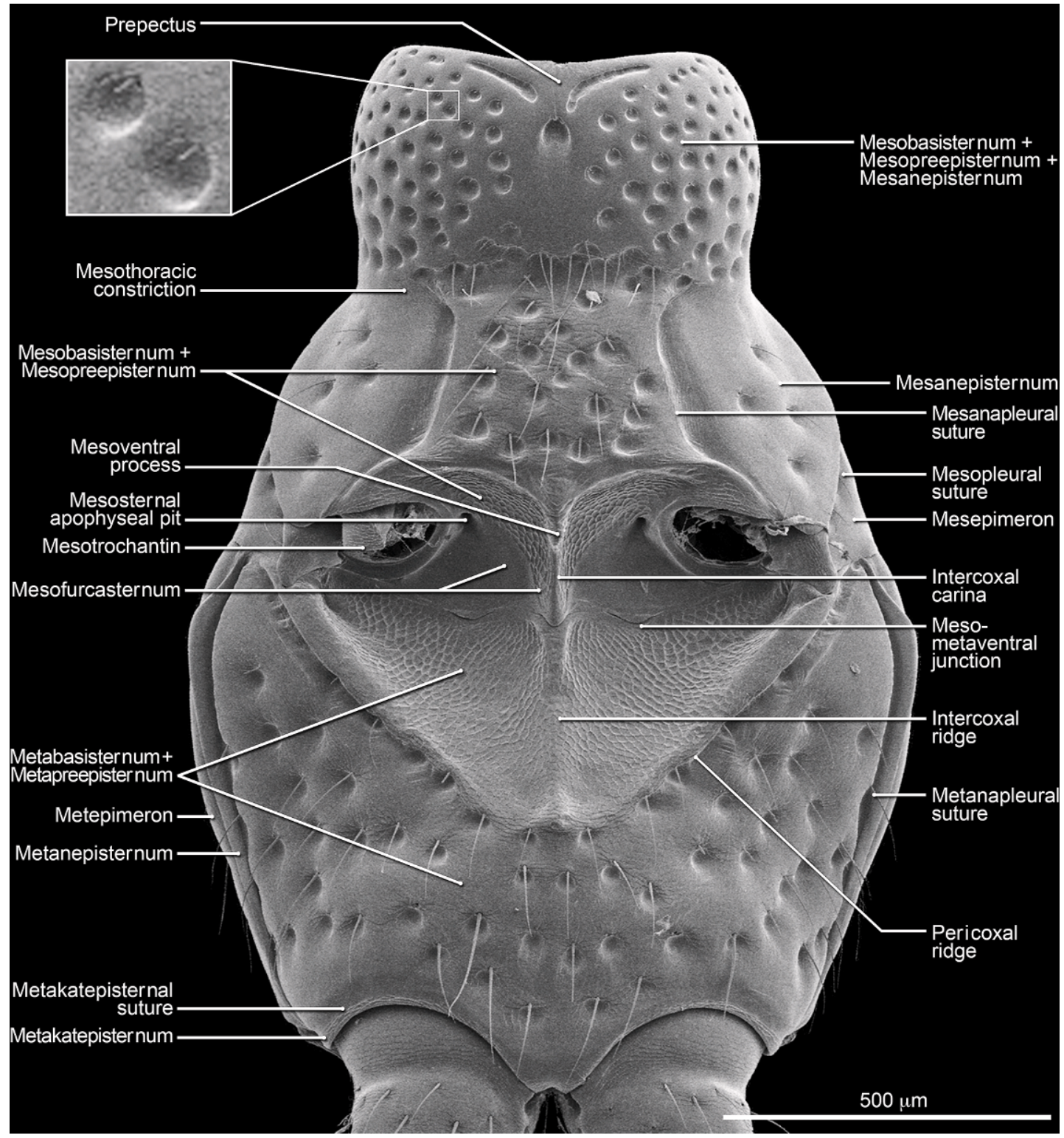

Fig. 20. Oedichirus geniculatus, Pterothorax, ventral. Inset to illustrate puncture with minute seta near anterior margin (SEM).

mesoventrite is separated from the metaventrite by a sinuous mesometaventral junction.

The mesopleura and mesoventrite are coarsely punctate (figs. 20, 21). The mesepimeron has a few coarse punctures along the anterior margin and the mesanepisternum has a cluster of coarse ones in the central region; the moderately long setae of both sclerites are inserted at the anterior margin of the punctures. Anterior to the mesothoracic constriction the punctures have minute setae (fig. 20, inset), whereas the punctures posterior to the constriction have long setae.

Metathorax of Oedichirus: The lateral sclerites of the metathorax (fig. 21) are the long, wide metepimeron dorsally separated by a metapleural suture from the more ventral, much narrowed metanepisternum. 


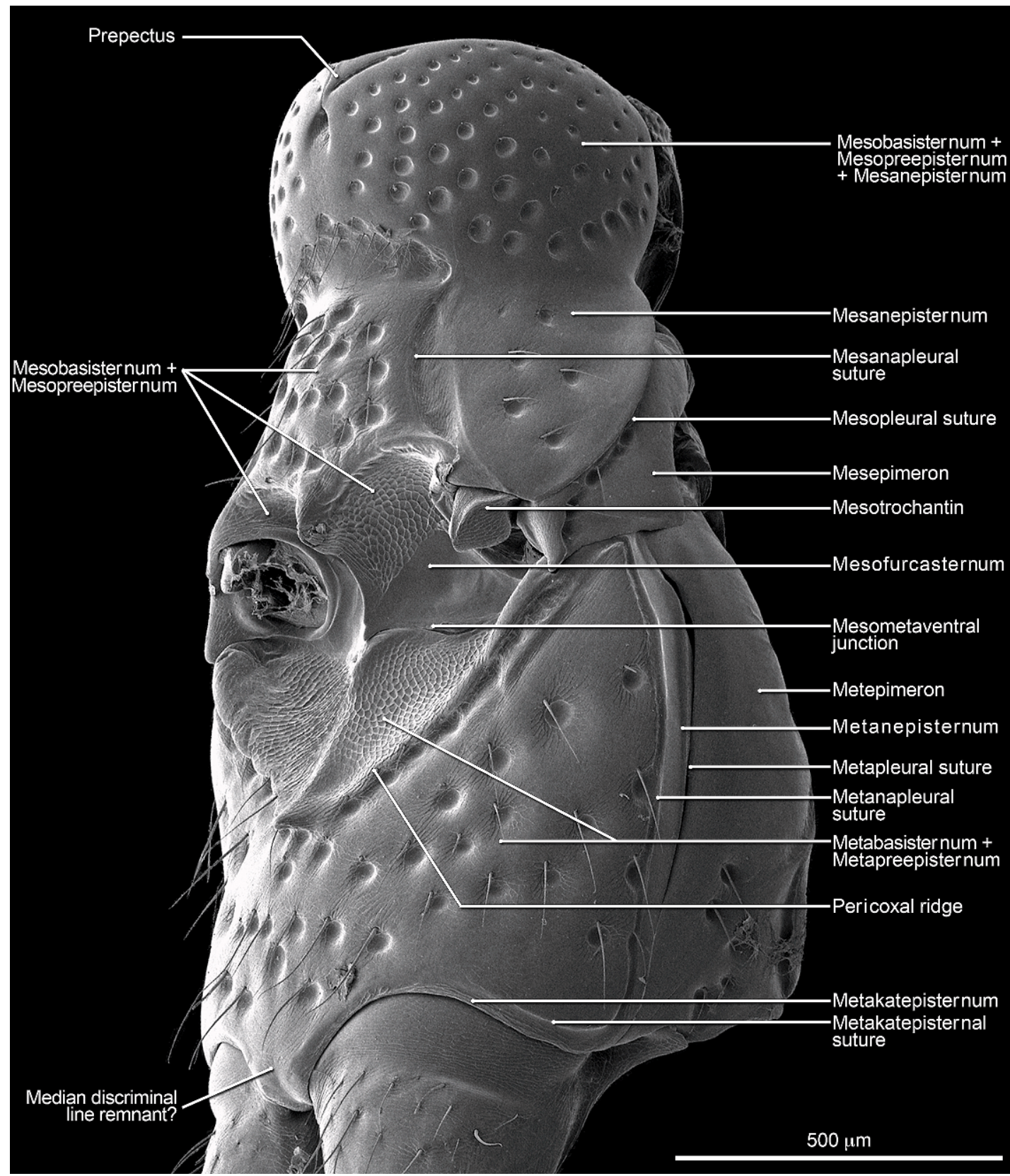

Fig. 21. Oedichirus geniculatus. Pterothorax, ventrolateral (SEM).

Distinguished ventrally from the metanepisternum by the metanapleural suture is the large metabasisternum + metapreepisternum (= metaventrite) which occupies the ventral surface. The metaventrite is not marked internally by a midlongitudinal ridge nor externally by a discriminal line (= median longitudinal suture, fig. 19), although the short, shallow, midlongitudinal groove between the metacoxae might be a remnant of the discriminal line (fig. 21). Along the posterior margin of the preepisternum, separated by the metakatepisternal suture, is a narrow metakatepisternum. 


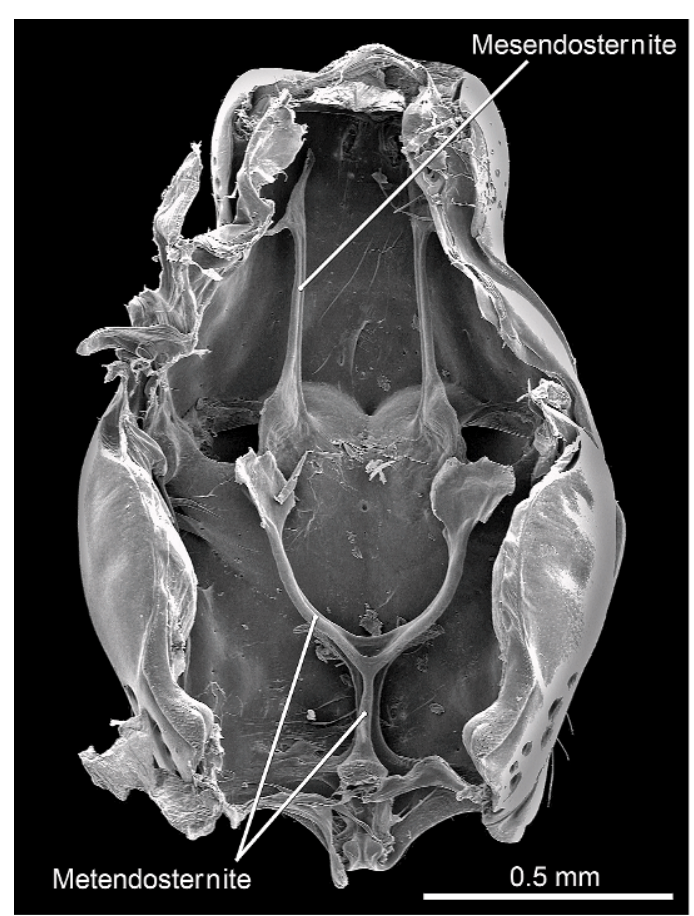

Fig. 22. Oedichirus geniculatus. Pterothorax, internal view, dorsal (SEM).

Most of the metaventrite is coarsely punctate and near the anterior edge of each puncture is a long seta. The mesocoxal cavity has strong microsculpturing. The mesocoxal cavity is formed by the inflexed posterior portion of the mesobasisternum + mesopreepisternum and the mesofurcasternum and is separated by the mesometaventral junction from the broadly depressed anterior portion of the metabasisternum + metapreepisternum. The mesocoxal cavity is margined posteriorly by a pericoxal ridge (figs. 20, 21) and has a midlongitudinal carina/ridge between the coxae; the anterior portion, on the mesoventrite, is a short intercoxal carina extending from the mesoventral process that continues on the metaventrite as a low, rounded ridge that reaches the pericoxal ridge that borders the posterior margin of the acetabulum.

In common with most Paederinae, the separated mesendosternite is a pair of straight, slender apophyses and a forked metendosternite (fig. 22).

LEGS: The forelegs of Oedichirus, in contrast to the middle and hind legs, are highly modified. The procoxa is elongate, the femur has a long slit ventrally that can open widely. The tibia has multiple rows of diagonally transverse combs on the ventral surface, which is not depressed; the apex is beveled. The basal four tarsomeres are inflated and are discussed in the description above. The function of the femoral opening is unknown, but it may be a secretory region (Herman, 2010: 17). Detailed examination of the enlarged protarsomeres requires SEM images, but most of the species were represented by so few specimens that exploration of the protarsomeres was impossible. The tibiae of all the legs lack spiniform setae along the length. The metatibial apical region is expanded and flattened and both sides of the apical margin have a comb of closely spaced, slender, spiniform setae. Mesotarsomere and metatarsomere 1 are longer than any of the four distal tarsomeres. The fifth tarsomere of the middle and hind legs originates at the base of tarsomere 4 , which extends beneath 5 and which is clothed ventrally by a dense pad of modified setae.

AbDomen: A term widely used by taxonomists of staphylinids for the one or two small sclerites between the tergum and sternum is paratergite. The term suggests that the sclerite is beside the tergite, but since the large, median, dorsal sclerite of each segment is the tergum (Snodgrass, 1935: 76$78,82)$ and not tergite, then the logical name for the adjacent sclerite(s) is paratergum (paraterga) (signifying "beside the tergum"). The term is purely descriptive and easily locates the sclerite without suggesting its origin. However, in the Staphylinidae these sclerites are probably of sternal origin (Herman, 1970: 350; Hansen, 1997: 26; Lawrence et al., 2011: 44, char. 279 [these authors appear to consider paratergites of staphylinids and the laterosternites and parasternites of other Coleoptera to be homologous]; Naomi, personal commun.) and it is possible that in the Staphylinidae they will be renamed to reflect this hypothesis, but until then paratergite is used.

The abdomen of Oedichirus is coarsely and densely to sparsely punctate; the punctures have a seta near the anterior margin. For most species the punctation is more or less evenly distributed, but in some species the punctures are arranged in transverse rows on 


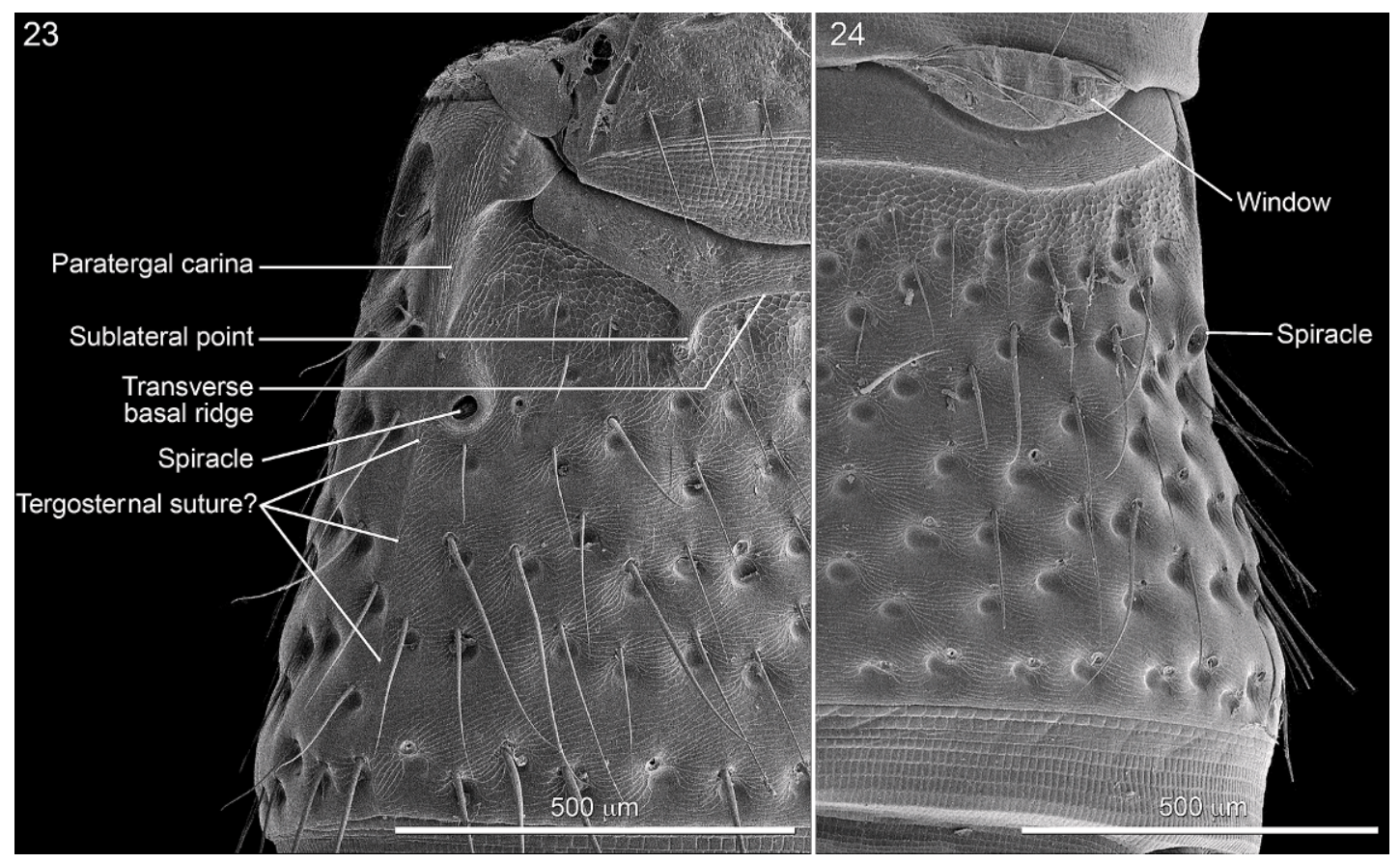

Figs. 23-24. Oedichirus geniculatus. 23. Abdominal segment III, dorsolateral (SEM). 24. Abdominal tergum VI, right half (SEM).

the apical half of the segment, and most, perhaps all, species have a row of small, setate punctures adjacent to the posterior margin. Punctures of the basal four segments (III to VI) are coarser, larger, and the distribution denser than on VII and VIII. Segments III to VII of Oedichirus have a dorsal and ventral pair of oval, opaquely membranous "windows" in the intersegmental membrane adjacent to the anterior margin (fig. 24). No glands nor glandular reservoirs associated with these structures have been found. Sternum IV of species of some paederine genera have an associated glandular reservoir; species of Oedichirus do not.

Sternum I, often represented in the Paederinae by a narrow, frequently medially divided sclerite near the anterior margin of sternum II, is absent in Oedichirus. Sternum II is as wide as segment III, is fused to the anterior margin of sternum III, has a row of setae along the posterior margin, and a median intercoxal ridge; the anterior margin is bisinuate and lobed medially. Sternum III has a median intercoxal carina that ends in an acute, ventroposteriorly directed point near the middle of the segment. A short, sublateral, posteriorly directed carina extends from the transverse basal ridge. The transverse basal ridge of tergum III has a similar, but shorter, sublateral, posteriorly directed ridge that is usually reduced to a trianguloid projection which herein is referred to as a sublateral point. Three New World species, $O$. bullaglaber, O. bullahirtus, and O. echinatus, have a third, similar medial projection, the median point (similar to sublateral point of fig. 23 and to that on tergum VIII, fig. 26). Tergum VIII also has a median point in $O$. exilis, $O$. clavolateralis, $O$. bullaglaber, $O$. bullahirtus, $O$. echinatus, and $O$. geniculatus, whereas other species lack it. The median point of tergum VIII is apically open (fig. 114) or closed (fig. 73).

The abdomen of Oedichirus is cylindrical, most segments lack paratergites, and the tergum and sternum of most segments are fused. Segment III for some species has one paratergite (on each side) that is about as long as the segment, narrow, and tapered posteriorly; for these species the tergum and sternum are separated. Paratergite III is 
present in six New World species (O. batillus, $O$. bicristatus, $O$. hamatus, $O$. isthmus, $O$. optatus, and $O$. sinuosus). For the other species a carina replaces the paratergite. This carina, the paratergal carina, although smaller, is of similar form and occupies the same position as would the paratergite and extends to, or slightly to well beyond, the spiracle (fig. 23). There may be a feeble line, a remnant of the tergosternal suture, extending posteriorly from the end of the paratergal carina (fig. 23), but the tergum and sternum are fused. Because the paratergal carina and the paratergite are of similar size, form, and position, it seems likely that the former is derived from the latter. Segments IV to VII lack paratergites, but the lateral surface of some segments of some species have a faint ridge just ventrad of the spiracle that may be a remnant of the tergosternal suture. Although segment VII lacks this feeble ridge, the separation of the tergum and sternum is marked posteriorly by an incision that may be the remainder of a tergosternal suture (fig. 25). This incision is tiny in some species, for example $O$. apiculus, $O$. glabrihamus, and O. misionesiensis. Tergum and sternum VIII are separated and the segment always lacks paratergites (fig. 26). As is the case for many paederines, sternum VIII of Oedichirus has species-diagnostic features in males, but not in females.

Segment IX differs from the preceding segments in that the base of tergum IX extends from the dorsal (figs. 27, 140) to the ventral side (fig. 28) and the lateroapical corners of the tergum are prolonged posteriorly beyond the median posterior margin and referred to as lateroapical processes (figs. 28, 29). In some paederines tergum IX is divided dorsally, and the halves can be referred to as hemitergites or laterotergites, but for Oedichirus tergum IX is fused middorsally (figs. 27, 140). Tergum IX of Oedichirus differs between males and females. Most males have a dorsoventrally flattened process extending anteriorly from the ventromedial edge of the anterior margin of the tergum; the process is short, wide, and apically rounded to long, moderately wide, and apically rounded to truncate; the females lack this process (fig. 29). The size and form of the anteroventral process of the males varies among species. For males and for most females, the anteroventral edges of tergum IX are separated midventrally (figs. 28, 29), but near the left margin in O. optatus (fig. 195). However, for females of $O$. dilophus, O. distortus, O. lunatus, O. ohausi, and $O$. procerus, the anteroventral angles are fused midventrally to form a narrow to moderately wide bridge or strap (figs. 108, $116,169,186,197)$. The lateroapical processes are long, slender, tapered, apically acute, tubular, ventrally curved, and usually widely separated. In most species the ventral curvature of the lateroapical processes is slight (fig. 158) to moderate and the processes parallel to each other or slightly divergent. Those of $O$. lunatus are semicircularly curved in lateral view (fig. 168) and widely separated apically in dorsal view (fig. 170). In dried specimens the lateroapical processes nearly touch distad of the base and perhaps do so in live individuals also or perhaps the processes touch only as an artifact of drying. Sternum IX, the median ventral sclerite, of the male is long, wide, and symmetrical or asymmetrical (figs. 28, 37, 45, 109, 117). The more complex female ventral sclerite of IX is discussed in the following paragraph. Tergum $X$ (fig. 27) is embedded in the gap between the lateroapical processes of tergum IX and attached to the middorsal posterior margin of tergum IX. Tergum $\mathrm{X}$ is large to small, shield shaped, and has cuticular processes on the posterior margin that is broadly rounded and that may be slightly produced medially. Tergum X of Oedichirus is exposed and only the basal edge is slightly covered by tergum IX.

As briefly discussed already (Herman, 2010: 26-27), the female genital sclerites exhibit wide variation in the Paederinae. In that same article, these sclerites were illustrated for one species of Oedichirus. However, despite the large number of species, about $75 \%$ of which were described in the last 40 years (Fagel, 1971; Lecoq, 1986, 1987, 1990, 1991, 1996; Janák, 1995, 1996, 1998, 2003; Last, 1980; Jarrige, 1978; Hayashi, 1989; Outerelo and Gamarra, 1988), the female genital sclerites of Oedichirus remain unknown. Females of 18 New World species were available for examination. For the species of Oedichirus examined, the median gonocoxal plate is wide, long, lacks styli, and 


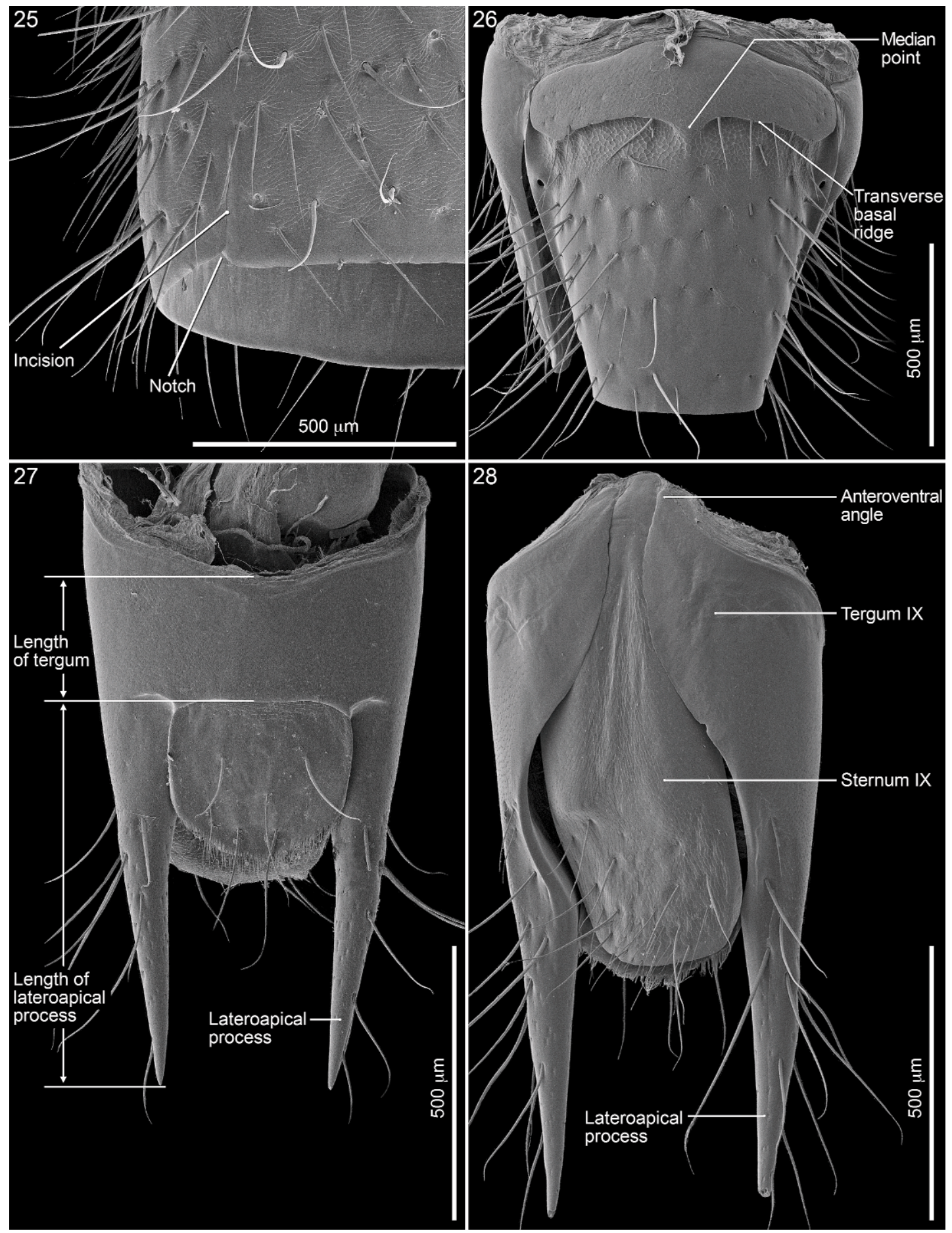

Figs. 25-28. Oedichirus geniculatus. 25. Segment VII, lateroapical apex, dorsolateral (SEM). 26. Segment VIII, dorsal (SEM). 27. Terga IX and X (SEM). 28. Segment IX, ventral (SEM). 
has an associated vulvar plate (figs. 29, 186). The size, form, and presence of the median gonocoxal plate anterior to the vulvar plate varies (figs. 52, 68, 76, 195) and for all species but $O$. optatus (fig. 195), the median gonocoxal plate is far larger posteriad of the vulvar plate than anteriad (figs. 29, 52). The anterior portion can be large and triangular or trapezoidal (figs. 68, 76, 148), or a narrow strap (figs. 52, 116). For $O$. lunatus and $O$. ohausi the anterior portion of the median gonocoxal plate is joined to the fused anteroventral angles of tergum IX (figs. 169, 186). For $O$. boehmi and $O$. dilophus, the anterior portion of the median gonocoxal plate is lost and the vulvar plate is attached only to the anterior edge of the posterior portion of the median gonocoxal plate rather than embedded in it (figs. 64, 108).

The vulvar plate of New World species is comprised of an anterior and posterior lobe that, in most species, is embedded in the median gonocoxal plate (figs. 29, 69). The two vulvar lobes are clear and distinct for most species, but for $O$. dilophus and $O$. lunatus the demarcation is subtle (figs. 111, 171) and appears to be incomplete. The posterior vulvar lobe is transverse (figs. 69, $118,159,185)$ to more or less rounded (figs. 97, 196) and includes the vulva (figs. 69,118 ) and the entrance to the vagina (Tuxen, 1956: 283); from the posterior vulvar lobe, on the interior side, the spermathecal duct can be seen extending (figs. 169, 171). For most species the anterior vulvar lobe is transverse (figs. 118, 159, 185) or transversely arc shaped (figs. 69, 118, 151) and may wrap around the anterior and lateral margins of the posterior vulvar lobe (figs. 55, 186, 196, $220,224)$. For two species, $O$. boehmi (figs. 64, 67) and $O$. ohausi (figs. 186, 187), the anterior vulvar lobe envelops the right anterolateral margin of the posterior vulvar lobe, which, for the latter species, is more irregularly shaped than in others. Both vulvar lobes of $O$. boehmi are strongly sclerotized, unlike other New World species. Generally the two lobes of the vulvar plate are membranous and adorned with variously distributed microstructures, or are without adornment or slightly to strongly sclerotized (fig. 186). The anterior vulvar lobe is smooth or wrinkled (figs. 118, 151, 159), covered with a reticulate fan (fig. 224) or cuticular processes of varying density, form, and length (figs. 55, 69, 111), or is membranous and without adornment (figs. 118, 220). The ornamentation of the posterior lobe includes cuticular processes (fig. 111), cuticular cobble (figs. 69, 88, 196), and reticulation (fig. 159). The cuticular processes may have one to five or six apical fimbriae (figs. 111, 185). The orientation of the vulva, which is often surrounded by membranes and which often appears to be in a depression, is vertical (fig. 69), diagonal (figs. 111, 196), or transverse (fig. 159), and straight (fig. 69) or curved (fig. 118). In the confocal laser scanning images membranous regions that lack surface microstructures are black, with perhaps white lines where the membrane is wrinkled and overlaps itself (fig. 220), and merge with the surrounding black background as though nothing is present. The form of the anterior margin of the median gonocoxal plate and the form, type, and distribution of the adornment of the vulvar plate and its two lobes are diagnostic, perhaps for species or perhaps only for species groups. No general statements are possible about the female genitalia of Old World species because few species were examined.

A sclerotized spermatheca was not found. The spermathecal duct is long and extends from the vulva far into the abdomen (figs. 169, 171).

The aedeagus is asymmetrical and diagnostic for Oedichirus species. The median lobe varies considerably and has many features useful for identification of species (for examples see illustrations herein and those of Fagel, 1971; Lecoq, 1986; and Janák, 2003) and some characters for defining groups of species. The ventral sclerite of two clusters of species has an apicoventral process (figs. 142, 212) that extends from the apical margin and, in dorsal view, curves laterally to the right and the apex is directed anteriorly. The surface and edges of the ventral sclerite have species specific tumescences and spines. The condition of the parameres is partially diagnostic for species, but characters of the median lobe are more easily seen and exhibit more variation. The parameres taper apically from the base, are long, slender, and cylindrical to short, broad, 

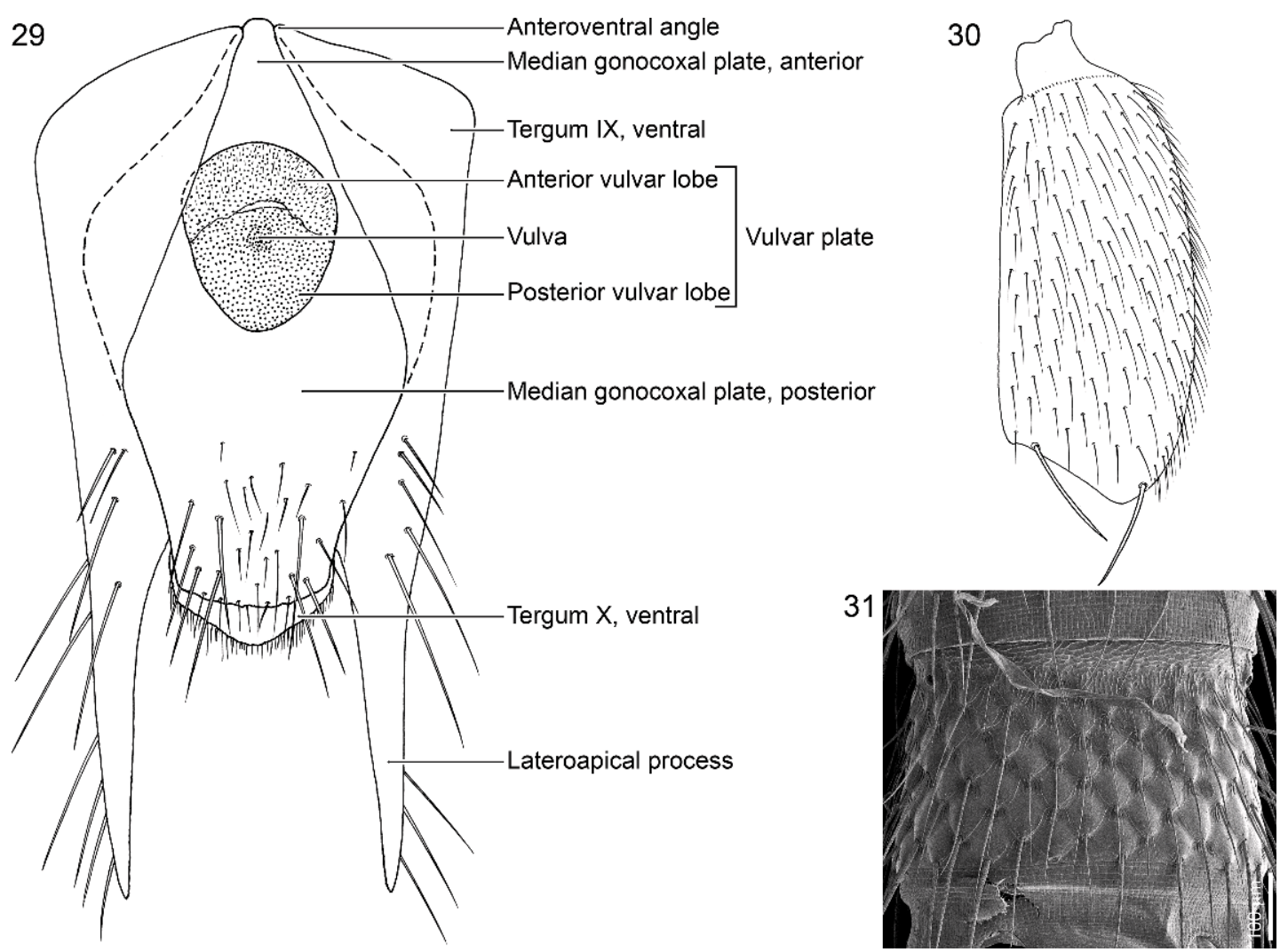

Figs. 29-31. 29. Oedichirus brunneus. Segment IX, ventral, female. 30. Palaminus sp. Right elytron. 31. Palaminus sp. Abdominal tergum V (SEM).

and flat. Short, broad, flat parameres are fused to the lateral sides of the median lobe. Long slender parameres are fused to the median lobe basally. The anterior portion of a basally broad, apically slender paramere is fused to the median lobe. For some species the paramere is so completely fused to the median lobe that only a shallow depression along the margin of an elongate tumescence marks the limit of the paramere. The internal sac is difficult to evert, but has processes, sclerites, spines, and microstructures that may help define species and/or perhaps groups of species. The internal sac of four species, $O$. bullaglaber, $O$. geniculatus, $O$. misionesiensis, and $O$. speculifrons (figs. 77, $146,178,215)$, everted spontaneously while clearing the aedeagus. The four exhibit significant, perhaps species-diagnostic differences. Two of them (O. speculifrons and $O$. misionesiensis) are in the same species group based on other characters, also share features of the internal sac. The other two species, $O$. geniculatus (fig. 152) and $O$. bullaglaber (fig. 78), are in different species groups and their respective internal sacs differ from each other and from the other two species. A wealth of diagnostic and phylogenetic characters may become available if techniques are developed that permit consistent, reliable eversion of the internal sac. Note that even without eversions, spines and processes often can be seen on the internal sac through the cuticle of the aedeagus. However, I have never been able to consistently and adeaquately clear the inside of the aedeagus of miscellaneous tissue to render structures of the internal sac visible. Furthermore, even when visible, the interspecific relationship of the structures is obscure - if the internal sac of one species is visible that of other species often is not. 
Keys to New World Species of Oedichirus (Two keys are presented here, one for males and one for females.)

\section{Key 1. Males of Oedichirus}

(Sternum VIII with emargination of posterior margin and with surface modified by depressions, tumescences, or clusters of spiniform setae. Males are unknown for $O$. brunneus, $O$. hamatus, O. lunatus, O. ohausi, O. procerus, and $O$. sparsipennis)

1. Sternum VIII weakly, barely detectably, and broadly emarginate (fig. 184); surface with subapical comb of spinelike setae; Costa Rica, Nicaragua (?) . . neotropicus Sternum VIII with distinct, shallow to deep emargination (figs. 102, 163); surface with or without comb of spinelike setae

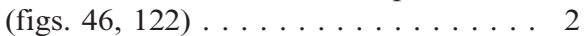

2 (1). Sternum VIII with asymmetrical emargination of posterior margin (figs. 73, 85, $102,114) \ldots \ldots \ldots \ldots \ldots \ldots$ Sternum VIII with symmetrical emargination of posterior margin (figs. 46, 53, 59) . . . 12

3 (2). Tergum VIII with median point extending from transverse basal ridge (fig. 26). . 4 Tergum VIII without median point extending from transverse basal ridge. . . 9

4 (3). Tergum III with median point extending from transverse basal ridge (as for sternum VIII, fig. 73) . . . . . . . . . 5 Tergum III without median point extending from transverse basal ridge. . . . . 6

5 (4). Aedeagus with posterior margin of ventral sclerite notched (fig. 71); tumescence of sternum VIII asetate and gradually sloped posteriorly (figs. 73, 74); Santa Catarina, Brazil. . . . . . . . . bullaglaber Aedeagus with posterior margin of ventral sclerite entire (fig. 81); tumescence of sternum VIII setate and sharply sloped posteriorly (figs. 84, 85); São Paulo, Brazil . . . . . . . . . bullahirtus

6 (4). Aedeagus with blunt peg on right lateroapical margin of ventral sclerite dorsad of apicoventral process (figs. 98, 99); Rio de Janeiro, Brazil . . . . . . . . clavulus Aedeagus not as described above . . . 7

7 (6). Aedeagus with broad lobe on left side of posterior margin of ventral sclerite (fig. 90); ventral sclerite with knob extending laterally from base of right margin of apicoventral process (fig. 89); Rio de Janeiro, Brazil . . . . . . . clavolateralis Aedeagus not as described above ... 8

8 (7). Aedeagus with flattened lobe extending dorsally from ventral sclerite near base of apicoventral process (fig. 129); labrum without tubercle near base of submedial denticle; Rio de Janeiro, Brazil. . . . exilis Aedeagus without adornment near base of apicoventral process (fig. 141); labrum with tubercle near base of submedial denticle (fig. 136); Rio de Janeiro, Brazil .

............. geniculatus Paratergite of segment III present, paratergal carina absent. . . . . . . . 10 Paratergite of segment III absent, paratergal carina present (fig. 23) . . . . . 11

10 (9). Sternum VIII with irregularly arranged, transverse cluster of subapical, spinelike setae (fig. 163); sternum VII with large, median cluster of short spinelike setae (fig. 165); Jalisco, Mexico . . . . . isthmus Sternum VIII with strongly curved, evenly arranged, transverse row of subapical, spinelike setae (fig. 203); sternum VII with small, median cluster of long, slender spinelike setae (fig. 205); Yucatan, Mexico ............. sinuosus

11 (9). Sternum VIII with prominent process on right side of emargination of posterior margin (fig. 114); sternum VII without median cluster of spinelike setae; Ecuador . . . . . . . . . . distortus Sternum VIII without process on posterior emargination (fig. 122); sternum VII with dense median cluster of spinelike setae (fig. 121); Dominican Republic ......... .......... dominicanensis

12 (2). Paratergite of segment III present, paratergal carina absent. . . . . . . . 13 Paratergite of segment III absent, paratergal carina present (fig. 23) . . . . . 15

13 (12). Sternum VIII with deep, narrow emargination (fig. 193); Pará, Maranhão, Mato Grosso, Brazil .......... optatus Sternum VIII with wide, shallow to moderately deep emargination (figs. 53, 59). . . . . . . . . . . . . . 14

14 (13). Sternum VIII without cluster of spinelike setae (fig. 53); emargination of posterior margin moderately deep (fig. 53); Pará, Brazil. . . . . . . . . . . batillus Sternum VIII with dense cluster of spinelike setae medially (fig. 59); cluster divided medially and with setae lateroposteriorly directed from middle; emargination of posterior margin shallow (fig. 59); São Paulo, Brazil . . . . . . . bicristatus 
15 (12). Tergum III with median point extending from transverse basal ridge (as for sternum VIII, fig. 73); Parana, Brazil ... echinatus

Tergum III without median point. . . 16

16 (15). Head with V-shaped depression dorsally; pronotum sparsely punctate and with deep, submedial, punctate groove; elytra longer than conjoint width (EW/ $\mathrm{EL}=0.9-0.8)$ and dorsal surface concave; Bahia, Brazil . . . . . boehmi Head without V-shaped depression dorsally; pronotum moderately densely punctate and with submedial cluster of punctures; elytral conjoint width greater than length $(\mathrm{EW} / \mathrm{EL}=1.1-1.4)$ and dorsal surface flat to convex . . . . 17

17 (16). Aedeagus with apicoventral process extending to right from apex of ventral sclerite (figs. 42, 212); sternum VIII without subapical, submedian carina (figs. 46, 155); sternum VIII with transverse basal ridge entire, not separated medially (figs. 46, 47) . . . . . . 18 Aedeagus without apicoventral process (fig. 104); sternum VIII with short, subapical, submedian carina adjacent to median depression (fig. 106); sternum VIII with transverse basal ridge separated medially (fig. 107); Bolivia...... .

18 (17). Aedeagus with posteriorly directed apically truncate, conical peg-boss at base of left side of apicoventral process (figs. 173); Misiones, Argentina ...... . . . . . . . . . . misionesiensis Aedeagus without peg-boss at base of apicoventral process (fig. 42, 212). . 19

19 (18). Aedeagus with apically acute, spiniform process at base of apicoventral process on apical margin of right lateral side of ventral sclerite (figs. 41, 44); Santa Catarina, Brazil ........ apiculus Aedeagus without spiniform process as above. . . . . . . . . . . . . 20

20 (19). Aedeagus with broad flat surface of apicoventral process facing ventrally and nearlyhorizontal (fig. 154); ventral sclerite of aedeagus with small, pointed lobe on right margin near base of apicoventral process (fig. 153); Santa Catarina, Brazil. . . . . . glabrihamus Aedeagus with flat surface of apicoventral process posteriorly facing and nearly vertical (figs. 211, 212); ventral sclerite of aedeagus without pointed lobe on right margin near base of apicoventral process (fig. 212); Santa Catarina, Brazil. . . . . . speculifrons
Key 2. Females of Oedichirus

(Sternum VIII unmodified. Females

unknown for $O$. apiculus, O. bicristatus,

$O$. clavolateralis, $O$. clavulus, $O$. dominicanensis, O. echinatus, O. exilis, O. glabrihamus, $O$. isthmus, O. misionesiensis, and $O$. sinuosus)

1. Paratergite of segment III present, paratergal carina absent. . . . . . . . . . 2 Paratergite of segment III absent, paratergal carina present (fig. 23) . . . . . 4 4

2 (1). Median gonocoxal plate strongly asymmetrical (fig. 195); tergum IX with right anteroventral angle extending across width of segment to left side and left anteroventral angle absent (fig. 195); legs unicolored, without dark femorotibial spot (as in fig. 1); Pará, Maranhão, Mato Grosso, Brazil .......... optatus Median gonocoxal plate symmetrical (figs. 52, 157); tergum IX with left and right anteroventral angles of approximately equal size (figs. 52, 157); legs bicolored (as in fig. 2) or unicolored (as in fig. 1) . . . . 3

3 (2). Tergum IX with large, posteriorly directed, flat spur on ventrolateral edge below lateroapical process (figs. 157, 158); legs bicolored, with dark femorotibial spot (as in fig. 2); Peru . . . . . . . . . hamatus Tergum IX without spiniform process on ventrolateral edge (fig. 52); legs unicolored, without dark femorotibial spot (as in fig. 1); Pará, Brazil . . . . . . . batillus

4 (1). Tergum III with median point (as for sternum VIII, fig. 73) . . . . . . . . 5 Tergum III without median point. . . 6

5 (4). Body bicolored, head and pronotum dark reddish brown to black, elytra and abdomen pale to dark reddish brown; Santa Catarina, Brazil . . . . . . bullaglaber Body unicolored dark reddish brown; São Paulo, Brazil . . . . . . . bullahirtus

6 (4). Tergum VIII with median point (fig.

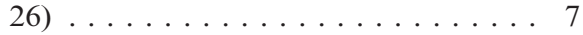
Tergum VIII without median point. ... .9

7 (6). Tergum IX with long, semicircularly curved, lateroapical process (figs. 168, 170); anteroventral angles fused to each other and to tergum IX (fig. 169); Bahia, Brazil . . . . . . . . . . lunatus Tergum IX with moderately long, slightly curved lateroapical process (as in fig. 158); anteroventral angles separated from each other and from tergum IX (fig. 68). . 8

8 (7). Median gonocoxal plate anteriad of vulvar plate triangular with strongly sloping lateral sides (fig. 68); lateroapical process of tergum IX less than two times longer than 
midbasal length of tergum (LLaP/T9 = 2.0); São Paulo, Brazil . . . . . . brunneus Median gonocoxal plate anteriad of vulvar plate triangular to trapezoidal and with gradually sloping lateral sides (figs. 148-150); lateroapical process of tergum IX two or more times longer than midbasal length of tergum (LLaP/ T9 = 2.0-3.0); Rio de Janeiro, Brazil . . ........... geniculatus Median gonocoxal plate anteriad of vulvar plate trapezoidal with gradually sloping lateral sides (fig. 206); lateroapical process of tergum IX about two times longer than midbasal length of tergum $(\mathrm{LLaP} / \mathrm{T} 9=1.7)$; Santa Catarina, Brazil ......... sparsipennis

9 (6). Tergum IX with anteroventral angles fused medially (figs. 108, 116) . . . . 10 Tergum IX with anteroventral angles separated medially (figs. 29) . . . . . 13

10 (9). Vulvar plate densely covered with apically acute cuticular processes (fig. 110); median gonocoxal plate absent anteriad of vulvar plate (fig. 108); Bolivia . . . . . ............ dilophus Vulvar plate without apically acute, cuticular processes (fig. 118); median gonocoxal plate anteriad of vulvar plate narrow and straplike (figs. 116, 197) . . . . 11

11 (10). Labrum with 2 denticles; elytral disc concave; Bahia, Brazil .... procerus Labrum with 4 denticles; elytral disc concave or flat. . . . . . . . 12

12 (11). Legs bicolored, with dark femorotibial spot (as in fig. 2); anterior vulvar plate not sclerotized (fig. 118); tergum VIII with broadly emarginate posterior margin and with small median lobe; Ecuador............. distortus Legs unicolored, without dark femorotibial spot (as in fig. 1); anterior vulvar plate partially sclerotized (fig. 187); tergum VIII with broadly rounded posterior margin and without distinct median lobe; São Paulo, Brazil . . . . . . ohausi

13 (9). Head with V-shaped depression dorsally; median gonocoxal plate absent anteriad of vulvar plate (fig. 64); Bahia, Brazil ............ boehmi Head without V-shaped depression dorsally; median gonocoxal plate present anteriad of vulvar plate (figs. 183, 210) . . . . . . . . . . 14

14 (13). Legs bicolored, with dark femorotibial spot (as in fig. 2); tergum VIII with broadly emarginate posterior margin; Costa Rica, Nicaragua . . . neotropicus
Legs unicolored, without dark femorotibial spot (as in fig. 1); tergum VIII with shallowly emarginate to rounded posterior margin; Santa Catarina, Brazil ........... speculifrons

\section{Oedichirus paederinus Erichson}

Figures 1, 32-38

Oedichirus paederinus Erichson, 1840: 685.

— Lucas, 1846: 121 (Algeria). — Redtenbacher, 1857: 217 (characters; Sicily). - Rottenberg, 1870: 34 (Sicily). — Fauvel, 1873a: 291 (= 1873b: 133) (Sicily; Barbarie). — Redtenbacher, 1874: 236 (characters). — Fauvel, 1878a: 105 (= 1878b: 25) (Algeria; Morocco). - Fauvel, 1886a: 33, 98 (= 1886b: 25, 90) (Algeria; Morocco; Tunisia). — Ragusa, 1891: 241 (Sicily). — Fauvel, 1897: 271 (Morocco; Algeria; Tunisia). - Champion, 1898: 98 (Gibraltar). - Fauvel, 1902: 81 (notes; Barbary). — Reitter, 1906: 263 (key). — Bernhauer and Schubert, 1912: 201 (catalog). — Porta, 1926: 67 (characters; Basilicata; Calabria; Sicily; Sardinia). - Scheerpeltz, 1933: 1218 (catalog; Spain). Normand, 1935: 365 (Tunisia; Algeria). Coiffait, 1978: 330 (characters; distribution). Outerelo and Gamarra, 1989: 377 (characters; notes; illustrations; Morocco). - Sparacio, 1995: 150 (characters; notes; Sicily). — Ciceroni and Zanetti, 1995: 20 (checklist; Italy; Sicily; Sardinia). - Smetana, 2004: 624 (subgenus Oedichirus; catalog; Italy; Spain; Algeria; Morocco; Tunisia). — Herman, 2010: 45 (Italy; Spain; Morocco; Algeria; Tunisia).

Oedichirus quedenfeldtii Schaufuss, 1888: 314 (Oedichirus; type locality: Marocco).

- Fauvel, 1897: 271 (synonym of paederinus). - Fauvel, 1902: 81 (synonym of paederinus). Bernhauer and Schubert, 1912: 201 (synonym of paederinus). - Coiffait, 1978: 330 (synonym of paederinus). - Smetana, 2004: 624 (synonym of paederinus).

Type Material: Not examined. Deposited in Berlin (MNHB).

TyPe LocAlity: Sicilia.

Diagnosis: This species is confined to southern Europe and northwestern Africa. It can be separated from all of the New World species by the Paederus-like coloration (fig. 1) and the transverse tergal carina on tergum IX that extends from the dorsal to the lateral and ventral surfaces (fig. 38) in both 


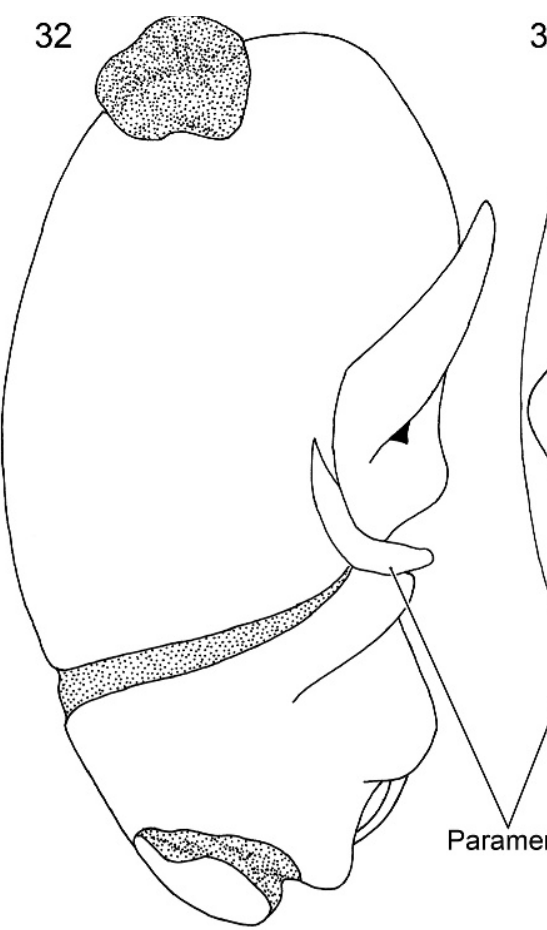

35

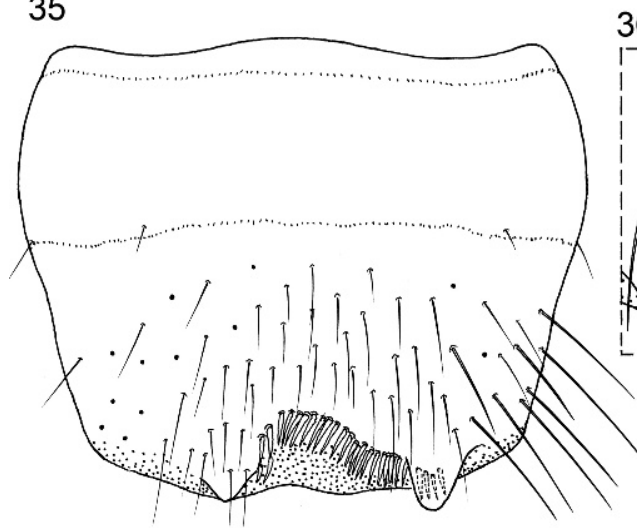

33

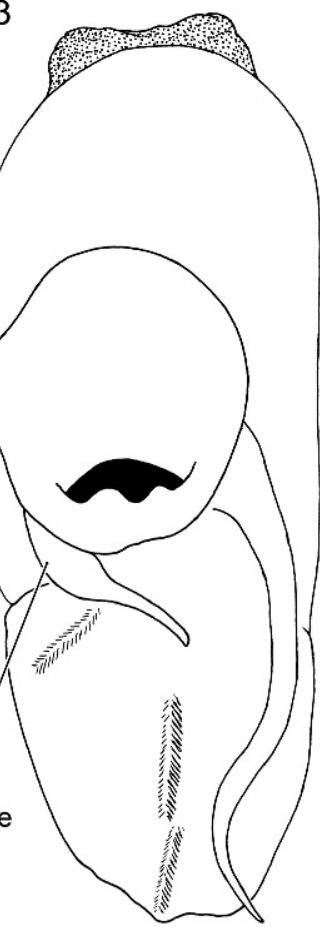

36

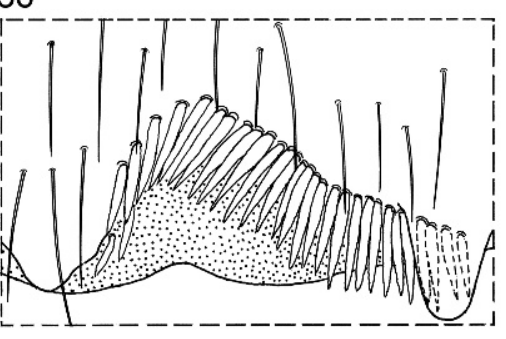

34

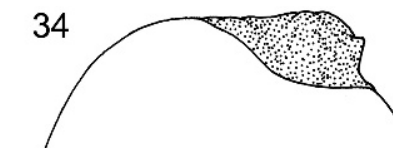




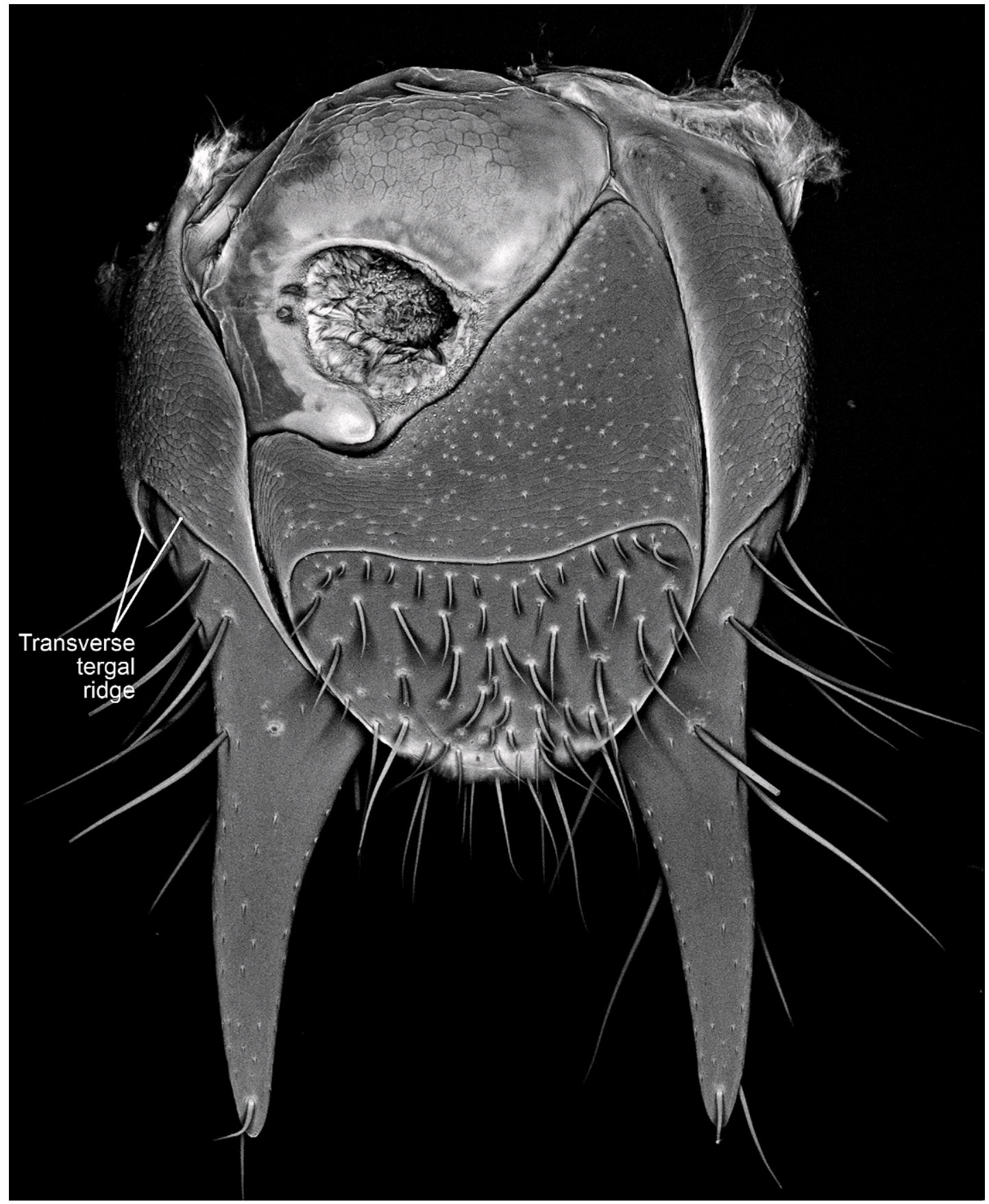

Fig. 38. Oedichirus paederinus. Segment IX, ventral, female (CLSM).

coarse, sparse punctation laterally and posteriorly and less dense medially and anteriorly. Labrum quadridentate; surface without tubercle near submedial denticle (compare fig. 3).
Pronotum about a tenth to a fifth longer than wide (PL/PW: 1.1-1.2). Pronotum with coarse punctation; punctation variable and arranged in scattered, dense clusters; submedial 
cluster large with punctures evenly arranged or with posterior punctures arranged in sinuous row; surface with or without moderately deep, submedial, punctate groove on basal half beginning near middle. Elytra with length about a fifth less than to equal to width (EW/EL: 1.0-1.2); surface coarsely punctate and slightly convex.

Abdominal segments III to VI with transverse rows of coarse punctation; VII with transverse rows of finer punctation. Segment III with short paratergal carina (as in fig. 23) reaching to or nearly to spiracle but not beyond; carina poorly to moderately well developed. Tergum III without median point extending from transverse basal ridge. Tergum VIII with broadly, slightly rounded to straight posterior margin; transverse basal ridge broadly, shallowly curved anteriorly, and without median point. Tergum IX with lateroapical process about a fifth longer to a fifth shorter than midbasal length (LLaP/L9 $=0.8-1.2$ ), straight to feebly bent ventrally, and slightly diverging from other process; surface with curved, sinuous, transverse tergal ridge dorsally and laterally to ventromedial margin (fig. 38); ventromedial margin without posteriorly directed spur (cf. fig. 158).

MALE: Sterna VI and VII unmodified. Sternum VIII (figs. 35, 36) asymmetrical; posterior marginal region divided into membranous to lightly sclerotized posterior margin and sclerotized submarginal region; posterior margin lightly pigmented, lightly sclerotized, and translucent left and right of posteriorly directed, sclerotized processes that gradually become membranous medially; posterior margin membranous between sclerotized processes, with shallow, basally rounded emargination, and extending beneath and between sclerotized processes; submarginal sclerotized region with process on each side of midsagittal line extending posteriorly to or slightly beyond posterior margin; right process closer to midsagittal line than left; margin of submarginal region with comb of spinelike setae between submarginal processes; comb with many more setae to left of midsagittal line than right; comb with setae of left end beneath left process; right process broader than left; remainder of surface without depressions, carinae, tumescences, combs, or setal clusters; transverse basal ridge sinuate. Tergum IX with process reduced to small lobe on right and feeble swelling on left of anterior margin of anterovental angle; lateroapical process about a fifth shorter than to equal to midbasal length (LLaP/L9 = 0.8-1.0).

Aedeagus (figs. 32-34) asymmetrical. Median lobe with deep incision extending from left lateral side of ventral surface around dorsal surface to right lateral side; ventral surface with carina extending from near middle of posterior margin to large ventrally directed, strongly carinate lobe at about anterior end of apical quarter, lobe just to left of midsagittal line; ventral surface with strong carina on right side adjacent to deep circumferential incision and extending from ventral surface toward dorsal surface, carina large and strong ventrally and gradually diminishing dorsally; lateral apical margin without spurs, lobes, or processes. Ostial operculum rounded and broadly attached to apical margin of dorsal sclerite. Parameres strongly tapered from wide base toward slender, acute apices; right paramere short, sinuate, strongly curved medially, restricted to ventral surface, and not nearly reaching apical margin; left paramere long, sinuous, with apical fifth strongly curved dorsally, restricted to lateral side, and extending to apical margin.

FeMAlE: Tergum IX with anteroventral angles widely separated from each other (fig. 38); lateroapical process about a fifth longer than midbasal length $(\mathrm{LLaP} / \mathrm{L} 9=$ 1.0-1.2).

Median gonocoxal plate absent anteriad of vulvar plate (fig. 38); gonocoxal plate posteriad of vulvar plate large, wide basally, and gradually tapered posteriorly; anterior margin strongly asymmetrical (fig. 38); posterior margin broadly rounded; surface with curved, transverse ridge; ridge extending posteriorly along lateral edge of sclerite. Vulvar lobe anteriad of median gonocoxal plate, not embedded. Vulvar plate represented by only one vulvar lobe; lobe with large, deep pit on right side and adjacent to posterior margin (fig. 38); surface moderately strongly sclerotized. Vulva presumably in pit, and orientation indeterminate.

MATERIAL EXAMINED: 6 males, 2 females. Italy: Sizilian, Ragusa (2 males, FMNH); 

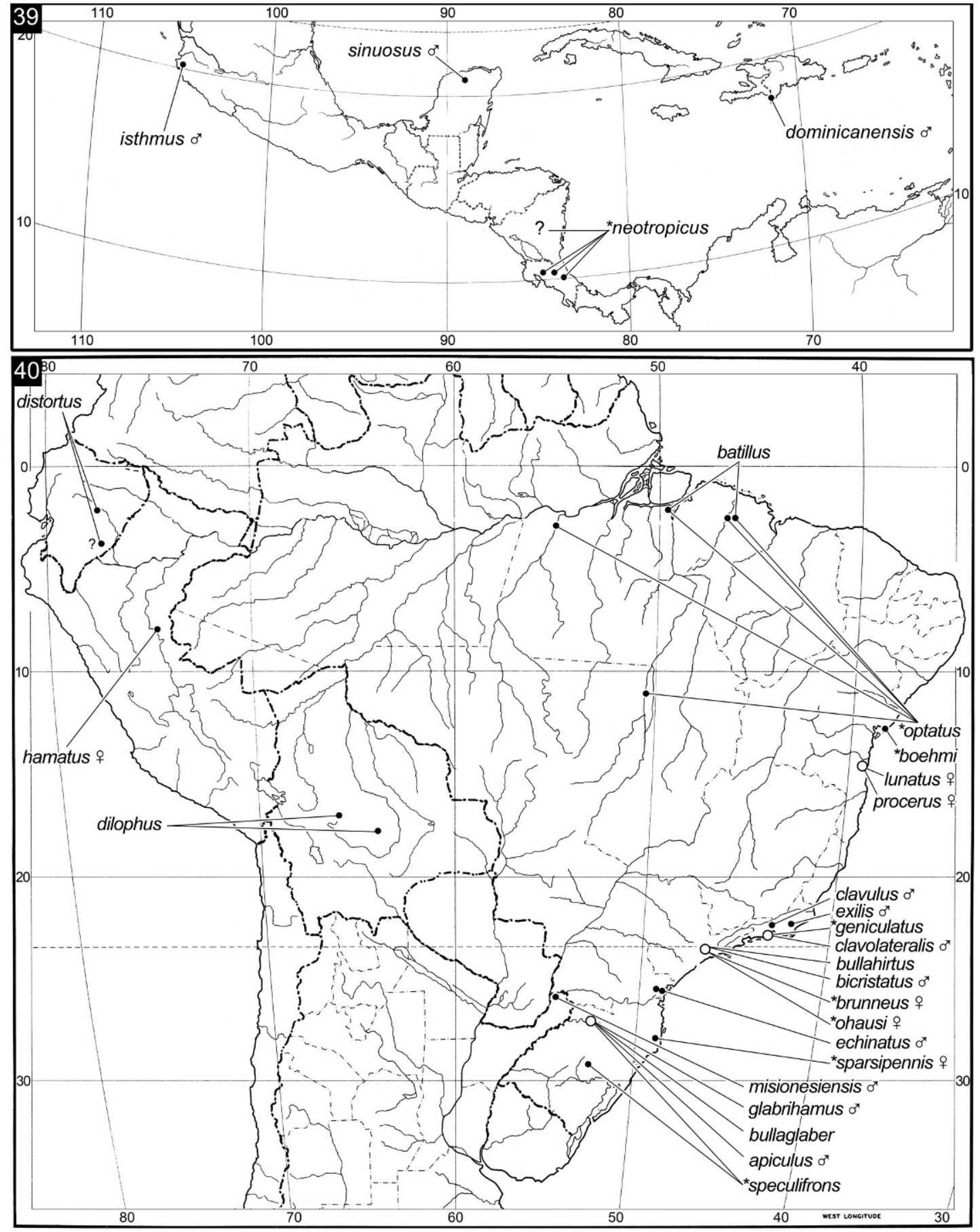

Figs. 39-40. Oedichirus species. Distribution. 39. Mesoamerica and the Caribbean. 40. South America. (Species described prior to present work preceded with *. Symbols $\delta$ or $q$ signify species known only by the sex indicated. Open circle denotes multiple collecting sites.) 
Sicilia, Pati (= Patti?), G. Leoni (1 male, FMNH); Sicilia (1 male, AMNH); Sicilien, Ficuzza, Geo. C. Kr. (1 male, FMNH); Calabria, Cimina, lg. Paganetti (1 female, FMNH); Calabria, Antonimina (1 male, FMNH); Calabria, Antonimina, 1905 (legit) Paganetti (1 female, FMNH).

DistRIBUTION: The species, described from Sicily, is recorded from southern Europe (Italy and Spain) and western Mediteranean Africa (Morocco, Algeria, and Tunisia) (Smetana, 2004: 624; see references at beginning of species account for articles to earlier citations of the distribution).

REMARKS: This European species is redescribed in the present article because it is the type species of the genus and it is important to compare and contrast it with the New World species of the genus.

Oedichirus paederinus shares with the Neotropical species and all other species of the genus the presence of the spiniform pencil of modified apical setae on antennomere 11 (fig. 9), the "window" at the anterior margin of the abdominal segments (fig. 24), and the dense cluster of setae on the ventral surface of protarsomere 5 (fig. 7).

Characters found in O. paederinus, but none of the New World species include: presence of a ridge on tergum IX that extends across the dorsal surface, then ventrally on both the male and female (fig. 38); presence of a transverse ridge across the basal third of the median gonocoxal plate, then posteriorly along the lateral margins (fig. 38); absence of a transverse groove on tergum IX at the base of the lateroapical process (cf. figs. 27 and 38); and absence of a paratergite and presence of a short paratergal carina on segment III (fig. 23).

Since so few specimens of $O$. paederinus were available for the present article, I plan to gather specimens to examine its distribution and morphological details.

\section{Oedichirus apiculus, new species} Figures 40-47

Type Material: Holotype: Male. "BRAZIL, 300$500 \mathrm{~m}$ Nova Teutonia $27^{\circ} 11^{\prime} \mathrm{S}$. $52^{\circ} 23^{\prime} \mathrm{W}$. V. 1960 Fritz Plaumann/Holotype Oedichirus apiculus Herman" Deposited in the Canadian National Collection of Insects, Ottawa.
PARATypes: 3 males. Brazil: Santa Catarina: Same locality, coordinates, and collector as holotype, March 1958 (2 males, CNCI, AMNH); Santa Catarina: Chapeco, $27^{\circ} 07^{\prime} \mathrm{S}, 52^{\circ} 36^{\prime} \mathrm{W}$, VII.1960, $600 \mathrm{~m}$. F. Plaumann (1 male CNCI).

Type Locality: Brazil: Santa Catarina: Nova Teutonia, $27^{\circ} 11^{\prime} \mathrm{S} .52^{\circ} 23^{\prime} \mathrm{W}$.

DiAgNOSIS: Oedichirus apiculus is one of a group of four externally similar species that also includes $O$. glabrihamus, $O$. misionesiensis, and $O$. speculifrons. Oedichirus apiculus can be separated from them all by the spiniform process on the right posterior margin of the ventral sclerite of the aedeagus dorsad of the base of the apicoventral process (figs. 41, 44). Sternum VIII of the male of $O$. apiculus has a wider, shallower emargination (figs. 46, 47) than do the other three species. Males of the Argentine O. misionesiensis (fig. 177) have a deeper emargination of sternum VIII than $O$. apiculus (fig. 47) and the aedeagus has a peg-boss on the apical margin of the apicoventral process (fig. 173) of the former species, which is lacking in the latter (fig. 42). A sympatric species, but belonging to a different species group, $O$. bullaglaber is separated by the presence on tergum III of a median point (as in sternum VIII, fig. 73) extending from the transverse basal ridge and the presence of dark femorotibial maculations. Other relevant diagnostic features that aid separation of $O$. apiculus from others include the quadridentate labrum, presence of a paratergal carina on segment III (as in fig. 23), and absence of dark femorotibial maculae.

DESCRIPTION: Length: $5.0-5.8 \mathrm{~mm}$. Length of head: $0.7 \mathrm{~mm}$. Width of head: $0.9 \mathrm{~mm}$. Pronotal length: $1.2 \mathrm{~mm}$. Pronotal width: $1.0 \mathrm{~mm}$. Elytral length: $0.9 \mathrm{~mm}$. Elytral width: $1.0 \mathrm{~mm}$.

Body concolorous, dark reddish brown to nearly black. Legs reddish brown to yellowish brown and without femorotibial maculation.

Head about two fifths wider than long (HW/HL: 1.4). Frontoclypeal ridge straight to curved and incomplete, separated medially. Dorsal surface without V-shaped depression; surface with coarse, moderately dense punctation; punctation absent or less dense anteriorly. Labrum quadridentate; surface without tubercle near submedial denticle. 


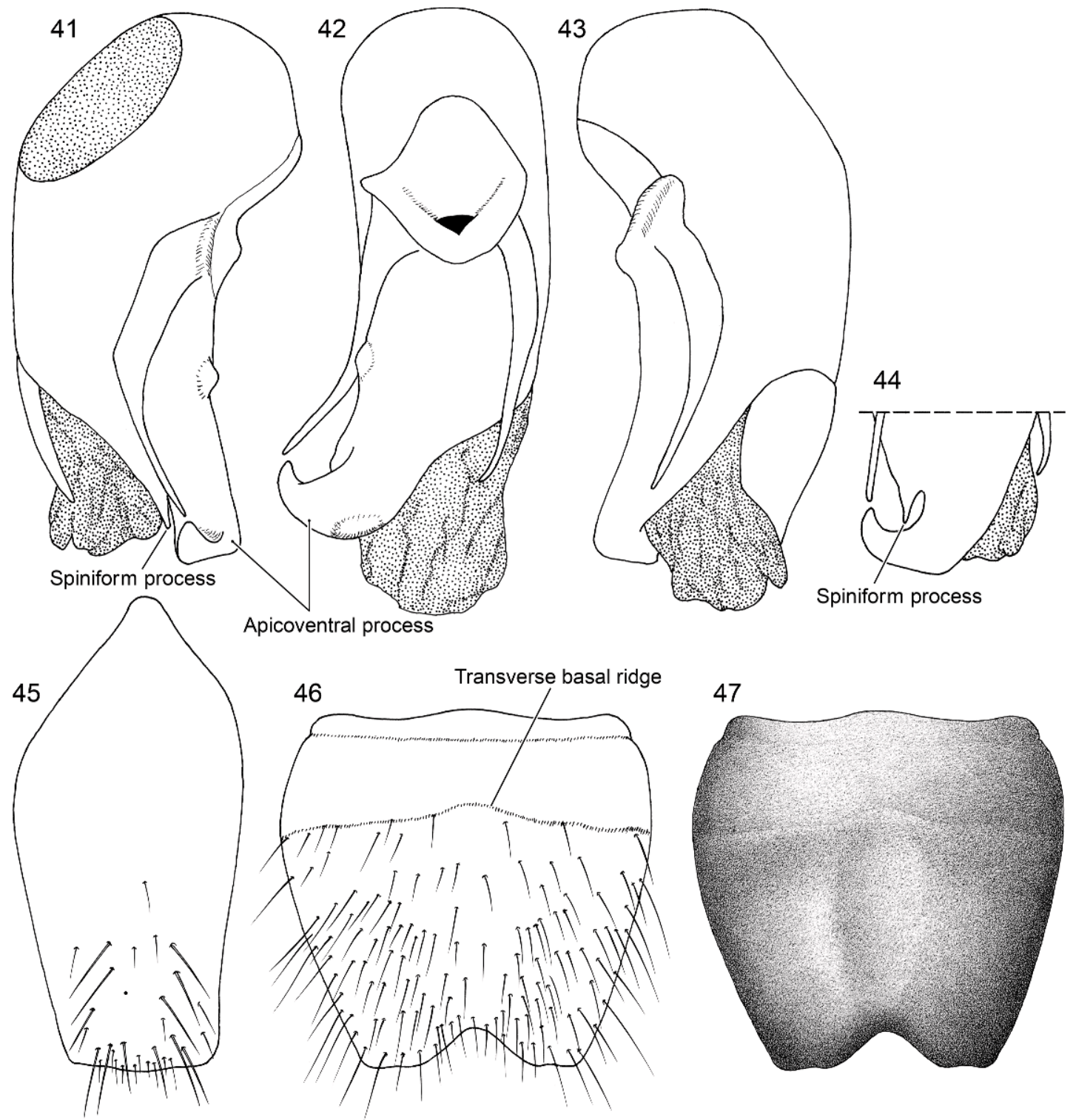

Figs. 41-47. Oedichirus apiculus. 41. Aedeagus, right lateral. 42. Aedeagus, ventral. 43. Aedeagus, left lateral. 44. Aedeagus, right ventrolateral, apex. 45. Sternum IX, male. 46. Sternum VIII, male. 47. Sternum VIII, setae removed, male.

Pronotum about one tenth longer than wide (PL/PW: 1.1). Pronotum polished, with coarse punctation arranged in irregular clusters, with submedial cluster occupying most of length, and with median polished, impunctate strip. Elytra about one to two tenths wider than long (EW/EL: 1.1-1.2); surface flat to slightly convex and coarsely punctate.
Abdomen with coarse, irregularly distributed punctation dorsally; segments VII and VIII less densely and coarsely punctate than preceding segments; segments III to VII with or without transverse, subapical row of punctures, but row irregular when present; VIII with slightly less dense punctation. Segment III without paratergite; paratergal 
carina present and extending beyond middle, but not reaching posterior margin and finely developed beyond spiracle. Tergum III without median point extending from transverse basal ridge. Tergum VIII with posterior margin broadly and shallowly rounded; transverse basal ridge broadly curved and without median point. Tergum IX long midlongitudinally; lateroapical process one to three tenths longer than midbasal length $(\mathrm{LLaP} / \mathrm{L} 9=1.1-1.3)$, slightly bent ventrally, and slightly divergent from other process; ventromedial margin without posteriorly directed spur (cf. fig. 158).

MALE: Sterna VI and VII unmodified. Sternum VIII with moderately deep, wide, symmetrical emargination of posterior margin (figs. 46, 47); emargination about one tenth of length of segment, wider than deep, and basal margin broadly rounded; subapical surface not translucent; surface with broad, moderately deep, oviform, median depression extending from near base of emargination to transverse basal ridge (fig. 47); surface without subapical, submedial boss and without ridge extending anteriorly along lateral side of depression; surface from posterior end of median depression beveled to posterior margin; median depression sparsely punctate; surface laterad of median depression densely pubescent (fig. 46), without cluster of setae or lateral depression; surface of sternum without comb; transverse basal ridge with median portion broadly and moderately strongly curved anteriorly. Tergum IX with moderatedly long, wide process on anterior margin of anteroventral angle. Sternum IX (fig. 45) slightly asymmetrical; anterior margin narrow and strongly rounded; posterior margin sinuate; lateral margins broadly rounded.

Aedeagus asymmetrical (figs. 41-43). Ventral sclerite with apicoventral process extending laterally from right side of apical margin (fig. 42); apicoventral process moderately long, anteroposteriorly flattened, thick basally and strongly tapered to rounded, lateroanteriorly bent apex, thick in ventral view and wide in posterior view; apicoventral process with moderate tumescence on ventroapical surface at rightward bend of process (fig. 42); ventral sclerite with moderately large, conical tumescence near middle of ventral surface on right side proximad of base of apicoventral process (figs. 41, 42); ventral sclerite with posteriorly directed, apically acute, spiniform process dorsad of base of apicoventral process (figs. 41, 44). Parameres long, tapered, moderately broad basally and slender apically; basal half fused to median lobe; apical half free of median lobe.

Female: Unknown.

ETYMOLOGY: The name is from the Latin for "point" (diminutive of apex) and refers to the small, sharply pointed process extending posteriorly from the right posterior margin of the ventral sclerite of the aedeagus.

Distribution: Known from two localities in Santa Catarina province, Brazil (fig. 40).

REMARKS: Oedichirus apiculus, part of a group of four similar species, is known from two localities. Two of these species, $O$. apiculus and $O$. speculifrons, are known from Chapeco and three of them, O. apiculus, $O$. glabrihamus, and $O$. speculifrons are known from Nova Teutonia. Although females of several apparent species of the species group were collected at the two localities, none of them could clearly be identified as $O$. apiculus. The genital segments of these unidentified females are depicted (figs. 221224) among the illustrations for O. speculifrons complex.

Oedichirus batillus, new species Figures 40, 48-55

Type Material: Holotype: Male. "Brazil: Para; Aldeia Aracu, Igarape, Gurupu-Umu, Maranhao, $50 \mathrm{~km} \mathrm{E}$ of Caninde. Leg: B. Malkin/ forest sweep, V: 1963/Holotype Oedichirus batillus Herman." Deposited in the Field Museum of Natural History. (Right antennomeres 3-11 are missing.)

PARATypes: 2 males, 5 females. Brazil: Pará (= Maranhão, not Pará): Same data as holotype ( 2 females, FMNH); Pará: Belem $\left(01^{\circ} 27^{\prime} \mathrm{S}\right.$, $48^{\circ} 28^{\prime}$ W), IPEAN, III-23-1970, J.M. \& B.A. Campbell (1 male, CNCI), III-17-1970 (1 female, CNCI); XII-1-4-1969 (1 female, CNCI); Pará: Belem, Utinga $\left(01^{\circ} 26^{\prime} \mathrm{S}, 48^{\circ} 26^{\prime} \mathrm{W}\right)$, III27-28-1970, J.M. \& B.A. Campbell (1 male, CNCI); Pará: $8 \mathrm{~km}$ E Belém, Ananindéua $\left(01^{\circ} 22^{\prime} \mathrm{S}, 48^{\circ} 22^{\prime} \mathrm{W}\right)$, April 20-29, 1973, R.T. Schuh (1 female, AMNH). (Coordinates for Belem are from Paynter and Traylor, 1991: 66; those for Utinga and Ananindéua are courtesy of A. Asenjo, personal commun.) 

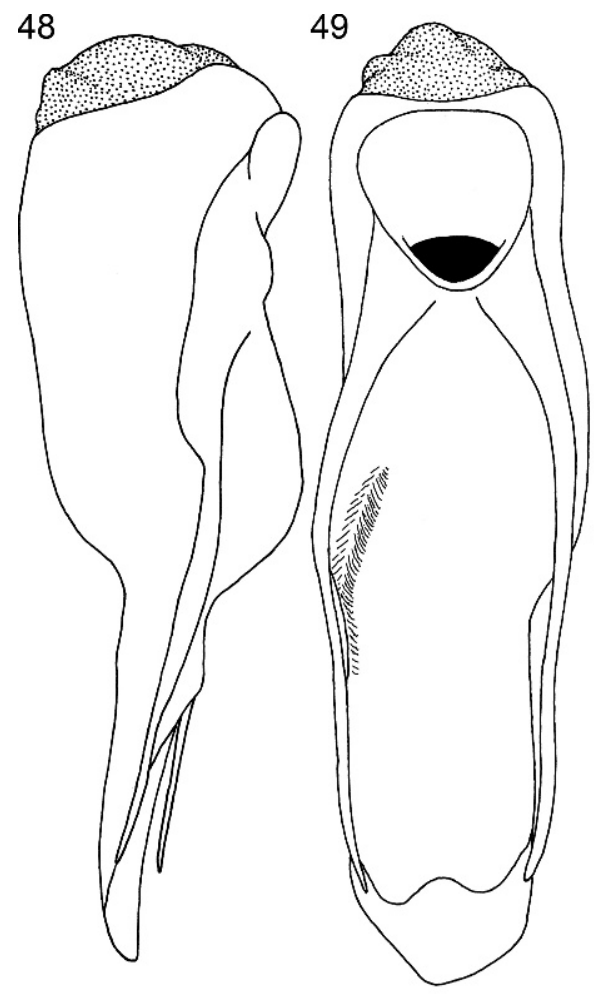

50

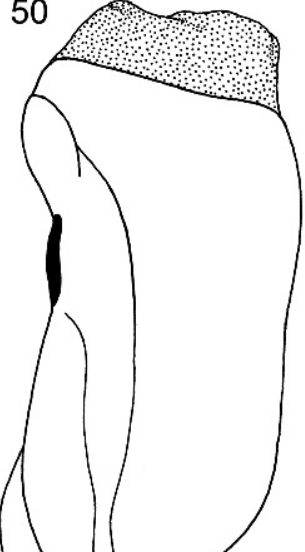

51

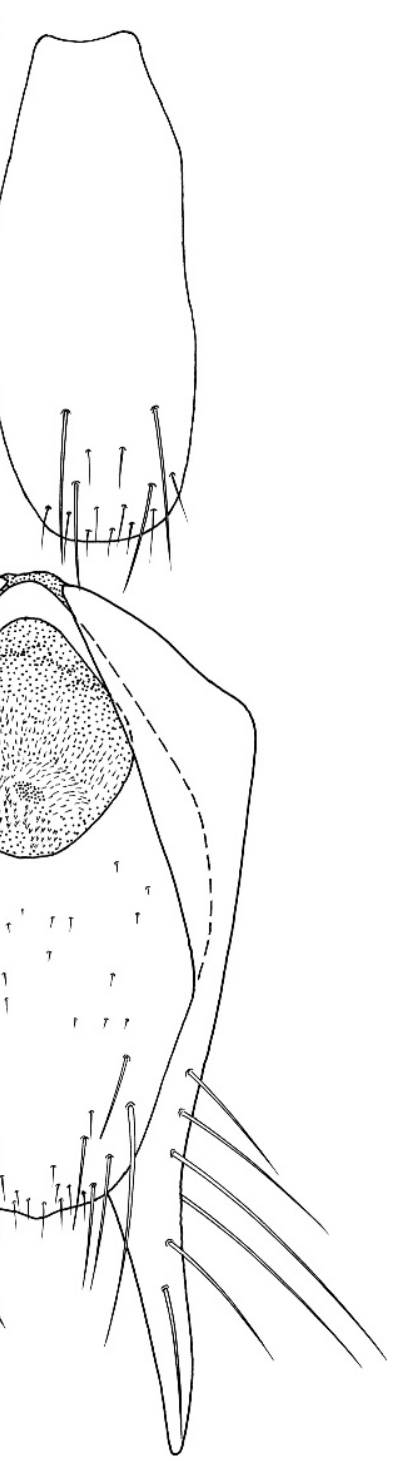

Figs. 48-53. Oedichirus batillus. 48. Aedeagus, right lateral. 49. Aedeagus, ventral. 50. Aedeagus, left lateral. 51. Sternum IX, male. 52. Segment IX, ventral, female. 53. Sternum VIII, male.

Type Locality: Brazil: Maranhão (not Pará): Aldeia Aracu (= Yararuhu?), Igarape GurupiUna, Rio Gurupi, $50 \mathrm{~km}$ E of Caninde $\left(2^{\circ} 34^{\prime} \mathrm{S}\right.$, $46^{\circ} 02^{\prime} \mathrm{W}$ ). (The type locality cited in this paragraph is a revision of the locality data on the label accompanying the holotype [see above Type Material: Holotype]. Oliviera [2006: 123] published a new species of a euglossine bee, some specimens of which were collected by Borys Malkin from "Aldeia Yararuhu [Aracu],
Igarape Gurupi-Una, Rio Gurupi" and are deposited in the AMNH. Oliviera cited the locality in Pará and did not include "Maranhao, about $50 \mathrm{~km} \mathrm{E}$ of Caninde" with the data he published for these specimens, but those data are on the locality labels attached to the specimens. Caninde is in Pará on the shore of Rio Gurupí; the other side, the east side, of the river is Maranhão state, so $50 \mathrm{~km}$ east of Caninde is in Maranhão, not Pará. The 

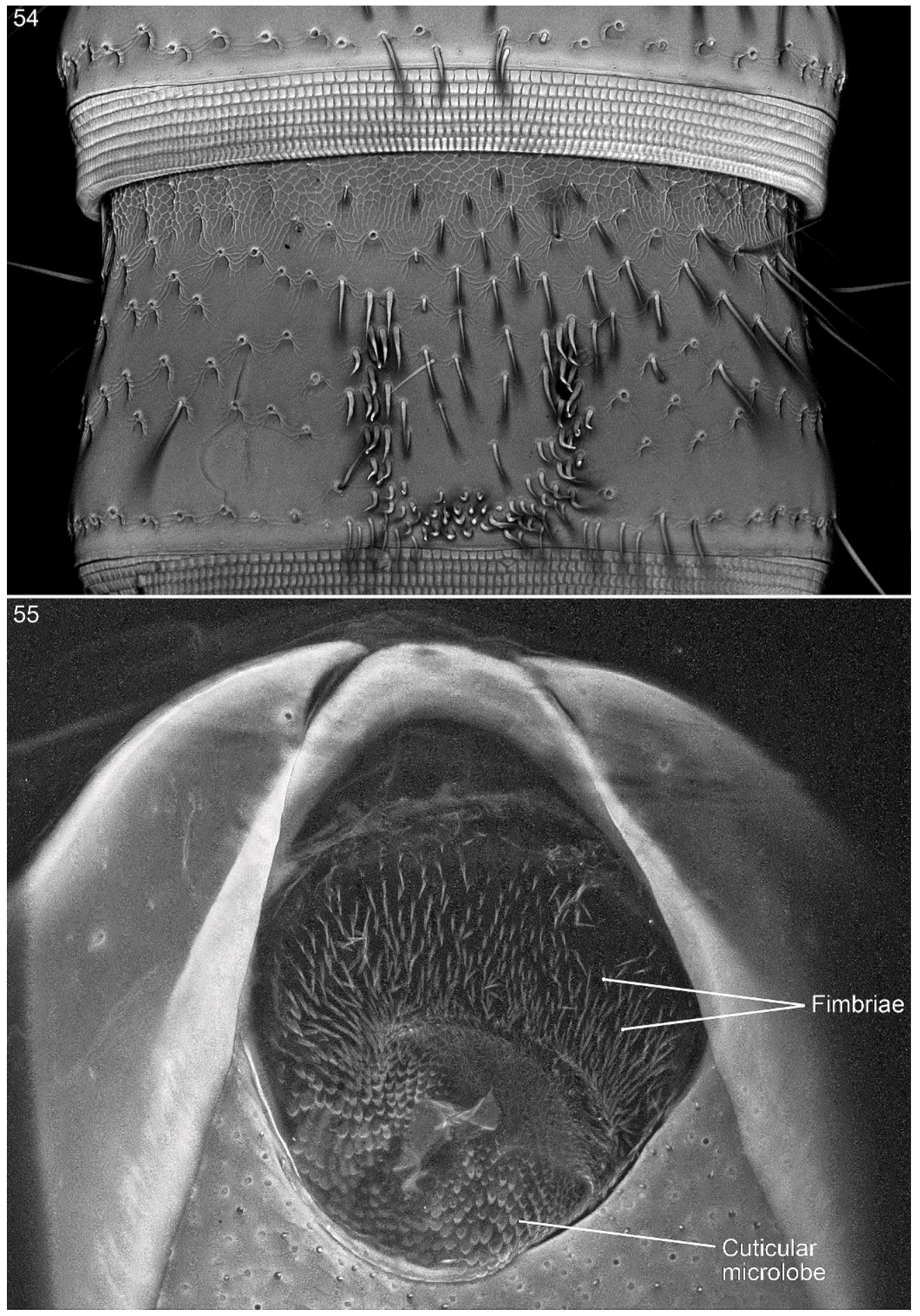

Figs. 54-55. Oedichirus batillus. 54. Sternum VI, male (CLSM). 55. Segment IX, vulvar plate and part of median gonocoxal plate, enlarged (CLSM). 
geographical coordinates included here are estimates of the collecting site based on "air" distance using Google Earth.)

DiAgNosis: Oedichirus batillus can be distinguished from all other New World species except $O$. bicristatus, $O$. hamatus, $O$. isthmus, O. optatus, and $O$. sinuosus by the presence of paratergite III. Of the preceding six species, five have unicolorous legs; the sixth, $O$. hamatus, has a dark tibiofemoral spot. The male of $O$. batillus can be separated from the remaining four species that possess paratergite III, and all other New World species, by the flattened spot bordered laterally and posteriorly by a dense cluster of long setae on sternum VI (fig. 54), the broad, deep, symmetrical emargination of sternum VIII (fig. 53), and the long slender parameres and broad, flattened apical third of the median lobe of the aedeagus (figs. 4850). Sternum VIII of $O$. isthmus and $O$. sinuosus have either a transverse cluster (fig. 163) or comb (fig. 203) of spiniform setae and the parameres (figs. 161, 200) are short, slender, thornlike, and free of the median lobe, except at the base. Sternum VIII of $O$. bicristatus has dense clusters of spiniform setae on each side of the midline and the posterior emargination is short and wide (fig. 59). Sternum VIII of O. optatus has a deep, narrow emargination (fig. 193).

Among the females known for the six aforementioned species, the median gonocoxal plate is nearly symmetrical in $O$. batillus (fig. 52), but strongly asymmetrical for O. optatus (fig. 195). For O. hamatus, part of the ventromedial edge of tergum IX extends ventrally as a strong, flat spur (fig. 158) that is lacking in $O$. batillus. Furthermore, the anterior vulvar lobe of $O$. batillus is smooth and covered with moderately long cuticular processes or fimbriae and the surface of the posterior vulvar lobe is cobbled (fig. 55), whereas the anterior vulvar lobe of $O$. hamatus is strongly wrinkled and the surface of the posterior lobe is reticulate (fig. 159). Females are unknown for $O$. bicristatus, $O$. isthmus, and $O$. sinuosus, but the males of those species and $O$. batillus are reddish brown with dark reddish brown abdominal segments VII to $\mathrm{X}$, whereas the terminal segments of $O$. optatus and $O$. hamatus are concolorous with the remainder of the abdomen.

DESCRIPTION: Length: 7.2-7.4 $\mathrm{mm}$. Length of head: $0.6-0.7 \mathrm{~mm}$. Width of head: 0.9-1.0 mm. Pronotal length: $1.2 \mathrm{~mm}$. Pronotal width: $1.0 \mathrm{~mm}$. Elytral length: $0.9 \mathrm{~mm}$. Elytral width: $1.0 \mathrm{~mm}$.

Body reddish brown with darker reddishbrown infusions; segments VII to $\mathrm{X}$ darker reddish brown than remainder of body. Legs concolorous, dark yellowish brown, without darker femorotibial spot.

Head about half wider than long (HW/HL: 1.4-1.5). Frontoclypeal ridge incomplete, separated medially. Dorsal surface without V-shaped depression; surface coarsely punctate; punctation moderately dense medially and sparse laterally; basal two fifths polished and largely impunctate, with only scattered punctures. Labrum quadridentate; denticles small to minute and easily overlooked; submedial denticle larger than sublateral; surface without tubercle near submedial denticle.

Pronotum about two fifths longer than wide (PL/PW: 1.2). Pronotum polished and coarsely punctate; punctation arranged in scattered, dense clusters; surface with submedial punctate groove extending posteriorly from near middle. Elytra with length about one to two tenths less than width (EW/EL: 1.1-1.2); surface slightly convex and coarsely punctate.

Abdominal segments III to VI with coarse, irregular punctation basally, segments $\mathrm{V}$ and VI with irregular, subapical transverse row of punctures; segments VII to VIII with less coarse and less dense punctation. Segment III with narrow paratergite extending from base to posterior margin. Tergum III without median point extending from transverse basal ridge. Tergum VIII with posterior margin feebly emarginate, trunctate, or feebly rounded; transverse basal ridge coarsely and irregularly serrate, broadly curved anteriorly, and without median point. Tergum IX with lateroapical process about a tenth shorter to nearly a third longer than midbasal length (LLaP/L9 $=0.9-1.3)$, slightly bent ventrally, and approximately parallel to other process; ventromedial margin without posteriorly directed spur (cf. fig. 158).

MALE: Labral surface without tubercle between denticles. Sternum VI with subapical, 
slightly flattened, polished, median spot bordered laterally and posteriorly by dense cluster of long, erect setae (fig. 54). Sternum VII with or without shallow median emargination of posterior margin. Sternum VIII with broad, deep emargination (fig. 53); emargination symmetrical, about one third of length of segment, wider than deep, and with basal margin rounded; surface adjacent to base of emargination beveled; surface without comb, tumescence, short and stout setae, cluster of setae, or hyaline edge of posterior margin. Tergum IX with lateroapical process about a tenth shorter than midbasal length of tergum IX (LLaP/L9 $=0.9)$; ventromedial margin without posteriorly directed spur (cf. fig. 158). Tergum IX with anteroventral angle extended anteriorly as moderately large process. Sternum IX (fig. 51) moderately asymmetrical; anterior margin wide and emarginate; posterior margin broadly rounded; right lateral margin broadly convex, left lateral margin slightly sinuate.

Aedeagus asymmetrical (figs. 48-50). Ventral sclerite broadly and shallowly depressed; apical third broad in ventral view and flattened in lateral view (figs. 48, 50); apical margin of dorsal sclerite rounded and slightly produced medially and apical margin of ventral sclerite emarginate (fig. 49); ventral sclerite with large carina beginning near middle of right edge and extending, adjacent to lateral margin, posteriorly to near apex (figs. 48, 49) and left side with low ridge of similar length (fig. 50); ventral sclerite without apicoventral process extending from posterior margin; carina of right side bisinuate in lateral view (fig. 48). Parameres long, slender, with base fused to median lobe and with apical half free of median lobe.

FEMALE: Sternum VIII with posterior margin slightly to moderately lobed medially. Tergum IX with lateroapical process about one fifth to nearly one third longer than midbasal length of tergum IX (LLaP/L9 = 1.2-1.3); anteroventral angles separated from each other (figs. 52, 55). Median gonocoxal plate anteriad of vulvar plate narrow and straplike and anterior margin strongly rounded medially (figs. 52, 55); gonocoxal plate posteriad of vulvar plate (fig. 52) wide and long and tapered to broadly rounded posterior margin; posterior margin with or without small median lobe. Vulvar plate embedded in median gonocoxal plate anteriorly (fig. 52). Anterior vulvar lobe large, embracing anterior and part of lateral margins of posterior vulvar lobe; surface moderately densely covered with long cuticular fimbriae (fig. 55). Posterior vulvar lobe rounded and smaller than anterior vulvar lobe; surface covered with cuticular microlobes, but for patch of small cuticular processes on anterior left side (fig. 55). Vulva of indeterminate orientation.

ETYMOLOGY: The name of this species is from the Latin batillum, "shovel," and refers to the wide, flattened apical portion of the aedeagus.

DisTRIBUTION: The species is known only from the Brazilian states of Maranhão and Pará (fig. 40).

\section{Oedichirus bicristatus, new species} Figures 40, 56-60

Type Material: Holotype. Male. "Brasilien San Paulo Barbiellini/barbiellinii Bernh. Typus unic./Chicago NHMus M.Bernhauer Collection/Holotype Oedichirus bicristatus Herman." Deposited in the Field Museum of Natural History, Chicago. (Left maxillary palpomeres 3 and 4 and right antennomeres 3-11 are missing. The head and prothorax are separated from the remainder of the body and both are glued to the card.)

Type Locality: Brazil: São Paulo: São Paulo $\left(23^{\circ} 35^{\prime} \mathrm{S}, 46^{\circ} 43^{\prime} \mathrm{W}\right)$. (The label reads "San Paulo,' corrected here to São Paulo.)

Diagnosis: This is one of six New World species with paratergite III; the others are $O$. batillus, O. hamatus, O. isthmus, O. optatus, and $O$. sinuosus. The males of $O$. bicristatus can be separated from the preceding five and all other New World species by two large, dense clusters of setae on sternum VIII (fig. 59). The setae of each cluster are posterolaterally directed and recumbent from the medial edge to a crest of erect setae on the lateral edge of each cluster. The two clusters are separated medially by a longitudinal, irregular row of setae. The aedeagus (fig. 57) has a lobe on the right lateral edge of the ventral sclerite and the lateral edge of the lobe is carinate. Both parameres are fused or strongly appressed to the median lobe for most of their lengths. The female is unknown. 

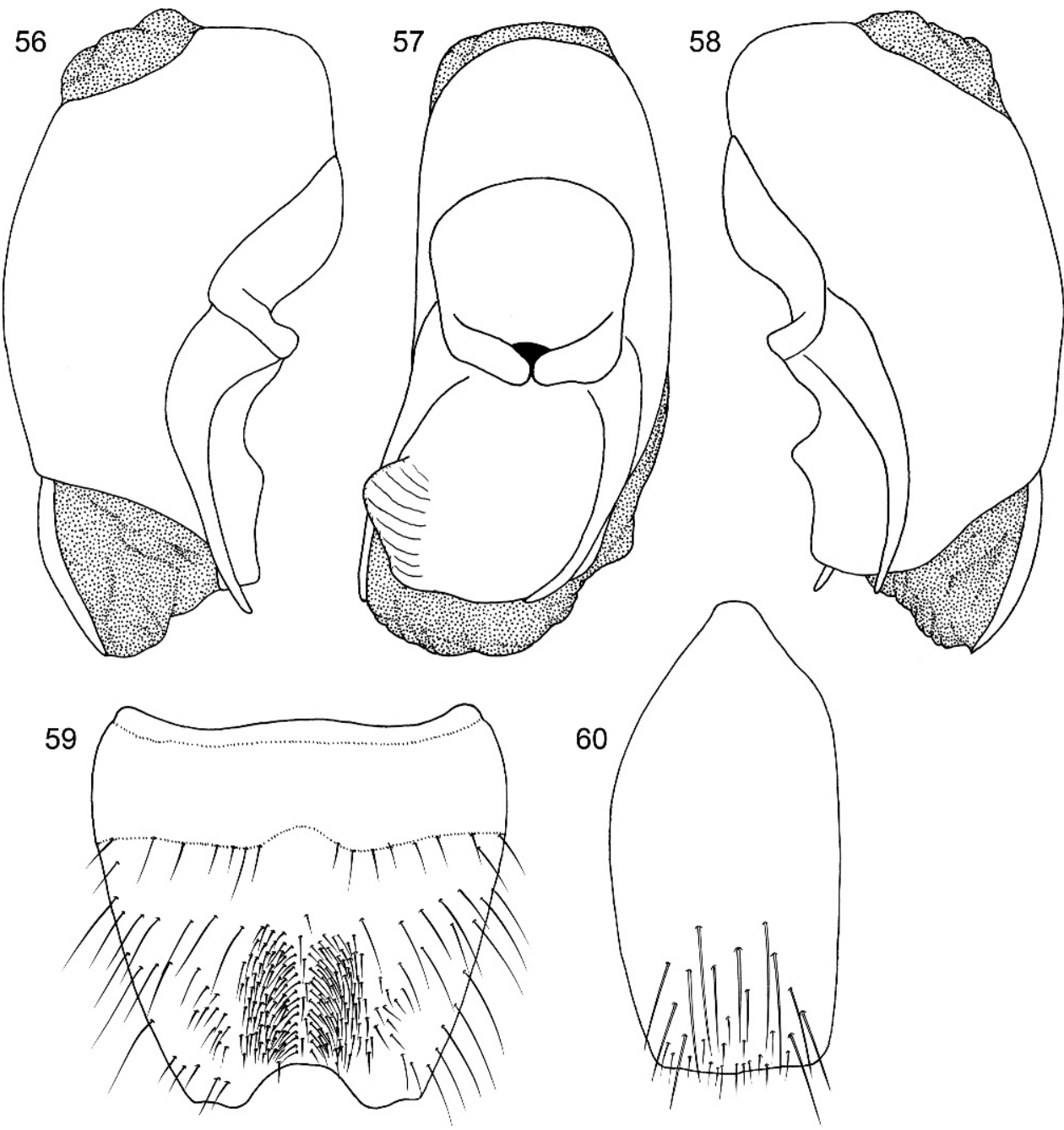

Figs. 56-60. Oedichirus bicristatus. 56. Aedeagus, right lateral. 57. Aedeagus, ventral. 58. Aedeagus, left lateral. 59. Sternum VIII, male. 60. Sternum IX, male.

DESCRIPTION: Length: $5.9 \mathrm{~mm}$. Length of head: $0.6 \mathrm{~mm}$. Width of head: $0.8 \mathrm{~mm}$. Pronotal length: $1.0 \mathrm{~mm}$. Pronotal width: $0.9 \mathrm{~mm}$. Elytral length: $0.8 \mathrm{~mm}$. Elytral width: $0.9 \mathrm{~mm}$.

Body concolorous reddish brown. Legs concolorous pale reddish brown, without femorotibial spots.

Head about a third wider than long (HW/ HL: 1.3). Frontoclypeal ridge incomplete, separated medially. Dorsal surface without V-shaped depression; punctation coarse and dense medially and laterally, and less dense posteriorly. Labrum quadridentate; surface without tubercle near submedial denticle.
Pronotum about a tenth longer than wide (PL/PW: 1.1). Pronotum with coarse punctation; punctation arranged in scattered, dense clusters; surface with moderately deep, submedial, punctate groove on basal half beginning near middle. Elytra with length about a fifth less than width (EW/EL: 1.2); surface coarsely punctate and slightly convex.

Abdominal segments III to $\mathrm{V}$ with dense, coarse punctation; VI with dense, moderately coarse punctation, and VII with sparse, fine punctation; III to VI with even basal punctation; III to $\mathrm{V}$ with moderately welldeveloped transverse row of punctures near 
middle. Segment III with narrow paratergite about half as long as segment; tergum and sternum separated from base to posterior margin. Tergum III without median point extending from transverse basal ridge. Tergum VIII with truncate posterior margin; transverse basal ridge irregularly microsinuate, broadly, shallowly curved anteriorly, and without median point. Tergum IX with lateroapical process about a fifth longer than midbasal length (LLaP/L9 = 1.2), moderately bent ventrally, and slightly diverging from other process; ventromedial margin without posteriorly directed spur (cf. fig. 158).

MALE: Labral surface without tubercle between denticles. Sterna VI and VII unmodified. Sternum VIII (fig. 59) with shallow, symmetrical emargination of posterior margin; emargination about one eighth of length of sternum, wider than deep, with rounded basal margin, and posterior margin not membranous; surface with two dense clusters of spiniform setae on each side of midline extending anteriorly from emargination; clusters separated medially by irregular row of setae; setae of each cluster recumbent and posterolaterally directed from mesial edge and increasingly erect to crest of erect setae on lateral edge of cluster; setae of lateral crest posteriorly directed; surface with shallow, median depression proximad of setal mass and reaching to basal ridge; depression impunctate and asetate; surface with lateroposteriorly directed ridge laterad of setal cluster and attached apically with sublateral, anteriorly directed ridge; transverse basal ridge with median fifth abruptly and strongly curved anteriorly. Tergum IX with process reduced to small lobe on anterior margin of anteroventral angle. Sternum IX (fig. 60) moderately asymmetrical; anterior margin narrow and broadly rounded; posterior margin slightly truncatosinuate; right lateral margin broadly rounded and left lateral margin broadly and shallowly curved from posterior end to about basal third, then strongly round, then slightly emarginate to basal margin.

Aedeagus (figs. 56-58) asymmetrical. Ventral sclerite with short, broad lobe extending lateroventrally from apical fifth of right side; lobe with lateral edge carinate; ventral sclerite without apicoventral process extending from posterior margin. Parameres long, tapered, moderately wide basally, slender apically, fused to median lobe basally, and free of median lobe apically.

Female: Unknown.

ETYMOLOGY: The name is from the Latin bi-, "two," and cristatus, "crested," and refers to the two tufts or clusters of seta on sternum VIII of the male.

Distribution: Brazil, São Paulo state (fig. 40).

\section{Oedichirus boehmi Bernhauer}

Figures 40, 61-67

Oedichirus boehmi Bernhauer, 1927: 156.

- Scheerpeltz, 1933: 1217 (catalog). — Blackwelder, 1944: 131 (checklist).

Type Material: Holotype, female. "Bahia, Bras. Cap. Boehm/don. (letter indecipherable) Müller/ Oedichirus boehmi Bernh. Typus unic./Chicago NHMus M.Bernhauer Collection/Oedichirus boehmi Bernhauer det. L. Herman, 2011." Deposited in Field Museum of Natural History, Chicago. (Left antennomeres 4-11, right antennomeres 7-11, left protibia and protarsus, and right metatarsomeres $1-3$ are missing. Metatarsomeres 4 and 5 are still glued to the card.) (The holotype was designated by Bernhauer [1927: 157] with the statement "Ein einziges Stück,..." [Article 73.1.2].)

Type Locality: Brazil: Bahia: Bahia (= Salvador de Bahia) $\left(12^{\circ} 57^{\prime} \mathrm{S}, 38^{\circ} 25^{\prime} \mathrm{W}\right)$. (Coordinates from Times Books, 1999.)

Diagnosis: Oedichirus boehmi is separated from other New World species by color, pronotal and abdominal punctation, and characters of the aedeagus (figs. 61-63) and sternum VIII for the males (fig. 65) and the genital sclerites for the females (figs. 64, 67). Externally the species is distinguished from all other New World species by the strongly concave elytral disc, sparse abdominal punctation arranged in transverse rows, V-shaped cephalic depression, and deep, submedial, punctate, pronotal groove; the remainder of the pronotum is sparsely punctate. These cephalic, pronotal, and elytra characters render the species one of the most easily recognized New World species. The species is one of 13 with a dark spot at the femorotibial joint.

Only $O$. boehmi, O. ohausi, and $O$. procerus have elytra that are longer than wide and a 

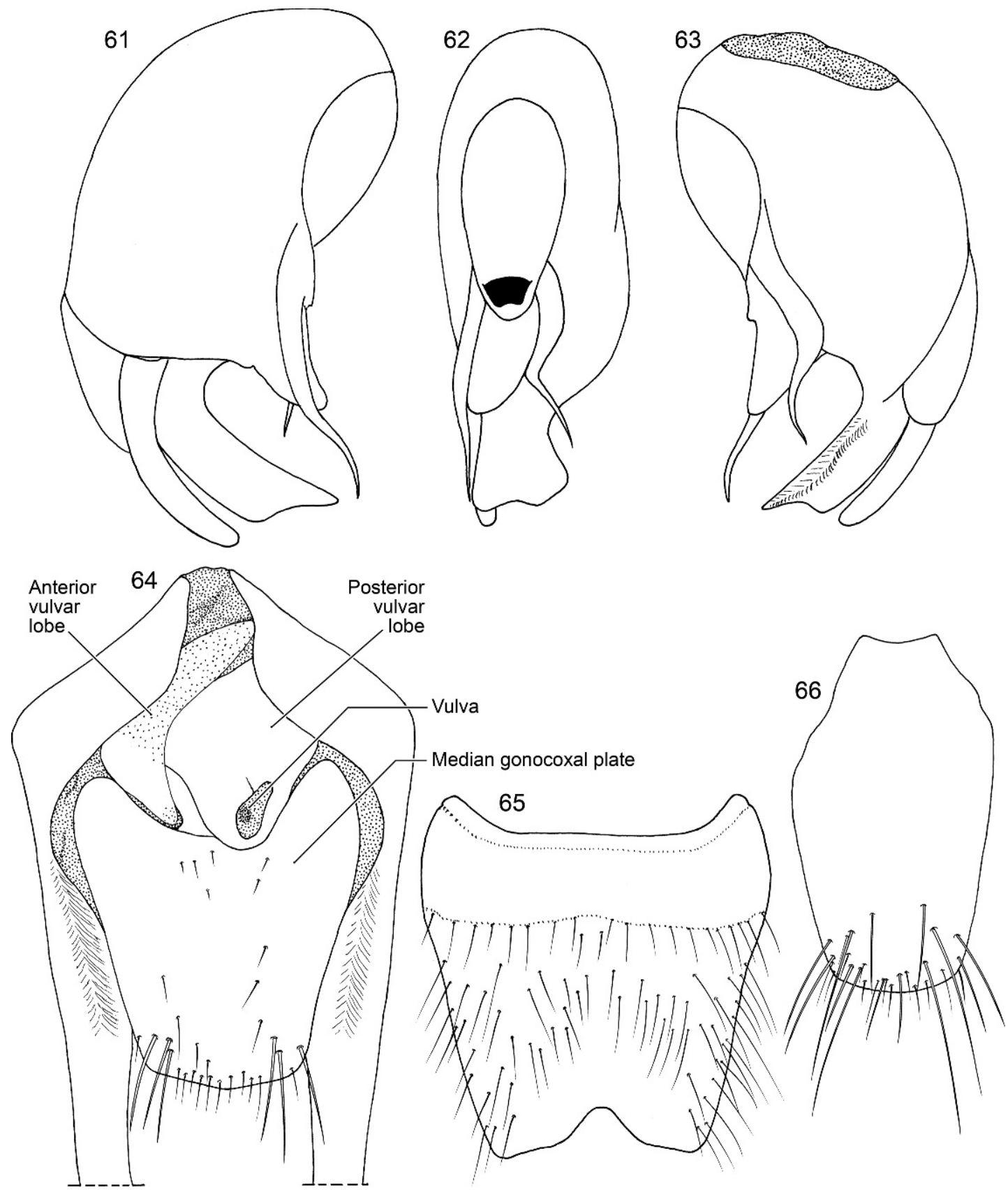

Figs. 61-66. Oedichirus boehmi. 61. Aedeagus, right lateral. 62. Aedeagus, ventral. 63. Aedeagus, left lateral. 64. Segment IX, ventral, apex of lateroapical processes omitted, female. 65. Sternum VIII, male. 66. Sternum IX, male.

strongly concave elytral disc. The deep, submedial, punctate, pronotal groove of the large, robust, nearly black O. boehmi separates it from $O$. ohausi and the small, slender, reddish-brown $O$. procerus and both of the latter two species lack the V-shaped cephalic depression present on O. boehmi. Oedichirus procerus, known only by females, is separated 


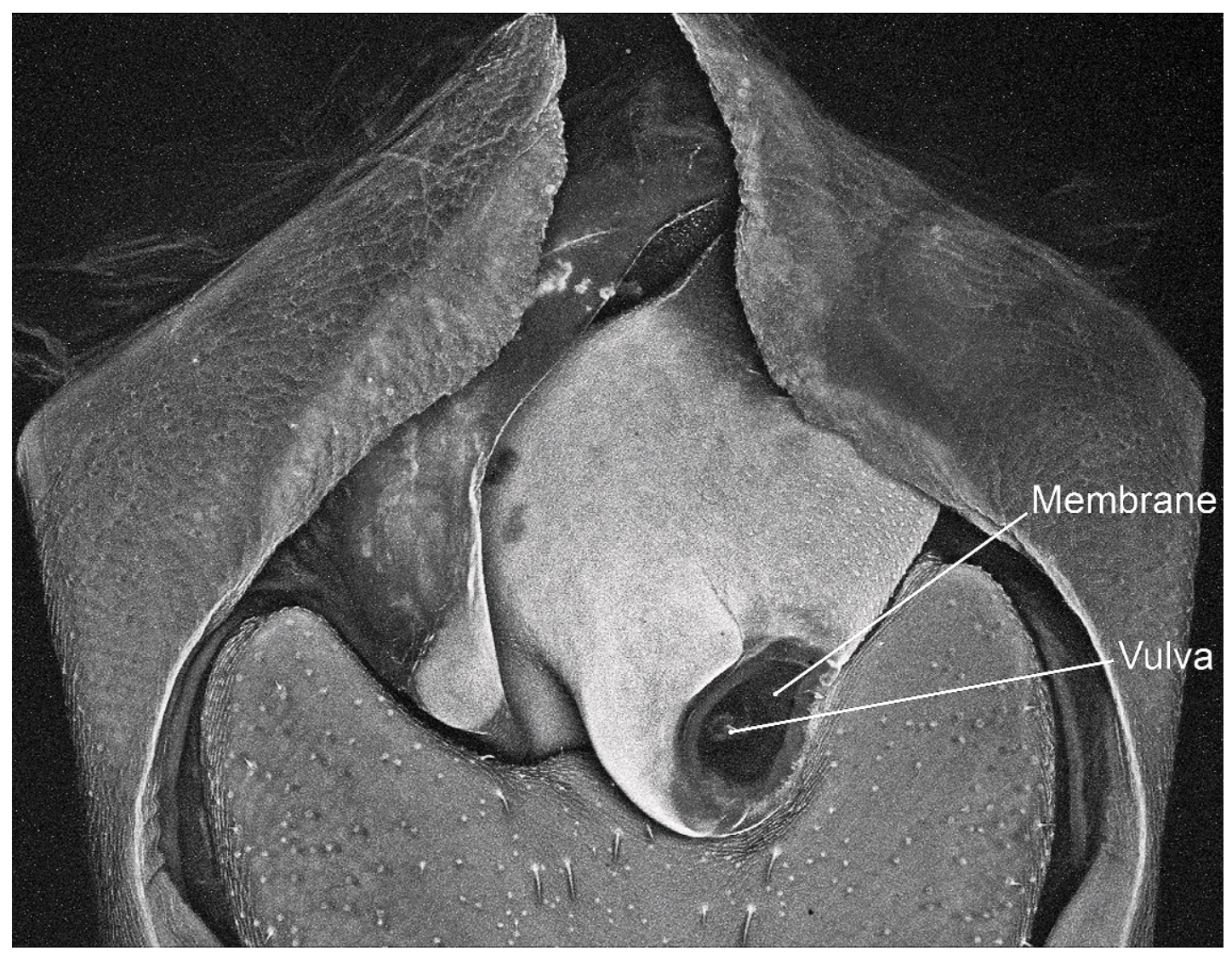

Fig. 67. Oedichirus boehmi. Segment IX, vulvar plate, enlarged (CLSM).

from females of $O$. boehmi by the configuration of the vulvar lobes (cf. figs. 197, 198 with 64,67 ) and the medially fused anteroventral angles of tergum IX (fig. 197), which are separated in the latter (fig. 64). The elytra of three other species, O. brunneus, O. hamatus, and $O$. neotropicus, have a feebly concave disc, the length and width are subequal, and in some individuals the length is marginally less than the width; both species are clearly separated from $O$. boehmi by the aforementioned characters and others found in the respective species accounts.

The males are distinguished from all others by the broad emargination of sternum VIII (fig. 65) that is shallow laterally and much deeper medially; the base of the emargination is rounded. The surface of sternum VIII lacks punctures or setae adjacent to the emargination (fig. 65). The apical third of the median lobe of the aedeagus is broad, flattened, strongly bent ventrally (figs. 61, 63), and slightly twisted. The parameres are moderately long, sinuous, tapered apically, and the left is shorter than the right (fig. 62).

The females are easily separated from females of all the other species by the large, moderately sclerotized posterior vulvar lobe (figs. 64, 67), the small, unadorned, membrane surrounding the vulva, and the partially sclerotized anterior vulvar lobe wrapped around the right lateroapical margin of the posterior lobe. The anteroventral angles of tergum IX are separated.

DESCRIPTION: Length: 9-10.5 mm. Length of head: $1.0-1.1 \mathrm{~mm}$. Width of head: 1.1$1.3 \mathrm{~mm}$. Pronotal length: $1.4-1.7 \mathrm{~mm}$. Pronotal width: 1.1-1.3 mm. Elytral length: 1.4 $1.6 \mathrm{~mm}$. Elytral width: 1.1-1.4 mm. 
Body concolorous, dark reddish brown to black. Legs bicolored, yellowish brown with femorotibial spot dark reddish brown to nearly black; tibial spot paler basally.

Head wider than long (HW/HL: 1.1-1.2). Frontoclypeal ridge complete, not separated medially. Dorsal surface polished and with shallow depression extending posteromedially from near anterior margin of eye, arms forming broad V; surface with two coarse punctures middorsally, remaining surface with sparse, fine punctation, and basal half with two fine punctures at base near neck. Labrum quadridentate; surface without tubercle near submedial denticle.

Pronotum about a third longer than wide (PL/PW: 1.3). Pronotal surface polished and with a few scattered groups of coarse punctures laterally; surface with prominent, coarsely punctate, deep, submedial, slightly sinuate groove extending from near anterior margin to near posterior margin. Elytra longer than wide (EW/EL: 0.8-0.9); surface of disc strongly concave and with moderately coarse punctation.

Abdomen with sparse, indistinct punctation; punctures arranged in transverse, ridged rows dorsally. Terga III to VII with subanterior row of punctures near middle, not reaching lateral margin and with sparsely punctate apical row; medial row well developed. Segment III without paratergite; paratergal carina present and extending to spiracle, but poorly developed beyond spiracle. Tergum III without median point extending from transverse basal ridge. Tergum VIII with posterior margin broadly and shallowly emarginate; emargination extending from one lateroapical angle to other; transverse basal ridge broadly curved anteriorly, slightly sinuate, and without median point. Tergum IX with lateroapical process nearly twice as long as midbasal length (LLaP/L9 $=1.8-2.0)$, slightly bent ventrally, and approximately parallel to other process; ventromedial margin without posteriorly directed spur (cf. fig. 158).

MALE: Sternum VI unmodified. Sternum VII with feeble, ovoid, median depression near posterior margin; depression bordered by setae, more setae near posterior margin of depression than near lateral or anterior margins. Sternum VIII (fig. 65) with broad, symmetrical emargination of posterior margin; emargination about one sixth of length of sternum, wider than deep, and with rounded basal margin; margin of emargination not membranous and with anterior portion more strongly sloped than posterior portion; base of emargination rounded; surface impunctate and without setae midsubapically and adjacent to emargination; surface without comb or depression, but median surface adjacent to base of emargination beveled to posterior margin; transverse basal ridge curved medially and without median point. Tergum IX with moderately large process extending from anterior margin of anteroventral angle. Sternum IX (fig. 66) moderately asymmetrical; anterior margin wide and emarginate; posterior margin broadly rounded; lateral margins of basal third slightly irregular.

Aedeagus asymmetrical (figs. 61-63). Ventral sclerite with apical third narrowed near base, strongly flattened, strongly bent ventrally, and surface twisted diagonally; posterior margin of ventral sclerite sinuate (fig. 62); ventral sclerite without apicoventral process extending from posterior margin. Parameres separated from median lobe for most of length, slender, sinuate, and tapered apically; right paramere longer than left. Internal sac with cluster of long spinelike processes (visible through cuticle, but not illustrated).

FEMALE: Tergum IX with anteroventral angles separated from each other (figs. 64, 67). Median gonocoxal plate absent anteriad of vulvar plate (fig. 64); gonocoxal plate posteriad of vulvar plate large, wide basally and gradually tapered posteriorly (fig. 64), anterior margin deeply emarginate (fig. 64), and posterior margin slightly produced medially. Vulvar lobes anteriad of median gonocoxal plate, not embedded. Anterior vulvar lobe wrapped around right anterolateral margin of posterior vulvar lobe (figs. 64, 67) and with surface lightly and partially sclerotized. Posterior vulvar lobe moderately sclerotized, without adornment (fig. 67). Vulva with indeterminate orientation.

MATERIAl EXAMINED: 2 males, 3 females. Brazil: Bahia: Bahia (= Salvador), Cap. Boehm (collector) (holotype female, FMNH); Bahia, Reed (collector), Fry coll. (1 male, 1 female, FMNH). Brazil (no further locality data) (1 male, FMNH; 1 female BMNH). 
DISTRIBUTION: The species is known only from Bahia, Brazil (fig. 40). Nothing is known of the habitat or date of collection.

REMARKS: The aedeagus of the only dissected male is pale, weakly sclerotized, seems easily liable to distortion, and appears to be what would be found with a teneral specimen. However, the specimen from which it was dissected is well sclerotized and pigmented and appears to be fully matured.

\section{Oedichirus brunneus Wendeler}

Figures 29, 40, 68-69

Oedichirus brunneus Wendeler, 1930: 185.

— Scheerpeltz, 1933: 1217 (catalog). — Blackwelder, 1944: 131 (checklist).

Type Material: One syntype. One specimen was sent to me from the Museum für Naturkunde, Berlin, where the Wendeler collection is distributed in the main collection. The locality data on the label differ slightly from those published by Wendeler (see Remarks below), but his identification label is attached to the specimen. Although a red "Holotypus" label is one of five attached to the specimen, the holotype selection was not published nor did Wendeler state or imply that he had studied only one specimen, so the specimen is a syntype (ICZN, 1999: Articles $73.1 .1,73.1 .2,73.2)$. To fix the identity of the species that specimen is herein designated as the lectotype.

LeCtOTYPE: Designated here. Female with the following labels: "Brasilien Sao Paulo, Alto da Serra, $700 \mathrm{~m}$ Biol Stat. Ohs. IX 1926/Naturschutzpark zw. Santos \& Sao Paulo, am Kamme d.Serra doMar/Sehr feuchter Regenwald/Oedichrus brunneus n.sp. Wendeler det./ Holotypus/Lectotype Oedichirus brunneus Wendeler des. L. Herman, 2011." Deposited in the Museum für Naturkunde, Berlin. (Left antennomeres 8-11, right antennomeres 3-11, left mesotarsus, and left metatibia and metatarsus are missing. The head and prothorax are separated from the pterothorax and abdomen; both are glued to a card.)

Type Locality: Brazil: São Paulo: Alto da Serra (= Paranapiacaba), $700 \mathrm{~m}$, biological station, Nature reserve, crest of Serra do Mar $\left(23^{\circ} 47^{\prime} \mathrm{S}\right.$, $46^{\circ} 19^{\prime} \mathrm{W}$ ). (Alto da Serra is equivalent to Paranapiacaba [Paynter and Traylor, 1991: 14, 439]. Serra do Mar is $40 \mathrm{~km}$ southeast of the city of São Paulo between that city and Santos. The coordinates are from Paynter and Traylor, 1991.)

DiAgnosis: The species is known only from the female lectotype. The position of the vulvar lobes of the median gonocoxal plate relative to one another and the surface microstructures (fig. 69) and the steeply sloped median gonocoxal plate anteriad of the vulvar plate (fig. 68) will separate $O$. brunneus from most other species. Species with the most similar form and adornment of the vulvar lobes include $O$. batillus, $O$. bullaglaber, $O$. distortus, $O$. geniculatus, and $O$. sparsipennis. Oedichirus brunneus can be separated from $O$. boehmi by the pronotal punctation and form of the posterior and anterior vulvar lobes (cf. fig. 69 with 67). The anteroventral angles of tergum IX of the female of $O$. distortus are fused (fig. 116), but separated in O. brunneus (fig. 68). Oedichirus batillus has paratergite III, which is replaced by a paratergal carina (see fig. 23) in $O$. brunneus. Tergum III of $O$. bullaglaber has a median point (as in sternum of fig. 73), which is lacking in $O$. brunneus. The anterior vulvar lobe of Oedichirus brunneus has short spicules (fig. 69) which are absent in $O$. geniculatus (fig. 151) and the anterolateral margin of the median gonocoxal plate of $O$. brunneus anteriad of the vulvar plate is steeply sloped (fig. 68), but more gradually sloped for $O$. geniculatus (figs. 148-150). The females of $O$. brunneus and $O$. sparsipennis are similar; both have bicolored legs, a paratergal carina; the median gonocoxal plate anteriad of the vulvar plate of both species is triangular, but the apex is wider in $O$. sparsipennis (fig. 206) than O. brunneus (fig. 68). The two species differ slightly as follows: for $O$. brunneus the lateral margin of the paratergal carina is nearly straight in dorsal view, the anterior vulvar lobe has small, scattered cuticular processes (fig. 69), and it is from the state of São Paulo, whereas for $O$. sparsipennis the lateral margin of the paratergal carina is convex in dorsal view, the anterior vulvar lobe lacks cuticular processes or any other adornment (fig. 207), and the species is from the state of Santa Catarina. However, the two species differ only slightly; it is likely that the question will remain unresolved until males and more females of $O$. brunneus have been found and compared to O. sparsipennis.

Externally, diagnostic features include the bicolored yellowish-brown legs with a dark reddish-brown spot at the femorotibial joint, 

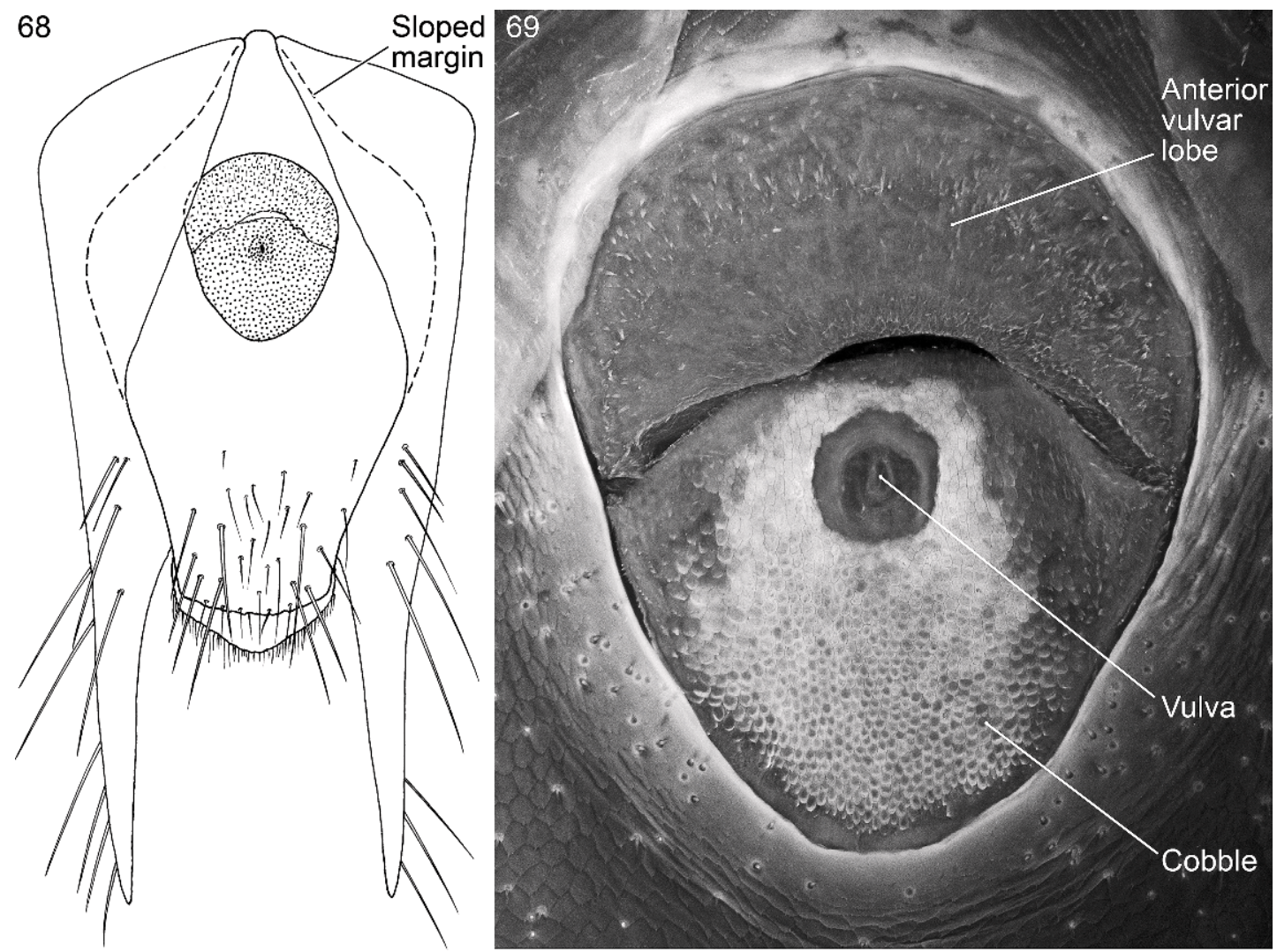

Figs. 68-69. Oedichirus brunneus. 68. Segment IX, female. 69. Segment IX, vulvar plate, enlarged (CLSM).

the quadridentate labrum, the equal length and width of the elytra, the short, welldeveloped paratergal carina of segment III reaches the spiracle, and the dense, coarse, dorsal cephalic punctation.

DESCRIPTION: Length: $10.2 \mathrm{~mm}$. Length of head: $1.2 \mathrm{~mm}$. Width of head: $1.5 \mathrm{~mm}$. Pronotal length: $2.0 \mathrm{~mm}$. Pronotal width: $1.5 \mathrm{~mm}$. Elytral length: $1.5 \mathrm{~mm}$. Elytral width: $1.5 \mathrm{~mm}$.

Body concolorous reddish brown. Legs bicolored, yellowish brown with femorotibial spot dark reddish brown.

Head wider than long (HW/HL: 1.2). Frontoclypeal ridge complete, not separated medially. Dorsal surface without V-shaped depression; surface uniformly, densely, and coarsely punctate medially, punctation less dense posteriorly and less coarse lateroposteriorly. Labrum quadridentate; surface without tubercle near submedial denticle.
Pronotum longer than wide (PL/PW: 1.3). Pronotal surface with scattered polished, impunctate spots and with coarse punctation arranged in scattered clusters and irregular rows; submedial punctate groove extending posteriorly from near middle. Elytra with length and width equal (EW/EL: 1.0); surface of disc feebly concave and with coarse punctation.

Abdomen irregularly punctate dorsally, punctures not arranged in transverse rows; punctation of III to VI coarse and dense; punctation of VII and VIII less dense and less coarse. Segment III without paratergite; paratergal carina present and short, reaching to spiracle and with lateral margin nearly straight in dorsal view. Tergum III without median point extending from transverse basal ridge. Tergum VIII with posterior margin truncate or feebly emarginate; transverse basal ridge with apically open median point. 
Tergum IX with lateroapical process moderately long, nearly twice as long as midbasal length $(\mathrm{LLaP} / \mathrm{L} 9=1.96)$, slightly bent ventrally, and approximately parallel to other process; ventromedial margin without posteriorly directed spur (cf. fig. 158).

MALE: Unknown.

Female: Tergum IX with anteroventral angles separated from each other (fig. 68). Median gonocoxal plate anteriad of vulvar plate large, strongly tapered, trianguliform, and with anterior margin narrowly rounded and strongly sloped lateroposteriorly; gonocoxal plate posteriad of vulvar plate gradually tapered posteriorly to broadly rounded posterior margin. Vulvar plate embedded in anterior half of median gonocoxal plate. Anterior vulvar lobe (fig. 69) transverse and extending across anterior margin of posterior vulvar lobe, with curved posterior margin, and surface moderately densely covered with short cuticular processes. Posterior vulvar lobe with most of surface densely covered with cobble, but with scattered cuticular processes anteriorly on each side of vulvar depression. Vulvar depression membranous and unadorned; vulva longitudinally oriented near midsagittal plane (fig. 69).

DistRIBUTION: Known from southeastern São Paulo state, Brazil (fig. 40).

REMARKS: Wendeler (1930: 185) reported the specimen was collected in November, but according to the label attached to the specimen it was collected in September.

Oedichirus bullaglaber, new species Figures 40, 70-79

Type Material: Holotype. Male. "Brasilien: Nova Teutonia, $27^{\circ} 11^{\prime}$ B. $52^{\circ} 23^{\prime} \mathrm{L}$. Fritz Plaumann, 292 1939/rufipennis Bernh. Typus/ Chicago NHMus M.Bernhauer Collection/Holotype Oedichirus bullaglaber Herman." Deposited in the Field Museum of Natural History.

PARATYPes: 2 males, 8 females. Brazil: Santa Catarina: Nova Teutonia, $27^{\circ} 11^{\prime} \mathrm{B}$. $52^{\circ} 23^{\prime} \mathrm{L}$. Fritz Plaumann, 242 1939, parcipennis Bernh. Typus (1 male, FMNH); Nova Teutonia, $27^{\circ} 11^{\prime}$ B. $52^{\circ} 23^{\prime} \mathrm{L}$. Fritz Plaumann (1 male, FMNH); Nova Teutonia, $300-500 \mathrm{~m}, 27^{\circ} 11^{\prime} \mathrm{B}$, $52^{\circ} 23^{\prime} \mathrm{L}$, January 1939, F. Plaumann (1 female, BMNH); Nova Teutonia, $300-500 \mathrm{~m}, 27^{\circ} 11^{\prime} \mathrm{B}$, $52^{\circ} 23^{\prime} \mathrm{L}$, February 1939, Fritz Plaumann (2 females, BMNH); Nova Teutonia, 300-500 m, $27^{\circ} 11^{\prime} \mathrm{S}, 52^{\circ} 23^{\prime} \mathrm{W}$, April 1971, Fritz Plaumann (1 female, CNCI); Nova Teutonia, 300-500 m, $27^{\circ} 11^{\prime} \mathrm{S}, 52^{\circ} 23^{\prime} \mathrm{W}$, July 1969 (2 females, CNCI); Nova Teutonia, Oedichirus plaumanni Brh Typ. unic. (1 female, teneral, FMNH). Santa Catarina: Linha Facao, May [1]954, F. Plaumann (1 female, CNCI).

Type Locality: Brazil: Santa Catarina: Nova Teutonia, $27^{\circ} 11^{\prime} \mathrm{S}, 52^{\circ} 23^{\prime} \mathrm{W}$. (This locality is cited by Paynter and Traylor [1991: 414], but with slightly different coordinates: $27^{\circ} 03^{\prime} \mathrm{S}$, $52^{\circ} 24^{\prime} \mathrm{W}$.)

Diagnosis: This species, O. bullahirtus, and $O$. echinatus are the only New World ones with a median point on tergum III (as on sternum VIII, fig. 73). The males of $O$. bullaglaber can be separated from $O$. bullahirtus by the rounded, asymmetrical, asetate tumescence adjacent to and proximad of the shallow emargination of sternum VIII (figs. 73, 74). On each side of the tumescence is an elliptical depression (fig. 74) the apical half of which has pale, translucent cuticle. The ventral sclerite of the aedeagus (fig. 71) has a notched posterior margin on the right side of the midline and on the right near the subapical lateral side is a small, rounded, subapical lobe (figs. 70,72), both of which are lacking in O. bullahirtus. Oedichirus echinatus is separated from $O$. bullaglaber by the bidentate labral margin and concolorous legs, which for $O$. bullaglaber are quadridentate and bicolored respectively.

The females of $O$. bullaglaber and $O$. bullahirtus are separated by the bicolored body of the former and the unicolored body of the latter; characters of the genital segment are similar for the two species (cf. figs. 79 and 88). The species are from Santa Catarina and São Paulo states respectively, but because the species are so similar and their distribution is unknown, caution should be observed when reporting new records based on females. Females of $O$. echinatus are unknown.

DESCRIPTION: Length: $8.8-10.8 \mathrm{~mm}$. Length of head: $0.9-1.0 \mathrm{~mm}$. Width of head: 1.2-1.4 mm. Pronotal length: $1.4-1.7 \mathrm{~mm}$. Pronotal width: $1.2-1.4 \mathrm{~mm}$. Elytral length: $1.0-1.2 \mathrm{~mm}$. Elytral width: $1.2-1.4 \mathrm{~mm}$.

Body bicolored, reddish brown and dark reddish brown to black. Head and pronotum dark reddish brown to black. Elytra and abdomen reddish brown to dark reddish brown and with segments VII to $\mathrm{X}$ darker reddish 


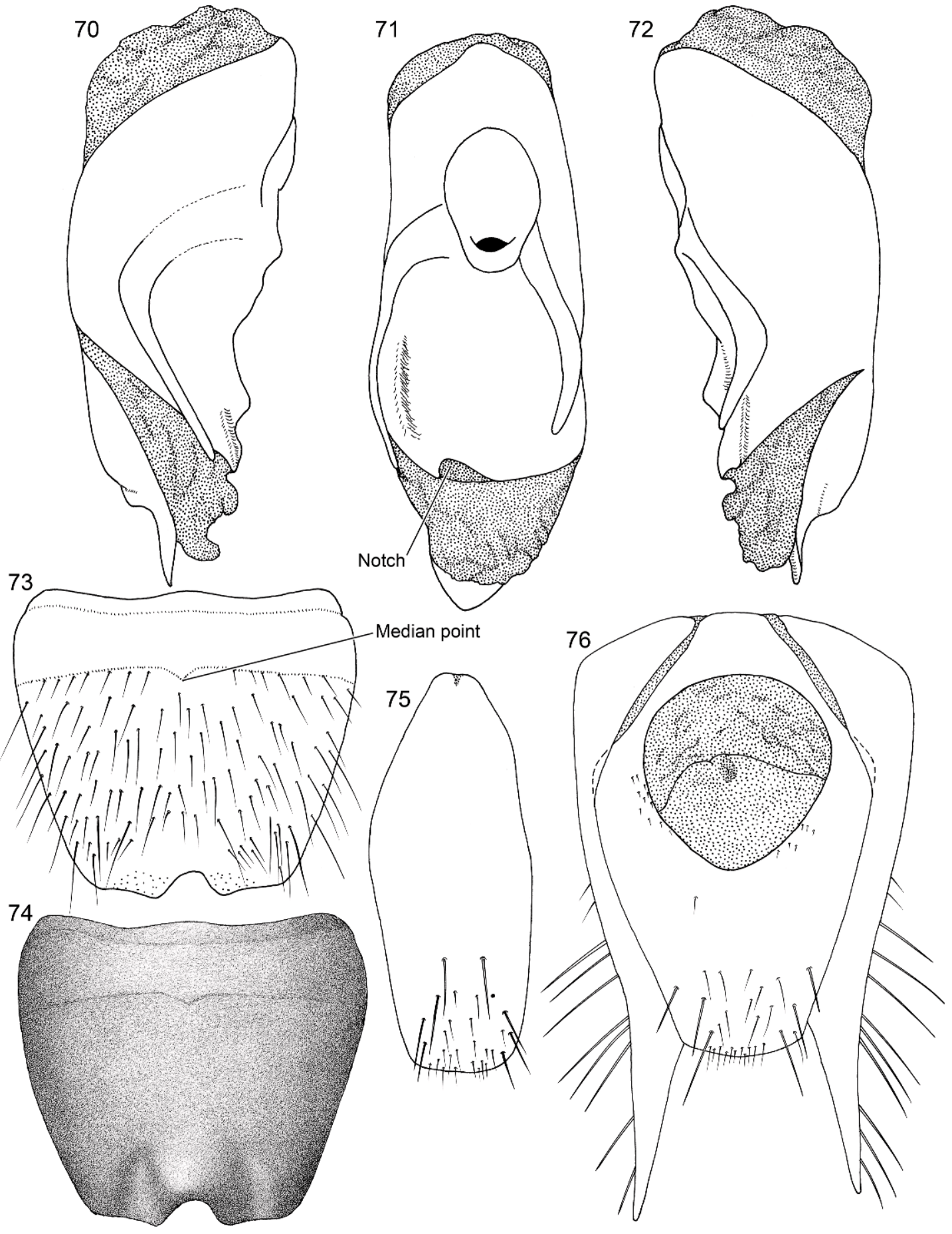

Figs. 70-76. Oedichirus bullaglaber. 70. Aedeagus, right lateral. 71. Aedeagus, ventral. 72. Aedeagus, left lateral. 73. Sternum VIII, male. 74. Sternum VIII, setae removed, male. 75. Sternum IX, male. 76. Segment IX, ventral, female. 


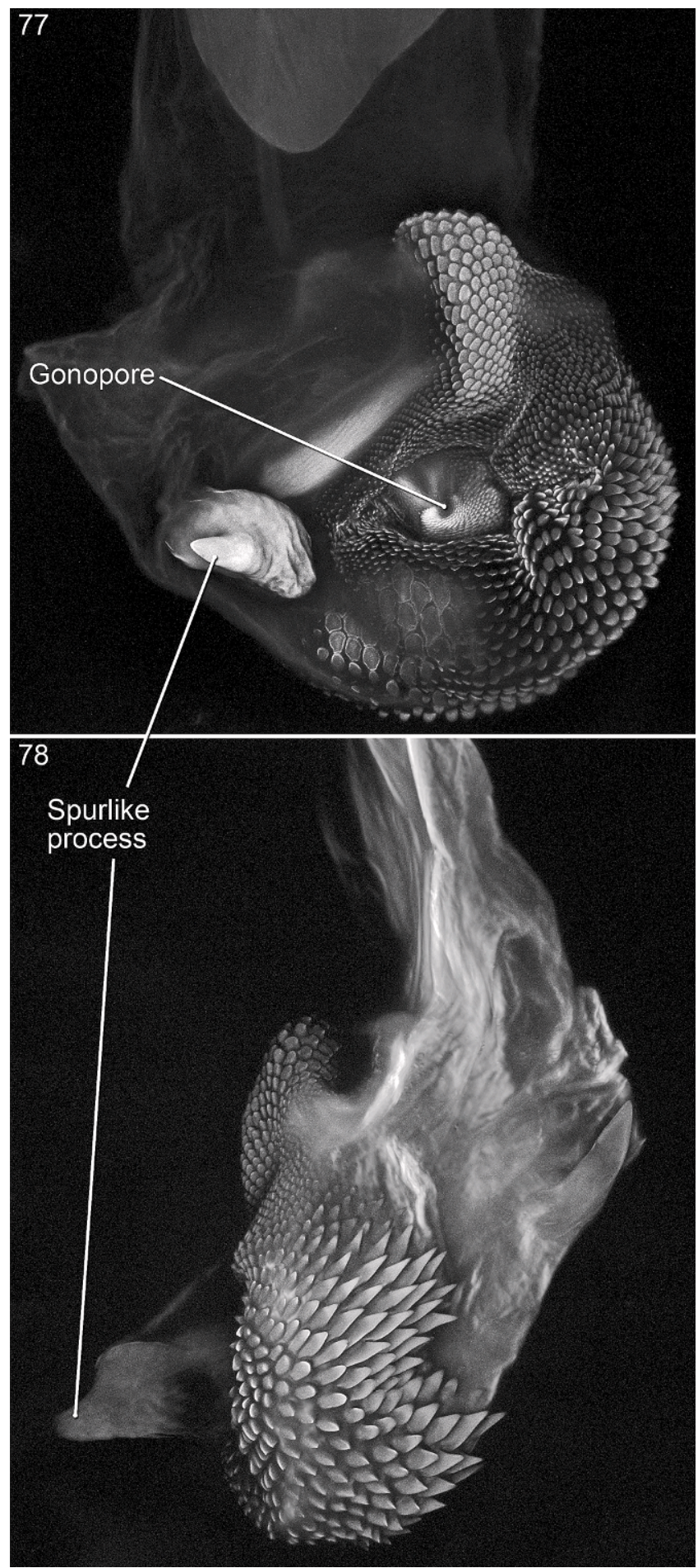

Figs. 77-78. Oedichirus bullaglaber. 77. Aedeagus, internal sac, everted, ventral (CLSM). 78. Aedeagus, internal sac, everted, right lateral (CLSM). 


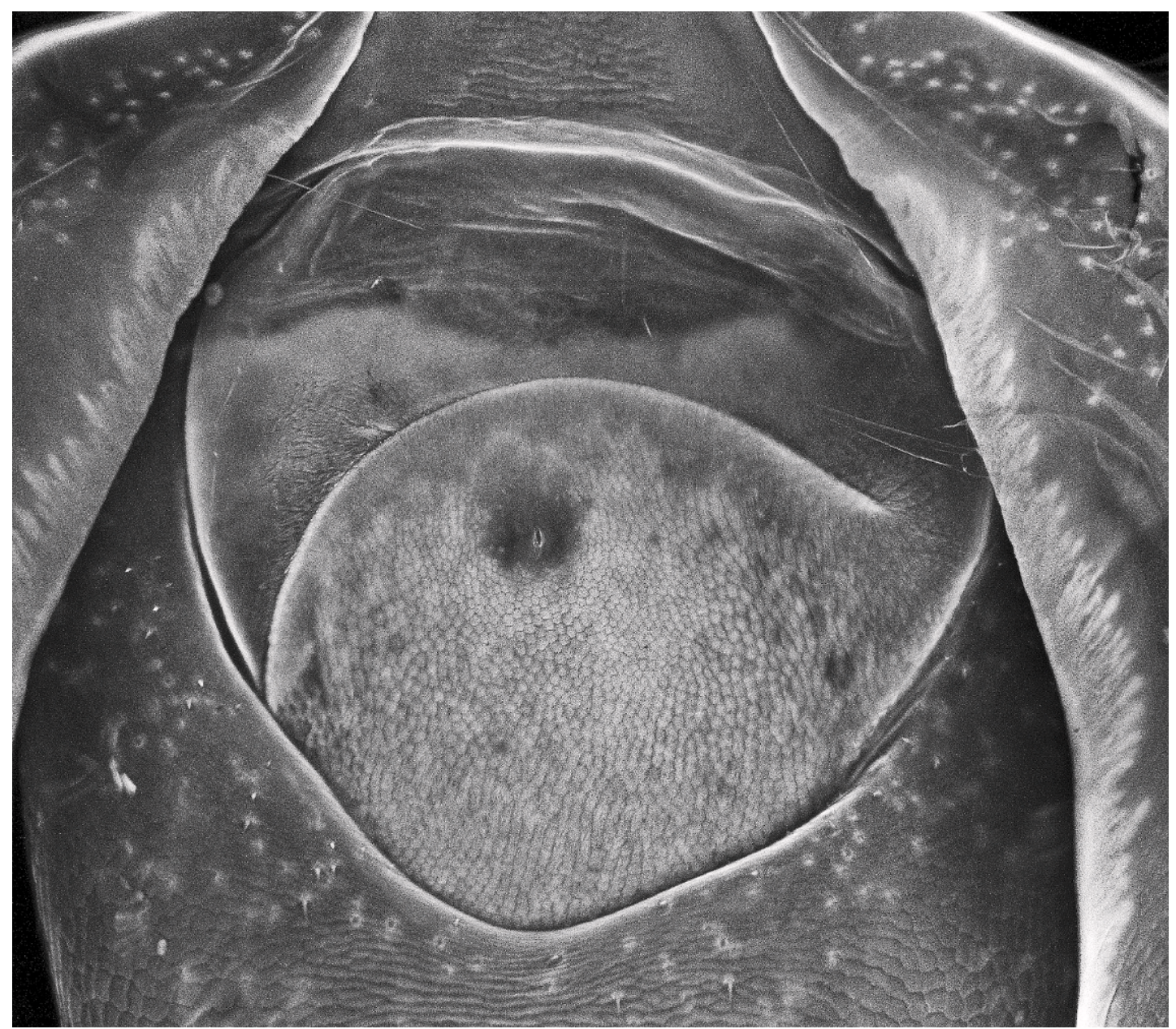

Fig. 79. Oedichirus bullaglaber. Segment IX, vulvar plate enlarged (CLSM).

brown to black. Legs bicolored, yellowish brown to pale reddish brown with dark reddish brown to nearly black femorotibial spot; femoral maculation of some individuals paler and less defined, more a dark infusion, and absent in a teneral specimen (see Remarks below).

Head about one third to two fifths wider than long (HW/HL: 1.3-1.4). Frontoclypeal ridge incomplete, separated medially. Dorsal surface without V-shaped depression; surface polished and coarsely punctate; punctation moderately dense medially and laterally and less dense basally; basal region with small impunctate, polished, median spot. Labrum quadridentate; surface without tubercle near submedial denticle.
Pronotum about a tenth to a third longer than wide (PL/PW: 1.1-1.3). Pronotum polished with scattered clusters of moderately dense, coarse punctation; submedial punctate groove moderately deep. Elytra about a tenth to a third longer than wide (EW/EL: 1.1-1.3); surface flat to slightly convex and coarsely punctate.

Abdomen evenly punctate, without subapical transverse row of punctures; segments III to VI with coarse, dense punctation; VII and VIII with less coarse punctation. Segment III without paratergite; paratergal carina extending to slightly more than half of length of segment; carina weakly developed beyond spiracle. Tergum III with median 
point extending from transverse basal ridge. Tergum VIII with trunctate posterior margin; transverse basal ridge with smooth margin and with apically open median point. Tergum IX with lateroapical process one to two fifths longer than midbasal length (LLaP/L9 = 1.2-1.4), moderately bent ventrally, and approximately parallel to or slightly divergent from other process; ventromedial margin without posteriorly directed spur (cf. fig. 158).

MALE: Sterna VI and VII unmodified. Sternum VIII (fig. 73) with shallow, asymmetrical median emargination; emargination about one sixteenth of length of segment, wider than deep, and with rounded basal margin; posterior margin laterad of median emargination slightly emarginate; surface with large, rounded, median tumescence proximad of emargination (fig. 74); tumescence asymmetrical, higher on right side of midline; tumescence steeply sloped on right and posterior sides and gradually sloped on left and anterior sides; tumescence with indistinct margins and surface polished, impunctate, and asetate; surface adjacent to tumescence with moderately deep, elliptical depression (fig. 74); depression with integument of apical half translucent; surface of sternum without comb or membranous margin; transverse basal ridge with median point (fig. 73). Tergum IX with process reduced to small to moderately large lobe on anterior margin of anteroventral angle. Sternum IX (fig. 75) moderately asymmetrical; anterior margin narrow, nearly truncate, and with short, membranous, median notch; posterior margin wide, broadly and shallowly rounded; right lateral margin broadly curved, left lateral margin slightly sinuate.

Aedeagus asymmetrical (figs. 70-72). Ventral sclerite with broad, moderately deep depression of apical third, with small, rounded ridge on right side near lateral margin (fig. 71), and with small tumescence near right lateral margin; posterior margin of ventral sclerite with rounded notch to right side of midsagittal line (fig. 71); notch filled with membrane; ventral sclerite without apicoventral process extending from posterior margin. Parameres moderately wide basally and tapered and slender apically; parameres with basal half of right and third of left fused to median lobe and both free of median lobe apically. Internal sac (figs. 77, 78) membranous to near apex; apical region with various types of spinelike armature; dorsal surface with isolated, slender spurlike process subapically (fig. 77); apical region with large cluster of spinelike and scalelike processes; most of dorsal, ventral, and lateral apical surfaces densely covered with spinelike (fig. 78) and scalelike processes (figs. 77); ventral surface with one stout, curved process on right side (fig. 77) and small scalelike processes surrounding gonopore (fig. 77).

FEMALE: Sternum VIII with irregularly sinuate transverse basal ridge; posterior margin rounded. Tergum IX with anteroventral angles separated (fig. 76). Median gonocoxal plate anteriad of vulvar plate large, wide and trapezoidal medially (fig. 76); anterior margin slightly rounded to truncate medially then gradually sloped lateroposteriorly; gonocoxal plate posteriad of vulvar plate gradually tapered to broadly rounded posterior margin and margin with or without small median lobe. Vulvar plate embedded in anteromedial region of gonocoxal plate (fig. 76). Anterior vulvar lobe (fig. 79) transverse, posterior margin contiguous with anterior margin of posterior lobe and extending along part of right lateral margin; surface smooth to slightly wrinkled and without ornamentation except laterally adjacent to margin of posterior vulvar lobe. Posterior vulvar lobe transverse and slightly oval (fig. 79); surface covered with cobble. Vulva oriented on longitudinal axis.

ETYMOLOGY: The name is from the Latin bulla, "boss or knob," and glaber, "hairless or bald," and refers to the absence of setae on the subapical tumescence of sternum VIII of the male.

DisTRIBUTION: Known only from two localities in Santa Catarina state, Brazil (fig. 40). For one site, Nova Teutonia, coordinates are included on the label and the place is cited by Paynter and Traylor (1991: 414). The other, Linha Facao, was not found.

REMARKS: The body is bicolored, the head, prothorax, and abdominal segments VIII to $\mathrm{X}$ are black to dark reddish brown and the elytra and abdominal segment III to VI are bright reddish brown, for all the specimens but two, a pale teneral specimen and a dark reddish-brown one. 
The teneral female is pale reddish brown, the head and prothorax are slightly darker than abdominal segment III to VI, segments VII to $\mathrm{X}$ are slightly darker and are approximately the color of the head and prothorax. The elytra are paler reddish brown, almost yellowish brown. The legs are unicolorous yellowish brown and lack the femorotibial spot. For the dark reddish-brown specimen the head and prothorax are black, the elytra reddish brown, and the abdomen dark reddish brown with apical infusions of paler reddish brown. Features of tergum and sternum VIII and the genital segments of these two specimens agree with those of the other six females of the species.

Because all the males and females (but one) were collected from the same locality and same collector, and all have the same color pattern of the body and legs (except the teneral specimen), and all have a median point on tergum III, the females cited in this species account are regarded to be conspecific with the males of $O$. bullaglaber.

The holotype and a male and a female paratype were each identified as different new species by Bernhauer.

\section{Oedichirus bullahirtus, new species}

Figures 40, 80-88

Type Material: Holotype. Male. "Bras. Sao Paulo Cantareira 9.8.14 • Mráz/optatus Sharp det Rambousek/v Rambousek vgl. m typus in Mus. London/Chicago NHMus M.Bernhauer collection/Holotype Oedichirus bullahirtus Herman." Deposited in the Field Museum of Natural History. (Left antennomeres 3-11 and right maxillary palpomeres 3 and 4 are missing. On the locality label the " $t$ " in Cantareira is faded and the pin hole goes through the second "r," so both require particular attention to decipher.)

Paratypes: Two females. Brazil: (São Paulo state): São Paulo, Mráz. Deposited in the Field Museum of Natural History.

Type Locality: Brazil: São Paulo: Cantareira $\left(23^{\circ} 27^{\prime} \mathrm{S}, 46^{\circ} 38^{\prime} \mathrm{W}\right)$. (Paynter and Traylor [1991: 121], from which the coordinates were taken, indicate this site is a northern suburb of São Paulo. The northern edge of the city is contiguous with a large, forested, mountainous area labeled as "Parque de Cantareira" on Google Earth.)

Diagnosis: This species and only two others in the New World have a median point on tergum III (as on tergum VIII, fig. 73). They are from the neighboring states of São Paulo (O. bullahirtus), Paraná (O. echinatus), and Santa Catarina (O. bullaglaber). The legs of $O$. bullahirtus and $O$. bullaglaber are bicolored, those of $O$. echinatus are unicolorous. The males of $O$. bullahirtus and $O$. bullaglaber have a moderately asymmetrical emargination of sternum VIII (figs. 73, 84), whereas the emargination is symmetrical for $O$. echinatus (fig. 127). The females of $O$. echinatus are not known.

Sternum VIII of the males of $O$. bullahirtus and $O$. bullaglaber has a subapical, submedial tumescence to the right of a small, asymmetrical emargination of the posterior margin. The males of the two species can be separated as follows: the median tumescence of sternum VIII of $O$. bullahirtus has a few setae (fig. 84), the surface is nearly flat (fig. 85), and the posterior and right margins are moderately well developed and slope sharply (fig. 85), whereas $O$. bullaglaber lacks setae on the tumescence (fig. 73), the surface is rounded (fig. 74), and the posterior and right margins are indistinct and slope gradually (fig. 74). As for the aedeagus, the posterior margin of the ventral sclerite of $O$. bullahirtus is entire (fig. 81), but has a rounded, submedial notch in O. bullaglaber (fig. 71). The internal sac of $O$. bullahirtus has a long, spiniform process (fig. 83); O. bullaglaber has a short spurlike process (figs. 77, 78). Sternum VIII has a well developed median point on sternum VIII in O. bullaglaber (fig. 73), but it is more weakly developed in O. bullahirtus (fig. 84).

The females of $O$. bullahirtus and $O$. bullaglaber are separated by the unicolored body of the former and the bicolored body of the latter. The median gonocoxal plate and the vulvar plate of the two species are similar (cf. figs. 88 and 79).

DESCRIPTION: Length: 7.0-9.7 $\mathrm{mm}$. Length of head: $0.8-1.0 \mathrm{~mm}$. Width of head: 1.1-1.3 mm. Pronotal length: $1.4-1.7 \mathrm{~mm}$. Pronotal width: $1.0-1.3 \mathrm{~mm}$. Elytral length: 1.0-1.2 mm. Elytral width: $1.1-1.3 \mathrm{~mm}$.

Body concolorous dark reddish brown; head and pronotum nearly black, elytra and abdomen slightly paler, black to dark reddish brown. Legs yellowish brown with dark femorotibial spot; femoral maculation dark 


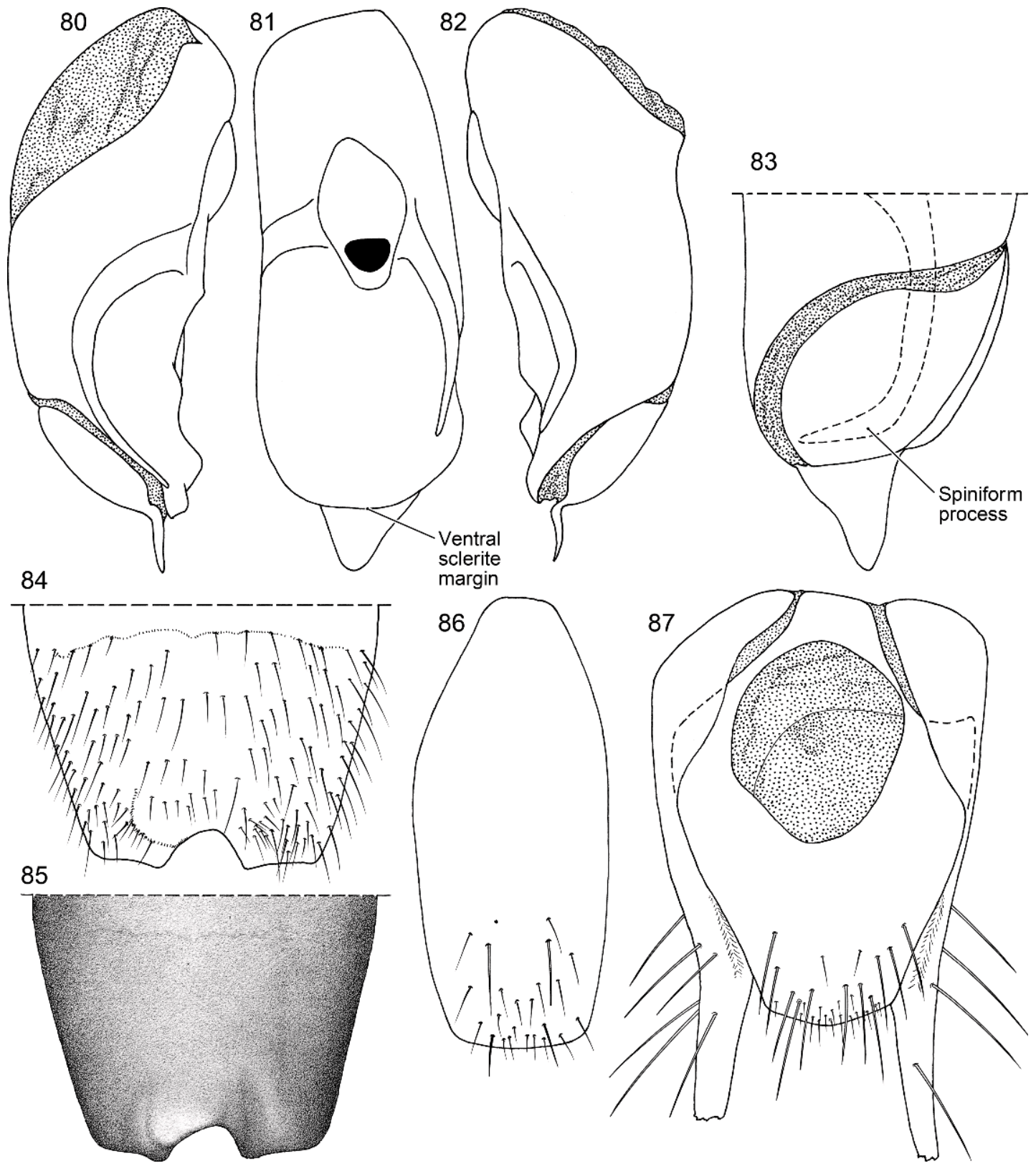

Figs. 80-87. Oedichirus bullahirtus. 80. Aedeagus, right lateral. 81. Aedeagus, ventral. 82. Aedeagus, left lateral. 83. Aedeagus, laterodorsal, apical third. 84. Sternum VIII, male. 85. Sternum VIII, setae removed, male. 86. Sternum IX, male. 87. Segment IX, ventral, female.

reddish brown, large, and distinct; tibial spot developed only as slightly darker infusion, small, and indistinct.

Head wider than long (HW/HL: 1.3). Frontoclypeal ridge incomplete, separated medially. Dorsal surface without V-shaped depression; surface coarsely punctate; punctation dense medially and laterally and sparser basally. Labrum quadridentate; surface without tubercle near submedial denticle. 


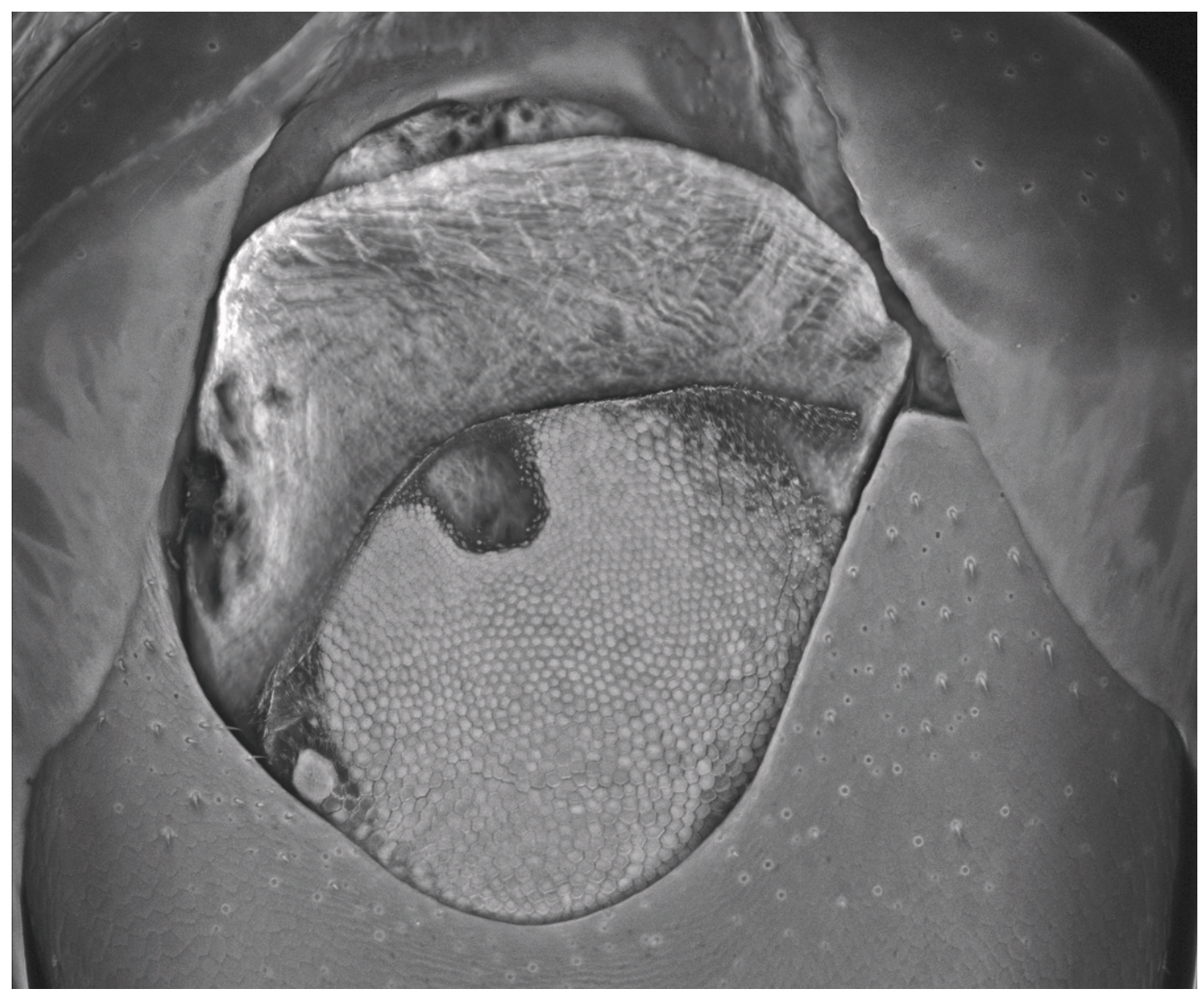

Fig. 88. Oedichirus bullahirtus. Segment IX, vulvar plate, enlarged (CLSM).

Pronotum longer than wide (PL/PW: 1.3). Pronotum polished and with coarse, moderately dense punctation; basal half with submedial punctures arranged in indistinct row. Elytral length about a tenth less than width (EW/EL: 1.1); surface slightly convex and coarsely punctate.

Abdomen segments evenly and coarsely punctate and without transverse rows of punctures; segments III to VI with coarser, denser punctation than VII and VIII. Segment III without paratergite; paratergal carina extending to about middle of segment, but poorly developed beyond spiracle. Tergum III with median point extending from transverse basal ridge. Tergum VIII with truncate posterior margin; transverse basal ridge with apically open median point. Tergum IX with lateroapical process about a fifth longer than midbasal length (LLaP/L9 = 1.2), moderately bent ventrally, and approximately parallel to or slightly divergent from other process; ventromedial margin without posteriorly directed spur (cf. fig. 158).

MALE: Sterna VI and VII unmodified. Sternum VIII with shallow, asymmetrical emargination (fig. 84); emargination about one seventh of length of segment, wider than deep, and with basal margin moderately broadly rounded; posterior margin laterad of median emargination slightly emarginate; surface with large, median tumescence proximad of emargination (fig. 85); tumescence asymmetrical, higher posteriorly and to right side of midline; tumescence steeply sloped, nearly perpendicular, on posterior and right sides and gradually sloped on anterior and left sides; tumescence with moderately 
distinct posterior and right margins; tumescence with surface nearly flat (fig. 85), polished, and with a few setate punctures (fig. 84); surface laterad of emargination with shallow, elliptical depression (fig. 85); depression with translucent integument on apical half to apical third; surface without comb or hyaline margin; transverse basal ridge with weakly developed median point (figs. 84, 85). Tergum IX with small rounded lobe on anterior margin of anteroventral angle. Sternum IX (fig. 86) slightly asymmetrical; anterior margin moderately wide and slightly rounded; posterior margin broadly and shallowly rounded; lateral margins broadly rounded.

Aedeagus asymmetrical (figs. 80-82). Ventral sclerite with broad, moderately deep, subapical depression, with low rounded ridge on right side, and without apicoventral process extending from posterior margin; posterior margin of ventral sclerite entire, without notch (fig. 81). Parameres moderately wide basally and tapered apically; parameres fused to median lobe from base to near apex, parameres free of median lobe apically. Internal sac with long, spiniform process (fig. 83).

FEMALE: Sternum VIII with irregularly sinuate transverse basal ridge; posterior margin rounded and slightly sinuate. Tergum IX with anteroventral angles separated medially (fig. 87). Median gonocoxal plate anteriad of vulvar plate trapezoidal medially and anterior margin nearly straight medially and lateral margins steeply sloped lateroposteriorly (fig. 87); gonocoxal plate posteriad of vulvar plate tapered to broadly rounded posterior margin. Vulvar plate embedded in gonocoxal plate anteriorly (fig. 87). Anterior vulvar lobe (fig. 88) embracing anterior and right lateral margin of posterior vulvar lobe; surface largely membranous, wrinkled, and with indeterminate ornamentation. Posterior vulvar lobe with most of surface covered with cobble (fig. 88). Vulva with indeterminate orientation.

ETYMology: The name is from the Latin bulla, "knob or boss," and hirtus, "hairy," and refers to the setose surface of the subapical tumescence of sternum VIII of the male.

Distribution: The species is known from the state and city of São Paulo (fig. 40).
REMARKS: The holotype and the two females were identified as $O$. optatus in the Field Museum collection, but differ from that species by the labral denticulation, color pattern of the legs, median point of the transverse basal ridge of tergum III, and features of sternum VIII of the males and aedeagus.

Four species, O. bicristatus, O. brunneus, $O$. bullahirtus, and $O$. ohausi are reported herein from the state of São Paulo. Of these only $O$. bullahirtus has a median point (as in sternum VIII, fig. 73) on tergum III. Among the four species, only O.brunneus and $O$. bullahirtus have bicolored legs, the other two have concolorous legs.

Two females from São Paulo are identified herein as $O$. bullahirtus. They share with the holotype the presence of a median point and paratergal carina on tergum III, bicolored legs, and unicolored body. These shared features, particularly the median point of tergum III, along with collections from nearby sites seem sufficient to propose their conspecificity with the holotype of $O$. bullahirtus.

\section{Oedichirus clavolateralis, new species} Figures 40, 89-95

Type Material: Holotype: Male. "Type/[upper side] Rio de Janeiro [underside] Squire/S.America Brazil/Sharp Coll. 1905-313./Oedichirus janeiroensis Bh. typ M.Bernhauer det./Manuscript name/Holotype Oedichirus clavolateralis Herman." Deposited in the Museum of Natural History, London. (Left antennomeres 3-11 are missing.)

Type Locality: Brazil: Rio de Janeiro: Rio de Janeiro (The type label includes the word "Squire," which may be the name of the collector and not the locality.)

Diagnosis: $O$. clavolateralis is one of four species that comprise a complex of species whose males have an emargination of sternum VIII that is short, wide, and asymmetrical (fig. 94) and the aedeagus has a stout, tapered, curved apicoventral process extending from the right apical side of the ventral sclerite (fig. 90). Oedichirus clavolateralis is separated from the three other species of the complex, $O$. clavulus, $O$. exilis, and $O$. geniculatus, by the characters of the aedeagus as follows. Unlike the other three species, $O$. clavolateralis has a lobe on the left side of 

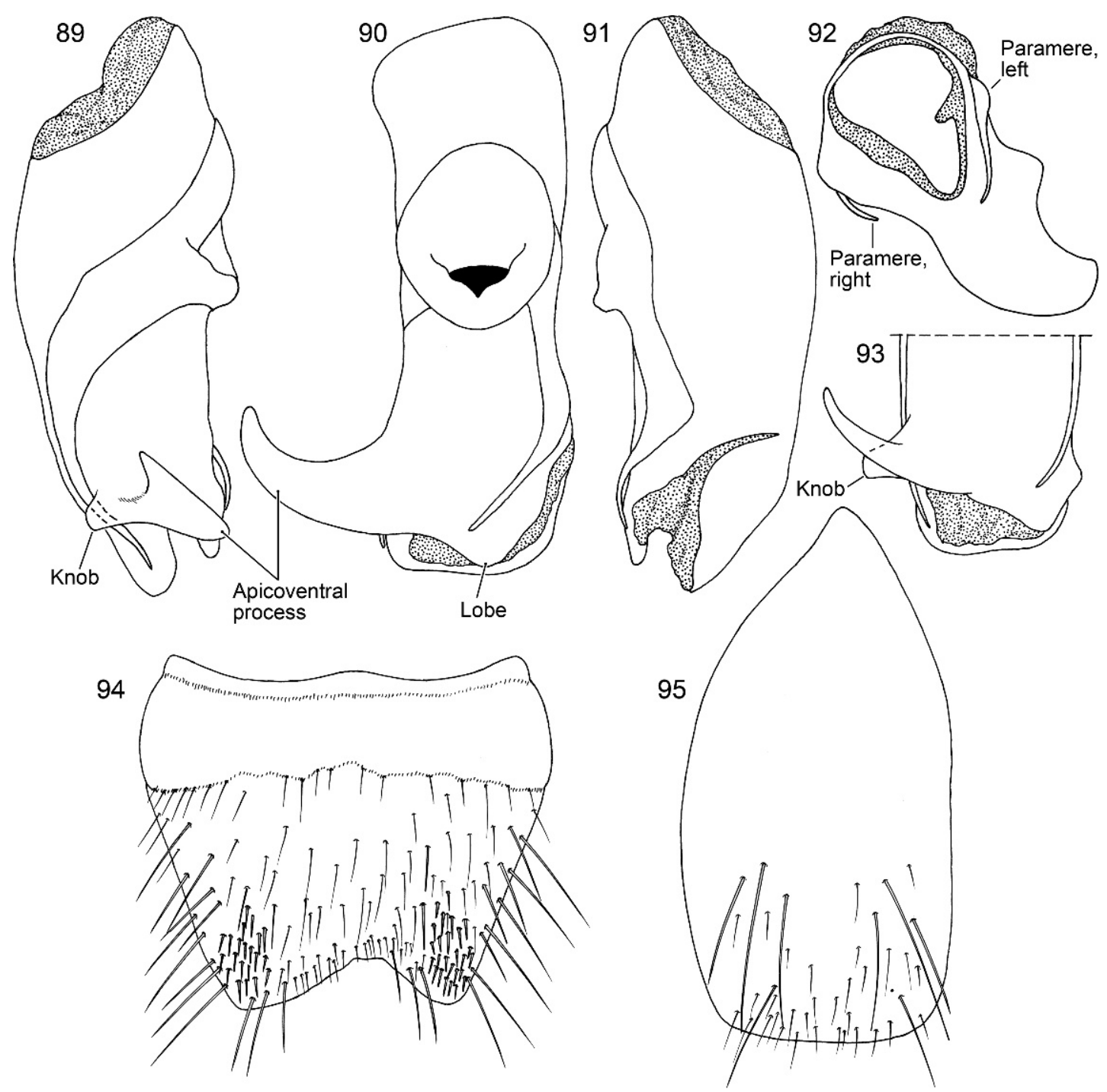

Figs. 89-95. Oedichirus clavolateralis. 89. Aedeagus, right lateral. 90. Aedeagus, ventral. 91. Aedeagus, left lateral. 92. Aedeagus, apex, posterior. 93. Aedeagus, lateroventral, posterior third. 94. Sternum VIII, male. 95. Sternum IX, male.

the posterior margin of the ventral sclerite (fig. 90) and to the right and dorsad of the strongly flattened apicoventral process is a short knob extending laterally (figs. 89, 93). The female is unknown, but potentially conspecific females are illustrated and discussed in the male/female association comments below; the illustrations and specimens are labeled as "O. clavolateralis?"

DESCRIPTION: Length: $9.8 \mathrm{~mm}$. Length of head: $0.9 \mathrm{~mm}$. Width of head: $1.3 \mathrm{~mm}$.
Pronotal length: $1.5 \mathrm{~mm}$. Pronotal width: $1.2 \mathrm{~mm}$. Elytral length: $1.2 \mathrm{~mm}$. Elytral width: $1.3 \mathrm{~mm}$.

Body black with dark reddish brown infusions. Legs bicolored, yellowish brown with dark reddish-brown femorotibial joint maculation.

Head about two fifths wider than long $(\mathrm{HW} / \mathrm{HL}=1.4)$. Frontoclypeal ridge strongly curved, incomplete with medial ends widely separated. Dorsal surface without V-shaped depression; surface with coarse punctation; 


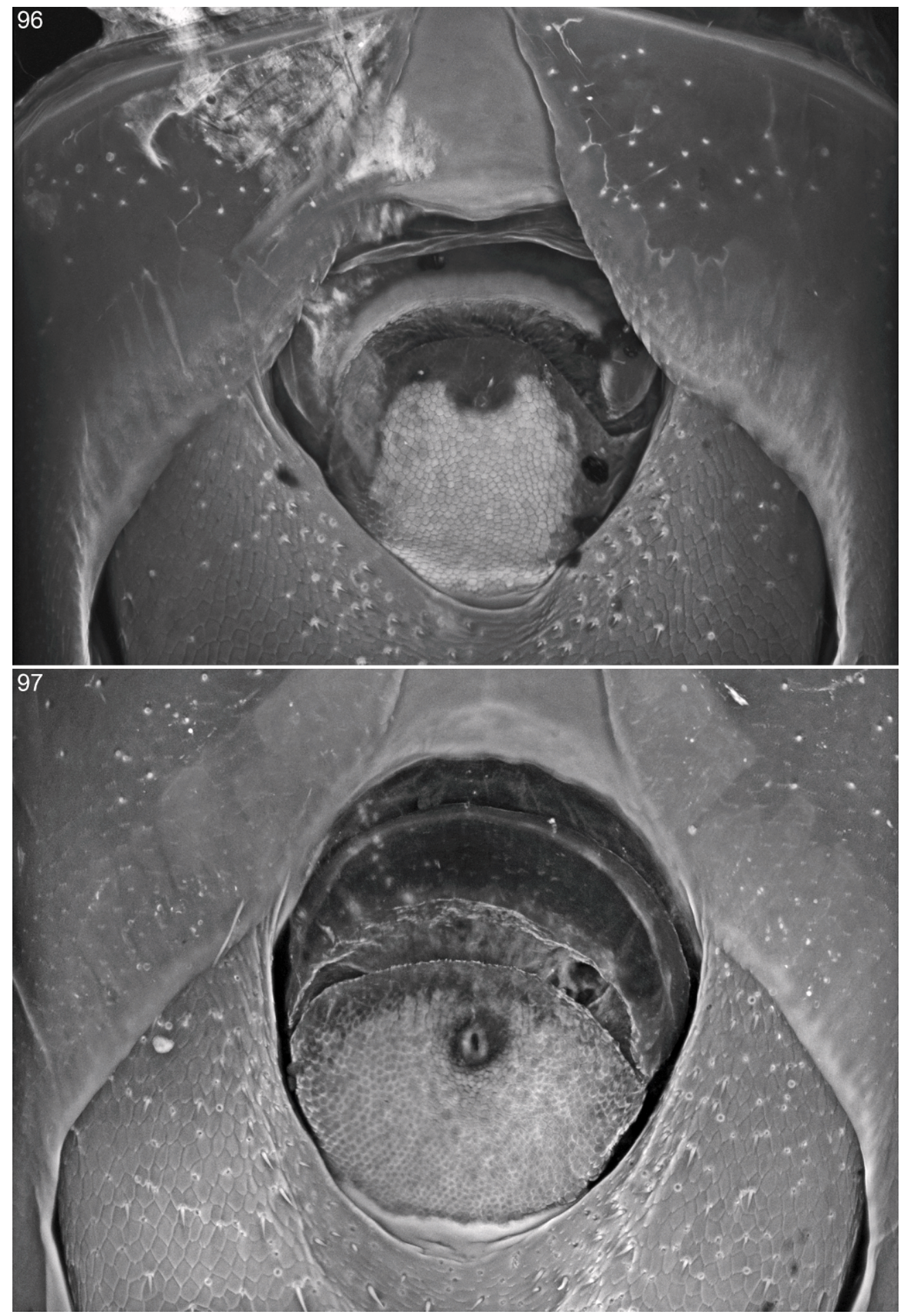

Figs. 96-97. Oedichirus clavolateralis?. 96. Segment IX, vulvar plate, variation (CLSM). 97. Segment IX, vulvar plate, variation (CLSM). 
punctation dense across middle and more sparse anteriorly and posteriorly; basal region largely impunctate. Labrum quadridentate; surface without tubercle near submedial denticle.

Pronotum about a fifth longer than wide $(\mathrm{PL} / \mathrm{PW}=1.2)$. Pronotum polished, with coarse, dense punctation and with scattered moderately large impunctate spots; surface with deep, submedial, punctate groove on basal two thirds. Elytra with length and width equal $(\mathrm{EW} / \mathrm{EL}=1.0)$; surface flat medially and coarsely punctate.

Abdominal terga III to V densely punctate and without transverse rows of punctures; punctation of VI coarse basally and finer apically; punctation of tergum VII finer and less dense. Segment III without paratergite; paratergal carina present and extending slightly beyond spiracle. Tergum III without median point extending from transverse basal ridge. Tergum VIII with posterior margin slightly rounded; transverse basal ridge with apically open median point. Tergum IX with lateroapical process more than twice as long as midbasal length $(\mathrm{LLaP} / \mathrm{L} 9=2.8)$, moderately bent ventrally, and diverging moderately from other process; ventromedial margin without posteriorly directed spur (cf. fig. 158).

MALE: Sterna VI and VII unmodified. Sternum VIII with wide, moderately deep, asymmetrical emargination of posterior margin (fig. 94); emargination about one seventh of length of sternum, wider than deep, with base slightly and posteriorly convex (fig. 94); emargination mostly to left of midlongitudinal line; left margin of emargination shorter and more steeply sloped than right (fig. 94); surface adjacent to margin of emargination translucent and beveled and with row of setae along edge of bevel; median surface broadly and slightly depressed; long pubescence more or less evenly distributed; surface laterad of emargination with dense cluster of short, spinelike setae; transverse basal ridge without median point and irregularly and coarsely serrate. Tergum IX with anteroventral angle extended anteriorly as moderately large process. Sternum IX (fig. 95) moderately asymmetrical; anterior margin narrow and strongly rounded; posterior margin broadly and shallowly rounded; lateral margins broadly rounded.
Aedeagus asymmetrical (figs. 89-91). Ventral sclerite with rounded lobe on apical margin to left of large, flattened, curved, strongly sclerotized apicoventral process extending from right lateroapical margin (fig. 90); apicoventral process broad (fig. 92) and strongly tapered to narrowly rounded apex (fig. 90); apex anterodorsally directed; apically rounded knob extending laterally from right base of apicoventral process (figs. 89, 93). Parameres moderately broad basally, flattened, tapered, and slender apically, fused to median lobe for most of length, and free of median lobe near apex; left paramere laying against lateral and ventral surfaces (figs. 90-92), right paramere against lateral surface (fig. 89); parameres of approximately equal length.

Female: Unknown.

ETYMOLOGY: The name is from the Latin clavus, "nail," and latus, "flank," and refers to the laterally directed knob or peg on the right lateral side of the ventral sclerite.

MATERIAL EXAMined: Holotype male and three possibly conspecific females from the type locality (see below for comments).

Distribution: Known only from Rio de Janeiro state, Brazil (fig. 40).

Male/Female Association: A species of the $O$. geniculatus complex, O. clavolateralis, one of three of the complex reported from Rio de Janeiro city, is represented by one male. The holotype has a small, green, oval label with the word "Squire." Three females have a similar label with "Squires" in place of Squire. Since no locality was found in Brazil with either of these names, Squire(s) likely refers to a person, perhaps the collector. All of the labels are in similar handwriting. The labels on none of the specimens included a date of collection, so it is not known whether the females and male were collected together at the same time, and the locality "Rio de Janeiro" is too ambiguous to be certain the males and females were collected at the same site. There are no morphological characters unique to the species and shared by the holotype male with any of the three females nor do any contradict their conspecificity. However, as they are potentially specimens of O. clavolateralis, illustrations and description of the vulvar plate of two of the three females 
are included (figs. 96, 97) and the specimens are labeled "O. clavolateralis?."

FEMALE: Tergum IX with anteroventral angles separated from each other (fig. 96). Median gonocoxal plate anteriad of vulvar plate triangular and anterior margin subacute medially then sloping lateroposteriorly; gonocoxal plate posteriad of vulvar plate gradually tapered to broadly rounded posterior margin. Vulvar plate embedded in anterior half of median gonocoxal plate (figs. 96, 97). Anterior vulvar lobe curved around anterior margin of posterior vulvar lobe; anterior lobe wider and shorter than posterior vulvar lobe; surface membranous and with a long, curved, irregular wrinkle across most of width and without other adornment. Posterior vulvar lobe wider than long; surface covered with cobble. Vulva with orientation approximately aligned with longitudinal axis.

\section{Oedichirus clavulus, new species} Figures 40, 98-102

Type Material: Holotype. Male. "Bras.Petropolis Prov. R. Janeiro III.1850.Sahlberg/geniculatus Sahlb. det. Bernh. minor/Chicago NHMus M.Bernhauer Collection/Holotype Oedichirus clavulus Herman." Deposited in the Field Museum of Natural History.

PARATYPE: One male. [Brazil:] Rio Jan ${ }^{\circ}$, Fry (FMNH).

Type Locality: Brazil: Rio de Janeiro: Petrópolis $\left(22^{\circ} 30^{\prime} \mathrm{S}, 43^{\circ} 08^{\prime} \mathrm{W}\right.$; (coordinates from Times Books, 1999).

Diagnosis: Oedichirus clavulus is one of a cluster of four species (see also $O$. clavolateralis, $O$. exilis, and $O$. geniculatus) that have both a stout, curved, strongly sclerotized process extending laterally from the right apical margin of the aedeagal ventral sclerite (fig. 99) and a short, wide, asymmetrical emargination of the posterior margin of sternum VIII (fig. 102). The males of $O$. clavulus can be separated from the other species of this species group by the short, stout, apically blunt peg on the right lateral apical margin of the ventral sclerite of the aedeagus at the base of the apicoventral process (figs. 98, 99). Among the other species, $O$. geniculatus (fig. 141) has no knob, peg, spine, lobe, or swelling in the aforementioned position. Oedichirus clavolateralis has an apically blunt knob extending lateroposteriorly (figs. 89, 93) from about the same position as for $O$. clavulus and the left side of the anterior margin of the ventral sclerite of the former is lobed (fig. 90), and the knob is lacking in $O$. clavolateralis. In lateral view the knob extending from the lateral dorsal region of the apicoventral process of $O$. exilis (fig. 129) is wider basally and more strongly tapered and the gap between the knob and the base of the apicoventral process wider than for O. clavulus (fig. 98), whose knob is more gradually tapered and the gap between the knob and the base of the apicoventral process is narrower.

Oedichirus clavulus is one of eight New World species with bicolored legs and a median point extending from the transverse basal ridge of tergum VIII. Also included among these species are $O$. brunneus, $O$. bullaglaber, $O$. bullahirtus, $O$. clavolateralis, $O$. exilis, $O$. geniculatus, and $O$. sparsipennis. Tergum III of both $O$. bullaglaber and $O$. bullahirtus has a median point (as for sternum VIII, fig. 73) that $O$. clavulus lacks. Characters that separate males of $O$. clavolateralis, $O$. exilis, and $O$. geniculatus from $O$. clavulus are presented in the preceding paragraph and only $O$. brunneus and $O$. sparsipennis remain; both are known only by females. The lateroapical process of IX for O. clavulus $(\mathrm{LLaP} / \mathrm{L} 9=2.3-$ 2.4) is more than twice as long as the midbasal length of tergum IX, but for the two remaining species the process is twice as long as the midbasal length for O. brunneus (LLaP/ L9 $=2.0$ ), and about a third shorter than the midbasal length of tergum IX for $O$. sparsipennis $(\mathrm{LLaP} / \mathrm{L} 9=1.7)$.

DESCRIPTION: Length: 7.0-7.7 mm. Length of head: $0.8 \mathrm{~mm}$. Width of head: $1.1 \mathrm{~mm}$. Pronotal length: $1.3 \mathrm{~mm}$. Pronotal width: $1.0 \mathrm{~mm}$. Elytral length: $1.0 \mathrm{~mm}$. Elytral width: $1.1 \mathrm{~mm}$.

Body concolorous dark reddish brown to nearly black, elytra paler and more notably reddish brown, particularly posteriorly and laterally. Legs bicolored, yellowish brown with femorotibial spot dark reddish brown; tibial spot smaller, paler, less demarcated.

Head wider than long (HW/HL: 1.4). Frontoclypeal ridge incomplete, separated medially. Dorsal surface without V-shaped 

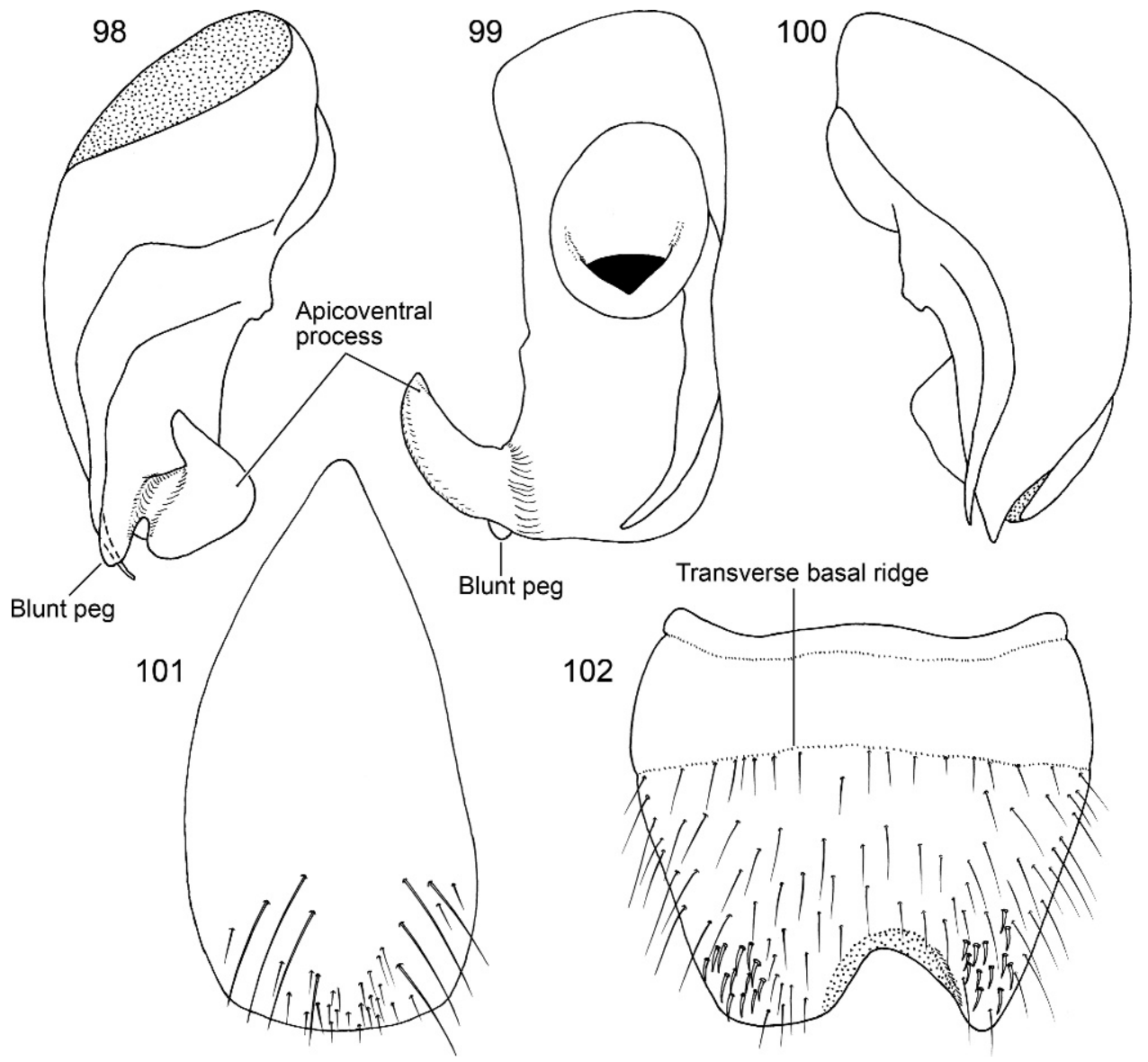

Blunt peg Transverse basal ridge

Figs. 98-102. Oedichirus clavulus. 98. Aedeagus, right lateral. 99. Aedeagus, ventral. 100. Aedeagus, left lateral. 101. Sternum IX, male. 102. Sternum VIII, male.

depression; surface with dense, coarse punctation anteriorly, medially, and laterally, but less dense midbasally. Labrum quadridentate; surface without tubercle near submedial denticle.

Pronotum about one fifth longer than wide (PL/PW: 1.2). Pronotum polished, with coarse, moderately dense punctation anteriorly and sparser laterally; surface with coarsely punctate, moderately deep, submedial groove on basal two thirds. Elytra about a tenth wider than long (EW/EL: 1.1); surface flat to slightly convex and coarsely punctate.

Abdomen densely and irregularly punctate and without transverse rows of punctures. Segment III without paratergite; paratergal carina present and extending to near middle of segment, but less strongly developed beyond spiracle. Tergum III without median point extending from transverse basal ridge. Tergum VIII with apically, narrowly open median point extending from transverse basal ridge; posterior margin feebly rounded to weakly emarginate. Tergum IX with lateroapical process more than twice as long as midbasal length $(\mathrm{LLaP} / \mathrm{L} 9=2.3-2.4)$, slightly bent ventrally, and approximately parallel to other process; ventromedial margin without posteriorly directed spur (cf. fig. 158).

MALE: Sternum VI unmodified. Sternum VII with small, impunctate, asetate, median spot near posterior margin. Sternum VIII with wide, deep, asymmetrical emargination of posterior margin (fig. 102); emargination about one sixth of length of sternum, wider than deep, and mostly to left of 
midlongitudinal line; right margin of emargination shorter and more steeply sloped than left; emargination moderately broadly rounded basally and submarginal edge translucent; surface with slight carina laterad of left margin of emargination and with cluster of short, spinelike setae laterad of both sides of emargination near posterior margin; surface without without comb or depression; transverse basal ridge unevenly sinuate and without median point. Tergum IX with anteroventral angle extended anteriorly as moderately large process. Sternum IX (fig. 101) slightly asymmetrical; anterior margin narrow and strongly rounded; posterior margin wide and broadly rounded; right lateral margin broadly rounded left margin slightly and broadly sinuate.

Aedeagus asymmetrical (figs. 98-100). Ventral sclerite with apical margin weakly sinuate (fig. 99), with large, thick, curved, strongly sclerotized apicoventral process extending from right apicolateral margin (figs. 98, 99); apicoventral process wide in lateral view and extending lateroventrally with apical portion bent dorsoanteriorly (figs. 98, 99); ventral sclerite with apically rounded, cylindriform peg arising from right dorsolateral margin at base of apicoventral process (fig. 98). Parameres moderately broad, flattened, tapered apically, and fused to median lobe for most of length, free of median lobe near apex; parameres of more or less equal length.

FeMAle: Unknown.

Male/Female Association: The type locality for $O$. clavulus, a species of the geniculatus complex, is Petropolis from which only one male is known. A paratype male of O. clavulus was collected from "Rio Jan" by (A.) "Fry" and is possibly from the city of Rio de Janeiro. The handwritten label is unique and seven other specimens, all females, have that label. However, although they share a characteristic label, the collecting dates and site(s) are unknown, so it is uncertain that they were collected at the same time and place. The genital segments of six of the seven specimens were removed for examination. Five specimens are $O$. geniculatus. The sixth female is a different species; unlike $O$. geniculatus and others of the species complex, its tergum III has a basal median point (as for sternum VIII, fig. 73), which is lacking in all the species of the complex and has not been found on any males from Rio de Janeiro. Only three species with a median point of tergum III are known, one each in Santa Catarina, Paraná, and São Paulo states. The sixth specimen lacked an abdomen.

ETYMOLOGY: The name is from the Latin clavus, "nail," and refers to the small, posteriorly directed peg on the right lateroapical margin of the aedeagal ventral sclerite.

DisTRIBUTION: Known only from the state of Rio de Janeiro, Brazil (fig. 40).

REMARKS: Oedichirus clavolateralis, $O$. clavulus, $O$. exilis, and $O$. geniculatus are the only species reported from the state of Rio de Janeiro. One of the two males of $O$. clavulus was collected at Petropolis by Sahlberg and identified by Bernhauer as $O$. geniculatus. Sahlberg made two trips to Brazil. During his second trip he was in Petropolis from December 1849 to May 1850, and then again in December 1850; it was on the first part of that second trip that he collected the holotype of $O$. clavulus in March (Rinne, e-mail, April 2, 2009). Based on the material I have seen and on the lack of contradictory published information, the holotype of $O$. clavulus is the second specimen of the genus collected in the New World.

The paratype was collected from "Rio Jan $^{\circ}$ " by Alexander Fry, but it is unclear whether the locality refers to the state or the city. Fry lived in Rio de Janeiro from 1838 to 1854 (Anonymous, 1905: 119), but certainly may have traveled outside the city to collect in other locales of the state.

Oedichirus dilophus, new species Figures 40, 103-111

Type Material: Holotype. Male. "Bolivia: Santa Cruz, Comarapa, $32.8 \mathrm{~km}$ NW Yungas de Siberia, $2400 \mathrm{~m} 17^{\circ} 49^{\prime} 24^{\prime \prime} \mathrm{S}, 64^{\circ} 24^{\prime} 26^{\prime \prime} \mathrm{W} 27$ JAN 1999/R. Anderson BOL1A99 001; ex litter berlese/SMO164510 KUNHM-ENT/Holotype Oedichirus dilophus Herman." Deposited in the University of Kansas Natural History Museum, Lawrence, Kansas.

PARATyPe: One Female. Bolivia: Cochabamba: Cochabamba, $72 \mathrm{~km}$ E. Yungas (Cochabamba - Villa Tunari Rd.) $2800 \mathrm{~m} ; 17^{\circ} 1^{\prime} 21^{\prime \prime} \mathrm{S}, 65^{\circ}$ 53'45"W 3 FEB 1999; R. Anderson BOL1A99 018; ex wet forest litter/SMO168942 KUNHMENT. Deposited in the University of Kansas Natural History Museum, Lawrence, Kansas. 


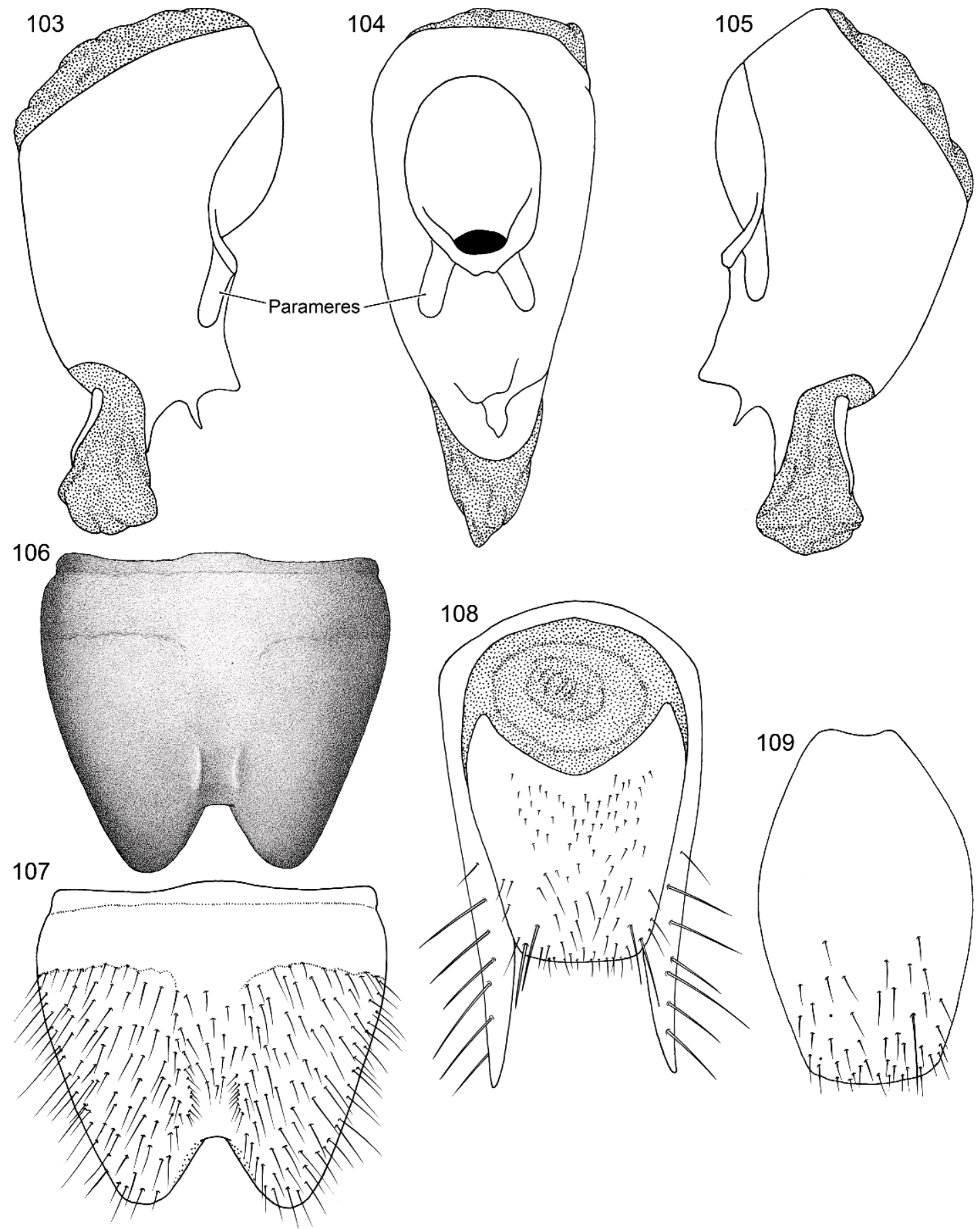

Figs. 103-109. Oedichirus dilophus. 103. Aedeagus, right lateral. 104. Aedeagus, ventral. 105. Aedeagus, left lateral. 106. Sternum VIII, setae removed, male. 107. Sternum VIII, male. 108. Segment IX, ventral, female. 109. Sternum IX, male. 

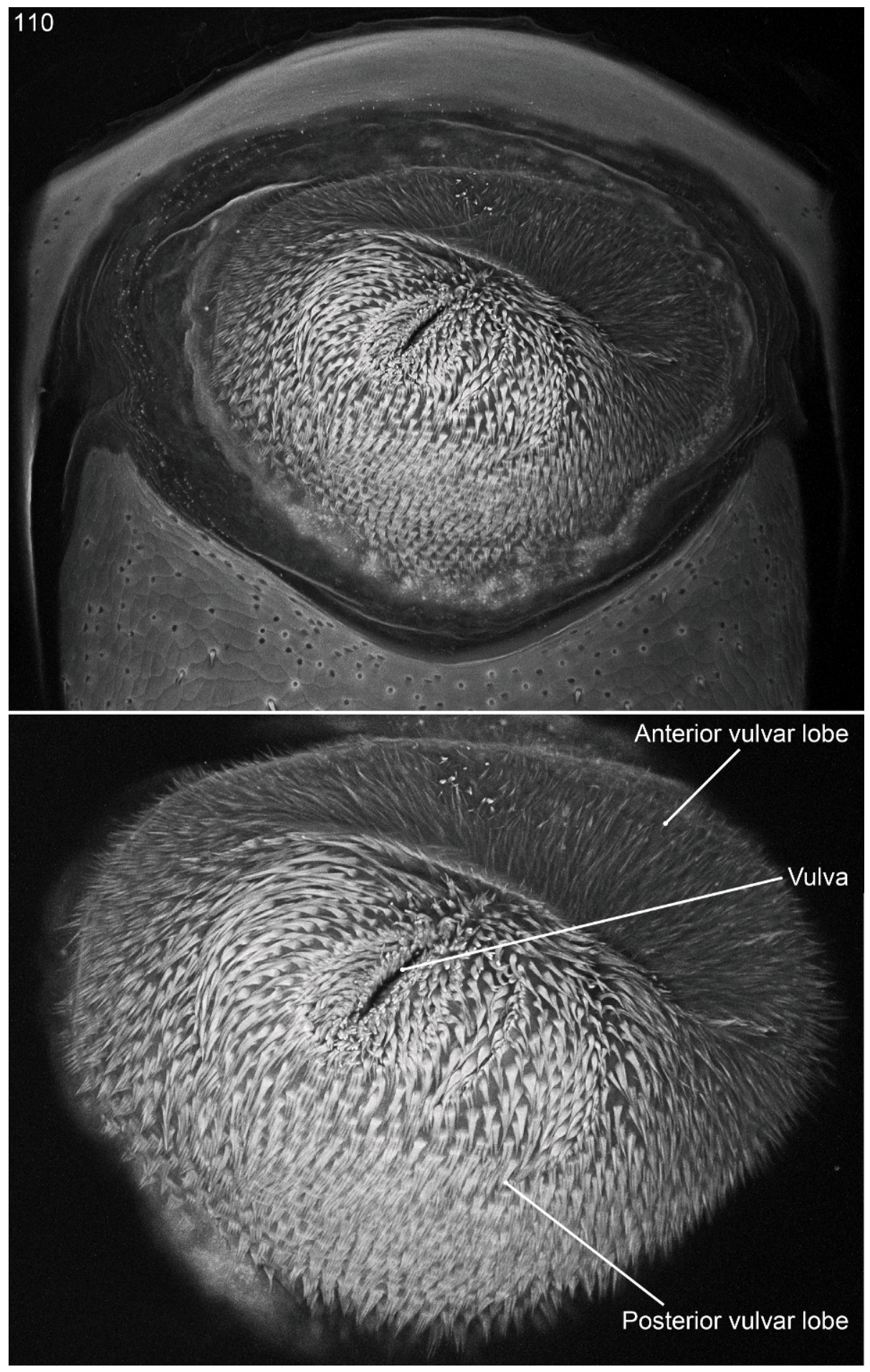

Figs. 110-111. Oedichirus dilophus. 110. Segment IX, vulvar plate (CLSM). 111. Segment IX, vulvar plate, enlarged (CLSM). 
Type Locality: Bolivia: Santa Cruz: Comarapa, $32.8 \mathrm{~km}$ NW Yungas de Siberia, $2400 \mathrm{~m}$ $17^{\circ} 49^{\prime} 24^{\prime \prime} \mathrm{S}, 64^{\circ} 24^{\prime} 26^{\prime \prime} \mathrm{W}$.

DiAgnosis: The males of $O$. dilophus can be separated from all other New World species by the pair of submedial, subapical carinae on sternum VIII and the broad, deep, symmetrical emargination of sternum VIII (fig. 106). The aedeagus (fig. 104) has short, broad parameres fused to the median lobe; the posterior margin of the ventral sclerite of the median lobe is strongly sloped near the apex and the slope has a dorsoventrally flattened, apically acute process extending from it posteriorly (figs. 103-105). Among all known New World species of the genus, $O$. dilophus has the least coarse cephalic and pronotal punctation. The legs are concolorous yellowish brown without a dark femorotibial spot.

The females of $O$. dilophus are separated from those of all other New World species by the dense mat of spiniform processes covering the vulvar plate (figs. 110-111). The anteroventral angles of tergum IX are fused medially forming a narrow strap (figs. 108, 110) and the median gonocoxal plate is absent anteriad of the vulvar plate (fig. 108).

DESCRIPTION: Length: 7.1-8.0 $\mathrm{mm}$. Length of head: $0.8 \mathrm{~mm}$. Width of head: 0.9-1.0 mm. Pronotal length: $1.2-1.3 \mathrm{~mm}$. Pronotal width: $1.0-1.1 \mathrm{~mm}$. Elytral length: 0.9-1.0 mm. Elytral width: $1.0-1.1 \mathrm{~mm}$.

Body reddish brown to dark reddish brown. Head, pronotum, and elytra dark reddish brown to reddish brown, elytra palest; abdomen dark reddish brown to slightly paler. Legs concolorous yellowish brown, without dark femorotibial spot.

Head about a tenth to a fifth wider than long (HW/HL: 1.1-1.2). Frontoclypeal ridge absent or present and incomplete, separated medially. Dorsal surface without V-shaped depression; surface with moderately coarse punctation; punctation more or less uniformly dense medially and basally and slightly denser at postocular lateral base. Labrum quadridentate; surface without tubercle near submedial denticle.

Pronotum about a tenth longer than wide (PL/PW: 1.1). Pronotum polished with moderately dense, moderately coarse punctation; surface without distinct submedial punctate groove. Elytra with length about a tenth less than width (EW/EL: 1.1); surface coarsely punctate and flat to slightly convex.

Abdomen uniformly punctate, without subapical or apical, transverse rows of punctures; segments III to V slightly more coarsely punctate than VI to VIII. Segment III without paratergite; paratergal carina extending slightly more than half of length of segment, but poorly developed beyond spiracle. Tergum III without median point extending from transverse basal ridge. Tergum VIII with broad, shallow, median emargination of posterior margin; transverse basal ridge broadly and shallowly curved anteriorly, slightly and irregularly serrate, and without median point. Tergum IX with lateroapical process about two fifths longer than midbasal length $(\mathrm{LLaP} / \mathrm{L} 9=1.4)$; moderately bent ventrally, and approximately parallel to other process; ventromedial margin without posteriorly directed spur (cf. fig. 158).

MALE: Sterna VI and VII unmodified. Sternum VIII with deep, wide emargination of posterior margin (fig. 107); emargination symmetrical, with broadly rounded base, about one fifth of length of segment, wider than deep, and with membranous anterolateral margins; surface with carina on each side of midline proximad of emargination (fig. 106); carina with medial wall more strongly sloped than lateral wall; carina with highest point subapically and from there carina strongly sloped posteriorly and gradually sloped anteriorly; carina with moderately dense concentration of setae; surface with broad, shallow, midlongitudinal depression extending anteriorly from base of emargination to about transverse basal ridge; transverse basal ridge separated medially and with medial ends widely separated and curved posteriorly (figs. 106, 107); surface without combs of setae. Tergum IX with small, slender process on anterior margin of anteroventral angle. Sternum IX (fig. 109) slightly asymmetrical; anterior margin moderately wide and emarginate; posterior margin broadly and shallowly rounded; lateral margins broadly rounded.

Aedeagus asymmetrical (figs. 103-105). Ventral sclerite with lateral margins gradually 
and more or less evenly convergent from base, with rounded apical margin, without lobe on left or right side, and without apicoventral process extending from posterior margin. Ventral sclerite sharply and steeply sloped apically (figs. 103, 105); slope with ventroposterior edge asymmetrical and posterior surface with moderately wide, dorsoventrally flattened, apically acute, posteriorly directed process on left side of midsagittal plane (figs. 104); Parameres (fig. 104) short, moderately broad, apically rounded, fused to median lobe, and not reaching apex of median lobe.

Female: Sternum VIII with irregularly microsinuate transverse basal ridge; posterior margin slightly emarginate. Tergum IX with anteroventral angles fused medially forming narrow strap (figs. 108, 110). Median gonocoxal plate absent anteriad of vulvar plate (figs. 108, 110); gonocoxal plate posteriad of vulvar plate tapered gradually to slightly rounded posterior margin (fig. 108). Vulvar plate anteriad of median gonocoxal plate, not embedded (fig. 108). Anterior vulvar (fig. 111) lobe narrow, transverse, and apparently poorly and incompletely separated from posterior vulvar lobe and contiguous with left lateroanterior margin of posterior vulvar lobe; surface densely covered with moderately long, apically undivided cuticular processes. Posterior vulvar (fig. 111) lobe large, convex, and densely covered with cuticular processes; cuticular processes broad basally and tapered and divided apically; processes with one to five or six apices. Vulva oriented at strong angle to longitudinal axis.

ETYMOLOGY: The name is from the Greek di-, "two," and lophos, "crest," and refers to the two submedial ridges on sternum VIII of the males.

DisTRIBUTION: The species is known only from central Bolivia (fig. 40).

REMARKS: This species is the first of the genus reported in Bolivia.

The female was collected at a different locality than the holotype, but is considered conspecific with the holotype because they share similar cephalic and pronotal punctation and color of the legs. It differs by having a frontoclypeal ridge which is absent in the male holotype.
Oedichirus distortus, new species Figures 40, 112-118

Type Material: Holotype. Male. "Ecuador: Pastaza. Ashuara indian village on R. Macuma nr. R. Morona. VII:11-16:1971. B. Malkin./ night sweeping along forest trail/Holotype Oedichirus distortus Herman." Deposited in the Field Museum of Natural History.

PARATYPES: One male, two females: Same data as holotype ( 2 females, FMNH, AMNH); Ecuador: Napo, Campana Cocha, E. pto. Misahualli, 2.VI.1982, H.Frania, $1100 \mathrm{ft}$, , palm leaf litter (1 male, CNC). (See Localities below.)

Type Locality: Ecuador: Pastaza: Ashuara indian village on Rio Macuma near Rio Morona. (This locality was not found and neither river seems to be in Pastaza province. Using the 1:1,000,000 maps for Ecuador from the American Geographical Society for Hispanic America both rivers were found in Morona Santiago province, but do not seem to be near each other.)

Diagnosis: The unique form of sternum VIII and its long, sinuate, subapical combs (fig. 114) and the form of the aedeagus (fig. 113) will separate the males of $O$. distortus from all others in the New World.

Among the New World females of Oedichirus, the anteroventral angles of tergum IX are fused in $O$. dilophus, $O$. distortus, $O$. lunatus, $O$. ohausi, and $O$. procerus. Tergum VIII of only $O$. distortus has a median lobe, although small, on the posterior margin and the legs of $O$. distortus are bicolored, but are unicolorous for the other four species. The median gonocoxal plate is present anteriad of the vulvar plate for $O$. distortus (figs. 116, 118), O. lunatus (fig. 171), O. ohausi (fig. 186), and $O$. procerus (fig. 197), but absent for $O$. dilophus (fig. 108). For $O$. ohausi the median gonocoxal plate anteriad of the vulvar plate is fused to the transverse anteroventral strap of tergum IX (figs. 186, 187), but both sclerites are separate for $O$. distortus (figs. 116, 118). The adornment of the vulvar plate differs for each of the five species (cf. fig. 118 to figs. 110, 171, 187, 198).

DESCRIPTION: Length: $8.2-9.8 \mathrm{~mm}$. Length of head: $0.9-1.1 \mathrm{~mm}$. Width of head: 1.0-1.1 mm. Pronotal length: $1.3-1.4 \mathrm{~mm}$. Pronotal width: 1.1-1.2 mm. Elytral length: 1.1-1.2 mm. Elytral width: $1.2-1.3 \mathrm{~mm}$.

Body bicolored. Head and pronotum black; elytra reddish brown; abdominal 

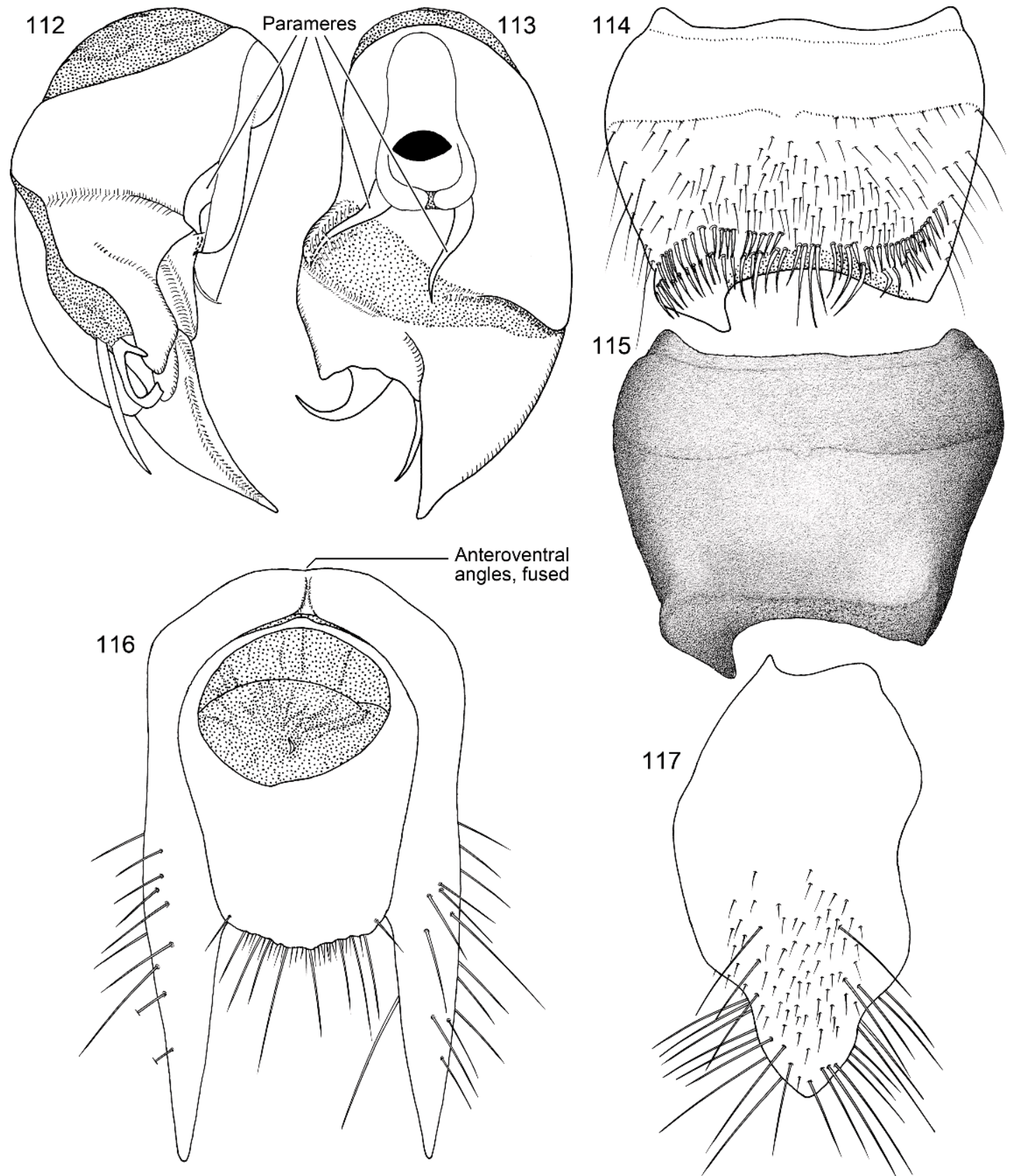

Figs. 112-117. Oedichirus distortus. 112. Aedeagus, right lateral. 113. Aedeagus, ventral. 114. Sternum VIII, male. 115. Sternum VIII, setae removed, male. 116. Segment IX, ventral, female. 117. Sternum IX, male.

segments III to $\mathrm{V}$ reddish brown with darker infusions basally; segments VI to VIII dark reddish brown with paler reddish-brown infusions. Legs bicolored, pale reddish brown to yellowish brown with dark reddish brown femorotibial spot.

Head with length and width equal to or about a fifth wider than long (HW/HL: 


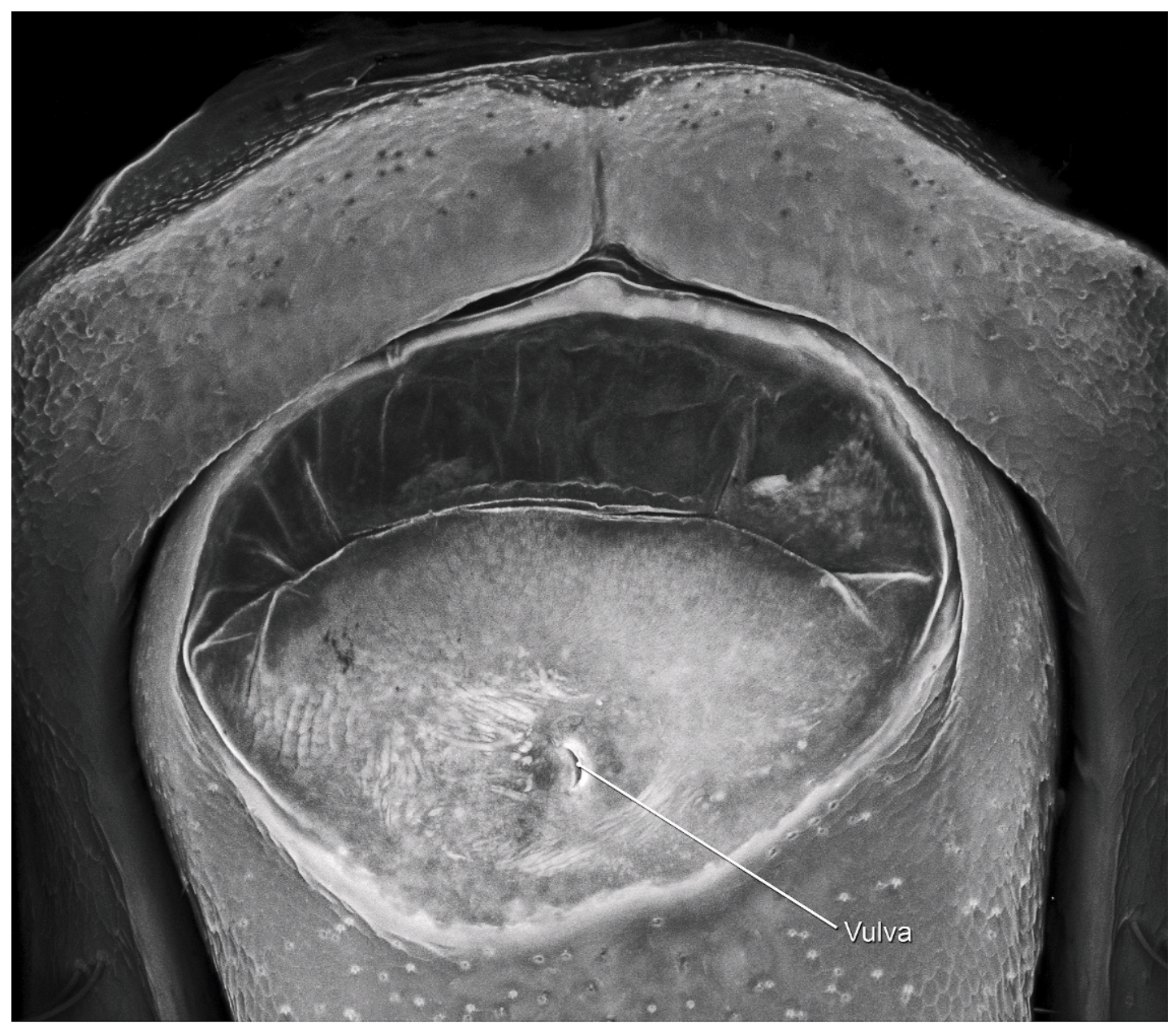

Fig. 118. Oedichirus distortus. Segment IX, vulvar plate, enlarged (CLSM).

1.0-1.2). Frontoclypeal ridge complete, not separated medially. Dorsal surface without V-shaped depression; surface polished and coarsely punctate; punctation dense, less dense basally and laterally. Labrum quadridentate; surface without tubercle near submedial denticle.

Pronotum about a fifth longer than wide (PL/PW: 1.2). Pronotum polished, with scattered clusters of moderately dense to dense, coarse punctation; surface with moderately deep, submedial, punctate groove on basal two thirds. Elytra length about a tenth less than width (EW/EL: 1.1); surface flat and coarsely punctate.

Abdominal segments III to VI coarsely punctate, VII and VIII less coarsely punctate;
III to VI with transverse, subapical row of irregularly arranged punctures. Segment III without paratergite; paratergal carina extending to near middle of segment, but poorly developed beyond spiracle. Tergum III without median point extending from transverse basal ridge. Tergum VIII with small, median, trianguloid lobe on posterior margin; posterior margin broadly emarginate; transverse basal ridge irregularly sinuate and without median point. Tergum IX with lateroapical process about twice as long as midbasal length $(\mathrm{LLaP} / \mathrm{L} 9=1.9-2.0)$, slightly to moderately bent ventrally, and approximately parallel to other process; ventromedial margin without posteriorly directed spur (cf. fig. 158). 
MAlE: Sterna VI and VII unmodified. Sternum VIII (figs. 114, 115) with moderately deep, asymmetrical emargination; emargination about one sixth of length of sternum, wider than deep, with wide and broadly rounded base, with right margin longer and steeper than left, and with basal margin and part of lateral margins membranous; surface adjacent to emargination with transverse comb of long, spiniform setae (fig. 114); comb curved anteriorly on left side and posteriorly on right; surface of sternum with anteriorly curved ridge at base of comb on left side and with posteriorly curved ridge at base of comb on right side (fig. 115); surface tumescent at proximal base of both left and right curves of transverse ridge (fig. 115); transverse basal ridge broadly sinuate, separated medially, and with weak, apically open, median point (fig. 114). Tergum IX with small, lobed process on anterior margin of anteroventral angle. Sternum IX strongly asymmetrial (fig. 117); anterior margin wide and broadly emarginate; posterior margin narrow, rounded, and bluntly pointed; lateral margin tapered apically to pointed apex; right margin broadly rounded on basal third, then strongly sinuate to apex, left margin strongly sinuate to apex.

Aedeagus asymmetrical (figs. 112, 113). Ventral sclerite with short, broad, apically acute lobe on right side of apex and long, basally broad, tapering, apically acute lobe on right side of apex (fig. 113); left lobe much longer than right (fig. 113), with diagonally transverse, membranous depression extending from left basal margin of left lobe to near right lateral margin (fig. 113), with robust, small tumescence near base of right lobe at right lateral margin, with small, tapered, apically rounded lobe on left side just distad of middle (fig. 113), and without apicoventral process (cf. fig. 99) extending from posterior margin. Parameres short, slender, tapered, sinuate, and free of median lobe except at base (figs. 112, 113).

FEMAle: Sternum VIII with transverse basal ridge broadly sinuate and curved anteriorly at middle and without median point; posterior margin with wide, slight, microserrate, median emargination. Tergum IX with anteroventral angles fused medially to form wide strap (figs. 116, 118); strap with shallow groove at point of fusion. Median gonocoxal plate anteriad of vulvar plate reduced to narrow strap (figs. 116, 118) with anterior margin broadly rounded with small median lobe; gonocoxal plate posteriad of vulvar plate gradually tapered to irregularly microsinuate posterior margin (fig. 116). Vulvar plate embedded midanteriorly in gonocoxal plate (fig. 116). Anterior vulvar lobe transverse and extending across anterior margin of posterior vulvar lobe; surface slightly wrinkled (fig. 118). Posterior vulvar lobe transverse, larger than anterior lobe; surface with ornamentation near right lateral side. Vulva crescent shaped and orientated at slight angle to longitudinal axis (fig. 118).

ETYMOLOGY: The name is from the Latin distortus, "distorted or misshapened," and refers to the strongly asymmetrical posterior margin of sternum VIII of the male.

Localities: Puerto Misahualli, Ecuador, is at the mouth of Río Misahualli at $431 \mathrm{~m}$ elevation at $01^{\circ} 02^{\prime} \mathrm{S}, 77^{\circ} 40^{\prime} \mathrm{W}$ (Paynter, 1993: 128). The actual locality is Campana Cocha, east of Puerto Misahualli; that site was not found, but is presumably on the east side of Río Misahualli.

Distribution: Ecuador in Napo and Pastaza provinces (fig. 40).

REMARKs: The two female paratypes were collected together with the holotype male and all three have dense coarse pronotal punctation, lateroapical processes of tergum IX that are about twice as long as the midbasal length of the tergum, and a small, triangular, median lobe on the broadly emarginate posterior margin of tergum VIII. The triangular lobe is more poorly developed on the male paratype from Puerto Misahualli and the pronotal punctation is more dense.

This species is the first record of the genus from Ecuador.

\section{Oedichirus dominicanensis, new species} Figures 39, 119-122

Type Material: Holotype. Male. "Rep. Dominicana Prov. Pedernales Sa. de Baoruco N. Cabo Rojo, km 28 10.II.1975/1200 m, pine for. on limestone/Coll. W.L. \& D.E. Brown/Holotype Oedichirus dominicanensis Herman." Deposited in the American Museum of Natural History. (Right antennomeres 7-11, right maxillary palpomere 3 and 4, and the right profemur, 
119

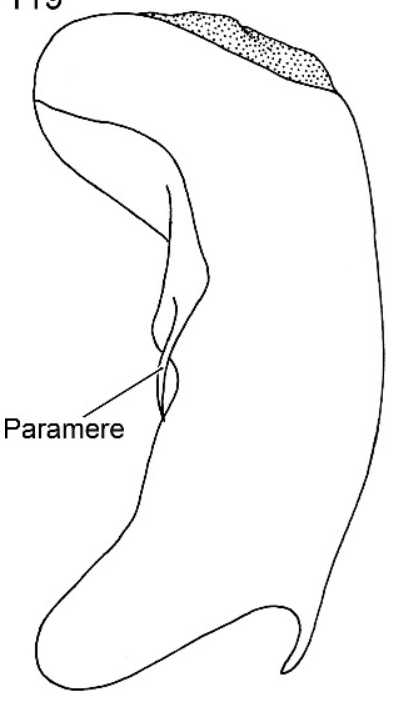

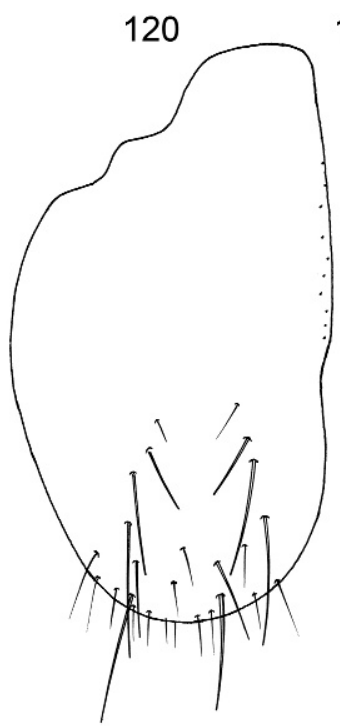

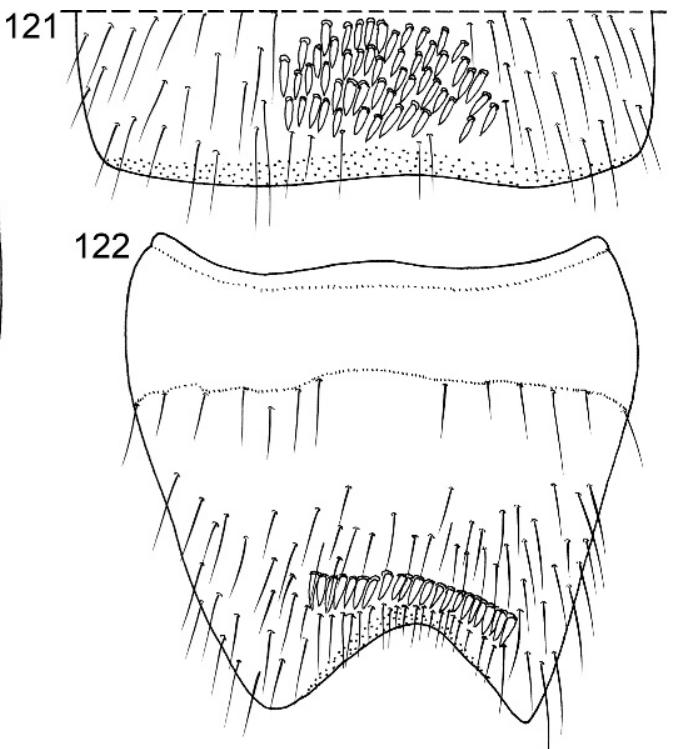

Figs. 119-122. Oedichirus dominicanensis. 119. Aedeagus, left lateral. 120. Sternum IX, male. 121. Sternum VII, apical region, male. 122. Sternum VIII, male.

protibia, and protarsus are missing. The left profemur, protibia, and protarsus are glued to the card and the thorax and abdomen are separated.)

Type Locality: Dominican Republic: Pedernales: Sierra de Baoruco, North of Cabo Rojo, km 28, $1200 \mathrm{~m}$.

Diagnosis: Oedichirus dominicanensis is the only species known from the Dominican Republic and the first record of the genus for the Caribbean. The males can be separated from all other New World species by the large cluster of spinelike setae on sternum VII (fig. 121) and the deep, wide asymmetrical emargination of sternum VIII that is bordered by a diagonal comb (fig. 122). The posterior margin of tergum VIII is broadly emarginate and lacks the median lobe found in $O$. distortus. The head and pronotum are sparsely and coarsely punctate and the pronotum has a submedial punctate groove that extends on most of the length of the segment. The paratergal carina of segment III is about half as long as the segment.

Oedichirus dominicanensis is one of five species with a subapical comb of spinelike setae on sternum VIII. The others are $O$. distortus, $O$. isthmus, $O$. neotropicus, and $O$. sinuosus, and along with $O$. dominicanensis, all have short, slender, thornlike parameres that, beyond their basal attachment, are free of the median lobe and for each a portion of the posterior margin of sternum VIII is membranous. The comb of $O$. distortus is sinuate (fig. 114), the spinelike setae of $O$. isthmus are more a cluster than a comb (fig. 163), the comb of $O$. sinuosus is strongly curved (fig. 203), that of $O$. neotropicus is short and nearly straight (fig. 184), and the comb is slightly curved in $O$. dominicanensis (fig. 122). The posterior margin of sternum VIII of $O$. distortus is broadly emarginate and the right side has a stout process (fig. 115). The posterior margin of sternum VIII of $O$. isthmus is wide and moderately deep (fig. 163), but that of $O$. neotropicus is nearly truncate (fig. 184). The emargination of the posterior margin of sternum VIII of $O$. dominicanensis (fig. 122) and $O$. sinuosus (fig. 203) is wide and deep; these two species are separated by the form of the comb (figs. 122 and 203) and the aedeagus (cf. figs. 119 and 201). Oedichirus dominicanensis, $O$. isthmus, and $O$. sinuosus each have a dense cluster of setae on sternum VII (figs. 121, 165, and 205 respectively).

DESCRIPTION: Length: $8.9 \mathrm{~mm}$. Length of head: $0.9 \mathrm{~mm}$. Width of head: $1.0 \mathrm{~mm}$. 
Pronotal length: $1.4 \mathrm{~mm}$. Pronotal width: $1.2 \mathrm{~mm}$. Elytral length: $1.1 \mathrm{~mm}$. Elytral width: $1.3 \mathrm{~mm}$.

Body yellowish and reddish brown. Head pale reddish brown, pronotum, elytra, and abdomen yellowish brown; head darker and elytra paler than pronotum and abdomen. Legs bicolored, yellowish brown with darker femorotibial maculation, apex of femora and base of tibiae with faint infusion of reddish brown (Specimen is probably teneral, so the color of a more mature specimen is likely to be darker than described here).

Head about a tenth wider than long (HW/ HL: 1.1). Frontoclypeal ridge incomplete, separated medially. Dorsal surface without V-shaped depression; surface polished with sparse, coarse punctation. Labrum quadridentate; surface without tubercle near submedial denticle.

Pronotum about a fifth longer than wide (PL/PW: 1.2). Pronotum polished and with sparse, coarse punctation laterally and with submedial punctures arranged in groove and extending most of length of pronotum. Elytra with length about a tenth less than width (EW/EL: 1.1); surface feebly convex and coarsely punctate.

Abdominal segments III to VI coarsely punctate; punctures arranged in poorly developed, irregular, subapical and subbasal transverse rows; VII and VIII with less coarse, more uniformly arranged punctures. Segment III without paratergite; paratergal carina about half as long as segment, but moderately to poorly developed beyond spiracle. Tergum III without median point extending from transverse basal ridge. Tergum VIII with posterior margin broadly and shallowly emarginate; emargination extending from one lateroapical angle to other; transverse basal ridge broadly and shallowly curved anteriorly, feebly sinuate, and without median point. Tergum IX with lateroapical process about a tenth shorter than midbasal length (LLaP/L9 = 0.9), slightly bent ventrally, and approximately parallel to other process; ventromedial margin without posteriorly directed spur (cf. fig. 158).

MALE: Sternum VI unmodified. Sternum VII (fig. 121) with large, median, transverse, subapical cluster of short, spinelike setae; posterior margin membranous. Sternum VIII (fig. 122) with wide, deep, asymmetrical emargination of posterior margin; emargination nearly one fifth as long as segment, wider than deep, basal margin broadly rounded, with membranous edge, and most of emargination positioned to left of midsagittal plane; surface with subapical comb of short, stout, spinelike setae near base of emargination (fig. 122); comb extending diagonally from left side medioanteriorly to beyond midsagittal line; comb slightly sinuate; surface with broad, median, moderately deep depression extending from transverse basal ridge to comb; depression with few setae; transverse basal ridge without median point, slightly sinuate, and with middle shallowly curved anteriorly. Tergum IX with small, slender process on anterior margin of anteroventral angle. Sternum IX (fig. 120) weakly sclerotized and moderately asymmetrical; anterior margin diagonal, wide and sinuate; posterior margin broadly rounded; right lateral margin broadly rounded, left margin sinuate.

Aedeagus asymmetrical. Median lobe, in ventral view, with apical half strongly compressed laterally to form lamina and, in lateral view (fig. 119), large, lobate, with ventroapical margin rounded, and with small, ventrally curved, apically acute process on dorsoapical edge; ventral sclerite without apicoventral process extending from posterior margin. Parameres short, slender, and free of median lobe except basally.

FEMAle: Unknown.

ETYMOLOGY: The name reflects the geographical origin in the Dominican Republic of the species, the first of the genus known for the Caribbean Islands.

DisTRIBUTION: The species is known only from the Sierra de Baoruco in southwestern Dominican Republic (fig. 39).

REMARKS: The holotype of this species may not be fully pigmented, but it appears to be fully sclerotized. However, the aedeagus is weakly sclerotized and the midventral region at the base of the parameres is damaged. Only one lateral view of the aedeagus is included because the base is damaged. In ventral view the aedeagus is strongly compressed laterally, but it is uncertain if that is the natural state of the aedeagus or the result of damage and/or the possible teneral condition of the specimen. 
If the specimen is teneral the color is certainly darker in mature specimens than stated in the preceding description; it is difficult to know if the femorotibial joints are actually darker than the remainder of the leg.

The species is new and despite the poorly sclerotized aedeagus and possibly incomplete pigmentation of the body, it is described because few species are known from the New World and this is the only one collected in the Caribbean. Given that one species has been found in the Caribbean, certainly others exist on Hispaniola, probably Cuba, and perhaps on other Caribbean islands. By describing one, collectors might be prompted to hunt for others.

\section{Oedichirus echinatus, new species} Figures 40, 123-128

Type Material: Holotype: Male. "Brazil, PR, San Jose dos Pinheiros Curitiba, 975 m II-71970, JM \& BA Campbell/Holotype Oedichirus echinatus Herman." Deposited in the Canadian National Collection of Insects, Ottawa.

Type Locality: Brazil: Paraná: São Jose dos Pinheiros (= Pinhais) $\left(25^{\circ} 31^{\prime} \mathrm{S}, 49^{\circ} 13^{\prime} \mathrm{W}\right)$, Curitiba, $975 \mathrm{~m}$. (Left antennmere 11, left protarsus, and right metatibia and metatarsus are missing. Curitiba and São Jose dos Pinhais are towns in a large urbanized region. The coordinates and elevation given here are for S.J. Pinhais and were taken from Times Books, 1999.)

Diagnosis: Oedichirus echinatus is one of three New World species with a median point extending from the transverse basal ridge of tergum III (as on sternum VIII, fig. 73). The other two species, $O$. bullaglaber and $O$. bullahirtus, can be separated from $O$. echinatus by the dark femorotibial maculae and the quadridentate labral margin; the latter species lacks the maculae and has only two labral denticles. Furthermore, sternum VIII of $O$. echinatus has a symmetrical emargination, a large, submedial cluster of spinelike setae (fig. 127), and a rather deep, sparsely punctate, ovoid, median depression, whereas for $O$. bullaglaber (figs. 73, 74) and $O$. bullahirtus (figs. 84, 85) the emargination is asymmetrical, the sternal surface has a submedial tumescence near the emargination, and both lack a submedial cluster of spinelike setae. The parameres of $O$. echinatus are fused to the median lobe, are short and strongly curved, and do not reach the apex of the median lobe (figs. 124-126). The parameres of the other two species are fused to the median lobe only basally and are long, reaching to near the apex of the ventral sclerite (figs. 70 and $71 ; 80$ and 81 ).

Among the New World species the labrum is bidentate in only $O$. echinatus, O. lunatus, and $O$. procerus; all the others have four denticles and one has six. Oedichirus procerus is separated from $O$. echinatus by the long, gracile form and concave elytral disc and $O$. lunatus is distinguished by the long, strongly curved, lateroapical process of tergum IX (fig. 168).

DESCRIPTION: Length: $5.9 \mathrm{~mm}$. Length of head: $0.7 \mathrm{~mm}$. Width of head: $0.9 \mathrm{~mm}$. Pronotal length: $1.1 \mathrm{~mm}$. Pronotal width: $1.0 \mathrm{~mm}$. Elytral length: $0.9 \mathrm{~mm}$. Elytral width: $1.0 \mathrm{~mm}$.

Body concolorous dark reddish brown. Legs pale reddish brown to yellowish brown; femorotibial joint without dark maculation.

Head about a third wider than long (HW/ HL: 1.3). Frontoclypeal ridge incomplete, separated medially. Dorsal surface without V-shaped depression; surface coarsely and sparsely punctate; punctation present across middle and across base of head, and laterally from base of antennae to base of head; surface with large polished, impunctate spot anteriorly and subbasally. Labrum bidentate; denticle small and laterad of median emargination; surface with minute, submarginal tubercle adjacent to median emargination.

Pronotum about a fifth longer than wide (PL/PW: 1.2). Pronotum polished, with coarse, moderately dense punctation, and with moderately large impunctate spots; surface deeply and coarsely punctate, punctate submedial groove on basal two thirds. Elytra about one fifth wider than long (EW/ EL: 1.2); surface flat medially and coarsely punctate.

Abdominal terga III and IV densely punctate and without transverse rows of punctures; terga $\mathrm{V}$ and VI with punctures arranged in poorly defined, irregular transverse rows; segment VII moderately densely punctate; segment VIII more sparsely and less coarsely punctate. Segment III without paratergite; paratergal carina present and extending slightly beyond spiracle. Tergum III with median 

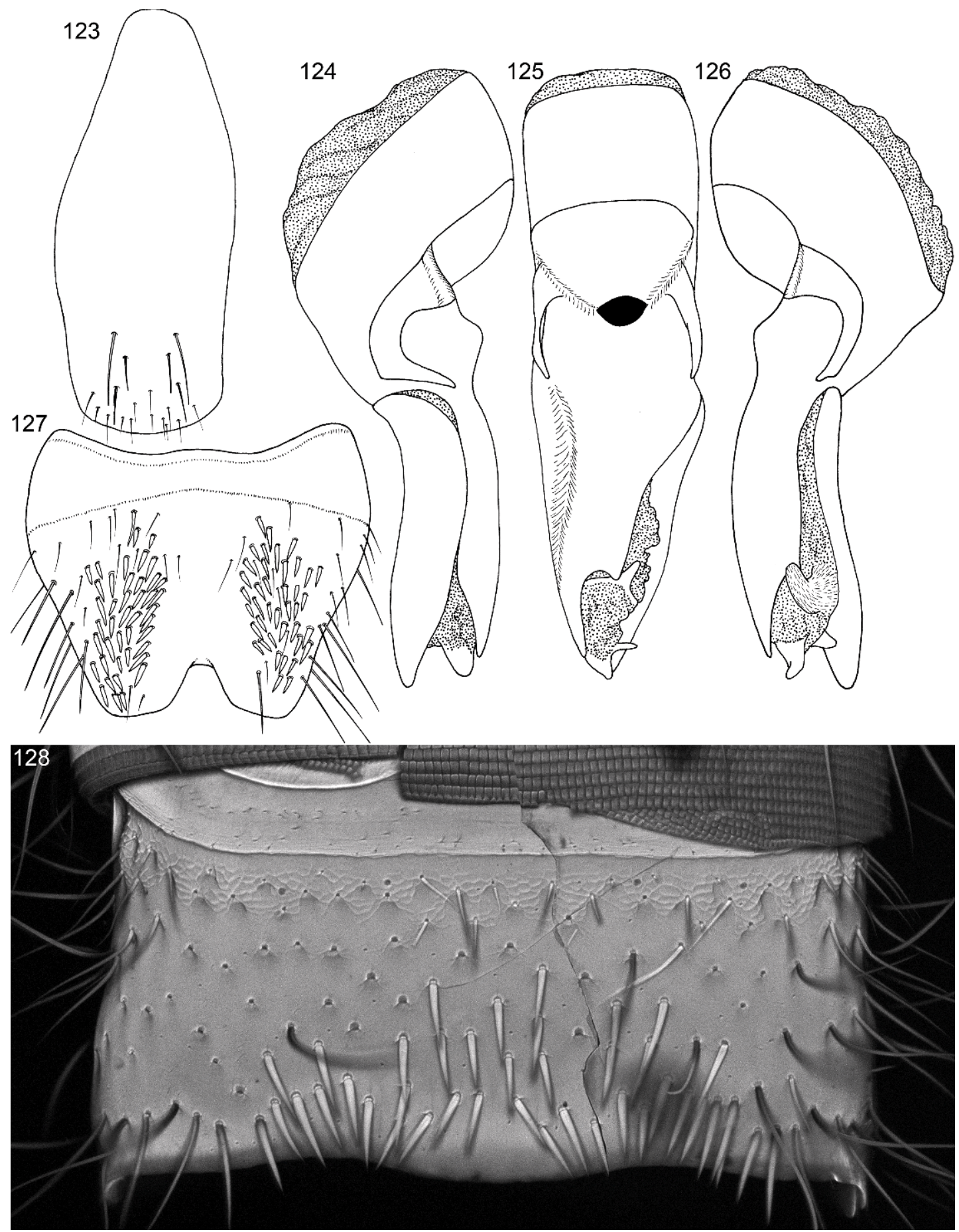

Figs. 123-128. Oedichirus echinatus. 123. Sternum IX, male. 124. Aedeagus, right lateral. 125. Aedeagus, ventral. 126. Aedeagus, left lateral. 127. Sternum VIII, male. 128. Sternum VII, male (CLSM). 
point extending from transverse basal ridge (as for tergum VIII, fig. 73). Tergum VIII with posterior margin shallowly and broadly rounded; transverse basal ridge with apically open median point. Tergum IX with lateroapical process moderately longer than midbasal length of tergum $(\mathrm{LLaP} / \mathrm{L} 9=1.4)$, slightly bent ventrally, and approximately parallel to other process; ventromedial margin without posteriorly directed spur (cf. fig. 158).

MALE: Sternum VI unmodified. Sternum VII (fig. 128) flattened medially and with wide, median cluster of moderately long, spinelike setae; posterior margin sinuate and broadly lobed medially. Sternum VIII (fig. 127) with moderately wide, moderately deep, symmetrical emargination of posterior margin; emargination about one fifth of length of sternum, wider than deep, with base shallowly rounded (fig. 127), and without membranous margin; surface laterad and proximad of emargination with broad, moderately deep, median depression; depression with polished surface, without punctation or pubescence, and bordered laterally by large cluster of spinelike setae; setal cluster bordered medially and laterally by ridge; cluster of setae depressed between carinae; ridges at diagonal to longitudinal axis; transverse basal ridge broadly curved anteriorly and without median point. Tergum IX with long, moderately wide process on anterior margin of anteroventral angle. Sternum IX (fig. 123) moderately asymmetrical; anterior margin moderately wide and broadly rounded; posterior margin wide and broadly rounded; lateral margins broadly sinuate.

Aedeagus asymmetrical (figs. 124-126). Ventral sclerite with emarginate apical margin and with lobe on each side of emargination (fig. 125); left lobe shorter than right and both posteriorly directed; ventral sclerite without apicoventral process extending from posterior margin and with strongly developed, ventrally directed carina adjacent to right lateral margin and extending from just distad of basal foramen to apex of lobe on lateral side of apex (fig. 125). Parameres short, fused to median lobe, moderately broad, and curved ventrally; right paramere broader, longer, and more strongly curved (fig. 124) than left (fig. 126). Internal sac with three spinelike processes (figs. 124-126).

\section{Female: Unknown.}

ETYMOLOGY: The name is from the Latin echinatus, "spiny or prickly," and refers to the sublateral cluster of short, spinelike setae on sternum VIII of the male.

Distribution: Known only from the state of Paraná in southern Brazil (fig. 40).

REMARKS: The holotype is darkly pigmented and appears to be well sclerotized and a mature adult, but the aedeagus is weakly sclerotized and lightly pigmented.

\section{Oedichirus exilis, new species}

Figures 40, 129-134

Type Material: Holotype: Male. "Brazil, Rio de Janeiro: Silva Jardim March 1974 F.M. Oliveira/Holotype Oedichirus exilis Herman." Deposited in the American Museum of Natural History. (Left metatibia and metatarsus are missing.)

Type Locality: Brazil: Rio de Janeiro: Silva Jardim $\left(22^{\circ} 39^{\prime} \mathrm{S}, 42^{\circ} 23^{\prime} \mathrm{W}\right)$. (Silva Jardim is ENE of the city of Rio de Janeiro in the south central region of the state; the coordinates are from Paynter and Traylor, 1991: 605).

Diagnosis: The species is part of a complex that also includes $O$. clavolateralis, $O$. clavulus, and O. geniculatus. Males of the complex have a short, wide, asymmetrical emargination of sternum VIII (figs. 94, 102, $132,147)$ and the aedeagus has a stout, tapered and curved apicoventral process arising from the apical or lateroapical margin of the ventral sclerite and protrudes to the right (figs. 90, 99, 130, 142). For $O$. exilis the apicoventral process is strongly flattened and directed anteriorly more strongly than for the other species, with the possible exception of $O$. clavulus (fig. 99). The median lobe of $O$. exilis has a short, blunt, posteriorly directed knob that extends from the right lateral side of the ventral sclerite (fig. 129); O. geniculatus (figs. 141) lacks a knob at that position. Along with $O$. exilis, both $O$. clavolateralis (fig. 89) and $O$. clavulus (fig. 98) have a knob in a similar position. For O. clavulus (fig. 98) the knob is a long, cylindrical, blunt peg. The knob extending from the lateral dorsal region of the apicoventral process of $O$. exilis (fig. 129) is wider basally and more strongly tapered and the gap between the knob and the base of the apicoventral process wider than for O. clavulus (fig. 98) for which the 


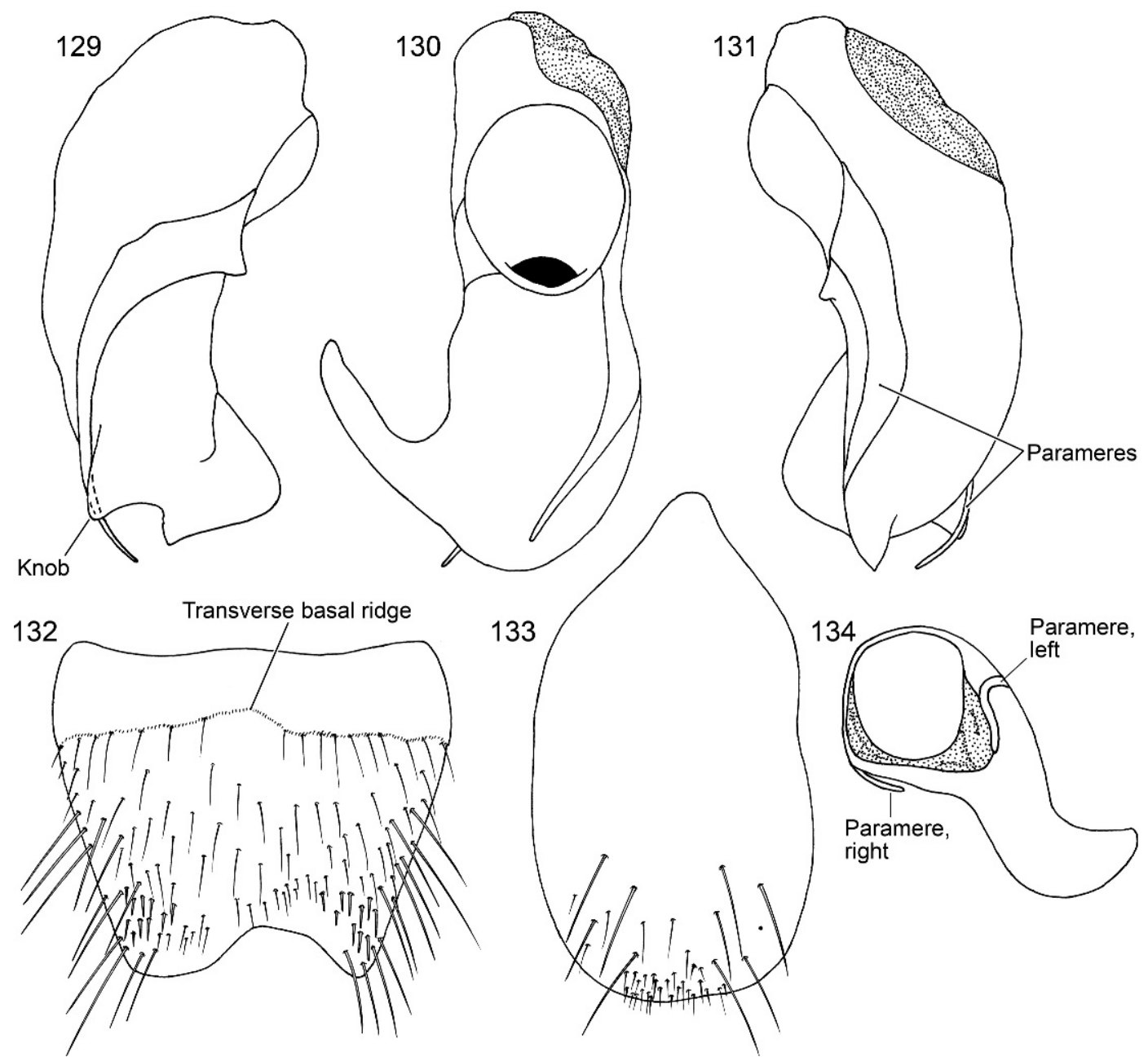

Figs. 129-134. Oedichirus exilis. 129. Aedeagus, right lateral. 130. Aedeagus, ventral. 131. Aedeagus, left lateral. 132. Sternum VIII, male. 133. Sternum IX, male. 134. Aedeagus, apex, posterior.

peg is more gradually tapered and the gap between it and the base of the apicoventral process is narrower. For $O$. clavolateralis and $O$. exilis the knobs are similar. However, the apicoventral process of $O$. exilis is strongly directed anteriorly (fig. 130), only moderately wide in posterior view (fig. 134), and the posterior margin of the ventral sclerite is broadly rounded and lacks a lobe. Whereas for $O$. clavolateralis the apicoventral process is directed laterally and the apex is pointed anteriorly (fig. 90), the apicoventral process is broad in posterior view (fig. 92), and the posterior margin of the ventral sclerite has a lobe (fig. 90).
DESCRIPTION: Length: $6.9 \mathrm{~mm}$. Length of head: $0.8 \mathrm{~mm}$. Width of head: $1.1 \mathrm{~mm}$. Pronotal length: $1.2 \mathrm{~mm}$. Pronotal width: $1.0 \mathrm{~mm}$. Elytral length: $1.0 \mathrm{~mm}$. Elytral width: $1.1 \mathrm{~mm}$.

Body pale reddish brown (teneral specimen). Legs bicolored yellowish brown with pale reddish brown femorotibial maculation.

Head about two fifths wider than long $(\mathrm{HW} / \mathrm{HL}=1.4)$. Frontoclypeal ridge strongly curved, incomplete with medial ends widely separated. Dorsal surface without Vshaped depression; surface with microsculpturing anteriorly adjacent to frontoclypeal ridge and remainder of surface polished; 
punctation coarse and dense anteriorly and medially and sparse near neck; subbasal region impunctate medially. Labrum quadridentate; surface without tubercle near submedial denticle.

Pronotum about one fifth longer than wide $(\mathrm{PL} / \mathrm{PW}=1.2)$. Pronotum polished, with coarse, moderately dense punctation and moderately large impunctate spots; surface with deep, submedial punctate groove on basal two thirds. Elytra about one tenth wider than long $(\mathrm{EW} / \mathrm{EL}=1.1)$; surface flat medially and coarsely punctate.

Abdominal terga III to V densely punctate and without transverse rows of punctures; tergum VI less densely punctate and tergum VII sparsely and less coarsely punctate. Segment III without paratergite; paratergal carina present and extending slightly beyond spiracle. Tergum III without median point extending from transverse basal ridge. Tergum VIII with apically open median point extending from transverse basal ridge; posterior margin slightly rounded. Tergum IX with lateroapical process about three times longer than midbasal length (LLaP/T9: 3.1), moderately bent ventrally, and diverging slightly from other process; ventromedial margin without posteriorly directed spur (cf. fig. 158).

MALE: Sternum VI and VII unmodified. Sternum VIII with wide, moderately deep, asymmetrical emargination of posterior margin (fig. 132), emargination about one sixth of length of sternum, wider than deep, base broadly rounded, and positioned mostly to left of midlongitudinal line; right margin of emargination shorter and more steeply sloped than left; surface adjacent to margin of emargination translucent and beveled and with a few fine setae along edge of bevel; median surface slightly flattened; long setae evenly distributed; surface laterad of emargination with small cluster of short, spinelike setae; transverse basal ridge without median point and irregularly sinuate. Tergum IX with anteroventral angle extended anteriorly as large process. Sternum IX (fig. 133) slightly asymmetrical; anterior margin narrow and strongly rounded; posterior margin broadly rounded; right margin broadly rounded; left margin slightly sinuate.
Aedeagus asymmetrical (figs. 129-131). Ventral sclerite with apical margin broadly rounded to left of apicoventral process (fig. 130), with large, flattened, curved, strongly sclerotized apicoventral process extending from right lateroapical margin; apicoventral process broad and strongly tapered to dorsally directed, acute apex and process directed lateroanteriorly; ventral sclerite with wide, short, dorsoventrally flattened, blunt knob extending posteriorly from right side of apical margin at base of apicoventral process (fig. 129). Parameres moderately broad basally, flattened, tapered and slender apically, fused to median lobe for most of length and free of median lobe near apex; left paramere laying against lateral and ventral surfaces (figs. 130, 131), right paramere against lateral surface and with apical portion strongly curved ventrally (fig. 129); parameres of approximately equal length.

Female: Unknown.

ETYMOLOGY: The name is from the Latin exilis, "thin, slender, narrow," and refers to the narrow, compressed apicoventral process of the aedeagus.

DisTRIBUTION: Known from only one locality in the state of Rio de Janeiro (fig. 40).

REMARKS: The specimen is teneral and, although the pale integument is firm, the aedeagus is lightly sclerotized and pigmented and the basal bulb is collapsed. The femorotibial maculation is pale and perhaps appears to be absent, but, like other species of the complex, I expect it will be dark in fully pigmented individuals.

Oedichirus geniculatus (Sahlberg)

Figures 2, 3-11, 20-28, 40, 135-152

Elytrobaeus geniculatus Sahlberg, 1847: 802. Oedichirus geniculatus (Sahlberg)

- Sharp, 1876: 338 (transferred from Elytrobaeus). - Bernhauer and Schubert, 1912: 201 (catalog). - Blackwelder, 1944: 131 (checklist).

Type Material. The type series of Elytrobaeus geniculatus was not found (see Remarks below in present species account).

Neotype: Designated here. "BRAZIL, Guanabara: Corcovado Sept.-Oct. 1969 Alvarenga \& Seabra/Neotype Elytrobaeus geniculatus Sahlberg des. L. Herman, 2011/Oedichirus geniculatus Sahlberg det. L. Herman, 2011.” Deposited 


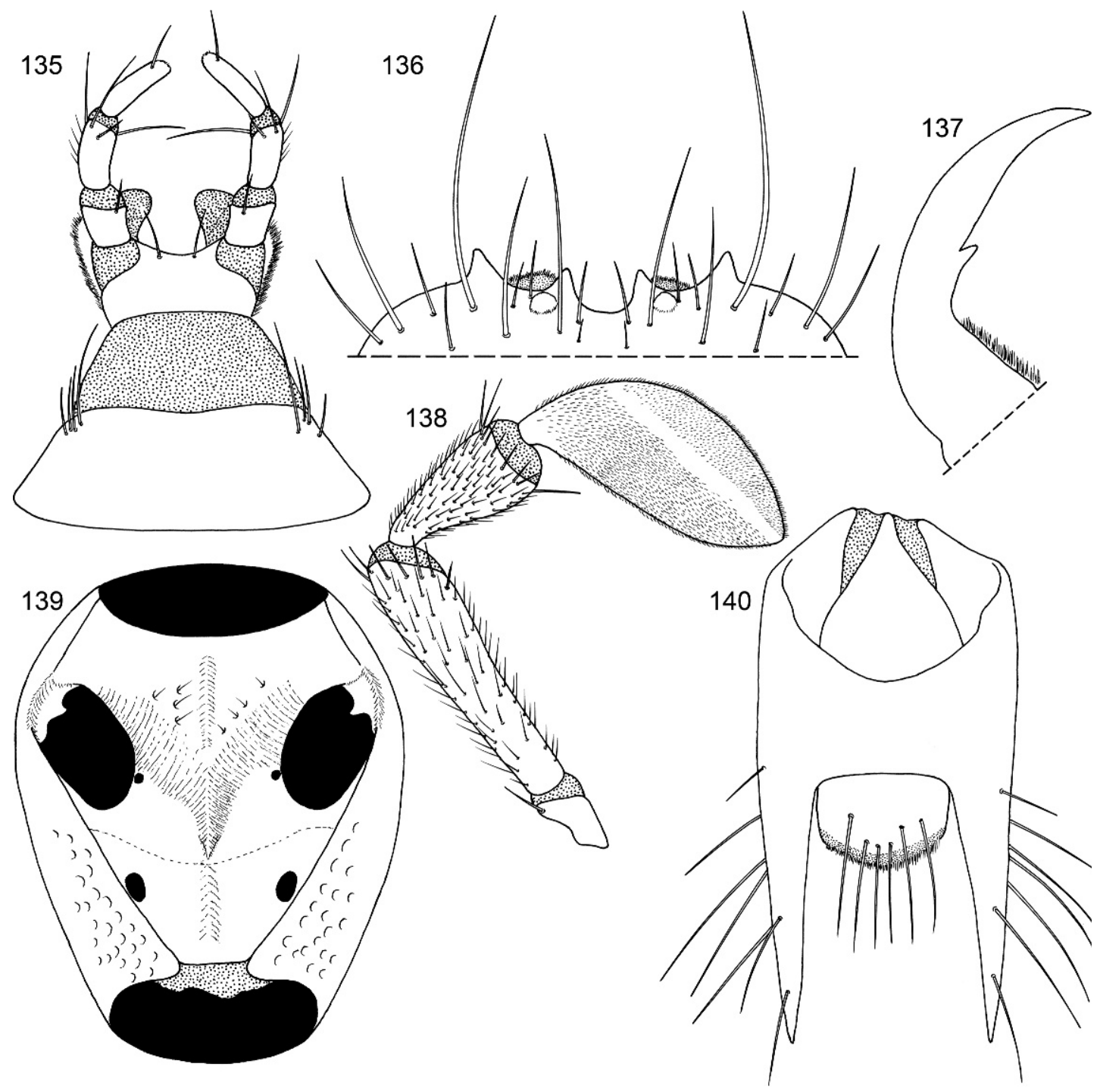

Figs. 135-140. Oedichirus geniculatus. 135. Labium, ventral. 136. Labrum, dorsal, male. 137. Mandible, left, dorsal. 138. Maxillary palpus. 139. Prothorax, ventral. 140. Terga IX and X, male.

in the American Museum of Natural History (see Remarks: Type Series below for discussion of neotype designation). (Left maxillary palpus is missing.)

Type Locality: Brazil: Rio de Janeiro: Corcovado $\left(22^{\circ} 58^{\prime} \mathrm{S}, 43^{\circ} 13^{\prime} \mathrm{W}\right)$.

Diagnosis: Oedichirus geniculatus is one of a group of four species (also including $O$. clavolateralis, O. clavulus, and $O$. exilis) whose males have an asymmetrical emargination of sternum VIII (figs. 94, 102, 132,
147), a stout, curved, apicoventral process extending to the right from the ventral sclerite of the aedeagus (figs. 90, 99, 130, 142), and bicolored legs (fig. 2). The surface of sternum VIII adjacent to the margin of the emargination of the four species of the group is translucent. Oedichirus geniculatus has no adornment associated with the apicolateral margin of the aedeagal ventral sclerite near the base of the apicoventral process (fig. 141), whereas near the apicoventral 


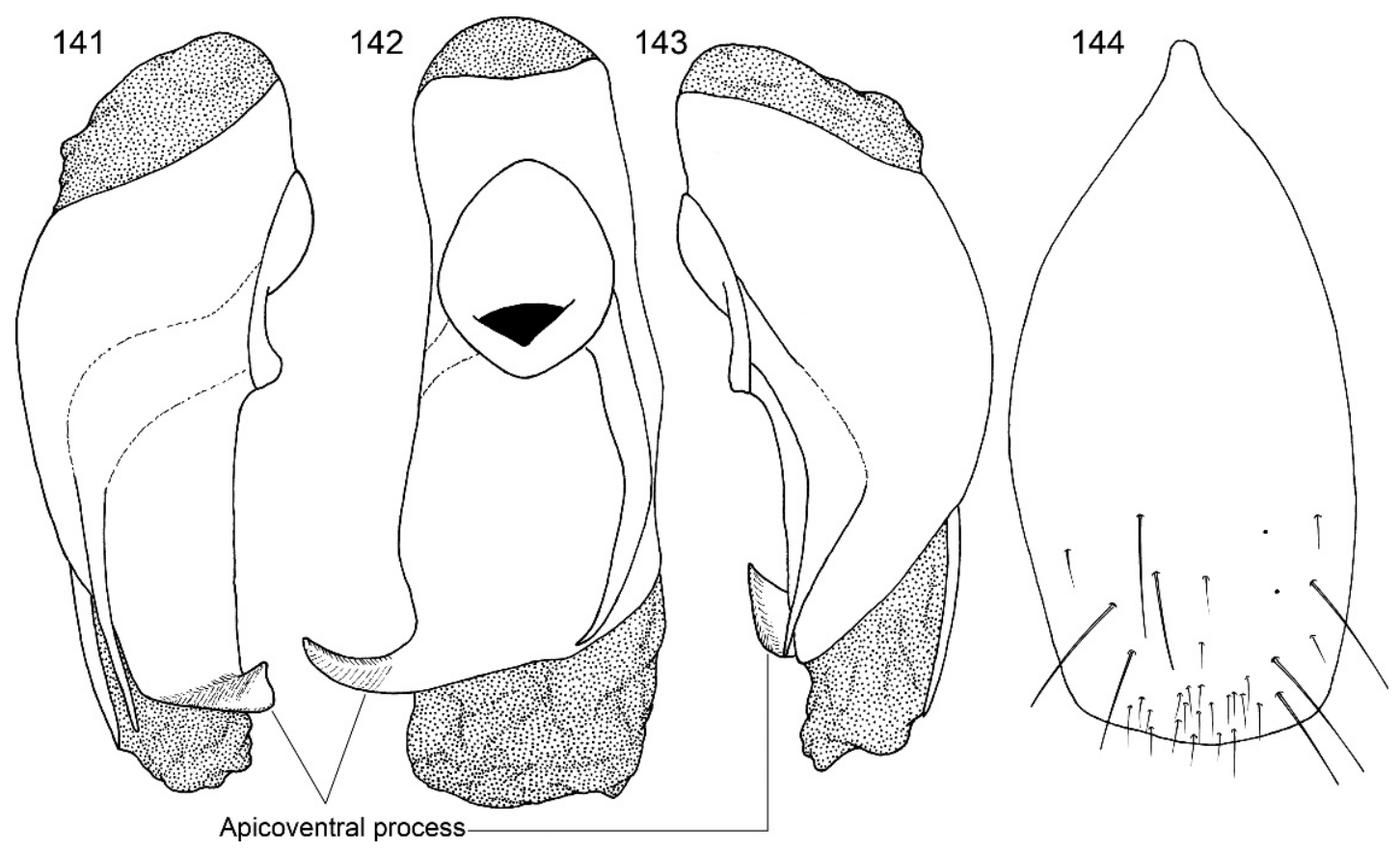

Figs. 141-144. Oedichirus geniculatus. 141. Aedeagus, right lateral. 142. Aedeagus, ventral. 143. Aedeagus, left lateral. 144. Sternum IX, male.

process $O$. clavulus has a peg (fig. 98), and $O$. clavolateralis (figs. 89, 93) and $O$. exilis (fig. 129) both have a laterally directed knob. The form of the apicoventral process, as depicted in the relevant figures, differs slightly among the four species (cf. figs. 90, $99,130,142)$. The labrum of the males of $O$. geniculatus has a tubercle at the base of the submedial denticle (fig. 136); the other species do not.

DESCRIPTION: Length: 7.7-10.0 $\mathrm{mm}$. Length of head: $0.8-1.0 \mathrm{~mm}$. Width of head: 1.2-1.3 mm. Pronotal length: $1.4-1.6 \mathrm{~mm}$. Pronotal width: $1.1-1.3 \mathrm{~mm}$. Elytral length: 1.1-1.4 mm. Elytral width: $1.2-1.4 \mathrm{~mm}$.

Body concolorous pale brown (teneral specimens) to dark reddish brown to nearly black and with or without paler infusions. Legs bicolored, yellowish brown with femorotibial spot reddish brown to dark reddish brown; tibial spot smaller, paler, and less demarcated than femoral spot.

Head wider than long (HW/HL: 1.3-1.4). Frontoclypeal ridge incomplete, separated medially. Dorsal surface without V-shaped depression; surface coarsely and densely punctate; base with moderately large polished, impunctate, medial spot. Labrum quadridentate (fig. 136).

Pronotum longer than wide (PL/PW: 1.21.3). Pronotum polished and with coarse, dense punctation and moderately large, impunctate spots; surface with deep, coarsely punctate, submedial groove on basal two thirds. Elytra with width equal to or slightly greater than length (EW/EL: 1.0-1.1); surface flat to feebly convex and coarsely punctate.

Abdomen densely and irregularly punctate; punctures not arranged in rows. Segment III without paratergite; paratergal carina present and extending to near middle of segment, but poorly developed beyond spiracle. Tergum III without median point extending from transverse basal ridge. Tergum VIII with posterior margin slightly to broadly and shallowly rounded (males) or truncate to slightly emarginate (females); transverse basal ridge feebly sinuate and with apically closed median point (fig. 26). Tergum IX (fig. 140) with lateroapical process 
145
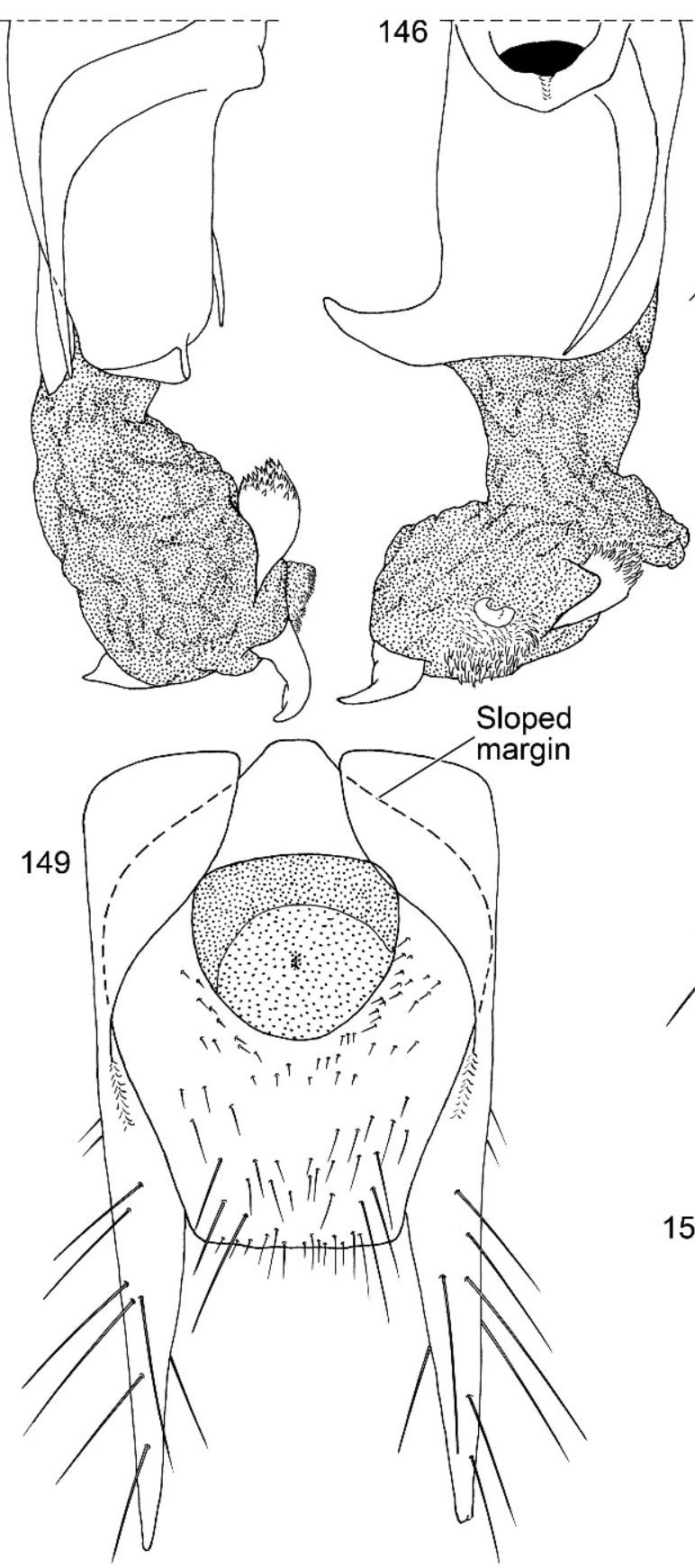

margin

Figs. 145-150. Oedichirus geniculatus. 145. Aedeagus, right lateral, base omitted, internal sac, everted. 146. Aedeagus, ventral, basal omitted, internal sac, everted. 147. Sternum VIII, male. 148-150. Segment IX, ventral, variation, female. 

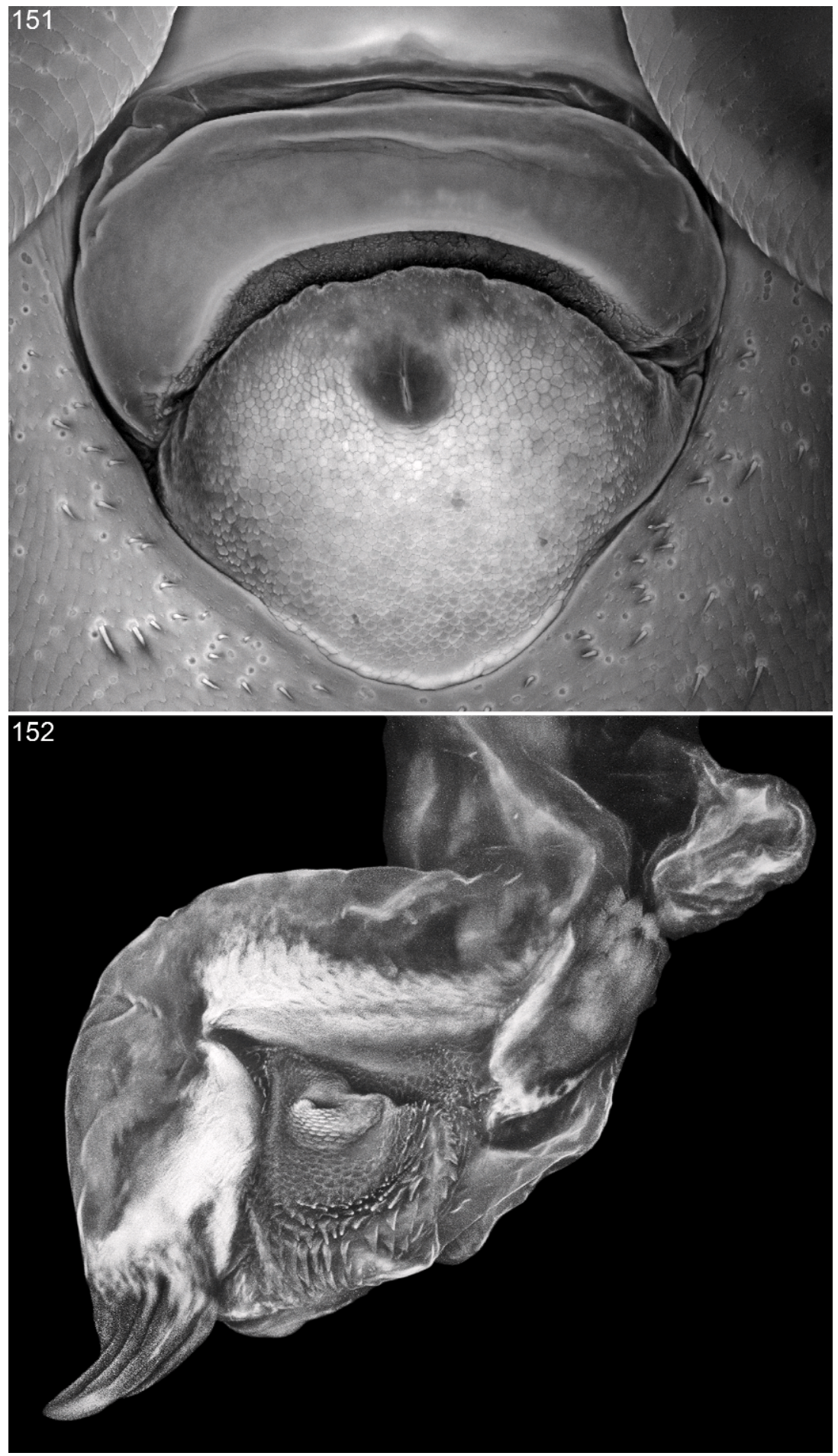

Figs. 151-152. Oedichirus geniculatus. 151. Segment IX, ventral, vulvar plate, enlarged (CLSM). 152. Aedeagus, internal sac, everted (CLSM). 
long, more than twice as long as midbasal length (LLaP/L9 = 1.9-3.0), slightly bent ventrally, and approximately parallel to other process; ventromedial margin without posteriorly directed spur (cf. fig. 158).

MALE: Labral surface with subapical tubercle near submedial denticle (fig. 136). Sternum VI unmodified. Sternum VII with small, median, impunctate, asetate spot near posterior margin. Sternum VIII (fig. 147) with broad, deep, asymmetrical emargination of posterior margin; emargination about one sixth of length of sternum, wider than deep, with moderately broadly rounded base, and mostly to left of midlongitudinal line; right edge of emargination shorter and more steeply sloped than left; surface of margin adjacent to emargination translucent; surface with slight carina laterad of left edge of emargination; surface with cluster of short, spinelike setae laterad of each side of emargination near posterior margin and without comb or depression; transverse basal ridge unevenly sinuate and shallowly curved anteriorly and median point absent. Tergum IX with anteroventral angle extended anteriorly as robust process. Sternum IX (fig. 144) slightly asymmetrical; anterior margin narrow and strongly rounded; posterior margin wide and broadly rounded; lateral margins broadly rounded.

Aedeagus asymmetrical (figs. 141-143). Ventral sclerite with apical margin more or less truncate (figs. 142, 146), with large, flattened, curved, strongly sclerotized apicoventral process extending from right apicolateral margin (figs. 141, 142, 146); apicoventral process strongly tapered to acute apex, extending lateroventrally, and with apex bent lateroanteriorly; ventral sclerite without lobe, peg, or knob arising from right lateral edge near base of ventral process (fig. 141). Parameres moderately broad basally, flattened, tapered apically, and fused to median lobe for most of length and free of median lobe near apex; right paramere slightly longer than left (figs. 141, 143). Internal sac largely membranous (figs. 145, 146, 152); apical region near gonopore with armature on ventral surface; dorsal surface with short, stout, thornlike spine (fig. 145); ventral surface with stout, strongly curved, heavily sclerotized, grooved spine (fig. 146, 152) lateroposteriad of and at right of gonopore; gonopore surrounded by cuticular cobble and with distal patch of spiniform, cuticular processes (figs. 146, 152).

FEMALE: Labrum without subapical, submedial tubercle between denticles. Sternum VIII with broadly rounded posterior margin; transverse basal ridge irregularly sinuate and broadly curved anteriorly. Tergum IX with anteroventral angles separated (figs. 148150). Median gonocoxal plate anteriad of vulvar plate trapezoidal (fig. 149) to triangular (figs. 148, 150) and anterior margin nearly flat to narrowly rounded medially then gradually sloping lateroposteriorly; gonocoxal plate posteriad of vulvar plate gradually tapered to broadly rounded to truncate posterior margin. Vulvar plate embedded in anterior half of median gonocoxal plate (fig. 149). Anterior vulvar lobe (fig. 151) curved around anterior margin of posterior vulvar lobe and wider and shorter than posterior vulvar lobe; surface membranous and without adornment. Posterior vulvar lobe (fig. 151) wider than long; surface covered with cobble except near margins. Vulva oriented at slight angle to longitudinal axis.

Male/Female Association: The $O$. geniculatus complex, based on shared features of the aedeagus and sternum VIII of the male, is comprised of four species, all known only from the state of Rio de Janeiro. One of the species, $O$. geniculatus, is represented by 51 males from two sites in the city of Rio de Janeiro. Specimens of 32 females were collected with the 51 males and are regarded to be conspecific.

MATERial ExAmined: Fifty-two males, 37 females. Brazil: (1 male, BMNH). Rio de Janeiro: Represa Rio Grande, AugustSeptember 1969, F.M. Oliveira $\left(22^{\circ} 54^{\prime} \mathrm{S}\right.$, $43^{\circ} 14^{\prime} \mathrm{W}$ ) (25 males, 18 females, AMNH); Corcovado, September-October 1969, Alvarenga \& Seabra $\left(22^{\circ} 58^{\prime} \mathrm{S}, 43^{\circ} 13^{\prime} \mathrm{W}\right)$ (26 males, 14 females, AMNH); Rio de Janeiro, Fry (4 females, FMNH), December 1856, H. Clark (1 female, FMNH).

LOCALITIES: Corcovado is a peak that reaches $710 \mathrm{~m}$ elevation in a national park in the south of Rio de Janeiro. The coordinates for it and Represa Rio Grande were taken from Paynter and Traylor (1991: 162, 522). 
DISTRIBUTION: This species is known only from the state of Rio de Janeiro, Brazil (fig. 40).

REMARKs: Type Series: In search of the type series of $O$. geniculatus, I discussed the issue with curators of collections in Helsinki, Turku, and Stockholm and examined collections and types of Oedichirus in the Natural History Museum, Field Museum of Natural History, Institut Royal des Sciences Naturelles, Museum für Naturkunde, Musée Royal de l'Afrique Centrale, and Senckenberg Deutsches Entomologisches Institut, but the type series was not found. Efforts to find it are discussed in the following paragraphs.

The R.F. Sahlberg collection is said to be in the Zoological Museum, University of Helsinki, and the Zoological Museum, University of Turku, Finland; the South American collections are specifically reported to be in Helsinki (Horn and Kahle, 1936: 236). Type material of Elytrobaeus geniculatus was not included in a list of the types in the Helsinki collection (Silfverberg, 1988).

In an e-mail message Jyrki Muona (Zoological Museum, University of Helsinki; 11 January 2009) wrote that "R. Sahlberg sold most of the Brazilian insects to Stockholm." In response to my query Bert Viklund (Naturhistoriska Riksmuseet, Stockholm) reported that "The type material of geniculatus is not in our museum and wasn't entered in our files and not even noted in our old Gemminger \& Harold catalogue." He stated that the museum has much material from Sahlberg's South American expedition, but that the types of species he described may not have been included in the purchase. On the other hand, Muona, in a January 2009 e-mail message, wrote that all of the types of Eucnemidae described by Sahlberg were in Stockholm.

Collections at the Zoological Museum, University of Turku, also have R.F. Sahlberg specimens. Veikko Rinne (27 March 2009, e-mail), at the Turku collection, wrote that "This species [E. geniculatus] is not in our type collection where most specimens recognized as type are." He continued that they have a large collection of R.F. Sahlberg's material from Brazil among which is a box, full of Staphylinidae. Included in the box are three specimens the first of which has an old handwritten label "Oedichirus geniculatus
Sahlb." Two specimens, each with a gray rectangular label, are from Petropolis, the third, with a violet triangular label, is from Rio de Janeiro, within which the type locality of E. geniculatus is included. Based on a photograph sent to me, the specimen from Rio is most probably a female and V. Rinne wrote that the specimen is about $9 \mathrm{~mm}$ long (30 March 2009, e-mail). Sahlberg (1847: 802) cited the length as 4 lines (about $8.5 \mathrm{~mm}$ ), so the specimen is about the right size and from the right locality. However, if this specimen were a syntype the expected generic name on the identifaction label would be Elytrobaeus, not Oedichirus. The next e-mail letter answered my concern about the identification label. The specimens in the box containing $O$. geniculatus had probably been lent to Bernhauer, who added the identification labels to the material (Rinne, 31 March 2009, e-mail) and thereby explaining the use of the currently accepted generic name. Elytrobaeus geniculatus was collected during Sahlberg's first trip to Rio de Janeiro (12 December 1839 to 5 January 1840) and, according to his diary, the specimens he collected then were labeled with shiny green squares (Rinne, 2 April 2009, e-mail). The diary indicates that specimens with a violet triangular label, such as that on the $O$. geniculatus in Turku, were collected in Rio during his second trip to South America (1849-1851) (Rinne, 2 April 2009, e-mail) after $O$. geniculatus had been described. In summary, none of the specimens in Turku identified as $O$. geniculatus are syntypes and no potential syntypes were found in the collections in Helsinki or Stockholm.

Sahlberg (1847) did not indicate the number of specimens he examined for this species. The characters he provided will not separate the species from others of the genus. However, one, the unique cluster of specialized seta (= spiniform pencil) on the apex of antennomere 11 (Sahlberg, 1847: 803 "ultimo oblongoovato, apices spina acuta armato..."), does permit generic assignment (see fig. 9). The locality from which the species was collected in Rio de Janeiro was clearly identified: "cum omnia in vicinitate urbis Rio Janeiro, atque qua maximam partem in tractu montuoso (Corcovado) capta sunt" (Sahlberg, 1844: 501). Although we know the size, color, generic assignment, and original collecting site 
for the type series, and although no specimens of the type series were found, is selection of a neotype justified?

To designate a specimen as a valid neotype, the Code (ICZN, 1999, article 75.3) explicitly qualifies that evidence be presented that the neotype be "consistent with what is known of the former namebearing type from the original description..." (Article 7.3.5) "and that the neotype [come] as nearly as practicable from the original type locality..." (Article 7.3.5). Beyond the character of antennomere 11 , only the originally stated size and locality help narrow the choice of a neotype from among the four species known in the state of Rio de Janeiro. In the present work only one species was collected at Corcovado and the range of the length of that species also overlaps the stated size of $O$. geniculatus. Although the remaining three species might be found at Corcovado, none were. Two were found well outside of the city limits of Rio de Janeiro in Petropolis (O. clavulus) and Silva Jardim $(O$. exilis) and the third was from an unspecified part of Rio de Janeiro $(O$. clavolateralis). Each of the remaining three species is within range of the size of $O$. geniculatus, but only one sample encompassed the size of the original specimen. I regard the specimens studied herein from Corcovado to be $O$. geniculatus as they provide the best fit for the few known facts.

The conditions required for designation of a neotype are that (1) no extant name-bearing specimen is believed to exist, (2) a type is needed to objectively define the nominal taxon (ICZN, 1999: Art. 75.1), and (3) there is an expressly stated exceptional need to designate a neotype (ICZN, 1999: Art. 75.3).

When designating a neotype authors generally state that the original type series is lost and that a neotype is needed to objectively fix the identity of the name. In addition to noting that the primary type is lost, two other reasons cited for neotype designation are to fix the identity of nomina dubia (Assing, 2008: 1239) and to fix a name with a long history of being identified in a manner that is contrary to the original description (Frisch and Herman, 2008). Another reason would be to fix the name of a species in a cluster of subtly differentiated species such as is the case for $O$. geniculatus, which, without examination of the aedeagus, is easily confused with $O$. clavolateralis, $O$. clavulus, and $O$. exilis. The type of $O$. geniculatus is lost; a name-bearing type will provide an objective basis for identification.

The conditions set forth in Article 75.3 are herewith addressed. A neotype is needed for $O$. geniculatus to provide an objective basis for its separation from three similar species; the diagnostic features are presented in the preceding diagnosis and description for the species; the label data are presented above in the paragraph "Neotype," and my neotype label is attached to the specimen pin; there is ample evidence presented in preceding paragraphs that the original type series cannot be found and is therefore presumed lost; the specimen selected is from the same locality and is approximately the same size; the specimen is deposited in the American Museum of Natural History. A neotype is hereby and herein designated for Elytrobaeus geniculatus Sahlberg.

R.F. Sahlberg's Types: The question of the depository of the syntype(s) of E. geniculatus concerns more than the location of the type material for one name. Sahlberg described 19 species of Staphylinidae in his 1844 and 1847 articles on beetles from Rio de Janeiro. According to Horn and Kahle (1936: 236) that material should be in the Zoological Museum of the University of Helsinki. In the list of staphylinid types for that collection (Silfverberg, 1988) only seven are reported; 12 were not mentioned. Among the missing are (arranged by subfamily): Falagria brasiliensis, Oxypoda lapidiola, Bolitobius gilvipes, Tachinus tropicus, Tachyporus albicornis, Tachyporus fulvus, Belonuchus vestitus, Quedius nigritulus, Dibelonetes biplagiatus, Elytrobaeus geniculatus, Taenodema villosa, and Oxytelus brasiliensis. Of the foregoing, Dibelonetes biplagiatus is the type species for the genus.

\section{Oedichirus glabrihamus, new species} Figures 40, 153-156

Type Material: Holotype: Male. "Brazil, Chapeco $27^{\circ} 07^{\prime}, 52^{\circ} 36^{\prime}$ VII.1960,600m. F. Plaumann/Holotype Oedichirus glabrihamus Herman." Deposited in the Canadian National Collection of Insects, Ottawa. 


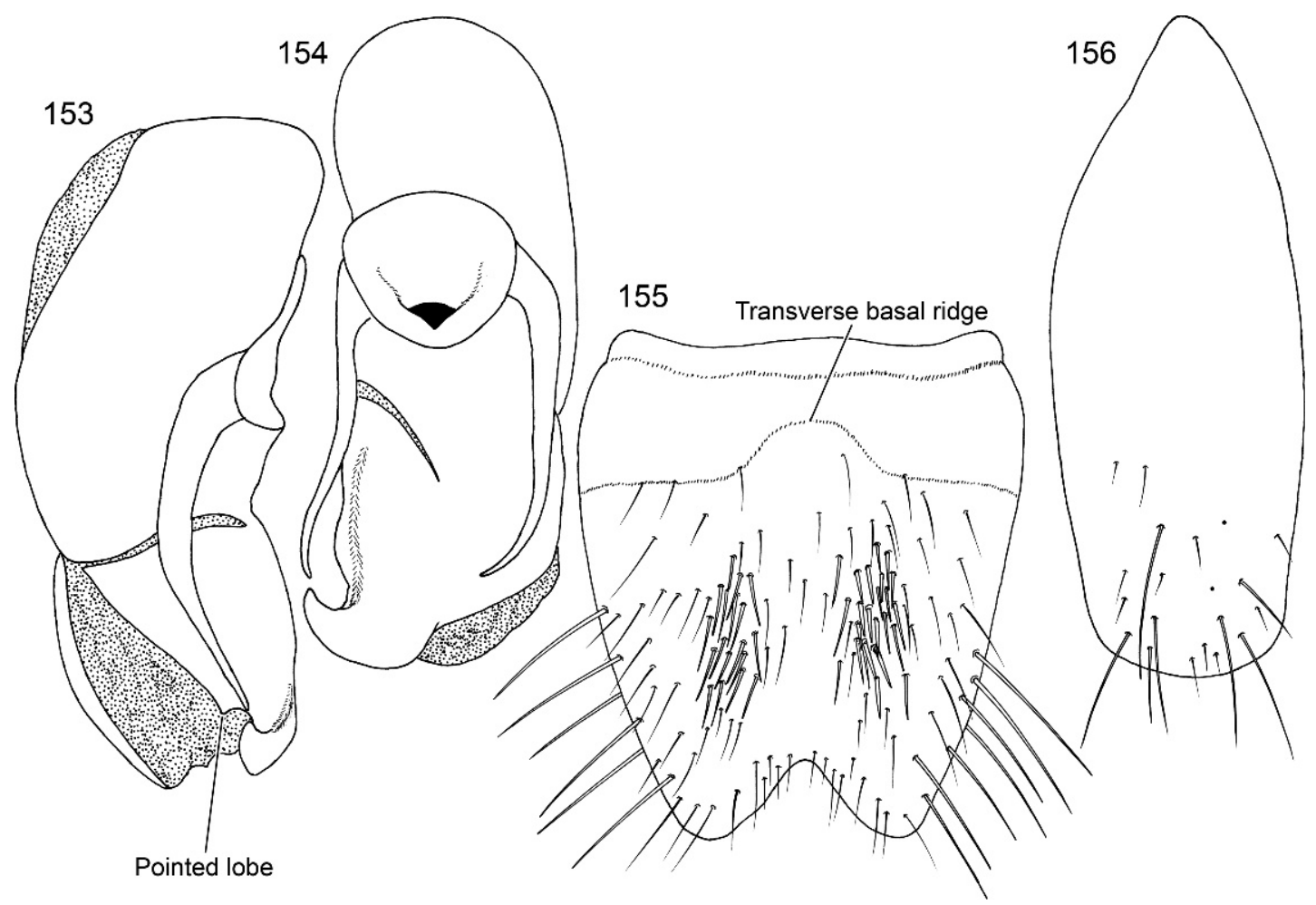

Figs. 153-156. Oedichirus glabrihamus. 153. Aedeagus, right lateral. 154. Aedeagus, ventral. 155. Sternum VIII, male. 156. Sternum IX, male.

Type Locality: Brazil: Santa Catarina: Chapeco, $27^{\circ} 07^{\prime} \mathrm{S}, 52^{\circ} 36^{\prime} \mathrm{W}, 600 \mathrm{~m}$.

Diagnosis: Oedichirus glabrihamus is one of five species, including $O$. sparsipennis, $O$. speculifrons, O. bullaglaber, and O. apiculus, from Santa Catarina state, Brazil. The dark femorotibial spots will separate $O$. sparsipennis and $O$. bullaglaber from $O$. glabrihamus that lacks the maculations. Tergum III of $O$. bullaglaber has a median point (as for sternum VIII, fig. 73), O. glabrihamus does not. The aedeagus of the remaining three species, $O$. glabrihamus, $O$. apiculus, and $O$. speculifrons, has an apicoventral process that curves apicolaterally to the right. The aedeagus of $O$. apiculus has a short, slender, posteriorly directed spiniform process on the right dorsolateral margin of the ventral sclerite just proximad of the base of the apicoventral process (figs. 41, 44) and $O$. glabrihamus has an acutely pointed lobe in about the same position (fig. 153); O. speculifrons (fig. 211) lacks either a spine or lobe. Sternum VIII of $O$. speculifrons has a transverse, rounded, subapical ridge that has a low boss at each end from which a low ridge extends anteriorly (fig. 208); O. glabrihamus lacks these ridges and bosses. Sternum VIII of $O$. glabrihamus has a broad median depression that extends for most of the length of the segment and is bordered laterally by a large cluster of spinelike setae (fig. 155); O. speculifrons has a less dense cluster of setae (fig. 209). In ventral view the aedeagal apicoventral process for O. glabrihamus is short and wide (fig. 154), but long and slender for $O$. speculifrons (fig. 212). A fourth species, O. misionesiensis, is a part of a cluster of similar species that includes $O$. speculifrons, $O$. glabrihamus, and $O$. apiculus. The left side of the aedeagal apicoventral process of $O$. misionesiensis has a large, cylindrical peg-boss (fig. 173) that is lacking in O. glabrihamus (fig. 154).

Oedichirus glabrihamus is distinguished from the males of other species in the New World by the symmetrical emargination of 
sternum VIII (fig. 155) and the stout apicoventral process of the ventral sclerite of the aedeagus (fig. 154). Furthermore, the labrum is quadridentate, the legs lack a femorotibial maculation, abdominal segment III has a paratergal carina, and tergum III has no median point (as in sternum VIII, fig. 73).

DESCRIPTION: Length: $7.1 \mathrm{~mm}$. Length of head: $1.0 \mathrm{~mm}$. Width of head: $0.8 \mathrm{~mm}$. Pronotal length: $1.3 \mathrm{~mm}$. Pronotal width: $1.2 \mathrm{~mm}$. Elytral length: $0.9 \mathrm{~mm}$. Elytral width: $1.1 \mathrm{~mm}$.

Body concolorous reddish brown. Legs reddish brown basally gradually changing to yellowish brown apically and without dark femorotibial spot.

Head wider than long (HW/HL: 1.4). Frontoclypeal ridge incomplete and separated medially. Dorsal surface without V-shaped depression; surface coarsely and densely punctate; punctation evenly distributed; surface polished between punctures and, except for frontoclypeal region, devoid of distinct, impunctate median, basal, or lateral spots. Labrum quadridentate; surface without tubercle near submedial denticle.

Pronotum longer than wide (PL/PW: 1.1). Pronotum polished and with coarse, dense punctation clustered in submedial and sublateral clusters; surface with medial, submedial, and sublateral impunctate spots; surface without submedial punctate groove. Elytra with width greater than length (EW/EL: 1.2); surface feebly convex and coarsely punctate.

Abdomen densely and uniformly punctate; punctures not arranged in rows on most of surface and with subapical impunctate strip; punctation of segments III to VI coarse, punctation of VII and VIII less coarse and less dense. Segment III without paratergite; paratergal carina present and extending beyond spiracle for nearly two thirds of length of segment. Tergum III without median point extending from transverse basal ridge. Tergum VIII with posterior margin broadly rounded and with median region slightly flattened; transverse basal ridge broadly curved anteriorly and without median point. Tergum IX with lateroapical process slightly longer than midbasal length of tergum (LLaP/L9 = 1.1), slightly curved ventrally, and slightly divergent posteriorly from other process; ventromedial margin without posteriorly directed spur (cf. fig. 158).
MALE: Sternum VI unmodified. Sternum VII with clustered row of five moderately closely spaced, slightly thicker setae at middle of posterior margin. Sternum VIII (fig. 155) with broad, moderately deep, symmetrical emargination of posterior margin; emargination about one sixth of length of sternum, wider than deep, and with basal margin narrowly rounded; margin of emargination sclerotized, not membranous; surface with moderately deep, oval, median depression extending from near transverse basal ridge to near base of posterior emargination; depression sparsely and finely punctate; surface adjacent to lateral margin of depression with dense cluster of slightly thicker setae (fig. 155); surface without combs or carinae; transverse basal ridge with middle strongly and abruptly curved anteriorly and without median point (fig. 155). Tergum IX with short, wide process on anterior margin of anteroventral angle. Sternum IX (fig. 156) slightly asymmetrical; anterior margin narrow and strongly rounded; posterior margin wide and broadly rounded; lateral margins broadly rounded.

Aedeagus asymmetrical (fig. 154). Ventral sclerite with apical margin of ventral sclerite broadly curved from left lateral margin to base of large apicoventral process extending from right side of apical margin (fig. 154); apicoventral process wide in ventral view, strongly and evenly tapered to acute apex, strongly curved laterally to right with apex curved anteriorly, and ventral surface broadly and shallowly convex; ventral sclerite with well-developed carina near right lateral margin extending to base and continuous with short, strongly curved anterior margin of apicoventral process; ventral sclerite with acutely pointed lobe on right dorsolateral edge near base of apicoventral process (fig. 153). Parameres curved ventrally, moderately broad basally, flattened, tapered and slender apically, basal half tightly appressed or perhaps fused to median lobe, apical half free of median lobe; parameres reaching to near posterior margin of ventral sclerite.

FEMALE: Unknown.

ETYMOLOGY: The name is from the Latin glaber, "hairless or smooth," and hamus, "hook," and refers to the hooked form of the apicoventral process and its smooth, unadorned, polished surface. 
DISTRIBUTION: Known only from southern Brazil (fig. 40).

\section{Oedichirus hamatus, new species} Figures 40, 157-159

Type Material: Holotype: Female. "Peru: Colonia Cal-leria, Rio Calleria, $15 \mathrm{~km}$ E Ucayali, 115-X-1961,/FMHD \#61 - 3002, sweeping in for. at night, B. Malkin/Holotype Oedichirus hamatus Herman." Deposited in Field Museum of Natural History. (The right profemur, protibia, and protarsus are missing.)

Type Locality: Peru: Ucayali: Colonia Calleria (= Callaría), Río Calleria (= Callaría), $15 \mathrm{~km} \mathrm{E}$ Ucayali $\left(08^{\circ} 01^{\prime} \mathrm{S}, 74^{\circ} 34^{\prime} \mathrm{W}\right)$. (On the locality label the site is reported as "Colonia Calleria," but that may be a misspelling for "Callaría." Neither Colonia Calleria, Colonia Callaría, nor a town named Ucayali were found in gazetters or atlases, but there is a Río Ucayali east of which three old atlases [Ambrosius, 1914; Bartholomew, 1922; Haack, 1925] cite "Callaria" on the bank of a small river that flows into the Ucayali. One of the three atlases [Haack, 1925] refers to the tributary as Río Callaría. In one atlas [Ambrosius, 1914] Callaría is cited with the symbol, signifying "ruins or historical site." Diamond and Terborgh [1967: 273] travelled 20-30 miles [32-48 km] upstream on Río Callaría searching for birds; they reported the coordinates of the mouth of the river as $08^{\circ} 08^{\prime} \mathrm{S}, 74^{\circ} 38^{\prime} \mathrm{W}$. Although they mentioned three small Indian villages with plantations and travelled sufficiently far upstream to have passed the collection site for $O$. hamatus, they referred to no town, village, plantation, or site as Callaría. Lamas [1976] reported Callaría at $08^{\circ} 01^{\prime} \mathrm{S}, 74^{\circ} 34^{\prime} \mathrm{W}$; the source of those coordinates was not stated.)

Diagnosis: Oedichirus hamatus is one of only six species with paratergite III; the other five are $O$. batillus, $O$. bicristatus, $O$. isthmus, $O$. optatus, and $O$. sinuosus. Of the six, only $O$. hamatus has dark femorotibial maculations (as in fig. 2). The pronotum is sparsely punctate and the punctures of the submedial row are deep and coarse. The elytra are coarsely punctate, the surface of the disc slightly concave, and the length and width are equal.

Oedichirus hamatus is the only New World species with a flat spur on the ventromedial edge of tergum IX (fig. 158). The anteroventral angles of tergum IX are separated medially. The median gonocoxal plate anteriad of the vulvar plate is reduced to a narrow strap (fig. 157). Unlike any other species, the anterior vulvar lobe of the vulvar plate (fig. 159) is densely wrinkled and most of the surface of the posterior vulvar lobe has a reticulate covering. The male is unknown, but perhaps the flat spur on the ventromedial margin of tergum IX of the holotype is not a sexually dimorphic feature.

DESCRIPTION: Length: $8.9 \mathrm{~mm}$. Length of head: $0.9 \mathrm{~mm}$. Width of head: $1.0 \mathrm{~mm}$. Pronotal length: $1.3 \mathrm{~mm}$. Pronotal width: $1.1 \mathrm{~mm}$. Elytral length: $1.3 \mathrm{~mm}$. Elytral width: $1.3 \mathrm{~mm}$.

Color black and reddish brown. Head and prothorax black with reddish-brown-infusions. Elytra reddish brown. Abdomen dark reddish brown with paler reddish brown infusions. Legs bicolored, yellowish brown with dark reddish brown femorotibial maculation (as in fig. 2).

Head across eye wider than long (HW/HL: 1.2). Frontoclypeal ridge incomplete, medial ends narrowly separated. Dorsal surface without V-shaped depression; punctation coarse and sparse medially, finer adjacent to margin of eye, most dense anteromedially between eyes and less dense anteriorly and basally; surface polished. Labrum quadridentate, without tubercle near submedial denticle.

Pronotum about a tenth longer than wide (PL/PW: 1.1). Pronotum polished, with coarse punctation in scattered clusters and with large impunctate spots; surface with deep, submedial, punctate groove. Elytra with length and width equal (EW/EL: 1.0); surface of disc slightly concave medially and coarsely punctate.

Abdominal terga III to VI with transverse subapical rows of punctures; terga VII and VIII more evenly punctate. Segment III with paratergite. Tergum III with median point extending from transverse basal ridge. Tergum VIII with posterior margin broadly and moderately deeply emarginate; transverse basal ridge without median point. Tergum IX with lateroapical process about three fifths longer than midbasal length (LLaP/ T9: 1.6), slightly bent ventrally, and moderately divergent from other process; ventromedial margin with apically acute spur extending posteriorly to about level of posterior margin of median gonocoxal plate (figs. 157, 158). 
157

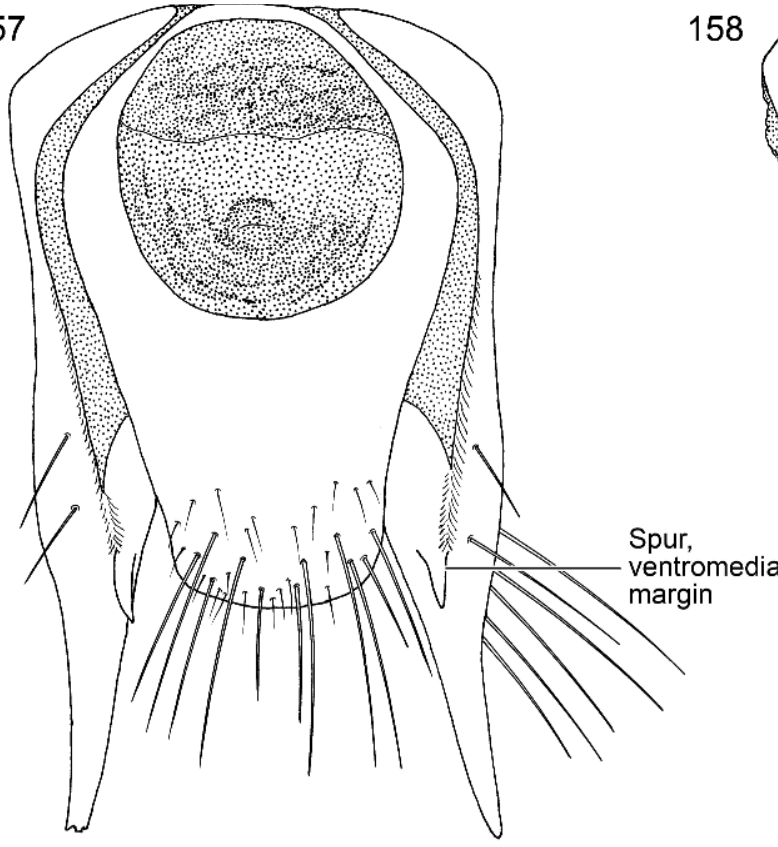

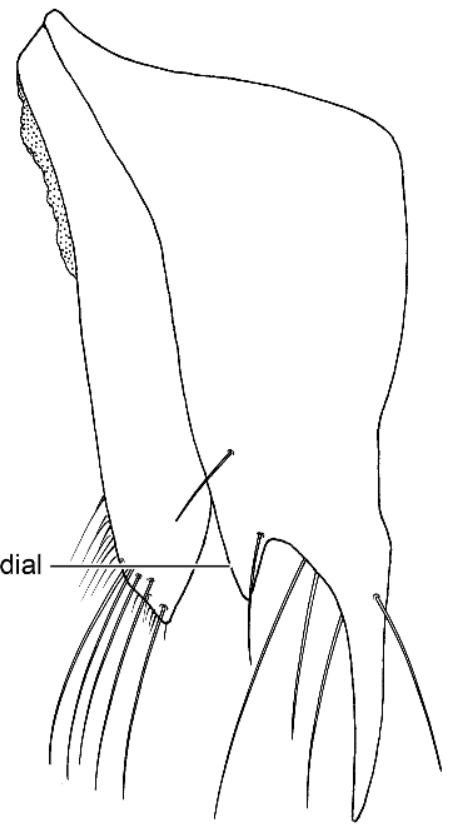

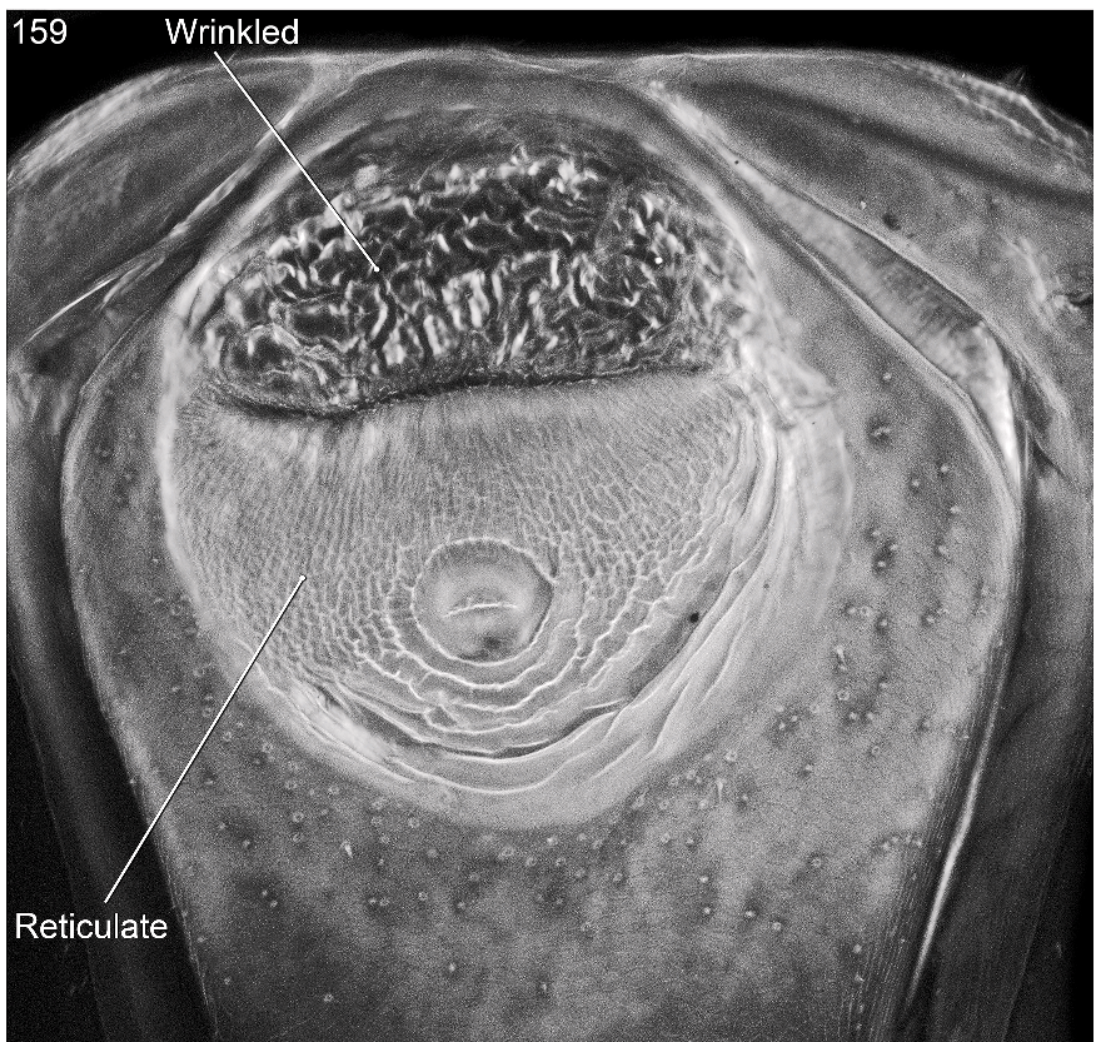

Figs. 157-159. Oedichirus hamatus. 157. Segment IX, ventral, female. 158. Segment IX, left lateral, female. 159. Segment IX, vulvar plate, enlarged (CLSM). 
Female: Sterna III to VII unmodified. Sternum VIII with posterior margin broadly and shallowly sinuate; transverse basal ridge moderately curved anteriorly and without median point. Tergum IX with anteroventral angles separated medially (fig. 157). Median gonocoxal plate anteriad of vulvar plate reduced to narrow strap and separated from tergum IX (fig. 157); anterior margin slightly flattened then sloped lateroposteriorly; gonocoxal plate posteriad of vulvar plate tapered to broadly rounded posterior margin. Vulvar plate embedded anteriorly in median gonocoxal plate (fig. 159). Proximal vulvar lobe transverse, posterior margin broadly sinuate, and surface strongly wrinkled (fig. 159). Distal vulvar lobe transverse; surface reticulate. Vulva transversely oriented.

MALE: Unknown.

ETYMOLOGY: The name is from the Latin hamatus, "furnished with a hook," and refers to the hook or spur on the ventral edge of tergum IX.

DisTRIBUTION: Known only from northeastern Peru in Ucayali department (fig. 40).

\section{Oedichirus isthmus, new species} Figures 39, 160-165

Holotype: Male. "Mex: Est. Biol. Chamela, Jalisco VII-20/27-1984 J.T. Doyen coll./Oedichirus 1st Mex. record M.K. Thayer det. 1999/ Holotype Oedichirus isthmus Herman." Deposited in the Essig Museum of Entomology, University of California, Berkeley, California.

Type Locality: Mexico: Jalisco: Estación Biologica de Chamela $\left(19^{\circ} 22^{\prime}-39^{\prime} \mathrm{N}, 1^{\circ} 104^{\circ} 56^{\prime}-\right.$ $105^{\circ} 10^{\prime} \mathrm{W}$ ). (Coordinates for the station are from a website of the Smithsonian Institution [http://botany.si.edu/projects/cpd/ma/ma7.htm].)

Diagnosis: Oedichirus isthmus is one of six New World species with paratergite III. Of these six, $O$. hamatus, known only by the female, has dark femorotibial maculations (as in fig. 2); $O$. isthmus lacks the spots. Among the remaining species only $O$. isthmus and $O$. sinuosus have short parameres (figs. 161, 200); the parameres of $O$. batillus, $O$. bicristatus, and $O$. optatus are long (figs. 49, 57, 189 respectively). The emargination of sternum VIII of both $O$. isthmus and $O$. sinuosus is broad; sternum VIII of the former has a transverse, subapical cluster of setae (fig. 163), the latter has a curved, transverse, subapical row of setae (fig. 203). The apical region of the median lobe of $O$. isthmus is broader (fig. 161) than it is for $O$. sinuosus (fig. 200). Sternum VIII of $O$. bicristatus has a deep, symmetrical emargination, a large, dense, median patch of spiniform setae, and the transverse basal ridge is strongly curved medially (fig. 59); for $O$. isthmus the asymmetrical emargination of sternum VIII is shallower, the cluster of setae of sternum VIII is smaller, and the transverse basal ridge of the sternum is sinuate and not strongly curved medially (fig. 163). In contrast to O. isthmus (fig. 163), sternum VIII of $O$. batillus lacks spinelike setae and has a wide deep emargination (fig. 53). Many features of $O$. optatus, including the deep, narrow emargination of sternum VIII (fig. 193), the form of the aedeagus (figs. 188, 189), and the presence of six labral denticles separate it from $O$. isthmus. The female of $O$. isthmus is unknown.

DESCRIPTION: Length $7.3 \mathrm{~mm}$. Width $1.1 \mathrm{~mm}$. Length of head: $0.8 \mathrm{~mm}$. Width of head: $1.0 \mathrm{~mm}$. Pronotal length: $1.2 \mathrm{~mm}$. Pronotal width: $1.0 \mathrm{~mm}$. Elytral length: $1.0 \mathrm{~mm}$. Elytral width: $1.1 \mathrm{~mm}$.

Body concolorous reddish brown. Legs concolorous yellowish brown; femorotibial joints without dark spots.

Head about one third wider than long (HW/HL: 1.3). Frontoclypeal ridge incomplete, separated medially. Dorsal surface without V-shaped depression; surface polished and sparsely punctate medially from anterior to posterior regions; lateral surface with shallow, moderately coarse, and moderately dense punctation from just before eye to near basal margin. Labrum quadridentate; surface without tubercle near submedial denticle.

Pronotum about one fifth longer than wide (PL/PW: 1.2). Pronotum polished, with coarse, dense punctation, and with moderately large impunctate spots; punctures clustered in large lateral group and in long, submedial group; surface without distinct submedial, punctate groove. Elytra with width about one tenth greater than length (EW/EL: 1.1); surface flat medially and coarsely punctate.

Abdominal terga V to VII with subapical row of punctures; punctation of terga III to V with irregularly arranged, poorly developed 


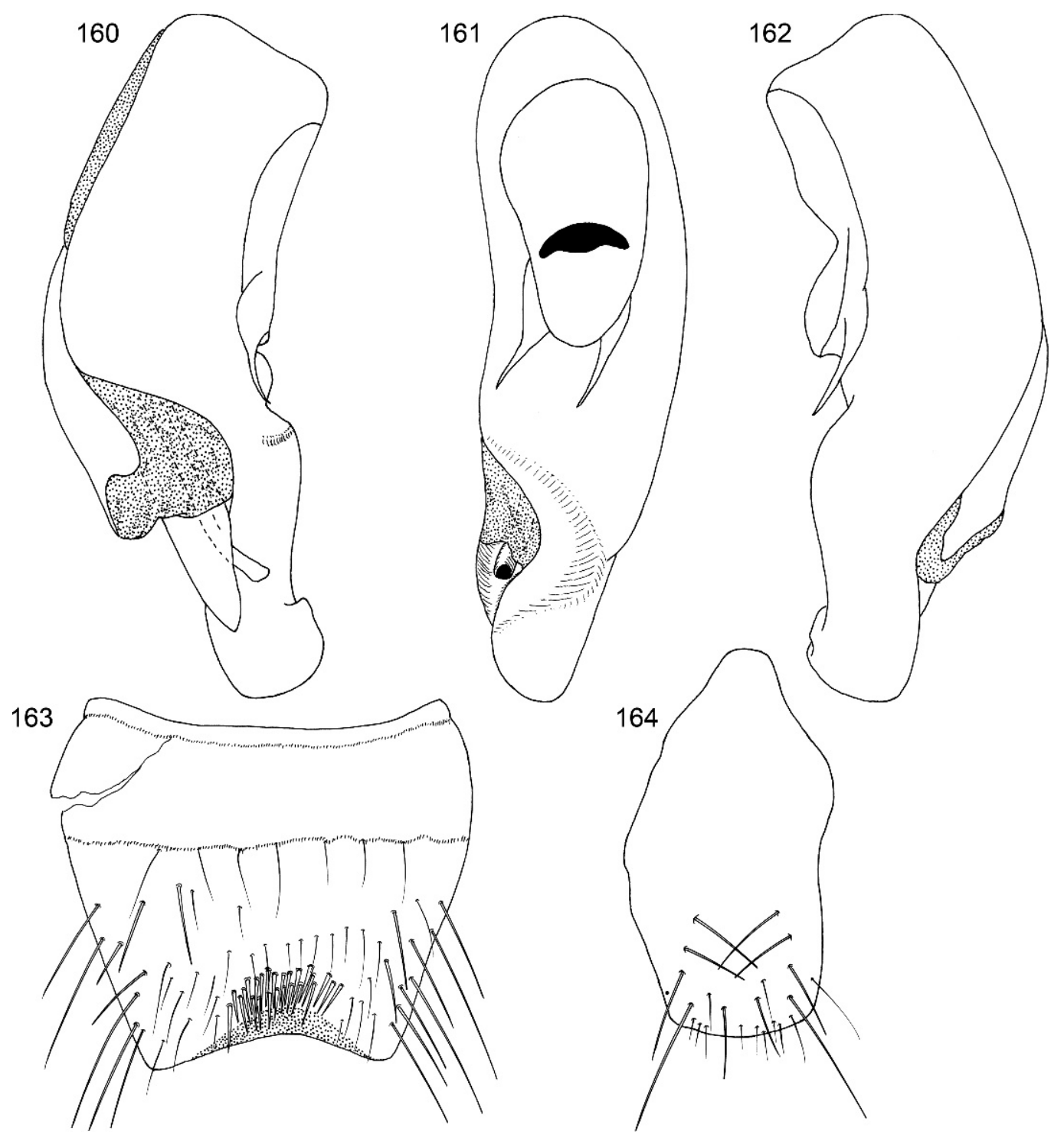

Figs. 160-164. Oedichirus isthmus. 160. Aedeagus, right lateral. 161. Aedeagus, ventral. 162. Aedeagus, left lateral. 163. Sternum VIII, male. 164. Sternum IX, male.

subapical transverse row of punctures; terga VI and VII with moderately developed, subbasal, subapical, and apical, transverse rows of punctures, subbasal and subapical rows with punctures irregularly arranged; VII and VIII with finer punctation than on preceding segments. Segment III with narrow paratergite; paratergal carina absent. Tergum III without median point extending from transverse basal ridge. Tergum VIII with broad, shallow emargination of posterior margin; transverse basal ridge broadly and shallowly curved anteriorly, not separated medially, and without median point. Tergum IX with lateroapical process about one third longer than midbasal length (LLaP/L9 = 1.3), moderately bent ventrally, and approximately parallel to other process; ventromedial margin without posteriorly directed spur (cf. fig. 158). 


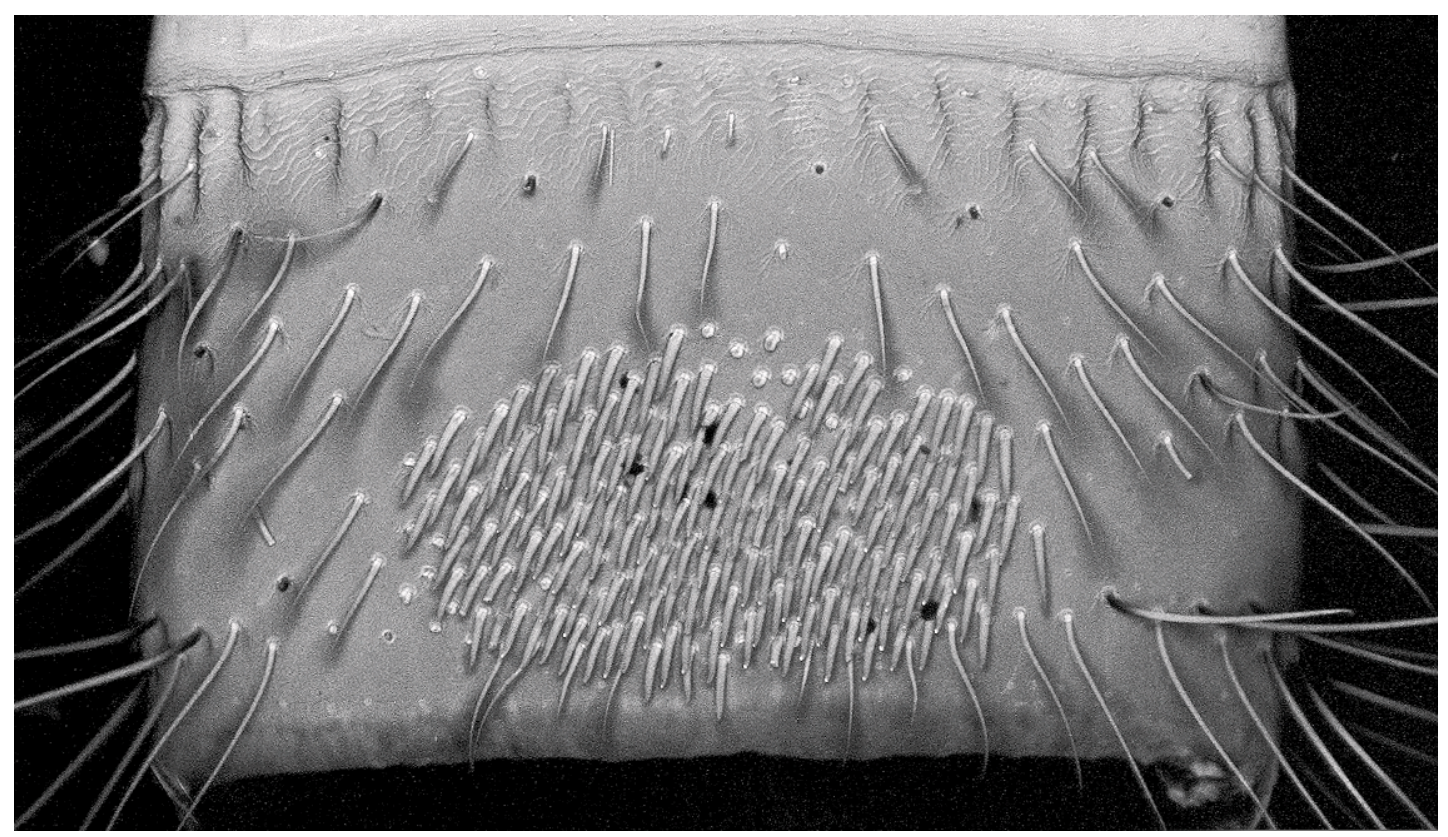

Fig. 165. Oedichirus isthmus. Sternum VII, male (CLSM).

Male: Sternum VI unmodified. Sternum VII (fig. 165) with large, median cluster of short, semirecumbent, spiniform setae near posterior margin. Sternum VIII (fig. 163) with wide, moderately asymmetrical, moderately deep emargination of posterior margin; emargination about one twelfth of median length of sternum, wider than deep, mostly to right of midlongitudinal line, and margin broadly rounded basally and membranous; surface with transverse, subapical cluster of spiniform setae near middle adjacent to posterior margin, without carinae, combs, or depressions, and with broad, moderately deep, sparsely punctate, polished, transverse depression between submarginal cluster of setae and transverse basal ridge; transverse basal ridge slightly sinuate and without posteriorly directed median point. Tergum IX with long, moderately wide process on anterior margin of anteroventral angle. Sternum IX (fig. 164) moderately asymmetrical; anterior margin narrow and broadly rounded; posterior margin wide and broadly rounded; lateral margins sinuate.

Aedeagus asymmetrical (figs. 160-162). Median lobe constricted subapically (fig. 161) and with swollen apical bulb (fig. 160); apical margin broadly rounded; ventral surface with curved carina extending anteriorly from apical bulb for about one third of length of medial lobe; ventral sclerite without apicoventral process extending from posterior margin. Parameres short, fused to median lobe basally, and free apically; parameres of approximately equal length. Internal sac with long, cylindrical, apically open flagellum (figs. 160, 161).

FEMALE: Unknown.

ETYMOLOGY: The name is from the Greek isthmos, :neck or narrow passage" and refers to the subapical constriction of the median lobe of the aedeagus.

DisTRIBUTION: Known only from the west central Mexican state of Jalisco (fig. 39).

REMARKS: This species, represented by one male, is one of two known for Mexico.

Oedichirus lunatus, new species

Figures 40, 166-171

Type MATERiAl: Holotype: Female. "BRAZIL: Bahia:Itabuna: CEPLAC, 26-1-1995 NR 100m, F95301 W1 $14^{\circ} 38^{\prime} \mathrm{S} 39^{\circ} 18^{\prime} \mathrm{W}$ D. Agosti, abandoned cocoa plantation/Holotype Oedichirus lunatus Herman." Deposited in the American Museum of Natural History. 


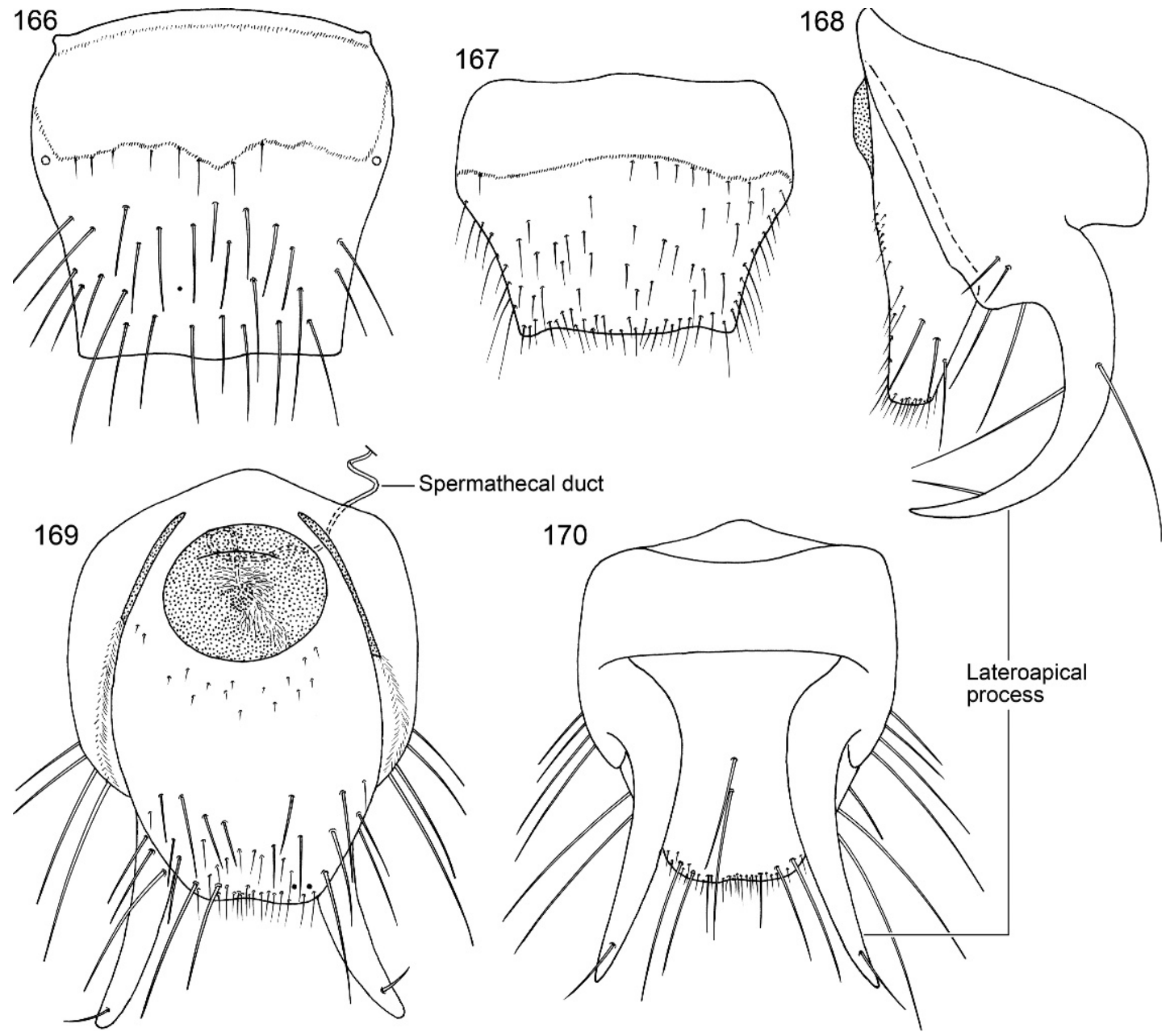

Figs. 166-170. Oedichirus lunatus. 166. Tergum VIII, female. 167. Sternum VIII, female. 168. Segment IX, left lateral, female. 169. Segment IX, ventral, female. 170. Terga IX and X, female.

PARATYPE: One female. Same data as holotype (AMNH)

Type LocAlity: Brazil: Bahia: Itabuna, CEPLAC, $14^{\circ} 38^{\prime} \mathrm{S} 39^{\circ} 18^{\prime} \mathrm{W}, 100 \mathrm{~m}$. (The species was collected at a facility of the Comissão Executiva do Plano da Lavoura Cacaueira [CEPLAC].)

DiAgNosis: The long, ventrally strongly bent, lateroapical process of tergum IX (fig. 168) will separate the species from all known New World species all of which have a slightly to moderately curved process (fig. 158). The lateroapical process of tergum IX is about five times longer than the midbasal length of the tergum and is longer than that of any other New World species. Oedichirus lunatus is the only New World species for which the pronotal length and width are about equal; for all others the pronotal length is greater than the width. Among the New World species only $O$. echinatus, O. lunatus, and $O$. procerus have a bidentate labrum; the preceding characters will permit separation. The male is unknown.

DESCRIPTION: Length: 4.2-4.7 mm. Length of head: $0.5 \mathrm{~mm}$. Width of head: $0.6 \mathrm{~mm}$. Pronotal length: $0.7 \mathrm{~mm}$. Pronotal width: $0.7 \mathrm{~mm}$. Elytral length: $0.6 \mathrm{~mm}$. Elytral width: $0.7 \mathrm{~mm}$. 


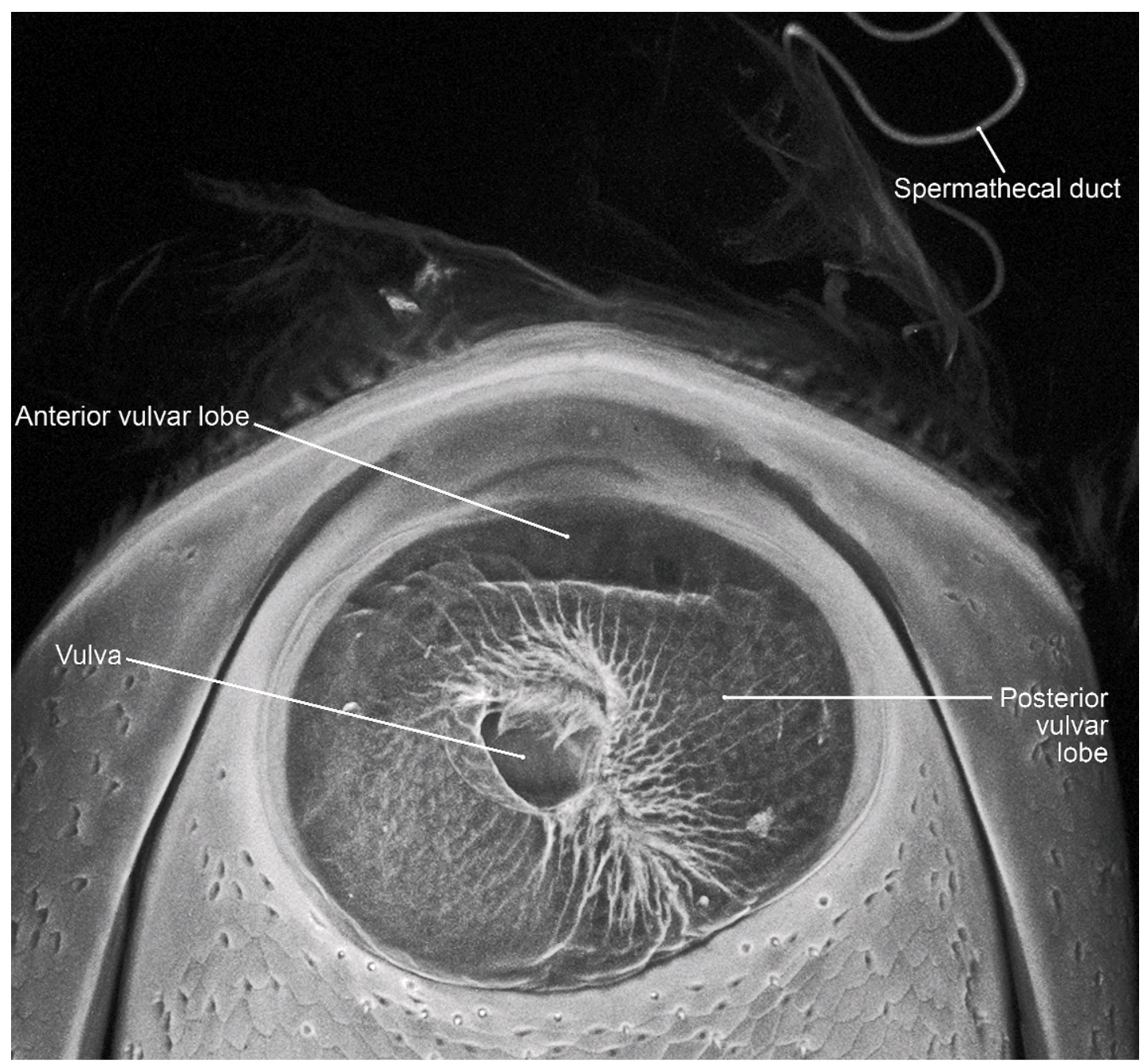

Fig. 171. Oedichirus lunatus. Segment IX, vulvar plate, enlarged (CLSM).

Body reddish brown. Head darker reddish brown than pronotum, elytra, or abdomen; pronotum paler than to concolorous with elytra and abdomen. Legs concolorous paler reddish brown to yellowish brown and without femorotibial maculation.

Head wider than long (HW/HL: 1.2). Frontoclypeal ridge absent. Dorsal surface without V-shaped depression; surface coarsely and densely punctate; punctation evenly distributed; surface polished between punctures except just proximad of frontoclypeus. Labrum bidentate; denticle small and adjacent to median emargination; surface without tubercle near denticle.
Pronotum with length nearly equal to or slightly less than width (PW/PW: 1.0). Pronotum polished, with coarse dense punctation and with medial and several sublateral impunctate spots; surface without submedial punctate groove. Elytra about a fifth wider than long (EW/EL: 1.2); surface moderately convex and coarsely punctate.

Abdominal terga III to $\mathrm{V}$ densely and coarsely punctate and punctures not arranged in rows; terga VI to VIII with less coarse, less dense punctation. Segment III without paratergite; paratergal carina present and extending for most of length of segment, nearly reaching posterior margin, and poorly 
developed beyond spiracle. Tergum III without median point extending from transverse basal ridge. Tergum VIII (fig. 166) with small median lobe on nearly truncate posterior margin; transverse basal ridge irregularly sinuate and with large median point; surface with broad, transverse depression. Tergum IX with lateroapical process five times longer than midbasal length (LLaP/T9 $=5.2)$, strongly bent ventrally (fig. 168), and, in dorsal view, processes nearer to one another near base and widely separated apically (fig. 170); ventromedial margin without posteriorly directed spur (cf. fig. 158).

Female: Sterna III to VII unmodified. Sternum VIII (fig. 167) with posterior margin sinuate, broadly rounded medially; transverse basal ridge broadly sinuate and without median point. Tergum IX with anteroventral angles fused medially forming narrow strap (figs. 169, 171). Median gonocoxal plate anteriad of vulvar plate reduced to strap and apparently fused to anteroventral strap of tergum IX (figs. 169, 171); gonocoxal plate posteriad of vulvar plate with broadly rounded lateral margins tapering to broadly, feebly emarginate posterior margin (fig. 169). Anterior vulvar lobe (fig. 171) apparently narrow and transverse, but poorly discernible. Posterior vulvar lobe large (fig. 171); surface with network of filaments surrounding anterior to left lateroposterior margin of vulvar area and remainder of surface with cobble. Vulva of indeterminate orientation.

MALE: Unknown.

ETYMOLOGY: The name is from the Latin lunatus for "crescent-moon shaped" and refers to the nearly semicircular bend of the lateroapical processes of tergum IX.

Distribution: Known only from Bahia province, Brazil (fig. 40).

REMARKS: This species, the smallest known from the New World, has a robust abdomen, the pronotal length is marginally shorter than the width, and the lateroapical processes of tergum IX are far longer than in other species and are so strongly bent that they nearly form a semicircle. The male is not known, but it is expected that the lateroapical processes of tergum IX would be similarly long and strongly curved. The lateroapical processes are narrowly separated prior to dissection and nearly touch each other for almost their entire length.
Oedichirus misionesiensis, new species Figures 40, 172-179

Type Material: Holotype: Male. "ARGENTINA: Prov. Misiones, $15 \mathrm{~km}$ SE Puerto Iguazo[sic], 30.XII.1990/FMHD\#90-312, forest, S \& J Peck, 90-141, treebase litter FIELD MUSEUM/Oedichirus P.N. Thomas det. 1993/ Holotype Oedichirus misionesiensis Herman." Deposited in the Field Museum of Natural History, Chicago. (Left metafemur, metatibia, and metatarsus are missing.)

Type Locality: Argentina: Misiones: $15 \mathrm{~km} \mathrm{SE}$ Puerto Iguazú $\left(25^{\circ} 41^{\prime} \mathrm{S}, 54^{\circ} 28^{\prime} \mathrm{W}, 240 \mathrm{~m}\right)$.

Diagnosis: Oedichirus misionesiensis, part of a group of narrowly separated species that includes $O$. apiculus, $O$. glabrihamus, and $O$. speculifrons, can be separated from them all by the cylindrical peg-boss on the posterior margin of the ventral sclerite near the left base of the aedeagal apicoventral process (fig. 173). Although the size of the basal boss on the apicoventral process of $O$. speculifrons varies, it differs from that of $O$. misionesiensis in that it is ventrally directed and manifests as a broadly rounded, undistinguished tumescence. It is separated from $O$. apiculus by the deeper emargination of sternum VIII (cf. figs. 177 and 46); O. apiculus has a spiniform process on the right dorsal edge of the ventral sclerite near the base of the apicoventral process (figs. 41, 44), O. misionesensis does not (fig. 72). Sternum VIII is similar in $O$. misionesiensis (fig. 177) and O. speculifrons (figs. 208, 209), but subtle differences of the median depression and associated subapical boss of the latter species will separate them. For O. misionesiensis (fig. 177) the median depression is more shallow and less distinct, the ridge marking the lateral side is feeble, the slope from the lateral side of the depression is slight, the subapical boss is a polished, feeble swelling at the lateroapical corner of the median depression, and the surface between the corners is almost flat. For $O$. speculifrons (figs. 208, 209) the median depression is deeper, the ridge marking the lateral side is well developed posteriorly, and the subapical boss is higher, more prominent, and the depression between them distinct. As is true for others of this complex of species, the males of $O$. misionesiensis can be separated from other New World species by the deep, basally rounded, symmetrical emargination 


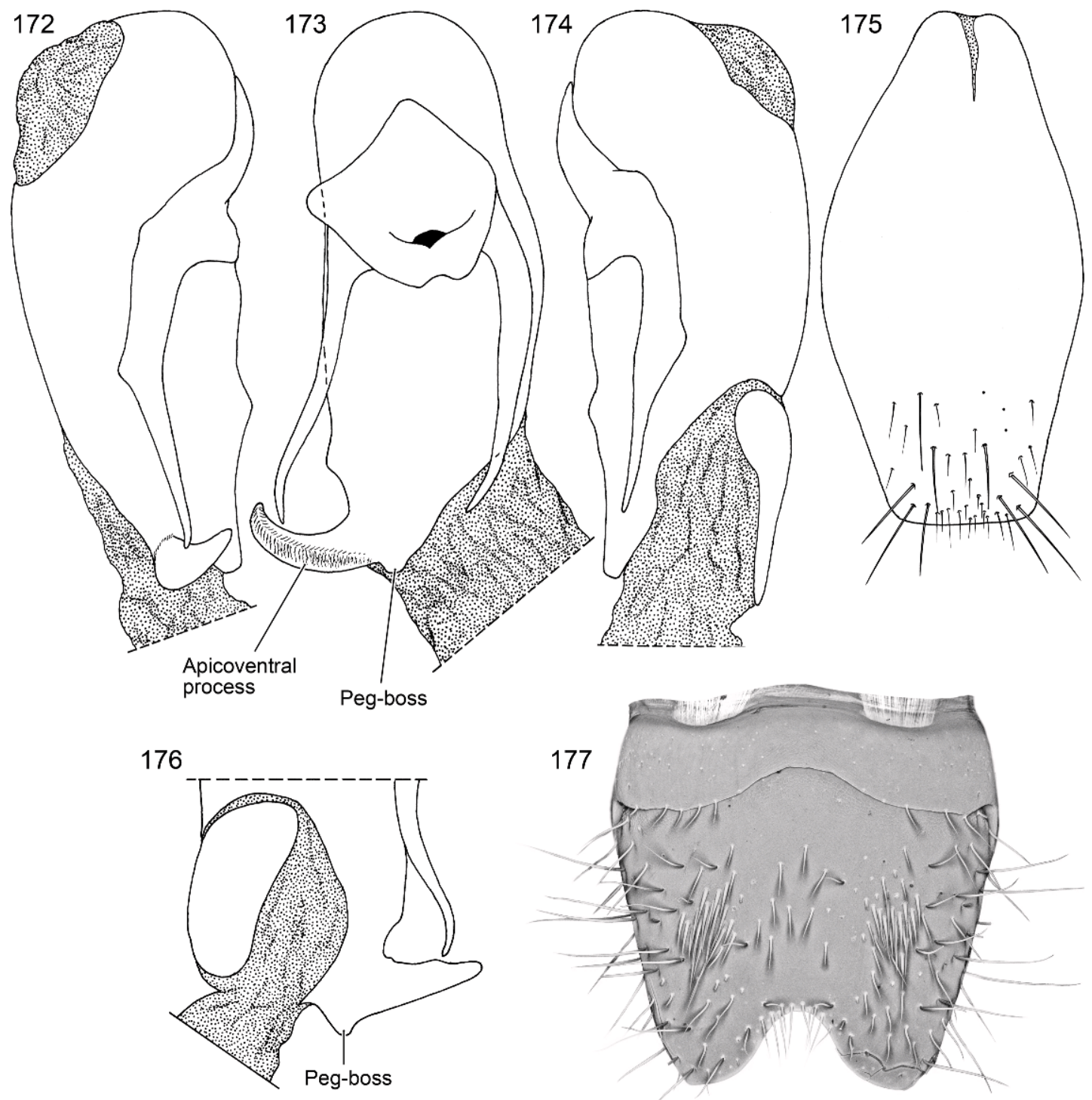

Figs. 172-177. Oedichirus misionesiensis. 172. Aedeagus, right lateral. 173. Aedeagus, ventral. 174. Aedeagus, left lateral. 175. Sternum IX, male. 176. Aedeagus, right dorsoposterior. 177. Sternum VIII, male.

of sternum VIII (fig. 177) and the rightwardly directed, stout apicoventral process of the aedeagus (figs. 172, 173).

DESCRIPTION: Length: $7.5 \mathrm{~mm}$. Length of head: $0.7 \mathrm{~mm}$. Width of head: $1.1 \mathrm{~mm}$. Pronotal length: $1.2 \mathrm{~mm}$. Pronotal width: $1.1 \mathrm{~mm}$. Elytral length: $0.8 \mathrm{~mm}$. Elytral width: $1.1 \mathrm{~mm}$.

Body black with scattered dark reddishbrown infusions. Legs yellowish brown, with pale reddish brown coxae; femorotibial joint without dark maculation.

Head about three fifths wider than long $(\mathrm{HW} / \mathrm{HL}=1.6)$. Frontoclypeal ridge incomplete with medial ends widely separated. Dorsal surface without V-shaped depression; punctation coarse, moderately dense, evenly distributed, but absent adjacent to frontoclypeal region and nuchal groove. Labrum 

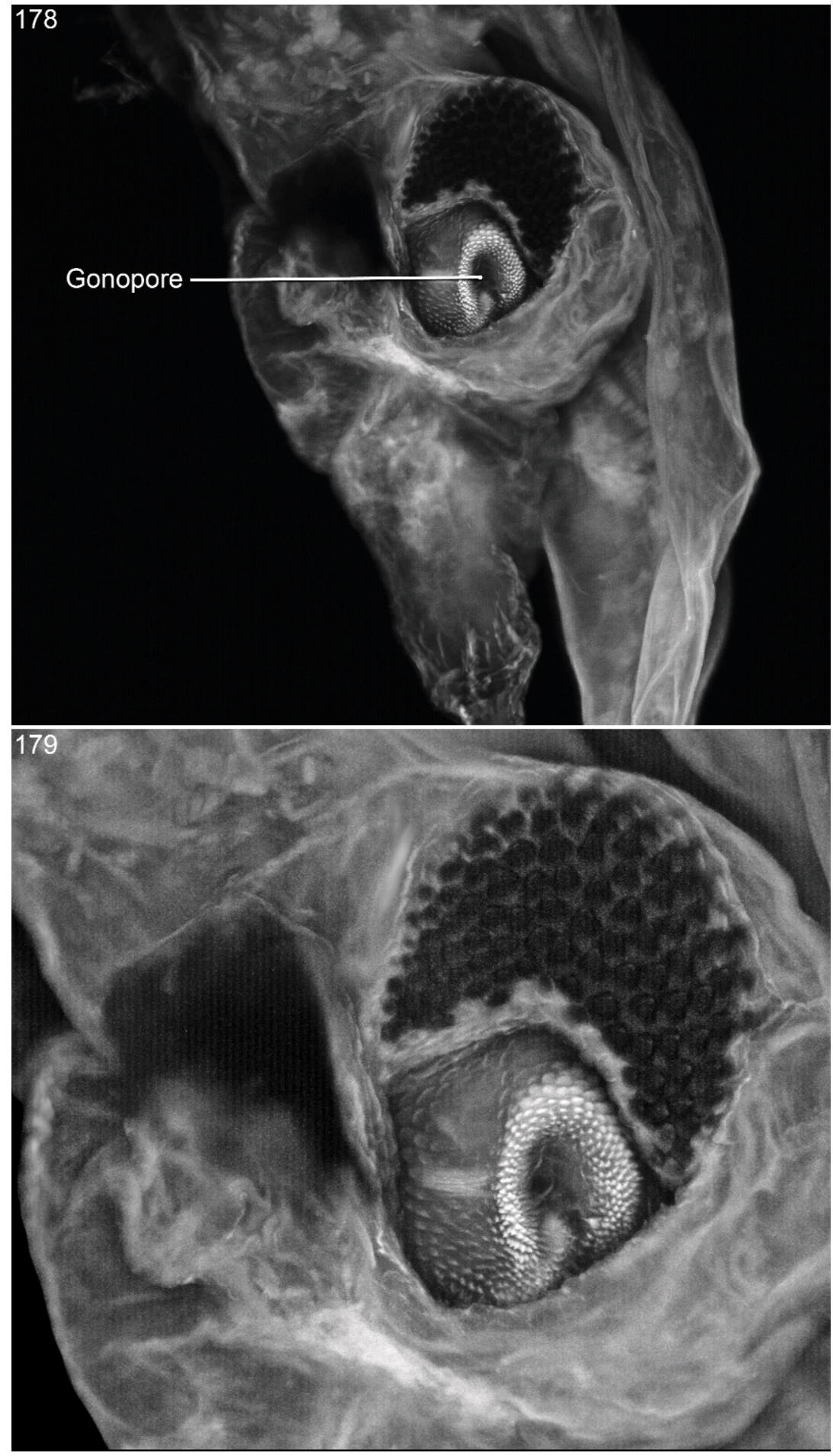

Figs. 178-179. Oedichirus misionesiensis. 178. Aedeagus, internal sac, everted (CLSM). 179. Aedeagus, internal sac, everted, enlarged (CLSM). 
quadridentate; surface without tubercle near submedial denticle.

Pronotum about a tenth longer than wide $(\mathrm{PL} / \mathrm{PW}=1.1)$. Pronotum polished with coarse, moderately dense punctation and with moderately large impunctate spots; submedial region with irregular cluster of punctures, but without distinct punctate groove. Elytra about two fifths wider than long $(E W / E L=1.4)$; surface slightly convex and coarsely punctate.

Abdominal terga III to VIII coarsely and densely punctate and without transverse rows. Segment III without paratergite; paratergal carina present, extending for about half of length of segment, and moderately well developed beyond spiracle. Tergum III without median point extending from transverse basal ridge. Tergum VIII with truncate posterior margin; transverse basal ridge broadly curved and without median point. Tergum IX with lateroapical process about one fifth longer than midbasal length of tergum $(\mathrm{LLaP} / \mathrm{L} 9=1.2)$, slightly bent ventrally, and slightly divergent from other process; ventromedial margin without posteriorly directed spur (cf. fig. 158).

MALE: Sterna VI and VII unmodified. Sternum VIII (fig. 177) with deep, wide, symmetrical emargination of posterior margin; emargination about one eighth of length of segment, wider than deep, and base broadly rounded; subapical surface not translucent and posterior margin not membranous; surface with broad, feeble, nearly flat depression extending from near base of emargination to transverse basal ridge; surface with feeble, polished swelling on lateroapical corner of median depression; median depression without distinct ridge on lateral side extending anteriorly from lateroapical corner, but lateral edge polished and slightly sloped; median depression with moderately dense punctation basally and impunctate apically; posterior end of depression beveled adjacent to emargination and with transverse row of closely spaced setae; surface laterad of median depression with shallow depression and with dense cluster of slender, spinelike setae just proximad of depression; surface distad of lateral depression with curved row of setate punctures; sternal surface without comb; transverse basal ridge with median portion broadly and strongly curved anteriorly and without median point. Tergum IX with moderately long, moderately wide process on anterior margin of anteroventral angle. Sternum IX (fig. 175) slightly asymmetrical; anterior margin moderately wide, slightly emarginate, and with median membranous notch; posterior margin nearly truncate; lateral margin broadly rounded.

Aedeagus asymmetrical (figs. 172-174). Ventral sclerite with apicoventral process extending laterally from right side of apical margin (fig. 173); apicoventral process moderately long, anteroposteriorly flattened, thick basally and strongly tapered to lateroanteriorly curved, acute apex; ventral sclerite with large, tapered, cylindrical, apically truncate peg-boss at base of left side of apicoventral process (figs. 173, 176), with small tumescence on right ventral side proximad of base of apicoventral process, and without spiniform process or pointed lobe on right dorsal margin dorsad of base of apicoventral process (fig. 172). Parameres long, tapered, moderately broad basally and slender apically and reaching to near posterior margin of ventral sclerite; base fused to median lobe, apical portion free of median lobe. Internal sac (figs. 178, 179) largely membranous; apical region with gonopore surrounded by short, apically acute and apically rounded cuticular processes (fig. 178); ventral side with dense cluster of short, apically round pegs lateroposteriad of and to right of gonopore (fig. 179); dorsal surface with short, robust, spinelike spur subapically.

Female: Unknown.

ETYMOLOGY: This, the first Argentine species of the genus, is named for Misiones province, from which it was collected.

DisTRIBUTION: Known only from the northeastern most province of Argentina, Misiones (fig. 40).

REMARKS: Oedichirus misionesiensis is the first species of the genus reported for Argentina. It is similar and related to $O$. apiculus, O. glabrihamus, and $O$. speculifrons, all found in southeastern Brazil at Nova Teutonia, about $350 \mathrm{~km}$ (by air) east of Puerto Iguazú, Argentina, which is near the type locality of $O$. misionesiensis. The Argentine species was collected in leaf litter at the base of a tree. Habitats for the three Brazilian species have not been reported. 
The internal sac of $O$. misionesiensis has three heavily sclerotized structures, none of which are well illustrated in the confocal images (fig. 178, 179). For the specimen of this species the structures simply did not fluoresce as well as homologous structures of other species.

\section{Oedichirus neotropicus Blackwelder} Figures 39, 180-185

Oedichirus neotropicus Blackwelder, 1944: 131 (replacement name).

Oedichirus pictipes Bierig, 1940: 604 (primary homonym of Oke, 1933).

Type Material: Two syntypes. Bierig cited two specimens, both from Costa Rica, one from Finca Castilla and the other from Hamburgfarm. A blue "Typus" label was affixed to the pin with the female from Hamburgfarm; however, there was no valid holotype designation because he did not indicate in the original description that either specimen was the "type" or holotype. Bierig (1940: 606) thought both specimens were females ["Ambos parecen ser hembras"']. To stabilize the name, the male rather than the female syntype is designated as lectotype because most of the species are based on the more consistently diagnostic males.

Lectotype: Designated here. Male. "Farm Castilla (Limón) VI.38. Costa Rica/Field Mus. Nat. Hist. 1966 A. Bierig Colln. Acc. Z-13812/ LECTOTYPE Oedichirus pictipes Bierig des. L. Herman 2011/Oedichirus neotropicus Blackwelder det. L. Herman." Deposited in the Field Museum of Natural History. (The right mesofemur, mesotibia, and mesotarsus are missing. The left elytron is separated from the body and glued to the card in front of the head.)

Paralectotype: One Female. Costa Rica: Hamburgfarm, Reventazon, Ebene Limon, Nevermann, 15.X. 27, welkem [sic] Blatt von Musa sapientum. Deposited in the Field Museum of Natural History. (Although the specimen has Bierig's "Typus" label, a holotype designation was not published [ICZN, 1999: Articles 73.1.1, 73.1.2, 73.2].)

Type Locality: Costa Rica: Limón: Finca Castilla $\left(10^{\circ} 14^{\prime} \mathrm{N}, 83^{\circ} 29^{\prime} \mathrm{W}, 15 \mathrm{~m}\right.$ elevation). (Finca Castilla is near Río Reventazón. The coordinates and elevation are from MoBot which associates the Finca with Parissmina, a coastal town about $16 \mathrm{~km}$ ENE.)

DiAgNosis: Oedichirus neotropicus can be separated from most other New World species by the bicolored body and legs. The body is reddish brown and abdominal segments VI and VII are black and the legs are bicolored yellowish brown and the femoral apex and tibial base are reddish brown to nearly black.

The males are easily distinguished from all other species in the New World by the small, subapical comb on the left side of sternum VIII and the nearly truncate, but feebly and broadly emarginate posterior margin of sternum VIII (fig. 184). The ventral sclerite of the aedeagus has a large, apical tumescence (fig. 180) and the parameres (figs. 180, 181) are short, slender apically, thornlike, and separated from the median lobe for most of their length. Only $O$. distortus, $O$. dominicanensis, $O$. neotropicus, and $O$. sinuosus have a subapical comb on sternum VIII. Among the preceding species three, $O$. dominicanensis, Oedichirus neotropicus, and O. sinuosus from the Dominican Republic, Costa Rica, and Mexico respectively, are three of the four most northerly known New World species; the fourth is $O$. isthmus from Mexico and is separated from the others by the median, subapical cluster of setae on sternum VIII (fig. 163) rather than a subapical comb. The posterior margin of sternum VIII of $O$. neotropicus is shallowly and broadly emarginate (fig. 184); O. dominicanensis (fig. 122) and O. sinuosus (fig. 203); each has a deep broad emargination. The comb of $O$. neotropicus (fig. 184) is nearly straight as is that of $O$. dominicanensis (fig. 122). The comb of O. sinuosus (fig. 203) is curved. In contrast to $O$. neotropicus with its short, nearly straight comb and posterior margin, the comb of $O$. distortus, from Ecuador, is strongly sinuate and extends nearly the entire subapical width of sternum VIII and the posterior margin is deeply and broadly emarginate (fig. 114).

The females are distinguished from those of other species by the liplike form of the juncture of the anterior and posterior vulvar lobes (fig. 185), the long fimbriae of the posterior edge of the honeycomblike cuticular cells of the posterior lobe and the scattered clusters of short cuticular processes on the wrinkled surface of the anterior lobe. The median gonocoxal plate anteriad of the vulvar plate is narrow, straplike, and separated from tergum IX (fig. 183), which distinguishes the females from all other species except $O$. batillus, $O$. distortus, $O$. 

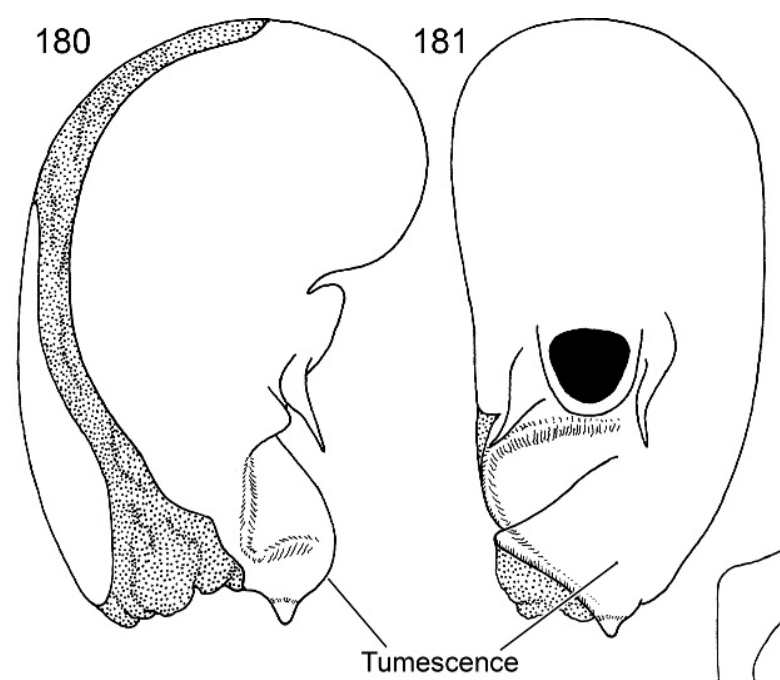

183
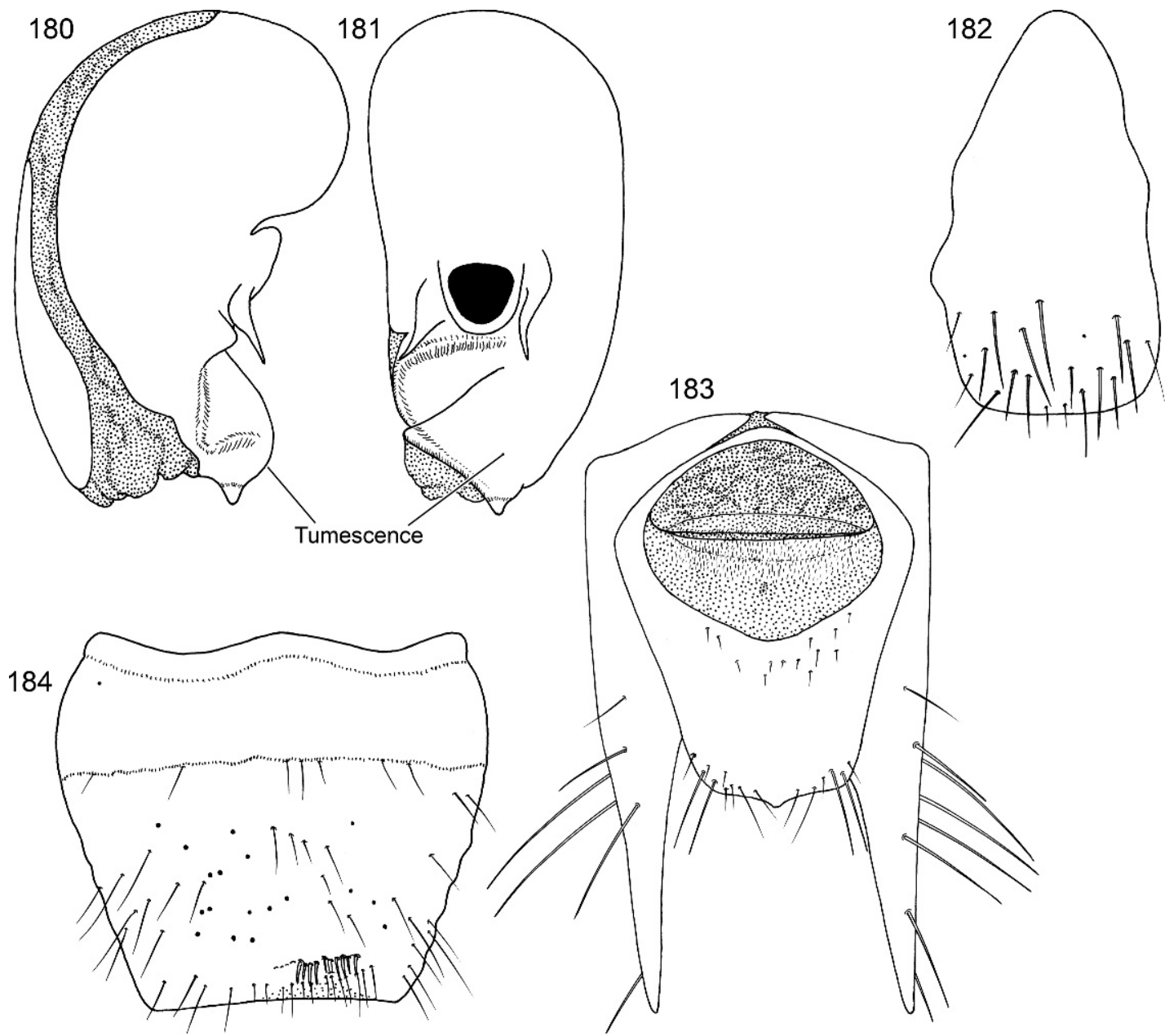

Figs. 180-184. Oedichirus neotropicus. 180. Aedeagus, right lateral. 181. Aedeagus, ventral. 182. Sternum IX, male. 183. Segment IX, ventral, female. 184. Sternum VIII, male, black dots mark missing setae, right side of comb missing.

hamatus, O. procerus, and $O$. speculifrons. The anteroventral angles of tergum IX of $O$. distortus (fig. 118) are fused to each other and to the anterior, straplike portion of the median gonocoxal plate, but are separated in O. neotropicus (fig. 185). Females are unknown for the two Mexican (O. isthmus, $O$. sinuosus) and one Caribbean $(O$. dominicanensis) species.

DESCRIPTION: Length: 8.4-11.3 $\mathrm{mm}$. Length of head: $0.8-1.0 \mathrm{~mm}$. Width of head: 1.0-1.2 mm. Pronotal length: $1.3-1.5 \mathrm{~mm}$. Pronotal width: $1.0-1.2 \mathrm{~mm}$. Elytral length: 1.2-1.4 mm. Elytral width: $1.1-1.4 \mathrm{~mm}$.
Body bicolored, reddish brown and black. Head, pronotum, elytra, segments III-V, VIII, and IX reddish brown and with or without darker infusions, segment VI black, VII black and with or without infusions of reddish brown. Legs bicolored, pale reddish to yellowish brown with femorotibial spot reddish brown to dark reddish brown to nearly black.

Head wider than long (HW/HL: 1.2-1.3). Frontoclypeal ridge incomplete, separated medially. Dorsal surface without V-shaped depression; surface coarsely and densely punctate medially, sparsely punctate anteriorly, and 


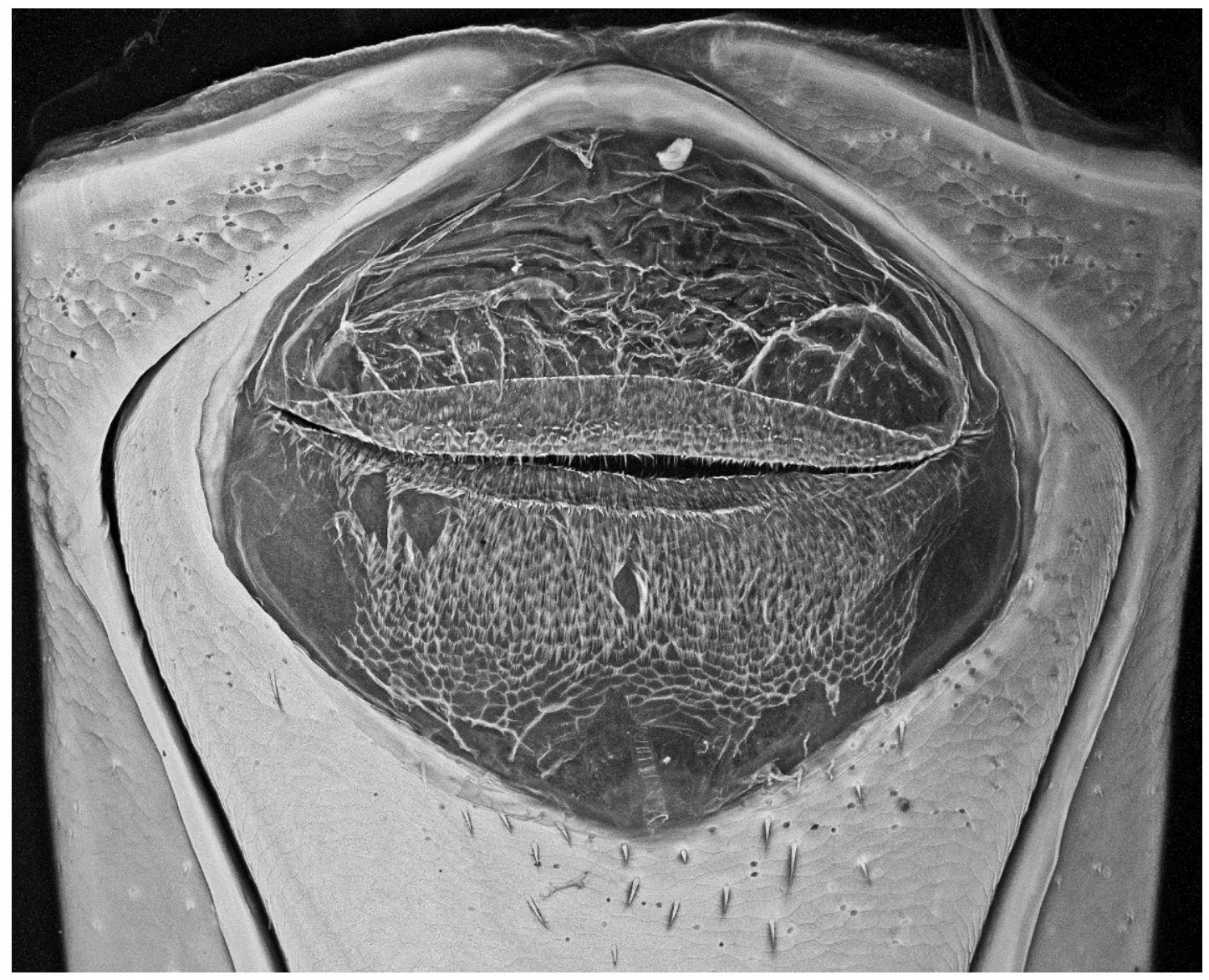

Fig. 185. Oedichirus neotropicus. Segment IX, vulvar plate, enlarged (CLSM).

impunctate and polished basally. Labrum quadridentate; surface without tubercle near submedial denticle.

Pronotum longer than wide (PL/PW: 1.21.3). Pronotum polished and with coarse, moderately dense punctation; surface with deep, curved, submedial, coarsely punctate row on most of basal two thirds. Elytra with width equal to or slightly greater than length (EW/EL: 0.96-1.0); surface of disc weakly concave and coarsely punctate.

Abdominal segments III to VI coarsely punctate; segments III to VI with transverse, erratically and poorly developed subapical row of punctures. Segment III without paratergite; paratergal carina present and extending to more than half of length of segment, but more poorly developed beyond spiracle. Tergum III without median point extending from transverse basal ridge. Tergum VIII with posterior margin broadly emarginate; emargination extending from one lateroapical angle to other; transverse basal ridge evenly and shallowly curved, weakly sinuate, and without median point. Tergum IX with lateroapical process less than twice as long as midbasal length (LLaP/ L9: 1.5-1.7), slightly bent ventrally, and approximately parallel to other process; ventromedial margin without posteriorly directed spur (cf. fig. 158).

MALE: Sterna VI and VII unmodified. Sternum VIII (fig. 184) with posterior margin broadly and shallowly emarginate; emargination slightly asymmetrical; surface with posteriorly directed, subapical comb on left side and extending slightly to right of midline; surface immediately anteriad of 
comb slightly tumid; subapical surface posteriad of comb membranous; surface without depressions. Tergum IX with moderately large process extending from anterior margin of anteroventral angle. Sternum IX (fig. 182) moderately asymmetrical and moderately strongly tapered anteriad; anterior margin narrow and moderately strongly rounded; posterior margin broadly and slightly rounded; lateral margins irregular for most of length.

Aedeagus asymmetrical (fig. 181). Ventral sclerite with large, irregularly shaped, apically pointed tumescence on left side of apical quarter (figs. 180, 181); posterior margin without apicoventral process. Parameres short, broad basally, slender apically, and separated from median lobe for most of length.

FEMALE: Tergum IX with anteroventral angles separated, but nearly touching (fig. 183). Median gonocoxal plate anteriad of vulvar plate reduced to narrow strap with anterior margin moderately rounded and more strongly rounded medially (figs. 183, 185); gonocoxal plate posteriad of vulvar plate tapered posteriorly to broadly rounded posterior margin (fig. 183) and posterior margin with or without small median lobe. Vulvar plate large and embedded medially and subbasally in gonocoxal plate. Vulvar lobes with adjacent edges with liplike appearance (fig. 183). Anterior vulvar lobe (fig. 185) transverse and surface wrinkled and with small, scattered clusters of short cuticular processes. Posterior vulvar lobe (fig. 185) transverse with lateral region curved anteriorly; surface with honeycomblike cuticular cells; posterior margin of cuticular cells fimbriate; fimbriae longer and denser anteriorly than posteriorly. Vulva with indeterminate orientation.

MATERial EXAmined: Two males, 4 females. Costa Rica: Heredia: La Selva Biological Station nr. Puerto Viejo de Sarapique, February 18, 1985, L. Herman, from debris at node of palm frond (1 male, AMNH), beating trees and shrubs ( 1 female, AMNH). Limón: Farm Castilla, VI-38 (lectotype, male, FMNH); Limón: Hamburgfarm (Río) Reventazón, Ebene Limón, X-15-1927, welkem [sic] Blatt von Musa sapientum (paralectotype, female, FMNH). Puntarenas: Monteverde, 4500 ft., 21-26.V.1979, J.M. \&
B.A. Campbell (1 female, CNC). Nicaragua (?): (intercepted at port of entry) USA: Alabama: Mobile, II-9-1932, J.R. Wood, Mob\#539 (1 female, USNM) (see Remarks below).

LOCAlities: Finca Castilla (See Type Locality above).

Hamburgfarm was described by Nevermann (1931: 186), who collected the paralectotype, as being at $20-25 \mathrm{~m}$ above sea level on Río Reventazón about $20 \mathrm{~km}$ north of Siquirres and about $12 \mathrm{~km}$ from the Atlantic. MoBot lists a Finca Hamburg at $10^{\circ} 15^{\prime} \mathrm{N}$, $83^{\circ} 28^{\prime} \mathrm{W}$ and $21 \mathrm{~m}$ elevation. This site is about $17.6 \mathrm{~km}$ from Siquirres, $14 \mathrm{~km}$ from the seacoast, and about $2 \mathrm{~km} \mathrm{SW}$ of Finca Castilla. The geograpical coordinates for the site listed by MoBot approximately fit the description of the locality given by Nevermann.

La Selva Biological Station is at the north base of Volcán Barva at the confluence of Río Sarapiquí and Río Puerto Viejo, $10^{\circ} 26^{\prime} \mathrm{N}$, $84^{\circ} 02^{\prime} \mathrm{W}$ (from MoBot).

Monteverde is a biological reserve straddling the border of Alajuela and Puntarena provinces. The approximate coordinates are $10^{\circ} 18^{\prime} \mathrm{N}, 84^{\circ} 48^{\prime} \mathrm{W}$ (from MoBot).

Distribution: The species is known from Costa Rica and possibly Nicaragua (fig. 39). It has been found at four localities in three Costa Rican provinces at sites on both the Atlantic and Pacific sides of the continental divide. Two of the four Costa Rican localities are farms that may or may not still exist. A Nicaraguan record is based on an interception at a port of entry in Mobile, Alabama, of a specimen in a shipment said to be from Nicaragua.

HABITAT: Bierig (1940: 606) reported that one specimen, the female paralectotype, was collected from dried leaves of a species of banana (cited by Bierig as Musa sapientum Linnaeus and currently named Musa paradisiaca Linnaeus) and the other, the male lectotype, from dense, riparian foliage in Limón Province, Costa Rica, at 20-25 m elevation. Two specimens were collected at La Selva in Heredia, Costa Rica, one by beating shrubbery, the other from the node of a palm frond. At another site the species was collected at about $1360 \mathrm{~m}$ elevation, but no habitat data was provided. 
REMARKS: The Nicaraguan citation is based on a single female taken at a port of entry in Alabama, and said to be from Nicaragua. The record must be confirmed by discovery in Nicaragua of additional specimens, particularly males. The intercepted specimen is consistent with the paralectotype of $O$. neotropicus; although slightly more robust, it shares the same bicolored pattern of the body and legs with those from Costa Rica along with the condition of the anteroventral angles of tergum IX, the liplike configuration at the juncture of the vulvar lobes, and the long fimbriae on the posterior vulvar lobe.

\section{Oedichirus ohausi Wendeler}

Figures 40, 186-187

Oedichirus ohausi Wendeler, 1930: 185.

- Scheerpeltz, 1933: 1218 (catalog). — Blackwelder, 1944: 131 (checklist).

Type Material: One Syntype. The Wendeler collection in the Museum für Naturkunde, Berlin, includes only one specimen of the species. The locality data on the label are the same as those published by Wendeler and his identification label is attached to the specimen. Although a red "Holotype" label is one of four attached to the specimen, the holotype designation was not published nor did Wendeler state or imply that he had studied only one specimen, so the specimen is a syntype. To stabilize the name a lectotype is hereby designated.

Lectotype: Designated here. Female. "Brasilien Sao Paulo, Bosque de Saude, 19. X. 26 Dr. Fr. Ohaus, S./Ganz isolierte kleine Waldinseln im Kamp/Oedichirus ohausi n.sp. Wendeler det./ Holotypus/Lectotype Oedichirus ohausi Wendeler des. L. Herman, 2011." Deposited in the Museum für Naturkunde, Berlin. (Antennomeres $3-11$ of both antennae, both mesotarsi, the right metatarsus, and the left metatarsomere 5 are missing. The head and prothorax are separated from the pterothorax and abdomen, but are glued to the card).

Type Locality: Brazil: São Paulo: Bosque de[da] Saude $\left(23^{\circ} 37^{\prime} \mathrm{S}, 46^{\circ} 37^{\prime} \mathrm{W}\right)$. (The coordinates and other information for this locality were supplied by Angelico Asenjo [personal commun.] at the Universidade Federal do Paraná, Curitiba, Brazil, who wrote that Bosque da Saude was a large park with many trees in the center of the city of São Paulo and was well-known to collectors in the early years of the 20th century. The remains of that large park now are a small garden known as "Jardim da Saude." Prior to corresponding with Angelica Asenjo and searching only "Saude" using Google Earth, Avenida Bosque da Saude was found in São Paulo city; the end point coordinates of the avenue are about: $23^{\circ} 37^{\prime} \mathrm{S}, 46^{\circ} 38^{\prime}$ and $23^{\circ} 37^{\prime}, 46^{\circ} 37^{\prime}$, so it appears that the avenue traverses what was formerly the Bosque da Saude. I also found a Bosque da Saude $\left(22^{\circ} 44^{\prime} \mathrm{S}, 47^{\circ} 19^{\prime} \mathrm{W}\right)$ in the state of São Paulo within the city of Americana near a small park, about $113 \mathrm{~km}$ NNW of São Paulo city.)

Diagnosis: The species is known only from the female holotype. The anteroventral angles of tergum IX of the female are fused to form a strap or bridge that covers the narrow anterior edge of the median gonocoxal plate the median portion of which is joined to the fused anteroventral angles of IX (figs. 186, 187). The right side of the anterior vulvar lobe is sclerotized (figs. 186, 187). The elytral length is about a tenth greater than the width.

Among the species with known females, the anteroventral angles of tergum IX are fused for only $O$. ohausi, $O$. dilophus (fig. 108), O. distortus (fig. 116), O. lunatus (fig. 169), and O. procerus (fig. 197), but the partially sclerotized anterior vulvar lobe of O. ohausi (figs. 186, 187) will separate it from the others. Furthermore, among these five species, the elytra disc of $O$. ohausi and $O$. procerus is concave; the disc of the others is flat to convex. The median gonocoxal plate is present anterior to the vulvar plate for $O$. ohausi (figs. 186, 187), but absent anteriorly in $O$. dilophus (fig. 108). The lobes of the vulvar plate for each of the other four species differ significantly from those of $O$. ohausi (cf. fig. 187 to figs. 110, 118, 171, and 198).

DESCRIPTION: Length: $7.2 \mathrm{~mm}$. Length of head: $0.9 \mathrm{~mm}$. Width of head: $1.0 \mathrm{~mm}$. Pronotal length: $1.3 \mathrm{~mm}$. Pronotal width: $1.0 \mathrm{~mm}$. Elytral length: $1.1 \mathrm{~mm}$. Elytral width: $1.0 \mathrm{~mm}$.

Body concolorous black. Legs concolorous yellowish brown.

Head wider than long (HW/HL: 1.1). Frontoclypeal ridge short, incomplete, and separated medially. Dorsal surface without V-shaped depression; surface polished and with coarse, dense punctation middorsally and more sparsely punctate anteriorly and posteriorly. Labrum quadridentate; surface without tubercle near submedial denticle. 

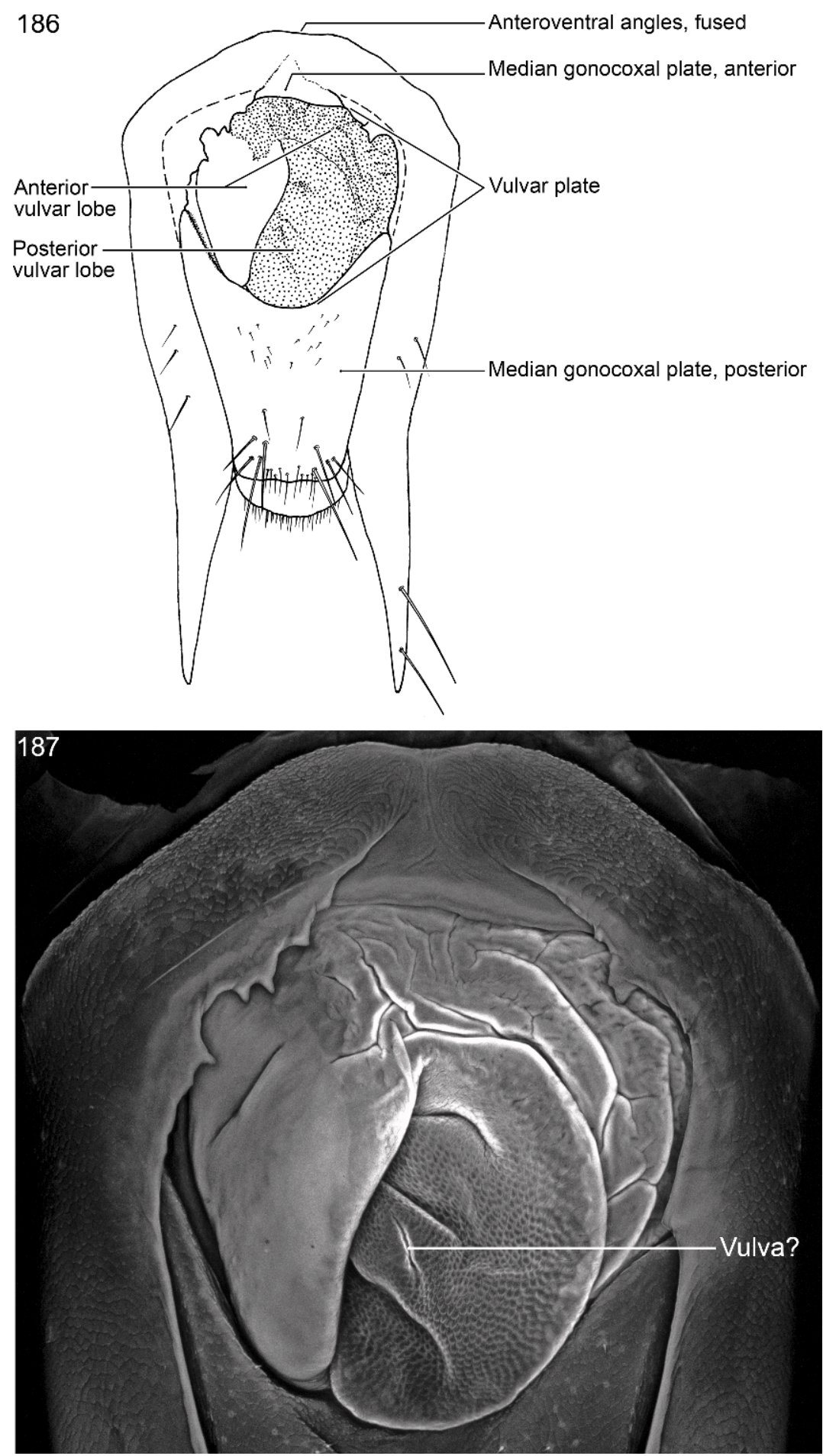

Figs. 186-187. Oedichirus ohausi. 186. Segment IX, ventral, female. 187. Segment IX, ventral, vulvar plate, enlarged (CLSM). 
Pronotum longer than wide (PL/PW: 1.3). Pronotal surface with scattered polished, impunctate spots and with coarse punctation arranged in scattered clusters and irregular rows; submedial punctate groove extending posteriorly from near middle. Elytra length and width subequal, length slightly greater than width (EW/EL: 1.0); surface of disc broadly concave and with coarse punctation.

Abdomen irregularly punctate, punctures not arranged in transverse rows. Segment III without paratergite; paratergal carina present for most of length of segment; lateral surface with shallow groove extending from apex of paratergal carina to posterior margin of segment. Tergum III without median point extending from transverse basal ridge. Tergum VIII with broadly rounded posterior margin; transverse basal ridge irregularly sinuate, slightly curved anteriorly, and without median point. Tergum IX with lateroapical process one and a half times as long as midbasal length of tergum (LLaP/L9 = 1.5), slightly bent ventrally, and approximately parallel to other process; ventromedial margin without posteriorly directed spur (cf. fig. 158).

MALE: Unknown.

Female: Tergum IX with anteroventral angles fused medially (fig. 186). Median gonocoxal plate anteriad of vulvar plate reduced to narrow strap and fused anteromedially to tergum IX (fig. 186); gonocoxal plate posteriad of vulvar plate large and gradually tapered to sinuate posterior margin (fig. 186). Vulvar plate embedded in basal half of gonocoxal plate. Anterior vulvar lobe embracing anterior and both lateral sides of posterior vulvar lobe; right side lightly sclerotized, smooth and unadorned; remainder of surface wrinkled, but otherwise unadorned (fig. 187). Posterior vulvar lobe with cobbled surface and with a few folds (fig. 187). Vulva of indeterminant orientation.

DisTRIBUTION: Known only from the state of São Paulo, Brazil (fig. 40).

REMARKS: The species was collected in a small, isolated forest-island in October (Wendeler, 1930: 186).

Abdominal segment III of $O$. ohausi apparently has a paratergal carina in place of a paratergite, but as only one specimen is available it is difficult to be certain which of the two structures it is because the abdomen cannot be removed and segment III cleared. The structure on the lateral side of III is larger and longer than the paratergal carina is for other species and although there may be a suture on the inner base of the ridge that separates it from the tergum there is no suture visible on the outer edge of the ridge that separates it from the sternum. The ridge tapers as it extends posteriorly toward the posterior margin of the segment. The structure is interpreted as a paratergal carina because it is short of the posterior margin of the segment and, apparently, is fused to the tergum and sternum.

However, if the structure interpreted here as a paratergal carina is paratergite III, then $O$. ohausi can be separated from $O$. batillus, $O$. bicristatus, $O$. hamatus, $O$. isthmus, $O$. optatus, and $O$. sinuous, which also have paratergite III as follows. Among the seven species, only $O$. ohausi has a concave elytra surface, but the elytral disc of $O$. hamatus is slightly concave and the bicolored legs of $O$. hamatus will separate it from $O$. ohausi, which lacks the dark femorotibial maculations.

The position of the vulva is indeterminant. It may be in a short diagonal fold on the right side of the posterior vulvar lobe (fig. 187, "vulva(?)"), but I was unable to find a spermathecal duct leading to it or to any other spot on the posterior vulvar lobe.

\section{Oedichirus optatus Sharp Figures 40, 188-196}

Oedichirus optatus Sharp, 1876: 339.

- Bernhauer and Schubert, 1912: 201 (catalog). - Blackwelder, 1944: 131 (checklist).

Type Material: Three syntypes: One male, two females, all from Tapajos. Sharp (1876: 339340) stated the species was represented by a male and two females, but did not designate a type. To stabilize the name a lectotype is designated.

LeCtOTYPE: Designated here. Male. "Type/Tapajos/Sharp Coll. 1905-313/Oedichirus optatus के Type D.S./LECTOTYPE Oedichirus optatus Shp. des. L. Herman, 2011.” Deposited in the Museum of Natural History, London. (The specimen is mounted between two rectangles of clear plastic and glued to a transverse strip across the opening of a card with the center removed. The specimen was dissected by someone, perhaps 


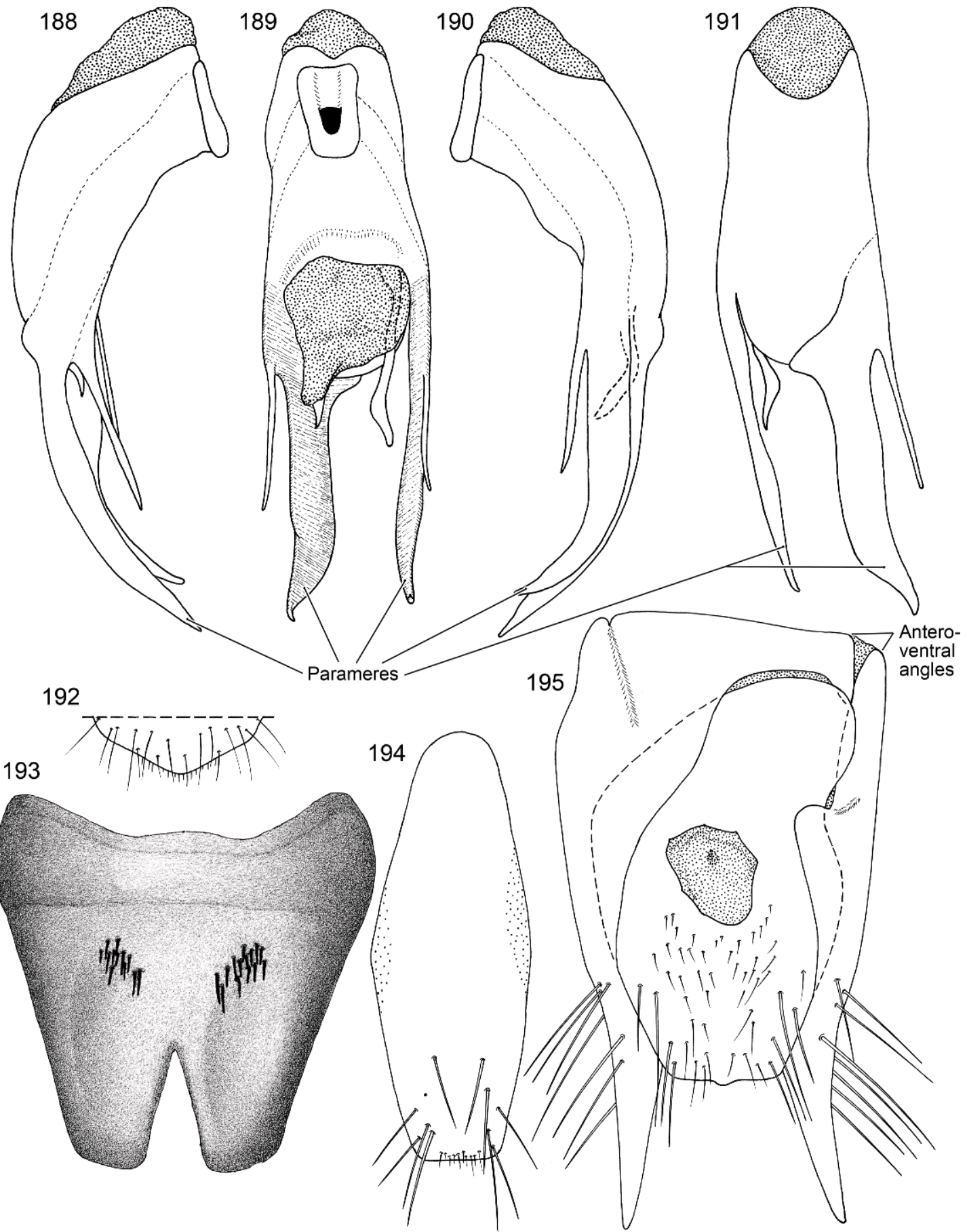

Figs. 188-195. Oedichirus optatus. 188. Aedeagus, right lateral. 189. Aedeagus, ventral. 190. Aedeagus, left lateral. 191. Aedeagus, dorsal. 192. Tergum VIII, apical margin, female. 193. Sternum VIII, setae removed except those near depression, male. 194. Sternum IX, male. 195. Segment IX, ventral, female. 


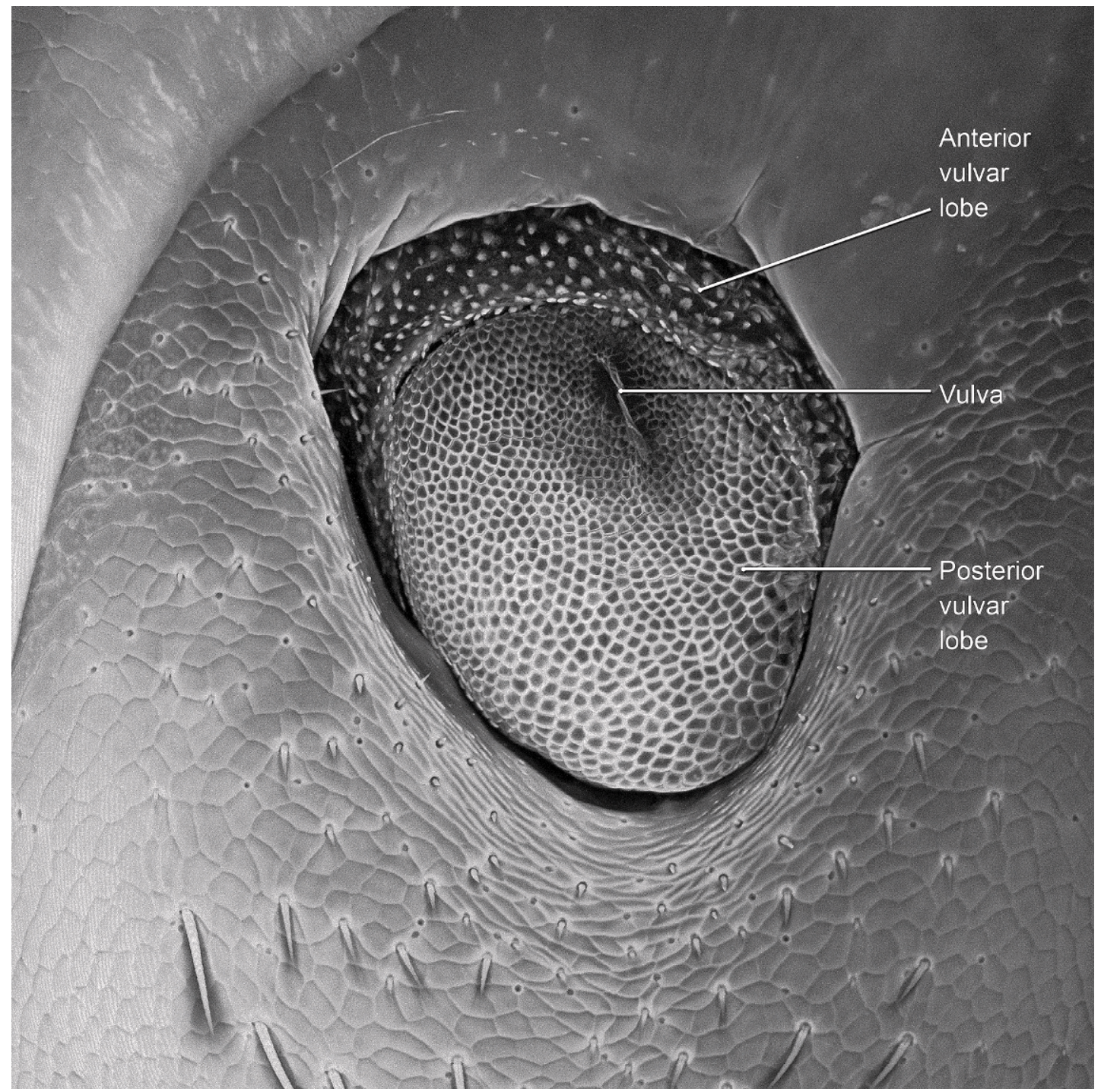

Fig. 196. Oedichirus optatus. Segment IX, vulvar plate, enlarged (CLSM).

Sharp, prior to my examination; segments IX/X and the aedeagus are glued to the left of the specimen and segment VIII to the right. The aedeagus is damaged; the basal half is collapsed and the apical third of the right paramere is missing. The right side of the pterothorax and right elytron has a pin hole. The specimen is pale reddish brown, not fully pigmented, and perhaps slightly teneral. For the present study, the lectotype was not removed from the card.)

Paralectotypes: Two females. Paralectotype 1: Same labels in same order as lectotype; bottom label differs as: "Oedichirus optatus of Type D.S." The specimen is undissected and mounted in the same manner as the lectotype. Paralectotype 2: "Cotype/Tapajos/Sharp Coll. 1905-313/ 187/Oedichirus optatus Indtype D.S." The second paralectotype is mounted on a card, is not covered by plastic rectangles, and was not dissected. Both specimens bear my printed paralectotype label.

Type Locality: Brazil: Pará: Tapajos $\left(2^{\circ} 26^{\prime}-\right.$ $3^{\circ} 43^{\prime} \mathrm{S}, 54^{\circ} 41^{\prime}-55^{\circ} 24^{\prime} \mathrm{W}$ ). (See Localities below for a discussion of the type locality).

Diagnosis: Externally Oedichirus optatus is separated from all other New World species by the presence of six labral denticles. 
However, since the second denticle, the one between the sublateral and submedial ones, is small to obsolete and might be overlooked, the character is marginally useful. The species is one of six (see also $O$. batillus, $O$. bicristatus, O. hamatus, O. isthmus, O. sinuosus) with paratergite III. The males of $O$. optatus differ from the five aforementioned species and all others by the deep, narrow emargination of sternum VIII (fig. 193), the form of the aedeagus (figs. 188-191), and the long, broad, flattened parameres, each of which has a long slender process arising from near the middle of the ventral edge. Sternum VIII of the males has a broad depression adjacent to the median emargination and the depression has a patch of short, coarse setae anteriorly (fig. 193).

Uniquely among the females of the New World species, the median gonocoxal plate of O. optatus is strongly asymmetrical (fig. 195). The vulvar plate is embedded near the middle of the gonocoxal plate. The anterior vulvar lobe is covered with short, stout cuticular processes and embraces the anterior and lateral sides of the posterior lobe (fig. 196). The posterior vulvar lobe, with its form and cobbled surface, is strawberrylike (fig. 196). For tergum IX the right anteroventral angle extends across to meet the left side for which the anteroventral angle is absent (fig. 195). The posterior margin of sternum VIII of females has a broad, rounded, median lobe (fig. 192).

DESCRIPTION: Length: $8.0-10.3 \mathrm{~mm}$. Length of head: $0.8 \mathrm{~mm}$. Width of head: 1.1-1.2 mm. Pronotal length: 1.4-1.5 mm. Pronotal width: $1.1-1.2 \mathrm{~mm}$. Elytral length: $1.1-1.3 \mathrm{~mm}$. Elytral width: $1.2-1.3 \mathrm{~mm}$.

Body concolorous, pale reddish brown (teneral specimens) to dark reddish brown to black, some specimens with paler reddishbrown infusions. Legs reddish brown with slightly darker infusion at femorotibial joint in paler specimens; tibiae paler reddish brown, yellowish brown in more teneral specimens.

Head wider than long (HW/HL: 1.3-1.4). Frontoclypeal ridge incomplete, separated medially. Dorsal surface without V-shaped depression; surface coarsely and moderately densely punctate laterally to base and medially; basal region impunctate medially. Labrum with six denticles; second pair smaller than sublateral or submedial pairs and obsolete in some specimens, particularly females; surface without tubercle near submedial denticle.

Pronotum longer than wide (PL/PW: 1.21.3). Pronotum polished and with coarse, moderately dense punctation; surface with prominent, coarsely punctate, submedial groove on basal half. Elytra with length equal to width to about one tenth shorter than wide (EW/EL: 1.0-1.1); surface flat to slightly convex and coarsely punctate.

Abdomen irregularly and densely punctate; punctures not arranged in rows on most of surface. Segment III with long, narrow, triangular paratergite extending entire length of segment. Tergum III without median point extending from transverse basal ridge. Tergum VIII with posterior margin truncate to broadly and shallowly rounded; transverse basal ridge irregularly sinuate, slightly curved anteriorly, and without median point. Tergum IX with lateroapical process about one tenth to a third longer than midbasal length (LLaP/L9 = 1.1-1.3), slightly bent ventrally, and approximately parallel to other process; ventromedial margin without posteriorly directed spur (cf. fig. 158).

MALE: Sternum VI unmodified. Sternum VII with slight, shallow, elliptical, median depression near posterior margin. Sternum VIII (fig. 193) with symmetrical, narrow, deep emargination of posterior margin; emargination more than a third to two fifths as long as segment and deeper than wide, base narrowly rounded, margins of apical third slightly less convergent than more strongly convergent basal two thirds; margins of emargination beveled; posterior margin without membranous marginal strip; surface with deep, oval depression laterad of basal half of emargination; depression deep basally and gradually shallower apically; depression without punctation or pubescence, but surface with cluster of setae adjacent to medial and basal margins of depression; surface without comb of setae; transverse basal ridge broadly and shallowly sinuate and irregularly submacrosinuate. Tergum IX with large process extending from anterior margin of anteroventral angle. Sternum IX (fig. 194) slightly asymmetrical; anterior margin moderately wide and strongly rounded; posterior margin nearly trunctate; lateral margins rounded. 
Aedeagus asymmetrical (figs. 188-191). Ventral sclerite with small tumescence to left of midsagittal line and proximad of posterior margin, with shallow depression on right side of tumescence, and without apicoventral process or other prominent lobes or processes. Parameres long, flattened, prominent, and tapered apically; basal third or half fused to median lobe almost indistinguishable (figs. 188, 190); apical half to two thirds free of median lobe and extending far beyond posterior margin of median lobe; parameres each with long, slender process extending posteriorly from about middle of ventral edge (figs. 188, 190); right paramere moderately longer than left; parameres asymmetrical and of differing form. Internal sac with one spinelike process and long, slender, subapically bent and sinuate process (figs. 189-191).

FEMALE: Sternum VIII with broad, rounded lobe on posterior margin (fig. 192). Tergum IX (fig. 195) with anteroventral angles strongly asymmetrical and touching, but not fused; angle of right side broad, long, apically hooked, and extending across width of segment to meet angle of left side of segment; carina present on right angle near right lateral margin; angle of left side absent and not extending toward middle; left ventromedial margin of tergum IX with large lobe proximad of middle and extending toward vulvar plate. Median gonocoxal plate strongly asymmetrical (fig. 195); gonocoxal plate anteriad of vulvar plate nearly as large as gonocoxal plate posteriad of vulvar plate; anterior margin of gonocoxal plate broadly rounded and at diagonal to midsagittal line; left margin strongly rounded and lobiform; gonocoxal plate posteriad of vulvar plate with gradually tapered to slightly rounded posterior margin. Vulvar plate (fig. 196) embedded in gonocoxal plate near middle. Anterior vulvar lobe narrow and embracing anterior margin and about half of lateral margin of posterior vulvar lobe; surface with short, stout cuticular processes. Posterior vulvar lobe large, rounded, "strawberrylike," and covered with cobble. Vulva diagonally oriented.

Material EXAmined: Ten males, 4 females, 1 damaged specimen of unknown sex. Brazil: Pará: Tapajos (1 male lectotype, 2 females paralectotypes, BMNH); Pará: Caninde, Rio Gurupi $\left(2^{\circ} 34^{\prime} \mathrm{S}, 46^{\circ} 31^{\prime} \mathrm{W}\right)$, IV/7-
15/1963, leg. B. Malkin, forest sweep (1 male, FMNH), II/27-28/1966, leg. B. Malkin (1 male, FMNH); Pará: Fazenda Pirelli $\left(01^{\circ} 25^{\prime} \mathrm{S}, 48^{\circ} 18^{\prime} \mathrm{W}\right.$; coordinate courtesy of A. Asenjo), Belem, III-30-31-1970, J.M. Campbell \& B.A. Campbell (1 male, 1 female, CNC). Maranhão (not Pará): Aldeia Aracu, Igarape, Gurupu-Umu, Maranhao, $50 \mathrm{~km} \mathrm{E}$ of Caninde $\left(2^{\circ} 34^{\prime} \mathrm{S}, 46^{\circ} 02^{\prime} \mathrm{W}\right)$, leg. B. Malkin, forest sweep, V-1963 (2 males, FMNH). Mato Grosso: Barra do Tapirape, 17/I-2/II/1964, FMHD \#64-3002, sweeping forest, night, B. Malkin (1 male, FMNH), I/ 4-11, 1963, FMHD \#63-3001, beating rain forest at night, B. Malkin (1 specimen (apical segments of abdomen missing), FMNH); Mato Grosso: Barrado [sic] Tapirape, XII/ 25/62, leg. B. Malkin (2 males, FMNH); Mato Grosso: Tapirape Indian village at confluence of R. Tapirape and R. Araguaia $\left(10^{\circ} 28^{\prime} \mathrm{S}, 50^{\circ} 25^{\prime} \mathrm{W}\right)$, Nov. 11-20, 1960, leg. B. Malkin (1 male [head and prothorax missing], 1 female, FMNH), Dec. 26-31, 1960 (1 female, FMNH).

LocAlities: The syntypes of $O$. optatus were collected by H.W. Bates from Tapajós, a river the mouth of which is near Santarém, Pará at about $2^{\circ} 26^{\prime} \mathrm{S}, 54^{\circ} 41^{\prime} \mathrm{W}$ (from Google Earth). Bates headquartered at Santarém for three and a half years. After living there for six months he left on June 8, 1852, on a fourmonth expedition up Rio Tapajós to Rio Cupari (at about $3^{\circ} 43^{\prime} \mathrm{S}, 55^{\circ} 24^{\prime} \mathrm{W}$ ) (from Google Earth), where he then travelled 30 to 40 miles upriver to a village of the Mundurucus (Bates, 1863: 71-152). Since the locality label gives no further information than "Tapajos" O. optatus could have been collected anywhere along the river, but perhaps not near a town or village since Bates includes no such information on the label, so herein the coordinates for "Tapajós" bracket his journey up the river $\left(2^{\circ} 26^{\prime}-3^{\circ} 43^{\prime} \mathrm{S}, 54^{\circ} 41^{\prime}-\right.$ $\left.55^{\circ} 24^{\prime} \mathrm{W}\right)$ to the mouth of the Cupari.

Other specimens were collected from Caninde near Rio Gurupi and from $50 \mathrm{~km}$ east of Caninde. The specimens were collected at both sites by the same person only two weeks apart, and one of the samples includes the name of the river. Although the locality label for specimens collected $50 \mathrm{~km}$ east of Caninde reads as though they were collected in Pará, Rio Gurupi is the border 
between Pará and Maranhão, so east of the river is in the latter state and that name is included on the label. The label for the specimen of $O$. optatus collected $50 \mathrm{~km}$ east of Caninde does not include Rio Gurupi, but Oliveira (2006: 123) reported a euglossine bee, Eulaema pseudocingulata Oliviera, collected by the same collector, Borys Malkin, with the label data: "Aldeia Yararuhu (Aracu), Igarape Gurupi-Una, Rio Gurupi." However, the locality information as published for the bee is incomplete. The specimens on which Oliveira's citation is based are deposited in the American Museum and the locality label also includes "Maranhao, about $50 \mathrm{~km}$ E Caninde," so despite the differences in the label for the paederine and the published data for the euglossine, the specimens were collected at the same locality. Caninde near Rio Gurupi is at $2^{\circ} 34^{\prime} \mathrm{S}$, $46^{\circ} 31^{\prime} \mathrm{W}$ and $50 \mathrm{~km}$ east (by air) of Caninde is at about $2^{\circ} 34^{\prime} \mathrm{S}, 46^{\circ} 02^{\prime} \mathrm{W}$; the latter site is in Maranhão state, not Pará.

All of the collecting sites in Mato Grosso are associated with Rio Tapirape. One site, a Tapirape Indian village at the confluence of Rio Tapirape and Rio Araguaia, is at $10^{\circ} 28^{\prime} \mathrm{S}, 50^{\circ} 25^{\prime} \mathrm{W}$. Santa Terezinha is now near the confluence (coordinates from Google Earth). The other locality records from Mato Grosso, "Barra do" or "Barrado" Tapirape, were not found.

Distribution: Known only from Brazil, Oedichirus optatus has been collected near three rivers in two states, Rio Tapirape in Mato Grosso, Rio Tapajós and Rio Gurupi in Pará, and it has been collected in Maranhão state (fig. 40).

BIONOMICS: Oedichirus optatus was collected by H.W. Bates on "trees" (Sharp, 1876: 338). Most of the specimens collected by Borys Malkin were taken by "sweeping the forest" vegetation. Specimens were collected from November to February, and March, April, and May.

Oedichirus procerus, new species Figures 40, 197-198

Type MATERial: Holotype: Female. "F95314 W2 BRAZIL Bahia Urucuca, Cerro Grande 01.28.1995 D.Agosti primary Atlantic forest $120 \mathrm{~m} 14^{\circ} 25^{\prime} 17^{\prime \prime} \mathrm{S}, \quad 39^{\circ} 3^{\prime} 43^{\prime \prime} \mathrm{W} /$ Holotype Oedichirus procerus Herman." Deposited in the
American Museum of Natural History. (Both maxillary palpi are missing.)

PARATYPE: One female. Brazil: Bahia: Ilhaus (= Ihéus), Mata da Esperanca, 01.29.1995, Atlantic forest, $50 \mathrm{~m}, 14^{\circ} 47^{\prime} 02^{\prime \prime} \mathrm{S}, 39^{\circ} 03^{\prime} 45^{\prime \prime} \mathrm{W}, \mathrm{D}$. Agosti, F95320 W3 (AMNH). (I cannot find "Ilhaus" anywhere in Brazil. Ilhéus, at the coordinates included on the locality label, is probably the town to which the collector was referring.)

Type Locality: Brazil: Bahia: Urucuca (= Uruçuca), Cerro (= Serra) Grande, $120 \mathrm{~m}$, $14^{\circ} 25^{\prime} 17^{\prime \prime} \mathrm{S}, 39^{\circ} 03^{\prime} 43^{\prime \prime} \mathrm{W}$.

DiAgNosis: The elytra of this species are longer than their combined width and the dorsal surface of the elytra is strongly concave; these two characters distinguish the species from all others in the New World except $O$. boehmi and $O$. ohausi, both of which have four labral denticles; $O$. procerus has two. The pronotum of $O$. procerus has a submedial row of coarse, moderately deep punctures, but $O$. boehmi has deep, submedial punctures that together form a prominent punctate groove. The pronotum of both $O$. boehmi and $O$. procerus is relatively sparsely punctate with large impunctate spots. The pronotum of $O$. ohausi is densely and coarsely punctate and the impunctate regions are smaller. Oedichirus procerus is smaller and more slender than either of these two more robust species (compare measurements of each). The anteroventral angles of tergum IX are separated in O. boehmi (fig. 64), but fused in O. procerus (fig. 197) and $O$. ohausi (fig. 186). For $O$. ohausi the right side of the anterior vulvar lobe is sclerotized (figs. 186, 187), but neither lobe is sclerotized in O. procerus (figs. 197, 198). The vulvar lobes of $O$. boehmi are largely sclerotized (figs. 64, 67). The male is unknown for $O$. procerus.

DESCRIPTION: Length: $6.1-7.0 \mathrm{~mm}$. Length of head: $0.7 \mathrm{~mm}$. Width of head: $0.7-0.8 \mathrm{~mm}$. Pronotal length: $1.0-1.1 \mathrm{~mm}$. Pronotal width: $0.7-0.8 \mathrm{~mm}$. Elytral length: 0.9-1.0 mm. Elytral width: $0.8 \mathrm{~mm}$.

Reddish brown, head and abdominal segments VIII to $\mathrm{X}$ darker reddish brown in one specimen. Legs yellowish brown with slight infusion of reddish brown on apical portion of femur of each leg, but without distinct spot. 
197

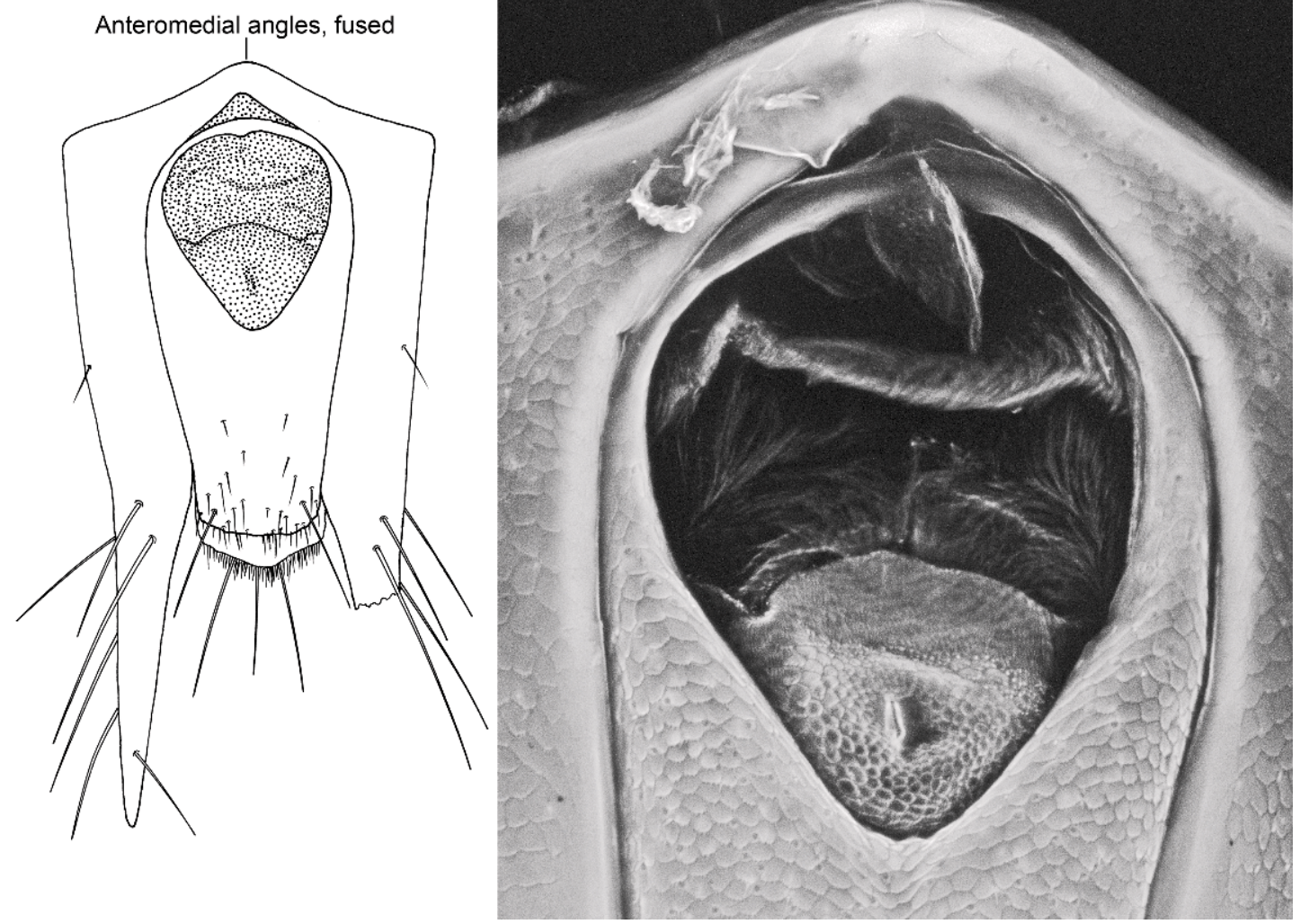

Figs. 197-198. Oedichirus procerus. 197. Segment IX, ventral, left lateroapical process broken, female. 198. Segment IX, vulvar plate, enlarged (CLSM).

Head slightly wider than long (HW/HL: 1.1). Frontoclypeal ridge extending anteromedially toward and to near frontoclypeal margin. Dorsal surface without V-shaped depression; surface coarsely and sparsely punctate; punctation present across middle and laterally from base of antenna to base of head; surface impunctate anteriorly and basally. Labrum bidentate; denticle small and adjacent to median emargination; surface without submarginal tubercle.

Pronotum longer than wide (PL/PW: 1.4). Pronotum polished, with coarse, sparse punctation, and with large impunctate spots; punctation clustered submedially, laterally, and midanteriorly; submedial row of punctures forming moderately deep groove. Elytra longer than wide (EW/EL: 0.8); surface of disc moderately deeply and broadly concave and with coarse, dense punctation.
Abdominal terga III to VI with moderately dense punctation and impunctate subapically; punctures not arranged in distinct rows; terga VII and VIII sparsely and finely punctate. Segment III without paratergite; paratergal carina present and extending for nearly length of segment, but weakly developed beyond spiracle. Tergum III without medium point extending from transverse basal ridge. Tergum VIII with posterior margin nearly truncate; transverse basal ridge without median point. Tergum IX with lateroapical process longer than midbasal length (LLaP/T9: 1.7), moderately bent ventrally, and slightly divergent from other process; ventromedial margin without posteriorly directed spur (cf. fig. 158).

Female: Sternum VIII with posterior margin rounded, more strongly rounded medially; transverse basal ridge broadly 
sinuate and microsinuate and without median point. Tergum IX (figs. 197, 198) with anteroventral angles fused medially forming narrow strap. Median gonocoxal plate anteriad of vulvar plate reduced to narrow strap and separated from tergum IX (fig. 197); anterior margin rounded; gonocoxal plate posteriad of vulvar plate tapered to sinuate posterior margin. Anterior vulvar lobe large, transverse, membranous and extending along anterior margin of posterior vulvar lobe; surface wrinkled (fig. 198). Posterior vulvar lobe small and with cobble on surface of posterior two thirds (fig. 198). Vulva oriented at slight angle to longitudinal axis.

MALE: Unknown.

ETYMOLOGY: The name is from the Latin procerus, "long, tall," and refers to the long, slender body and legs of this species.

Distribution: Known only from the eastern portion of Bahia province, Brazil (fig. 40).

REMARKS: Whereas the vulvar plate of most of the species examined is more or less flat, that of $O$. procerus is deeply bowed inward toward the dorsal side of the segment that (see fig. 198, but seen best in lateral view on a slide mount) created a large transverse fold near the middle of the anterior vulvar lobe; this fold differs from invaginations of the surface seen in, for example, $O$. ohausi (fig. 187).

\section{Oedichirus sinuosus, new species Figures 39, 199-205}

Type Material: Holotype. Male. "Mexico, Yucatán: Hoctun, August 12, 1973 J. Reddell/ Holotype Oedichirus sinuosus Herman." Deposited in the American Museum of Natural History. (Right antennomeres 7-11 are missing. Abdominal segments IV-VI are separted from the thorax and segment III and are glued to the point.)

Type Locality: Mexico: Yucatán: Hoctun $\left(20^{\circ} 52^{\prime} \mathrm{N}, 89^{\circ} 12^{\prime} \mathrm{W}\right)$. (In Yucatán two towns are named Hoctun. In correspondence J. Reddell, the collector of the species, wrote that the place at which he collected is $45-50 \mathrm{~km}$ SSE of Merida. The coordinates are from Google Earth.)

Diagnosis: Oedichirus sinuosus is one of six New World species with paratergite III. The others are O. optatus, O. batillus, $O$. bicristatus, $O$. isthmus, and $O$. hamatus. The legs of $O$. hamatus are bicolored, those of $O$. sinuosus are unicolorous. In contrast to $O$. sinuosus (fig. 203), sternum VIII of the males of O. batillus (fig. 53), O. bicristatus (fig. 59), and O. optatus (fig. 193) lack a transverse, subapical row of spinelike setae. The male of $O$. sinuosus has a curved, transverse, subapical row of spinelike setae on sternum VIII (fig. 203), whereas $O$. isthmus has a transverse, subapical cluster (fig. 163). The pronotal punctation of Oedichirus sinuosus is similar to that of $O$. boehmi in that both have few punctures and a well-defined submedial row, but the two are easily separated by the features cited in the preceding sentences.

DESCRIPTION: Length: $9.3 \mathrm{~mm}$. Length of head: $0.9 \mathrm{~mm}$. Width of head: $1.2 \mathrm{~mm}$. Pronotal length: $1.4 \mathrm{~mm}$. Pronotal width: $1.2 \mathrm{~mm}$. Elytral length: $1.2 \mathrm{~mm}$. Elytral width: $1.4 \mathrm{~mm}$.

Body bicolored, reddish brown. Head dark reddish brown. Pronotum and elytra reddish brown, but elytra paler. Abdomen moderately dark reddish brown with paler infusions. Legs yellowish brown with feeble, pale reddish-brown infusions at femorotibial joints.

Head about one third wider than long (HW/HL: 1.3). Frontoclypeal ridge incomplete, separated medially. Dorsal surface without V-shaped depression; surface sparsely punctate, with a few punctures extending from frontoclypeal ridge to postocular lateral base and with small middorsal cluster; surface polished. Labrum quadridentate; surface without tubercle near submedial denticle.

Pronotum about one fifth longer than wide (PL/PW: 1.2). Pronotum polished; punctation sparse, coarse, and with lateral cluster and moderately deep, submedial, punctate groove extending most of length of pronotum. Elytra about one tenth wider than long (EW/EL: 1.1); surface slightly convex and coarsely punctate.

Abdominal segments III to VI coarsely punctate; punctation of III to V even basally and with irregularly arranged, poorly developed, subapical, transverse row of punctures; segments VI and VII with subbasal, subapical, and apical transverse rows of punctures dorsally, subbasal and subapical rows with 

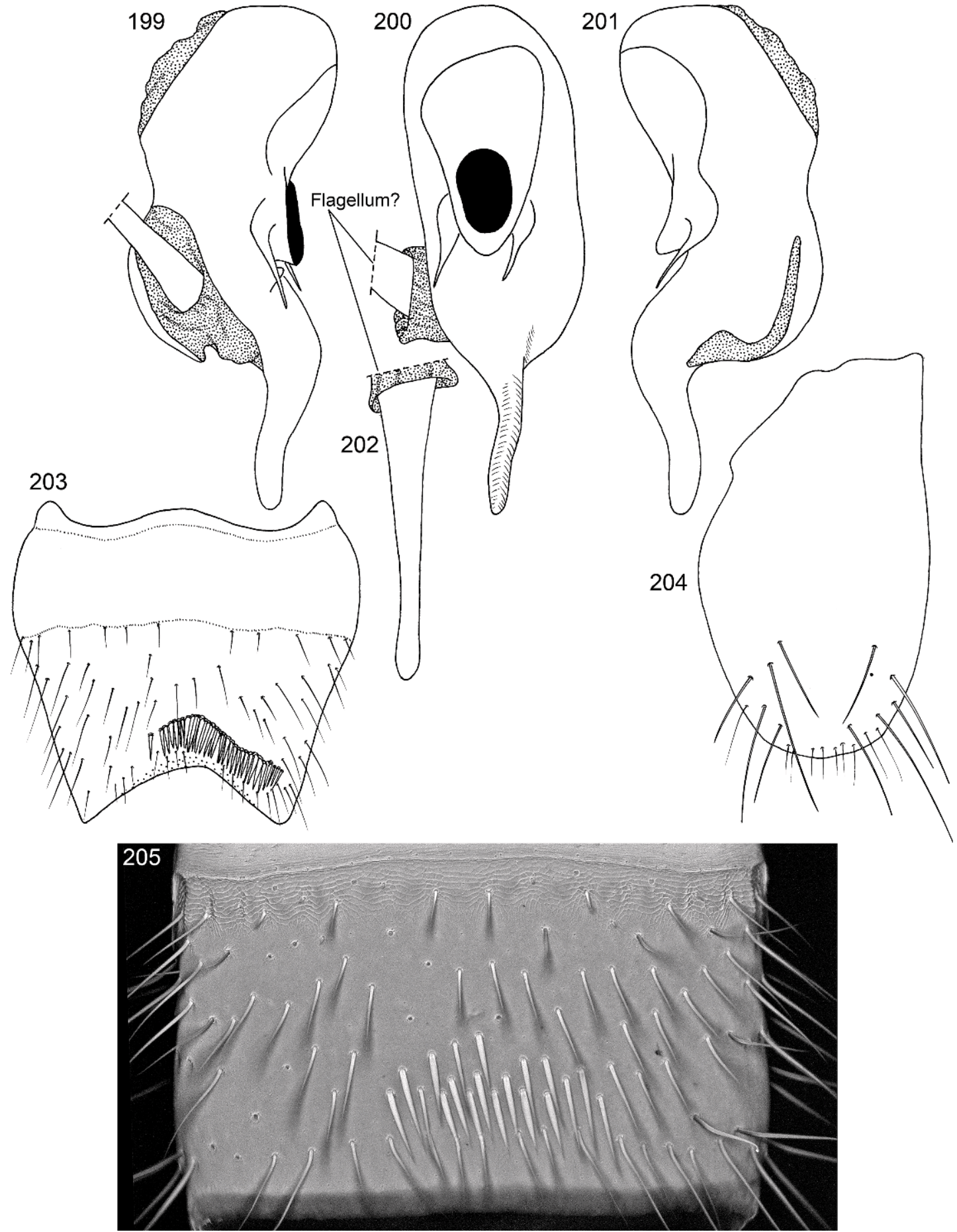

Figs. 199-205. Oedichirus sinuosus. 199. Aedeagus, right lateral. 200. Aedeagus, ventral. 201. Aedeagus, left lateral. 202. Aedeagus, everted flagellum? of internal sac. 203. Sternum VIII, male. 204. Sternum IX, male. 205. Sternum VII, male (CLSM). 
punctures irregularly arranged; VII and VIII with finer punctation than on preceding segments. Segment III with paratergite; paratergal carina absent. Tergum III without median point extending from transverse basal ridge. Tergum VIII with posterior margin broadly emarginate; transverse basal ridge irregularly sinuate and shallowly curved anteriorly and without median point. Tergum IX with lateroapical process about one third longer than midbasal length of tergum $(\mathrm{LLaP} / \mathrm{L} 9=1.3)$, slightly bent ventrally, and approximately parallel to other process; ventromedial margin without posteriorly directed spur (cf. fig. 158).

Male: Sternum VI unmodified. Sternum VII (fig. 205) with median, subapical cluster of slightly shorter, slightly stouter, recumbent setae. Sternum VIII (fig. 203) with broad, deep, asymmetrical emargination of posterior margin; emargination about one seventh of length of sternum, wider than deep, left side more strongly sloped than right, and margin broadly rounded basally and membranous; surface with comb of short, stout setae bordering emargination (fig. 203); comb extending medioanteriorly from near left lateral margin diagonally to just beyond midsagittal line; comb slightly sinuate on left side and strongly curved lateroposteriorly near middle of segment; right end of comb on low tumescence. Surface of sternum VIII with broad, moderately deep, polished, sparsely punctate, transverse depression between comb and transverse basal ridge; transverse basal ridge weakly sinuate, slightly curved anteriorly at middle, and without median point. Tergum IX with long, moderately wide process on anterior margin of anteroventral angle. Sternum IX (fig. 204) moderately asymmetrical; anterior margin wide and sinuate; posterior margin wide and broadly rounded; right lateral margin broadly rounded posteriorly and sinuate anteriorly, left margin broadly and gently sinuate.

Aedeagus asymmetrical (fig. 199-201). Ventral sclerite with apical third long, slender, sinuate, tapered from broad base, compressed laterally, and narrowly rounded apically and in lateral view broad and thick basally, sinuate, tapered apically, and with rounded apex; ventral sclerite without apicoventral process extending to right from posterior margin. Parameres short, broad basally, strongly tapered and, from about middle, slender; parameres fused to median lobe basally, but mostly free of median lobe. Internal sac with with long, cylindrical, strongly sclerotized, apically blunt process (flagellum ?) (fig. 202).

Female: Unknown.

ETYMOLOGY: The name is from the Latin sinuosus, "sinuous," and refers to the slender, sinuous apical third of the ventral sclerite of the aedeagus.

Distribution: Known only from the Yucatán peninsula of Mexico (fig. 39).

REMARKS: The aedeagus of the holotype has a long, sclerotized, gradually tapered cylinder extending laterally and slightly anteriorly from the right side of the median lobe (figs. 199, 202). This process has a narrow central canal that opens at the distal end; it may be the flagellum.

The long sinuous apical portion of the ventral sclerite might be interpreted as an apicoventral process that is not curved. That view is not adopted since, herein, the apicoventral process is defined as curving to the right and extending from the lateroapical region of the posterior margin.

The species, collected in 1973 and identified by me in 1974, is the earliest known record for Oedichirus in Mexico.

\section{Oedichirus sparsipennis Bernhauer}

Figures 40, 206-207

Oedichirus sparsipennis Bernhauer, 1927: 155.

- Scheerpeltz, 1933: 1218 (catalog). — Blackwelder, 1944: 131 (checklist).

Type Material: Syntypes: Two females. Bernhauer reported that specimens of the species from "Brasilien: S. Catharina, Theresopolis" were deposited in his collection and that of the "Deutschen entomol. Institutes in Berlin-Dahlem," but he neither selected a type nor indicated the number of specimens studied. One specimen was found in the Bernhauer collection in Chicago (FMNH) and another in the collection in Müncheberg (SDEI), the present home of the collections formerly in Berlin-Dahlem. The species is part of a cluster of like species and as no type was designated, a lectotype is designated to stabilize the name. 


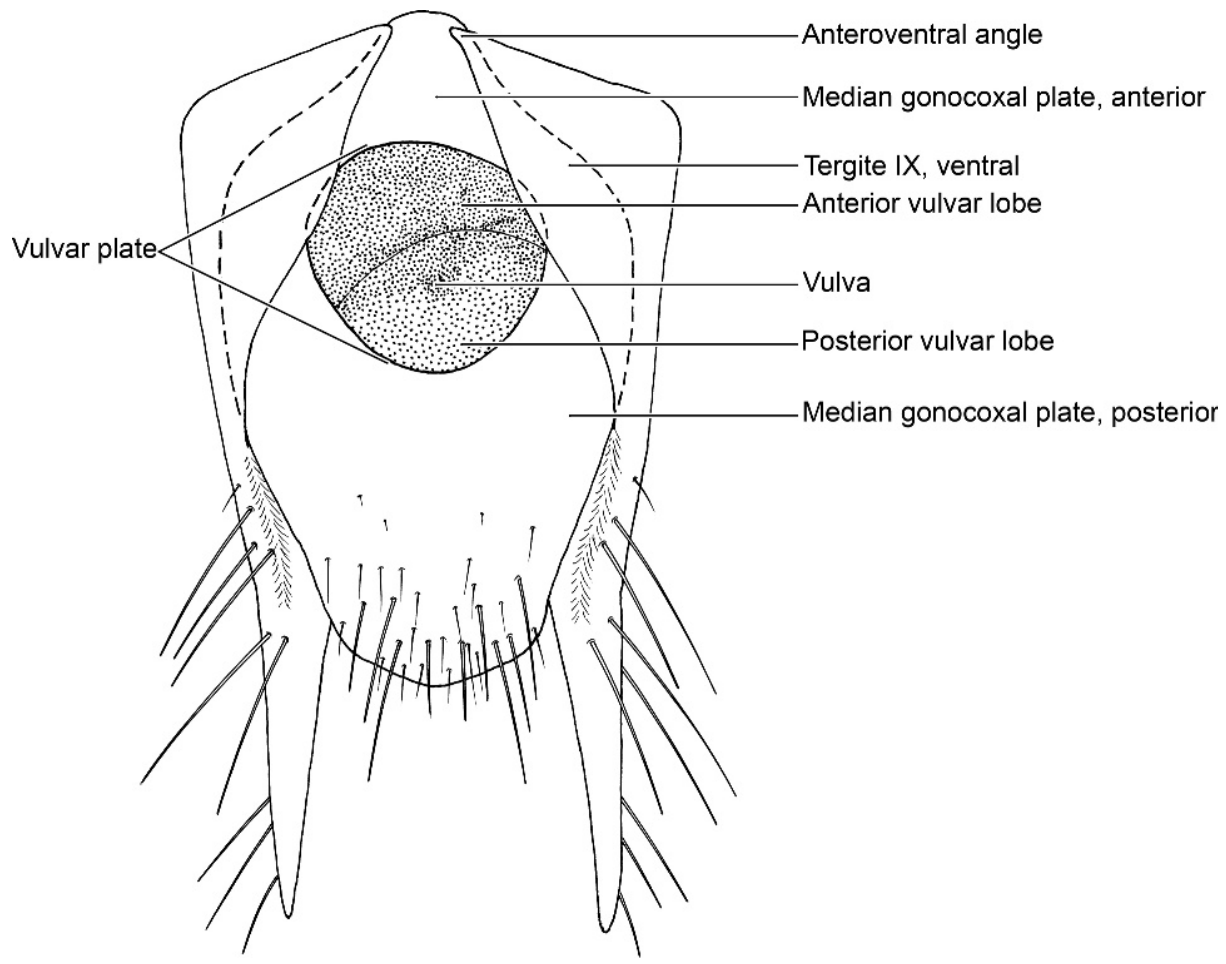

Fig. 206. Oedichirus sparsipennis. Segment IX, ventral, female.

Lectotype: Designated here. Female. "S. Catharina Theresopolis Fruhstorfer 1887/Oedichirus sparsipennis Bernh Cotypus. don. Mus. Germ./ Chicago NHMus M.Bernhauer Collection/Lectotype Oedichirus sparsipennis Bernhauer des. L. Herman, 2011." Deposited in the Field Museum of Natural History, Chicago. (Left antennomeres 3-11 are missing.)

Paralectotype: Female. "S. Catharina Theresopolis Fruhstorfer 1887/Syntypus/sparsipennis Bhnr./Bernhauer det./coll. DEI Müncheberg." Deposited in the Senckenberg Deutsches Entomologisches Institut, Müncheberg.

Type Locality: Brazil: Santa Catharina: Theresopolis, at about $27^{\circ} 43^{\prime} \mathrm{S}, 48^{\circ} 55^{\prime} \mathrm{W}$. (The name of the town given on the label and in the original publication is also referred to as Teresopolis or Terezopolis, but is now known as Queçaba, Quiçaba, or Quicaba [from www.fallingrain. com].)

Diagnosis: This species, known only by female specimens, is one among six species with bicolored legs (fig. 2) and a median point on tergum VIII. Included are $O$. brunneus, O. bullaglaber, O. bullahirtus, $O$. clavulus, O. geniculatus, and $O$. sparsipennis.
Both $O$. bullaglaber and $O$. bullahirtus have a median point on tergum III that $O$. sparsipennis lacks. The lateroapical process of IX for both $O$. clavulus (LLaP/L9 $=2.2-2.3)$ and O. geniculatus $(\mathrm{LLaP} / \mathrm{L} 9=2.8-2.9)$ is more than twice as long as the midbasal length of tergum IX; that of $O$. sparsipennis is about two thirds longer (LLaP/T9: 1.7). The two remaining two species, $O$. sparsipennis and $O$. brunneus, share many features. The following characters permit their separation. The anterior vulvar lobe of $O$. sparsipennis is large, membranous, and lacks adornment (fig. 207), the median gonocoxal plate anteriad of the vulvar plate is broadly trapezoidal with a broad apex and gradually sloping margins (fig. 206), the lateral margin of the paratergal carina is convex (in dorsal view), and the species is from Santa Catarina state. The anterior vulvar lobe of $O$. brunneus is smaller and covered with scattered cuticular processes (fig. 69), the median gonocoxal plate anteriad of the vulvar plate is more narrowly trianguloid with a narrow apex and strongly sloped lateral margins (fig. 68), the 


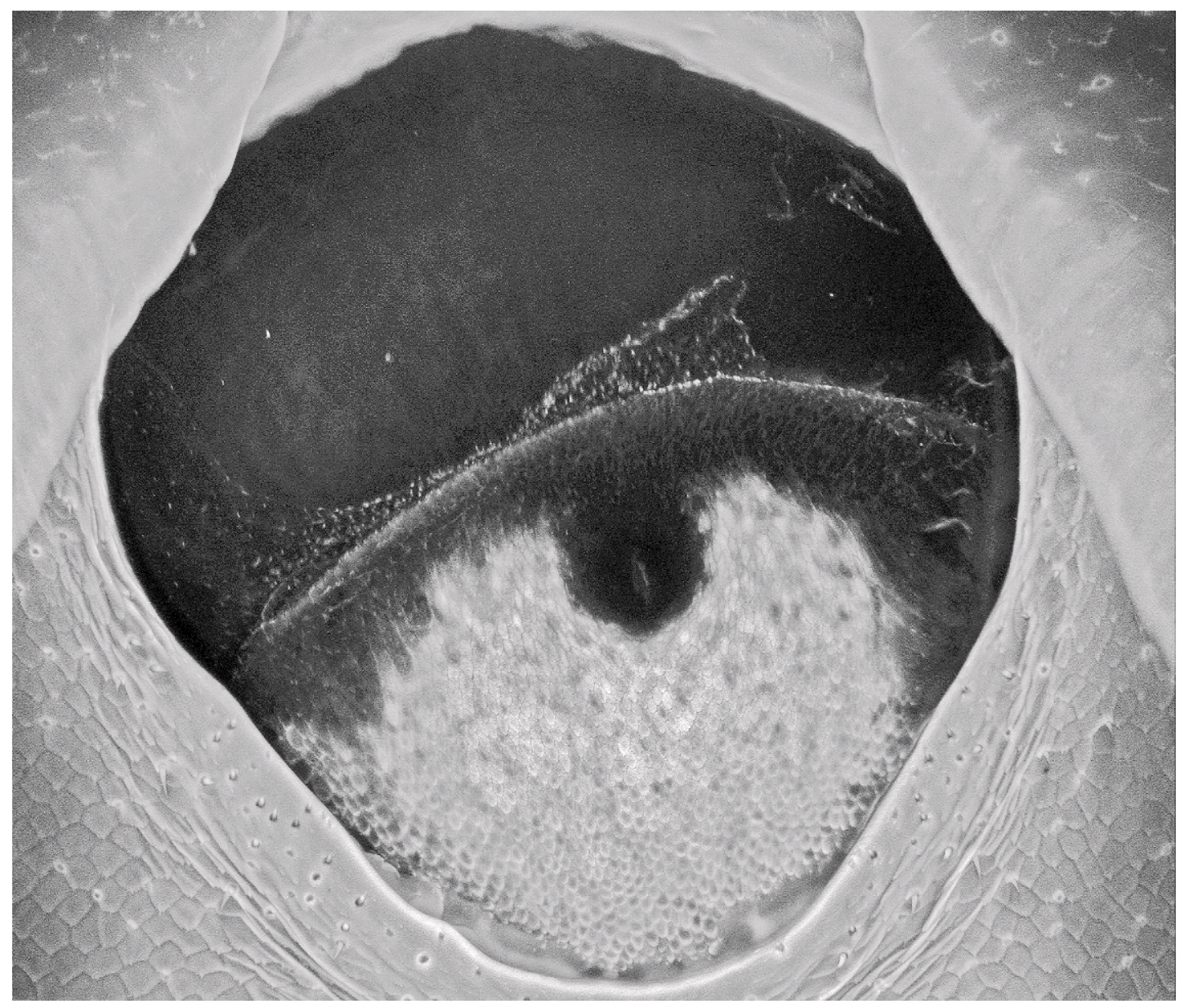

Fig. 207. Oedichirus sparsipennis. Segment IX, vulvar plate, enlarged (CLSM).

lateral margin of the paratergal carina is nearly straight in dorsal view, and the species is from São Paulo state.

DESCRIPTION: Length: 8.8-9.3 $\mathrm{mm}$. Length of head: $1.1 \mathrm{~mm}$. Width of head: $1.4 \mathrm{~mm}$. Pronotal length: $1.8 \mathrm{~mm}$. Pronotal width: $1.4 \mathrm{~mm}$. Elytral length: $1.3 \mathrm{~mm}$. Elytral width: $1.4 \mathrm{~mm}$.

Body concolorous reddish brown with scattered darker infusions to dark reddish brown. Legs bicolored, yellowish brown to pale reddish brown with large and dark reddish-brown femorotibial spot.

Head about one third wider than long (HW/HL: 1.3). Frontoclypeal ridge incomplete, separated medially. Dorsal surface without V-shaped depression; surface coarsely and densely punctate on most of surface, but with small impunctate spot basally. Labrum quadridentate; surface without tubercle near submedial denticle.

Pronotum about one third longer than wide (PL/PW: 1.3). Pronotum polished with coarse punctation arranged in irregular and scattered, dense to moderately dense clusters; surface without well-developed submedial punctate groove. Elytra with length about a tenth less than width (EW/EL: 1.1); surface coarsely punctate and flat medially.

Abdomen irregularly punctate, punctures not arranged in transverse rows. Segment III without paratergite; paratergal carina present and extending to, but not beyond, spiracle, and with lateral margin convex in dorsal view. Tergum III without median point extending from transverse basal ridge. Ter- 
gum VIII with posterior margin broadly rounded; transverse basal ridge broadly curved anteriorly and with apically open median point; posterior margin rounded. Tergum IX with lateroapical process nearly three-quarters longer than midbasal length $(\mathrm{LLaP} / \mathrm{L} 9=1.7)$, moderately bent ventrally, and approximately parallel to other process; ventromedial margin without posteriorly directed spur (cf. fig. 158).

MALE: Unknown.

Female: Tergum IX with anteroventral angles separated (fig. 206). Median gonocoxal plate anteriad of vulvar plate trapezoidal (fig. 206) and anterior margin broadly and shallowly rounded medially, then gradually sloping lateroposteriorly; gonocoxal plate posteriad of vulvar plate tapered to posterior margin and posterior margin rounded and with small median lobe. Vulvar plate moderately large and embedded in gonocoxal plate subbasally. Anterior vulvar lobe (fig. 207) transverse and posterior margin oriented at slight diagonal to posterior vulvar lobe; surface membranous and without ornamentation. Posterior vulvar lobe (fig. 207) broad and transverse and surface covered with cobble. Vulva oriented at slight diagonal to longitudinal axis.

Distribution: Known only from Santa Catarina, Brazil (fig. 40).

REMARKS: The lectotype is reddish brown and may be slightly teneral; the paralectotype is dark reddish brown. Only the lectotype was dissected for genitalic characters.

\section{Oedichirus speculifrons Bernhauer}

Figures 40, 208-220

Oedichirus speculifrons Bernhauer, 1939: 238.

- Blackwelder, 1944: 131 (checklist). - Fernandez et al., 2007: 31 (syntype deposition).

Type Material: Syntypes: One male (FMNH) and one female (MLPA). In the original description Bernhauer neither designated a holotype nor indicated the number of specimens of the species he examined. In the Bernhauer collection (FMNH) only one specimen from the published type locality is identified as "speculifrons Brnh. typus" in Bernhauer's handwriting. A female in the Museo de La Plata (MLPA) is identified as "Oedichirus speculifrons Brnh. n. sp." in Bernhauer's handwriting and is from the type locality of that species. The locality labels for both are identical in that they are the same size, are printed in the same typeface, read 'Brasilien Nova Teutonia $27^{\circ} 11^{\prime}$ B. $52^{\circ} 23^{\prime}$ L. Fritz Plaumann" on the obverse, and have the handwritten notation "Coll: M. Viana 6-1938" on the reverse. Details of the identification and locality labels support the possibility that both specimens were examined by Bernhauer when he described the species. Because $O$. speculifrons is variable and part of a complex of species, a lectotype is designated to fix the name.

Lectotype. Designated here. Male. "Brasilien Nova Teutonia $27^{\circ} 11^{\prime}$ B. $52^{\circ} 23^{\prime} \mathrm{L}$. Fritz Plaumann [topside, printed] Col. M. Viana 6-1938 [bottom side, handwritten]/speculifrons Bernh. Typus/speculifrons Bernh. Typus Oedichirus/ Chicago NHMus M.Bernhauer Collection/Lectotype Oedichirus speculifrons Bernhauer des. L. Herman, 2011." Deposited in the Field Museum of Natural History, Chicago. (Left maxillary palpomeres 3 and 4 , left metatarsus, and right mesotarsus are missing.)

Paralectotype: Female. "Brasilien Nova Teutonia $27^{\circ} 11^{\prime}$ B. $52^{\circ} 23^{\prime} \mathrm{L}$. Fritz Plaumann [topside, printed] Col. M. Viana 6-1938 [bottom side, handwritten]/99/Oedichirus speculifrons Brnh. n.sp./Sintipo/168/Paralectotype Oedichirus speculifrons Bernhauer det. L.Herman, 2011." Deposited in the Museo de La Plata, La Plata, Argentina.

Type Locality: Brazil: Santa Catarina: Nova Teutonia, $27^{\circ} 11^{\prime} \mathrm{S}, 52^{\circ} 23^{\prime} \mathrm{W}$. (This locality is cited by Paynter and Traylor [1991: 414], but with slightly different coordinates: $27^{\circ} 03^{\prime} \mathrm{S}$, $52^{\circ} 24^{\prime} \mathrm{W}$.)

Diagnosis: Oedichirus speculifrons is one of four externally similar species that also includes $O$. apiculus, $O$. glabrihamus, and $O$. misionesiensis, all of which have a symmetrical emargination of sternum VIII (fig. 208) and, on the aedeagus, a stout, tapered, curved apicoventral process extending from the right side of the apex of the ventral sclerite (fig. 212). Oedichirus apiculus can be separated from $O$. speculifrons by the shallower emargination, the oviform median depression, and the absence of a densely pubescent depression laterad of the median depression of sternum VIII (cf. figs. 46, 47 with 208, 209). The lateral margin of the median depression of $O$. speculifrons is bordered lateroapically by a straight ridge, a boss is present at the posterior end of the ridge, and the apical margin of the median 


\section{8}

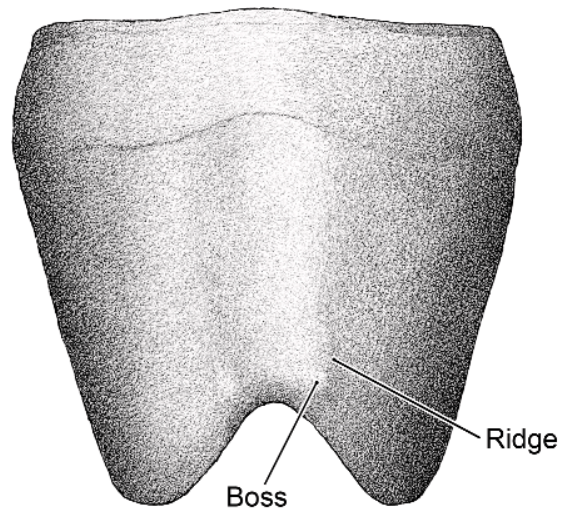

209

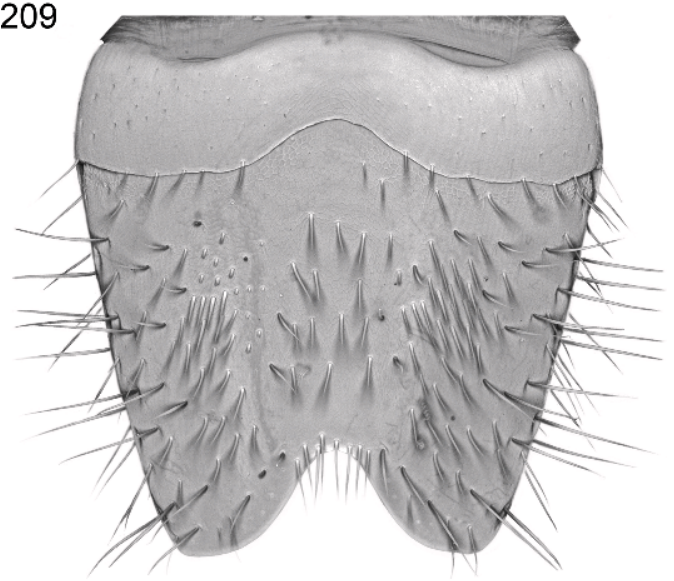

210

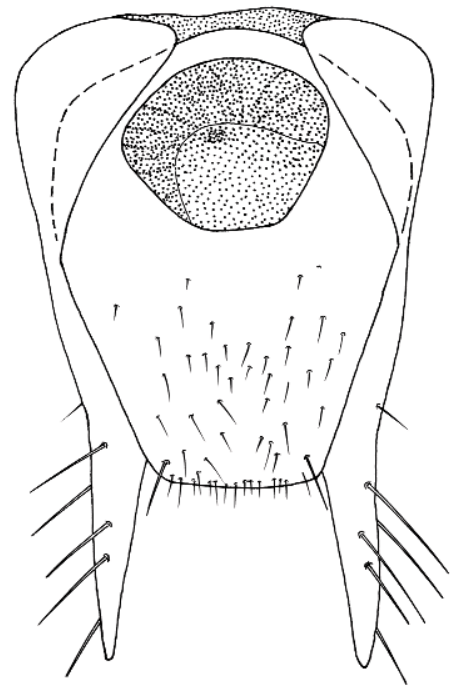

Figs. 208-210. Oedichirus speculifrons. 208. Sternum VIII, setae removed, male. 209. Sternum VIII, male. 210. Segment IX, ventral, female. depression is beveled (fig. 208). The aedeagus of $O$. apiculus has a spiniform process on the right side of the apical margin of the ventral sclerite dorsad of the anteroventral process (figs. 41, 44) that $O$. speculifrons lacks (fig. 211). Sternum VIII is similar for the males of $O$. speculifrons and $O$. misionesiensis, but the two are separated by the peg-boss on the apical margin of the apicoventral process of the aedeagus of the latter (figs. 173, 176), whereas the swelling at nearly the same position (fig. 212) on O. speculifrons is diagonally transverse and the ventral surface is ridged. On sternum VIII the lateroapical boss near the posterior margin is more strongly defined (fig. 208) and the pubescence laterad of the median depression is moderately dense (fig. 209) in O. speculifrons. For $O$. misionesiensis the lateroapical corner of the slightly depressed, median plane is polished, low, and feebly raised and the pubesence laterad of the median plane is more dense (fig. 177) than for O. speculifrons (fig. 209). The median depression of sternum VIII of $O$. glabrihamus is bordered laterally by a dense cluster of setae (fig. 155), the aedeagus has a pointed lobe on the right dorsal edge of the ventral sclerite (fig. 153), the apicoventral process of the aedeagus lacks a boss and is short and broad (fig. 154). For O. speculifrons, the cluster of setae laterad of the median depression is moderately dense (fig. 209), the aedeagus lacks a pointed lobe on the right dorsal edge of the ventral sclerite (fig. 211), and the apicoventral process of the aedeagus has a broad boss on the posterior surface (fig. 212).

As for females, the anterior vulvar lobe is membranous and lacks adornment (figs. 219, 220 ), the posterior vulvar lobe is covered with cobble, and the median gonocoxal plate anteriad of the vulvar plate is reduced to a narrow strap (figs. 210, 219) for $O$. speculifrons. The females are unknown for other described species of the complex, but included below is a discussion and illustrations for females of other species of the complex (see below, Remarks: Females).

DESCRIPTION: Length: 7.3-8.8 $\mathrm{mm}$. Length of head: $0.7 \mathrm{~mm}$. Width of head: 1.0-1.1 mm. Pronotal length: $1.2-1.3 \mathrm{~mm}$. 


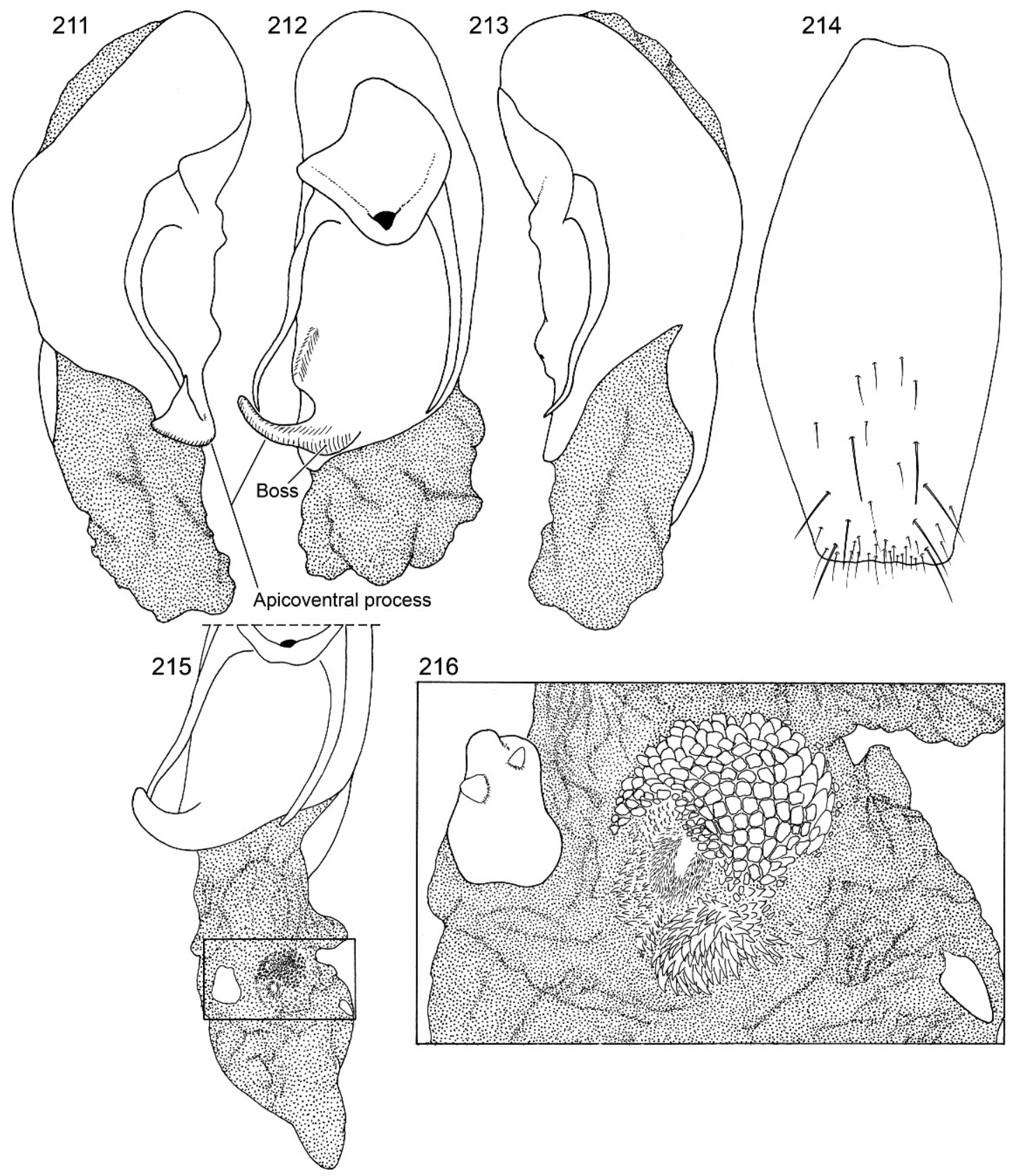

Figs. 211-216. Oedichirus speculifrons. 211. Aedeagus, right lateral. 212. Aedeagus, ventral. 213. Aedeagus, left lateral. 214. Sternum IX, male. 215. Aedeagus, with everted internal sac. 216. Aedeagus, internal sac, enclosed region enlarged.

Pronotal width: $1.1 \mathrm{~mm}$. Elytral length: 0.8$0.9 \mathrm{~mm}$. Elytral width: $1.0-1.1 \mathrm{~mm}$.

Body concolorous dark reddish brown to black with infusions of paler reddish brown particularly on elytra. Legs yellowish brown, some specimens with slightly darker infusion at femorotibial joint.

Head about two fifths to one half wider than long (HW/HL: 1.4-1.5). Frontoclypeal ridge curved and incomplete, separated 


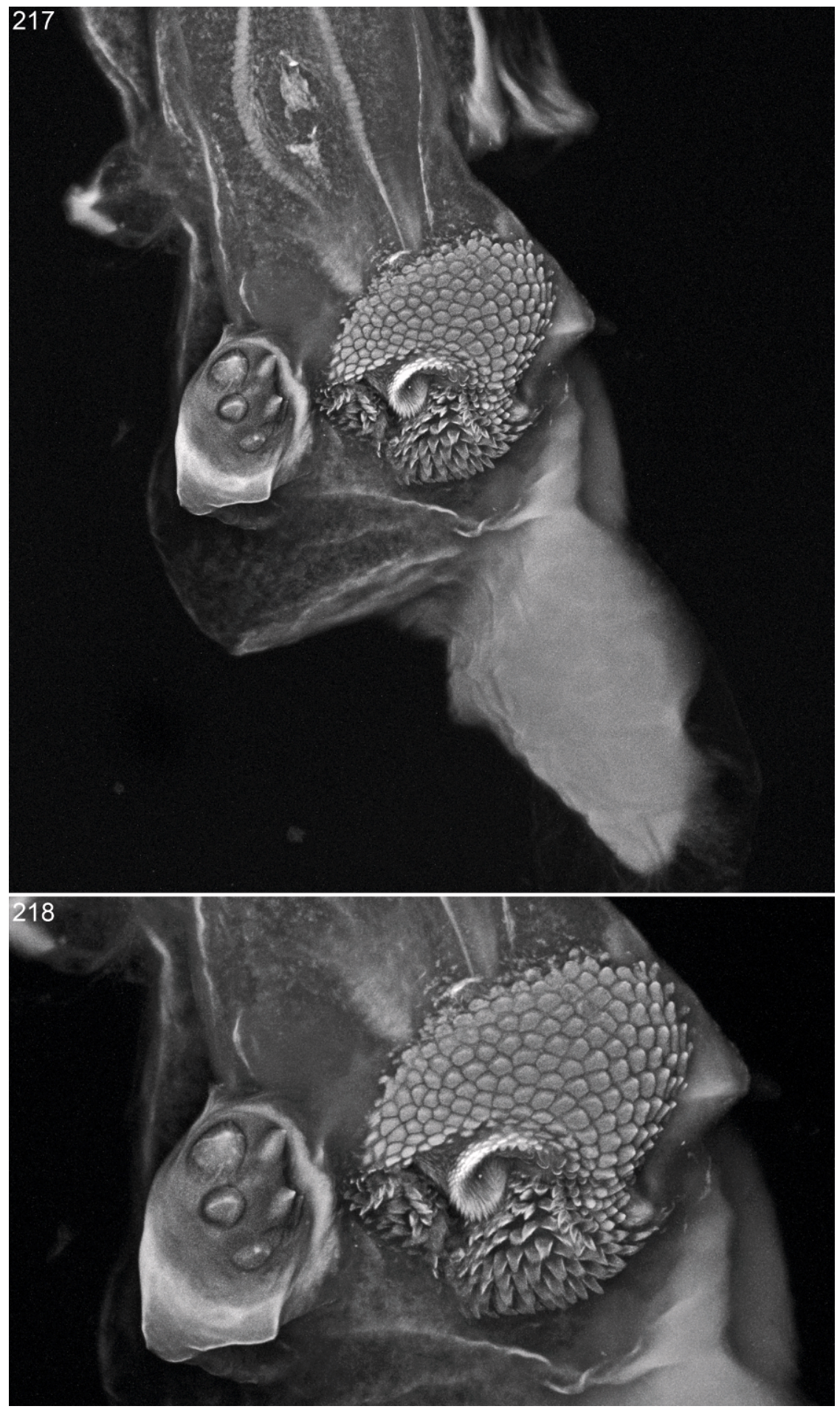

Figs. 217-218. Oedichirus speculifrons. 217. Aedeagus, internal sac, everted (CLSM). 218. Aedeagus, ornamentation of internal sac, enlarged, male (CLSM). 
medially. Dorsal surface without V-shaped depression; surface polished and with coarse, moderately dense punctation, punctation less dense anteriorly and some specimens with small impunctate spot basally. Labrum quadridentate; surface without tubercle near submedial denticle.

Pronotum about one tenth to one fifth longer than wide (PL/PW: 1.1-1.2). Pronotum polished with coarse punctation arranged in irregular and scattered dense to moderately dense clusters and with irregularly punctate, submedial groove on basal third to half. Elytra about one fifth to one third wider than long (EW/EL: 1.2-1.3); surface weakly convex and coarsely punctate.

Abdomen with coarse, irregularly distributed punctation dorsally; segments VII and VIII slightly less densely punctate than preceding segments; segments III to VII with or without transverse, subapical row of punctures, but row irregular when present. Segment III without paratergite; paratergal carina extending beyond spiracle for most of length of segment, but not reaching posterior margin and poorly developed beyond spiracle. Tergum III without median point extending from transverse basal ridge. Tergum VIII with posterior margin broadly and feebly rounded to nearly truncate; transverse basal ridge broadly curved anteriorly and without median point. Tergum IX with lateroapical process equal to midbasal length to about a third longer (LLaP/L9 $=1.0-1.3$ ), slightly bent ventrally, and slightly divergent from other process; ventromedial margin without posteriorly directed spur (cf. fig. 158).

MALE: Sterna VI and VII unmodified. Sternum VIII (figs. 208, 209) with deep, wide symmetrical emargination of posterior margin; emargination about one seventh of length of segment, wider than deep, with basal margin wide and rounded; subapical surface not translucent; surface with broad, shallow, median depression extending from near base of emargination to transverse basal ridge; surface with low, polished boss on each side of apex of median depression and with low ridge extending anteriorly from boss along lateral margin of depression; median depression with moderately dense setate punctation medially and without punctation basally or apically; posterior end of depression beveled and with transverse row or cluster of closely spaced setae extending between lateroapical bosses; surface laterad of median depression with feeble to shallow depression and with small, slightly denser cluster of fine setae at proximal end of depression; surface distad of lateral depression with curved, subapical row of setate punctures; sternal surface without comb; transverse basal ridge with median portion broadly and strongly curved anteriorly and without median point. Tergum IX with long, wide process on anterior margin of anteroventral angle. Sternum IX (fig. 214) slightly asymmetrical; anterior margin shallowly emarginate and moderately wide; posterior margin wide and sinuatotruncate; lateral margins broadly rounded.

Aedeagus asymmetrical (figs. 211-213). Ventral sclerite with apicoventral process extending laterally from right side of apical margin of ventral sclerite; apicoventral process moderately long, anteroposteriorly flattened, thick basally, strongly tapered to lateroanteriorly bent and acute apex, slender in ventral view (fig. 212), wide in posterior view, and with small to large, slightly compressed tumescent boss on ventroapical surface at rightward bend of process; boss with diagonally transverse orientation and with ridge on ventral surface; ventral sclerite with slightly curved carina on right side proximad of base of apicoventral process and without pointed lobe or spiniform process on right side dorsad of base of apicoventral process (fig. 211). Parameres long, tapered, moderately broad basally and slender apically; base half fused to median lobe; apical half free of median lobe. Internal sac (figs. 215-218) largely membranous; apical region near gonopore with various types of armature on ventral surface (figs. 217, 218); dorsal surface with short, robust spinelike process subapically; ventral side with heavily sclerotized mass lateroposteriad of and to right of gonopore, surface with spines extending from surface (figs. 217, 218); gonopore surrounded by short, apically acute and apically rounded cuticular processes (figs. 216-218).

Female: Sternum VIII with posterior margin truncate to slightly sinuate; transverse 
basal ridge irregularly and slightly sinuate and with median portion curved anteriorly, and without median point. Tergum IX with anteroventral angles separated from each other (fig. 210). Median gonocoxal plate anteriad of vulvar plate reduced to narrow strap with broadly rounded anterior margin (figs. 210, 219); anterior margin broadly rounded then sloping lateroposteriorly; gonocoxal plate posteriad of vulvar plate gradually tapered to broadly rounded posterior margin. Vulvar plate embedded in gonocoxal plate anteromedially. Anterior vulvar lobe (figs. 219, 220) transverse, posterior margin contiguous with anterior margin and extending along all of right lateral margin of posterior lobe; surface membranous, wrinkled, and without ornamentation. Posterior vulvar lobe irregularly ovoid; surface cobbled. Vulva at slight angle to longitudinal axis.

VARIATION: Unlike any other specimens collected in the New World, a series of two males and four females from Nova Teutonia were completely black including the legs, which are normally yellowish brown. These melanistic forms were collected by F. Plaumann in May 1972 and, but for color, are indistinguishable from other specimens of O. speculifrons.

MALES: Sternum VIII of the males exhibits subtle variation in the depth, density, and posterior extent of punctation of the median depression, development of the ridge bordering that depression, and development of the subapical boss on the lateroapical corner of the depression, but there seems to be little geographical pattern to this variation. However, specimens from Nova Teutonia have a transverse row of relatively few setae on the beveled, posterior margin of the median depression, whereas for those from Chapeco and Sinimbu, the row of setae is more irregular and includes a few more setae. On the aedeagus, the apicoventral process varies in thickness and length and the size of the boss on the posterior margin at the corner of the rightward bend of the process varies. The boss is a wide transverse swelling with a ridge on the ventral surface. It is moderately tumid on specimens (fig. 212) from Nova Teutonia and larger on a specimen from Chapeco and another from Sinimbu. Characteristically the boss is ventrally directed and is a diagonally transverse swelling that is continuous with a ventral ridge that extends to the apex of the apicoventral process. By contrast, the boss of $O$. misionesiensis, near the same bend of the apicoventral process, is a posteriorly directed, cylindrical peg that lacks a ridge (fig. 173).

MATERIAL EXAMINED: Twenty-seven males, 36 females. Brazil: Rio Grande do Sul: Sinimbu, $29^{\circ} 30^{\prime}, 52^{\circ} 30^{\prime}, 200$ m, IX 1960, F. Plaumann (1 male, CNCI). Santa Catarina: Chapeco, $27^{\circ} 07^{\prime}, 52^{\circ} 36^{\prime}, 600 \mathrm{~m}$, VII - 1961, F. Plaumann (2 males, CNCI), VII - 1960 (10 females, CNCI), IX - 1960 (1 female, CNCI); Santa Catarina: Nova Teutonia, Plaumann (3 males, FMNH), XII -

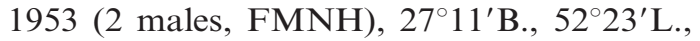
Fr. Plaumann (1 male, Lectotype, FMNH; 1 female, Paralectotype, MLPA), ii - 1939 (1 female, BMNH), V - 1972 (1 male, 5 females, CNCI), $27^{\circ} 11^{\prime}, 52^{\circ} 23^{\prime}, 300-500 \mathrm{~m}$, IV - 1954, leg. F. Plaumann (1 male, FMNH), $27^{\circ} 11^{\prime} \mathrm{S}, 52^{\circ} 23^{\prime} \mathrm{W}$, III - 1958 (5 males, 6 females, CNCI), V - 1961 (1 male, CNCI), VII - 1961 (1 male, CNCI), VII - 1969 (5 males, 11 females, CNCI), II - 1971 (3 males, CNCI), April 1971 (1 male, 1 female, CNCI).

DisTRIBUTION: Oedichirus speculifrons is known from three localities in Santa Catarina and one in Rio Grande do Sul (fig. 40).

REMARKS: Females: Thirty-two males of the speculifrons complex were collected from two sites in Santa Catarina, Chapeco, and Nova Teutonia. Collected together with those males were 41 females. The females lacked characters that associated any of them with any species in the speculifrons group, they could not be assigned to the speculifrons complex without collecting-based associations with males, and they could not be segregated into groups using only external features. However, dissection of the genital segment revealed four groups based on characters of the median gonocoxal plate and anterior vulvar lobe; these groups included 36 (figs. 219, 220), two (figs. 221, 222), two (fig. 223), and one specimens (fig. 224). Three species of the complex, $O$. speculifrons, $O$. apiculus, and $O$. glabrihamus, are represented in Santa Catarina by 26, four, and one males respectively. The males and females were all collected by Fritz Plaumann. The simplest hypothesis would be that the males and females 

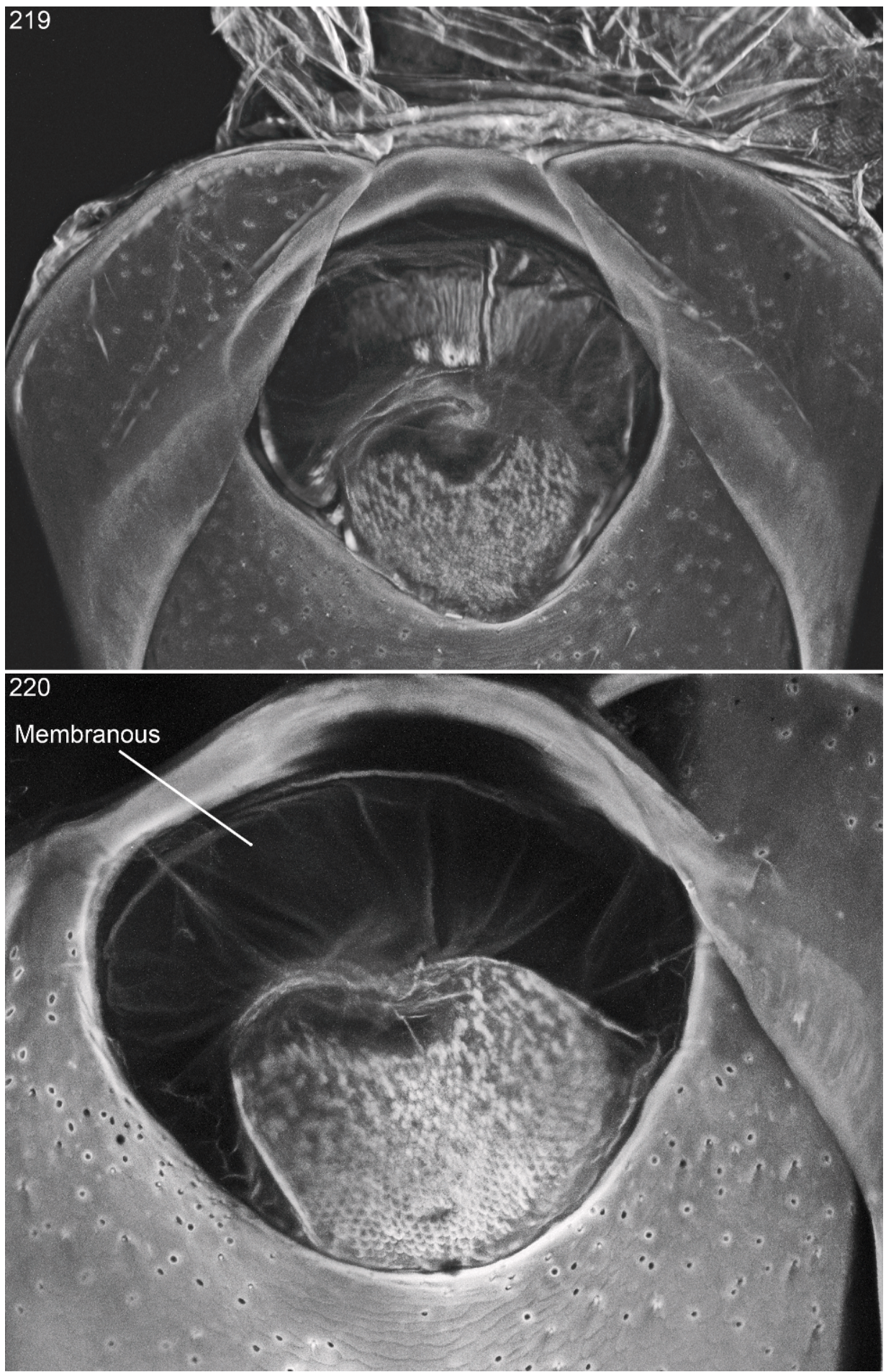

Figs. 219-220. Oedichirus speculifrons. 219. Vulvar plate, variation (CLSM). 220. Vulvar plate, variation (CLSM). 

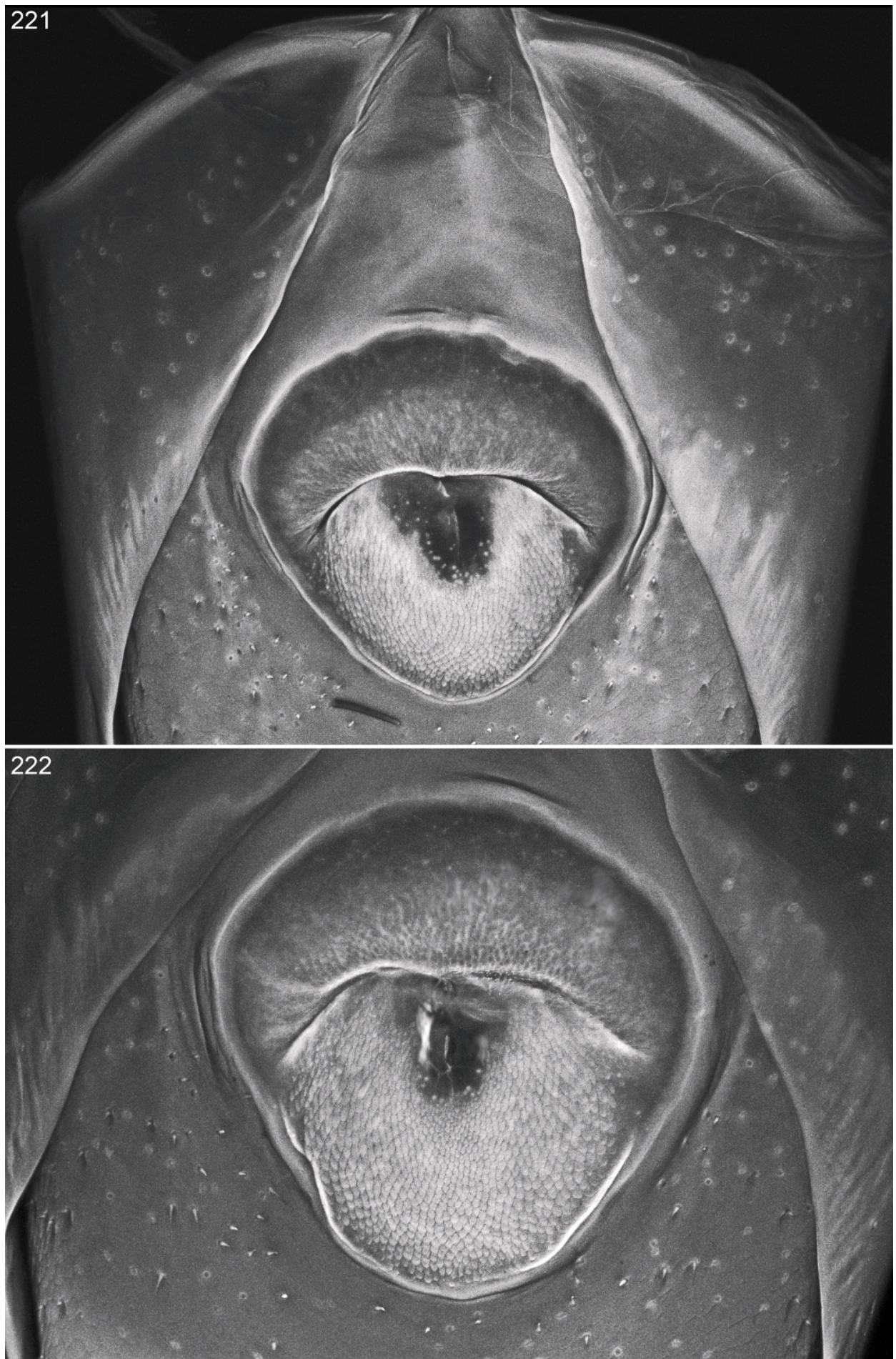

Figs. 221-222. Oedichirus speculifrons complex, Group 1. 221. Vulvar plate, variation (CLSM). 222. Vulvar plate, variation (CLSM). 

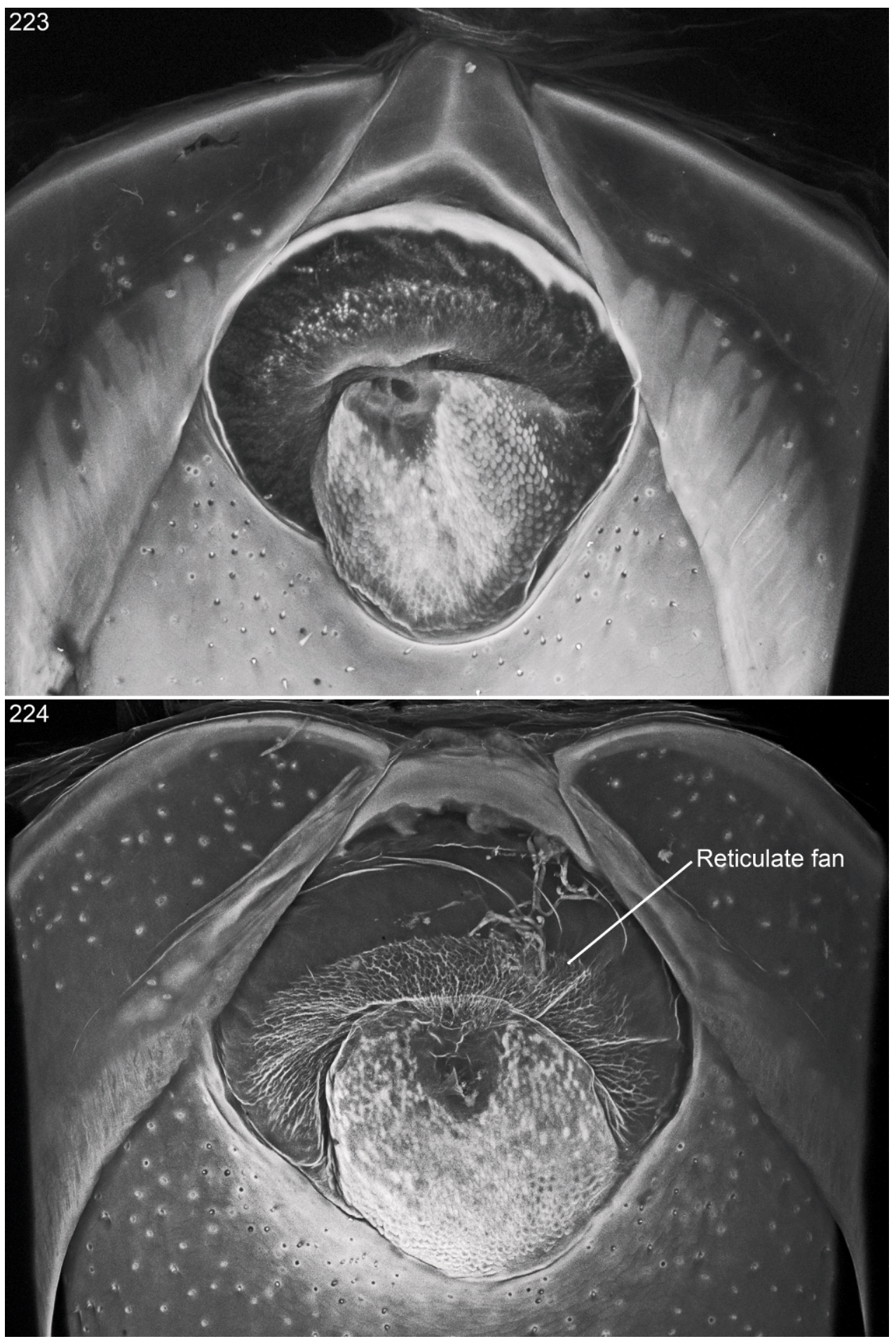

Figs. 223-224. Oedichirus speculifrons complex. 223. Group 2. Vulvar plate (CLSM). 224. Group 3. Vulvar plate (CLSM). 
were represented in the same relative proportions. Thus, O. speculifrons would include 26 males and the group of 36 females. As ancillary evidence on the identity of these females, the lectotype and paralectotype for $O$. speculifrons, both from Nova Teutonia, may have been collected together (see Type Material above) and are presumed to be conspecific. The median gonocoxal plate of the paralectotype matches those of the 36 dissected females thought to be $O$. speculifrons.

The disposition of the remaining three groups $(1,2$, and 3$)$ of females is uncertain. Oedichirus apiculus is known by four males, three from Nova Teutonia and one from Chapeco. Oedichirus glabrihamus is known by a male from Chapeco. Among the five unidentified females, all collected on different dates, one from Chapeco and four from Nova Teutonia, three groupings can be recognized. Two groups, speculifrons complex groups 1 and 2, have indeterminate surface structure on the anterior vulvar lobe (figs. 221-223). In group 1, represented by two specimens from Nova Teutonia, the median gonocoxal plate anteriad of the vulvar plate is large and triangular (fig. 221), and the anterior margin is narrow and rounded medially; the posterior margin of the anterior vulvar lobe extends along the anterior margin of the posterior vulvar lobe of one specimen (fig. 222) and along part of the right lateral margin of the other (fig. 221). For group 2, represented by a specimen from Chapeco and another from Nova Teutonia, the median gonocoxal plate anteriad of the vulvar plate is short and triangular/trapezoidal with a nearly straight or slightly rounded anterior margin and the anterior vulvar lobe extends strongly around the right lateral side of the posterior vulvar lobe (fig. 223). The third group, speculifrons complex group 3, from Nova Teutonia, has a network of fine fimbriae on the anterior vulvar lobe; the anterior lobe embraces the lateral sides of the posterior vulvar lobe equally, and the median gonocoxal plate anteriad of the vulvar plate is a narrow strap (fig. 224). It was impossible to decide which of the three groups of females were conspecific with the two remaining species from Santa Catarina.
BIONOMICS: Upon dissection of specimens collected in 1960 at Chapeco, an egg was found in the abdomen of each of four females collected in July and in a female collected in September. Two other specimens, each with an egg, were collected from Nova Teutonia in May 1972 and June 1938.

MATERIAL EXAMINED: Groups of $O$. speculifrons complex: Group 1. Brazil: Santa Catarina: Nova Teutonia, $27^{\circ} 11^{\prime} \mathrm{S}, 52^{\circ} 23^{\prime} \mathrm{W}$, 300-500 m, VI - 1972, Fritz Plaumann (1 female, CNC); VII - 1969 (1 female, CNC). Group 2. Brazil: Santa Catarina: Nova Teutonia, $27^{\circ} 11^{\prime} \mathrm{S}, 52^{\circ} 23^{\prime} \mathrm{W}, 300-500 \mathrm{~m}, \mathrm{~V}$ 1960, Fritz Plaumann (1 female, CNC); Chapeco, $27^{\circ} 07^{\prime}, 52^{\circ} 36^{\prime}, 600 \mathrm{~m}$, VII - 1960 (1 female, CNC). Group 3. Brazil: Santa Catarina: Nova Teutonia, $27^{\circ} 11^{\prime} \mathrm{S}, 52^{\circ} 23^{\prime} \mathrm{W}$, 300-500 m, III - 1958, Fritz Plaumann (1 female, $\mathrm{CNC}$ ).

\section{DISCUSSION}

This examination of Oedichirus was conducted because of the implausibly few species reported in the New World. It was startling to realize that for a pantropical group with 295 Old World species, 254 of which are found in Madagascar and subsaharan Africa, only eight were known for the New World. In the present work 19 new species are described and the Neotropical distribution increases from the seven species found mostly along the eastern edge of Brazil and an eighth in Costa Rica to now include representation in Argentina, Bolivia, Peru, Ecuador, Mexico, Dominican Republic, and perhaps Nicaragua. Although species are still reported in only a few countries and as yet mostly along the eastern edge of Brazil, it is certain that the genus is widespread in the New World tropics and that many species remain to be discovered. As of the present work, the genus is known from about $21^{\circ} \mathrm{N}$ in Yucatan, Mexico to about $30^{\circ} \mathrm{S}$ in Rio Grande do Sul, Brazil. Additional collections are needed to establish the actual northern and southern limits for the genus. Currently the genus is reported only east of the Andes; that also requires confirmation.

The 27 species described herein were found at only 39 localities. Twelve species $(O$. apiculus, $O$. batillus, $O$. bullaglaber, $O$. 
bullahirtus, $O$. clavulus, $O$. dilophus, $O$. distortus, O. geniculatus, $O$. neotropicus, $O$. optatus, $O$. procerus, and $O$. speculifrons) were found at more than one locality and for only $O$. batillus and $O$. optatus were the sites widely separated; the localities for the remaining 10 are clustered near Nova Teutonia, São Paulo, and Rio de Janeiro. Obviously this clustering is an artifact of collectiong. Fifteen species are known from one locality (O. bicristatus*, O. boehmi, $O$. brunneus*, O. clavolateralis*, O. dominicanensis*, O. echinatus*, O. exilis*, O. glabrihamus*, O. hamatus*, O. isthmus*, O. lunatus, $O$. misionesiensis*, O. ohausi*, $O$. sinuosus $^{*}$, and $O$. sparsipennis) and 11 , those with an asterisk, are each known by only one specimen. The point is that among all these species, not only were most species collected from one or only a few sites, but only one or a few specimens of most species were collected at each locality. Only $O$. geniculatus and $O$. speculifrons were collected in significant numbers, with 88 and 63 specimens respectively, but for both only a few localities are known. Oedichirus geniculatus was collected in large numbers at two of three localities during two short intervals, August-September and September-October. Specimens of the other species, O. speculifrons, were all collected by Fritz Plaumann, who found only a few at a time at three localities over a period of 33 years (1939 to 1972).

Not only are the species rarely collected, they are also collected in small numbers. The present work is based on 229 specimens, 151 of which are two species, the remaining 78 represent 25 species. In addition there are 30 unidentified females. I collected only two specimens in many trips to Central and South America and even some collectors known to be highly proficient captured only one or a few. During a 10 day winter trip to New Caledonia, I found 12 specimens by sifting litter from near streams, but in all of my sifting in Central and South America not a single specimen was found. Habitat data have been reported for only seven New World species. Only O. misionesiensis, from Argentina, and $O$. dilophus, from Bolivia, were reported as collected from forest floor litter. One or a few specimens each of five species $(O$. batillus, $O$. distortus, $O$ hamatus, $O$. neotropicus, and $O$. optatus) were collected by sweeping forest vegetation. One specimen of $O$. neotropicus was collected from the node of a palm frond and another from dried leaves of a banana tree. The labels for the two most commonly collected species, $O$. geniculatus and $O$. speculifrons, included no habitat information.

Habitat data for 105 species of Oedichirus from Madagascar and subsaharan Africa was published by Fagel (1971) and Janák (1995, 1996, 1998, and 2003). Most of the species $(92 \%)$ were collected from the ground in forests or grasslands from humus, leaf litter, decaying leaves, moss, and detritus. Some species were from the soil and debris of swampy areas and near streams, from epiphytes or collected by sweeping or beating forest vegetation; a few flying species were collected at lights, O. mariepskopensis Fagel was reported with Crematogaster tricolor Gerst., and $O$. transvaalensis Fagel in the nest of a termite. In southern Turkey, Oedichirus simoni was collected in litter in a pine/oak forest (Assing, 2004: 683; 2006: 227).

The New World species have been collected in lowlands from about $20 \mathrm{~m}(O$. neotropicus) to as high as 2400 and $2800 \mathrm{~m}$ (O. dilophus). Similarly, Old World species are found in lowland forests, but many live in montane forests where they occur to as high as $3500 \mathrm{~m}$. At least 10 African species have been collected at or above $3000 \mathrm{~m}$ elevation (see Fagel, 1971; Herman, 2010: 40).

The New World species have shortened elytra with subequal length and width; they lack or have reduced wings and are flightless. Because of the flightlessness, it is probable that most species have a relatively limited geographical distribution. Only O. optatus was found at widely separated localities in the drainage basin of the Amazon. It is further postulated that, like the $O$. bullaglaber, $O$. geniculatus, $O$. neotropicus, and $O$. speculifrons species groups, monophyletic clusters of species will be distributed with the members living in relatively close proximity to one another.

Without doubt more species will be collected in the New World. Of significant interest would be discovery of why so few species and specimens are collected. Is it the 
result of the lack of collecting effort or the wrong techniques are used or the true, breeding microhabitat has not been discovered or collections have been made during the wrong season or are the populations actually poor in individuals?

Any species of Oedichirus for which the male is known is easily identified and for the species reported herein the males are known for all but six. More than half of the Neotropical species are known by only one sex, 11 by the male and six by the female. For the remaining nine species the male/female association was nearly always determined by having been collected at the same time and place by the same collector. Most of the species have no characters uniquely possessed by the male and female of the same species. Exceptions are $O$. dilophus, which has finer cephalic and pronotal punctation than the other more coarsely punctate species and $O$. optatus, which has six labral denticles; most species have four labral denticles and three have only two.

Of the six species known only by females, three, $O$. brunneus, $O$. ohausi, and $O$. sparsipennis, described in 1927 and 1930, have no unique features that might be shared with the male and thereby make it possible to associate males and females. Association might be possible by collecting more specimens at or near the respective type localities in the hope that males and females of the species can be found together and corroborated by finding the males and females together at other sites. The other three species, $O$. hamatus, $O$. lunatus, and $O$. procerus, each have unique structures that are likely to be present in the males, so I departed from my reticence about describing species from only the female. Tergum IX of $O$. hamatus has a huge cariniform spur (fig. 158) on the ventromedial edge; the male may have a similar structure. Tergum IX of $O$. lunatus has long, slender, strongly curved lateroapical processes (figs. 168, 170) and the male is expected to be similarly endowed. The least distinctive of the three, $O$. procerus, is long and gracile with elongate appendages and a strongly concave elytra disc. Although $O$. procerus is not as dramatically distinct as the other two female-based new species, there are few species with dorsally concave elytra and only one that is gracile with two labral denticles. The females of many of the species can be identified by characters of tergum IX and the median gonocoxal and vulvar plates, which are discussed in the descriptions and in the section on morphology. To study, understand, and explore the characters of the vulvar plates, a confocal laser scanning microscope was used for the present work and that type of equipment or an SEM will be needed in the future to see these characters. The microstructures can be seen with a compound microscope, but are difficult to interpret and they cannot be studied with a stereoscopic microscope. Although association of the males and females is possible by collecting them together they can be more efficiently and accurately associated by using DNA-barcoding techniques. Barcoding efforts were begun and later halted for lack of adequate specimens. Most of them had been collected 40 or more years ago and had been stored in $70 \%$ ethanol for indeterminate periods of time.

Although the work herein is presented with the hypothesis that the females have species-diagnostic features of the genital segment, far more work is required to corroborate this idea. It may be that the perceived species-specific features are actually characters of species groups. Only examination of additional specimens, males and females, from more localities will resolve this question and the present work might be regarded as an initiation of that investigation.

Only about half of the New World species can be grouped into four species groups. The remainder may share one or more characters with one or more of the species groups or with one or more of the unassigned species, but they do not seem to be part of any species group and may each be the only representatives yet known of their particular cluster of species. Using WinClada to analyze a matrix of the characters and taxa yielded numerous trees with species scattered in various positions and combinations. The following paragraphs are a discussion of possible species groups based on characters that are derived and unique. Not all of the species have shared derived characters beyond those used to assign them to Oedichirus.

OEDICHIRUS GENICULATUS AND O.


mostly Brazilian species have a stout, compressed, strongly sclerotized, hooked process that curves rightward from the ventroapical margin of the aedeagus (fig. 142). The $O$. geniculatus group with four species, $O$. clavolateralis, $O$. clavulus, $O$. exilis, and $O$. geniculatus, is in the state of Rio de Janeiro. The $O$. speculifrons group, with $O$. apiculus, $O$. glabrihamus, $O$. misionesiensis, and $O$. speculifrons, is in Rio Grande do Sul and Santa Catarina states, Brazil, and Misiones province, Argentina. In addition to the stout aedeagal process, species of the $O$. geniculatus group have a median point on tergum VIII (fig. 26), the emargination of sternum VIII is asymmetrical (figs. 94, 147), and the legs have a femorotibial maculation (fig. 2). For the $O$. speculifrons group, tergum VIII lacks a median point, the emargination of sternum VIII is symmetrical (figs. 46, 208), and the legs lack the dark spot (as in fig. 1).

OEDICHIRUS BULLAGLABER GROUP: This group includes $O$. bullaglaber, $O$. bullahirtus, and $O$. echinatus and is based on the presence of a median point on both terga III and VIII (as illustrated for sternum VIII, fig. 73). The median point of tergum III is present only in the $O$. bullaglaber species group and only species of the $O$. bullaglaber and $O$. geniculatus groups have a median point on tergum VIII. The point on tergum VIII is open apically in the $O$. bullaglaber group, but is open (as illustrated for sternum VIII, fig. 114) or closed (as illustrated for sternum VIII, fig. 73) in the O. geniculatus group. Oedichirus echinatus differs from the other two species in the $O$. bullaglaber group in that it lacks the dark femorotibial maculation, sternum VIII lacks a subapical tumescence, and the emargination of the posterior margin is symmetrical. The median gonocoxal plate is trapezoidal anterior to the vulvar plate for both $O$. bullaglaber (fig. 76) and $O$. bullahirtus (fig. 87). The female for $O$. echinatus is unknown. The three species are known from adjacent Brazilian states, namely São Paulo, Paraná, and Santa Catarina. It is likely that $O$. bullaglaber and $O$. bullahirtus are sister species, but less certain that $O$. echinatus is related.

Oedichirus neotropicus group. Included in the group are $O$. dominicanensis, $O$. isthmus, $O$. neotropicus, and $O$. sinuosus, from Costa
Rica, Mexico, and Dominican Republic. The group is based on the comb of setae on sternum VIII of males (figs. 122, 184, 203), the broadly emarginate posterior margin of tergum VIII, and thornlike parameres with a swollen base and slender, spinelike apical portion (figs. 181, 200). Sternum VIII of $O$. isthmus has a cluster of setae (fig. 163) in place of a comb. The female is known for only $O$. neotropicus. Segment III of $O$. isthmus and $O$. sinuosus has a pair of paratergites, which is absent in the other two species of the group and which is present in only four other species.

Another species, the Ecuadorian $O$. distortus, has basally enlarged, apically spinelike or thornlike parameres (fig. 113) similar to those found in the $O$. neotropicus group and sternum VIII has a sinuous comb (fig. 114). However, the posterior margin of tergum VIII is rounded rather than emarginate and the anteroventral angles of tergum IX of the female are fused (fig. 118), whereas for $O$. neotropicus these angles are separated (fig. 185).

Four species, O. dilophus, O. distortus, $O$. lunatus, O. ohausi, and O. procerus, have one feature in common, the anteroventral angles of tergum IX of the female are fused (figs. 108, 118, 171, 186, 197). Because of the lack of other shared, derived characters and wide diversity of other features among the species it is unlikely these four species represent a monophyletic cluster. One of them, O. lunatus, is unique in that tergum IX has long, strongly curved lateroapical processes that are attached to the segment by a membrane and may be mobile. The anterior portion of the median gonocoxal plate of $O$. lunatus is fused medially to the fused anteroventral angles of tergum IX (fig. 169); the species is the smallest in the New World and one of three with only two labral denticles. Oedichirus ohausi is a gracile species with reduced, dorsally concave elytra. The gonocoxal median plate anterior to the vulvar plate is reduced to a narrow strap and fused to the medially fused anteroventral angles of tergum IX (fig. 186). The vulvar lobes differ markedly from other species (fig. 187). Only the female is known. With only two labral denticles, O. procerus is a long, gracile species with a strongly concave 
elytral disc. No characters were found that suggested relationship with other species. The male is unknown. Oedichirus dilophus, the only Bolivian species, is notable for its robust appearance, rather fine cephalic and pronotal punctation, and, for the female, the dense mat of cuticular processes on the vulvar plate (fig. 110). The male is known, but neither it nor the females have any features that support or even suggest relationship with another species. The aedeagus and sterna VIII and IX of $O$. distortus are strongly asymmetrical and sternum VIII has a pair of subapical combs (figs. 113, 114, 117). Each of the five species cited in this paragraph may be the only representatives known now of five species groups.

Oedichirus hamatus, known by only one female and one of six New World species with a paratergite on segment III, is a large, robust species with a unique large spur on the ventromedial edge of tergum IX (fig. 158) and the only named species from Peru. This spur is a defining feature of the species, but no characters were found to place the species with any of the others. Tergum III also has paratergites in $O$. batillus, $O$. bicristatus, and $O$. optatus, but they share no derived features with each other nor do any characters link them with other species. The preceding four species may also each represent the only known species of four species groups.

Two other species, O. brunneus and $O$. sparsipennis, are known by only one female each; they share no derived features with each other nor can they be placed with other species.

SUMMARY: Oedichirus is an immense genus about which little is known. Many species are described from Africa and Madagascar and many fewer in all other parts of the world and many more are likely to be discovered, particularly in tropical Asia and in the Neotropical region. Most of the species are found in tropical regions, most are known from a few specimens, and most are collected in small numbers. Most species have been collected in ground litter and debris and some by sweeping vegetation, but because large samples are rare, the breeding habitat is probably unknown and until it is discoverd specimens may continue to be rarely collected.

For nearly all species little is known beyond the collecting site and features of the aedeagus, sternum VIII of the males, and external features such as punctation, pubescence, and color. For all but 16 Neotropical species and $O$. paederinus, the females are known only by superficial features of the body and nothing is known about the form and microstructures of the genital segment. The median gonocoxal plate varies in form and has a vulvar plate that varies in form and includes a variety of microstructures that appear to define species or, perhaps, species groups. The function of the various forms of the vulvar plates and microstructures is unclear. Equally unclear is the function of the enlarged, elaborate protarsomeres. Whether there are features of taxonomic or phylogenetic value associated with the protarsomeres awaits discovery and many new species are yet to be described. Although the antennal spiniform pencil might be a means of wicking a chemical, what might the function of that chemical be and what is the precursor of the pencil? If the pencil is not a wicking device, what does it do and is it really comprised of modified setae?

\section{ACKNOWLEDGMENTS}

I thank the following individuals for lending or permitting on site study of specimens from collections in their care: Alfred Newton and Margaret Thayer (Field Museum of Natural History), Cheryl Barr (Essig Museum, University of California), Roger Booth (The Natural History Museum), Anthony Davies and Pat Bouchard (Canadian National Collection), Liliana Fernandez (Museo de La Plata), Johannes Frisch (Museum für Naturkunde), Jenny Thomson (Snow Museum, University of Kansas), and Lothar Zerche (Senckenberg Deutsches Entomologisches Institut). In the effort to find the type series of Elytrobaeus geniculatus Sahlberg, I thank Jyrki Muona (Zoological Museum, University of Helsinki), Viekko Rinne (Zoological Museum, University of Turku), and Bert Viklund (Naturhistoriska Riksmuseet, Stockholm). I am particularly grateful to Viekko Rinne with whom many e-mail messages on the subject were exchanged and who made special efforts to search his collections for the type series. I thank Aleš Smetana who 
translated several Latin sentences in Sahlberg's paper. I am grateful to Johannes Frisch for our discussion of paederine morphology and taxonomy and for his comments on an earlier version of the manuscript. I thank Steve Thurston for converting my line illustrations into digital files, for helping with the labelling of the figures, for the habitus photos, and for organizing the illustrations into pages. The images from the confocal laser scanning microscope would have been impossible without the work of Rebecca Rudolf and James Thostenson of the AMNH imaging facility. I thank Anjelico Asenjo (Universidade Federal do Paraná, Curitiba, Brazil) who generously supplied geographical coordinates for several of the Brazilian collecting sites. I thank two anonymous reviewers for their remarks that improved the manuscript.

\section{REFERENCES}

Ambrosius, E. (editor). 1914. Andrees allgemeiner Handatlas in 221 Haupt- und 192 Nebenkarten. ... Bielefled: Velhagen \& Klasing.

Anonymous. 1905. Obituary. Alexander Fry. Entomologist's Monthly Magazine (2) 16: $119 \mathrm{pp}$.

Assing, V. 2004. New species and records of Staphylinidae from Turkey III (Insecta: Coleoptera). Linzer Biologische Beiträge 36 (2): 669-733.

Assing, V. 2006. New species and records of Staphylinidae from Turkey VI, with six new synonymies (Coleoptera: Staphylinidae). Koleopterologische Rundschau 76: 223-276.

Assing, V. 2008. On the taxonomy and zoogeography of some Palaearctic Paederinae and Xantholinini (Coleoptera: Staphylinidae). Linzer Biologische Beiträge 40 (2): 1237-1294.

Bartholomew, J.G. (editor). 1992. The Times survey atlas of the world. London: The Times.

Bates, H.W. 1863. The naturalist on the River Amazons, a record of adventures, habits of animals, sketches of Brazilian and Indian life, and aspects of nature under the Equator, during eleven years of travel. Vol. 2. London: John Murray, 423 pp. [Vol. 1, published the same year, has 351 pages]

Bernhauer, M. 1927. 32. Beitrag zur Staphylinidenfauna Südamerikas insbesondere Brasiliens. Memorie della Società Entomologica Italiana 5: 152-169.

Bernhauer, M. 1939. Zur Staphylinidenfauna Argentiniens und Brasiliens (Col.). Revista de Entomologia 10 (1): 231-249.
Bernhauer, M., and K. Schubert. 1912. Staphylinidae III. In S. Schenkling (editor), Coleopterorum catalogus 5 (40): 191-288. Berlin: Junk.

Bierig, A. 1940. Un Oedichirus neotrópico (Col. Staph.) nuevo. Revista de Entomologia 11: 604-606.

Blackwelder, R.E. 1936. Morphology of the coleopterous family Staphylinidae. Smithsonian Miscellaneous Collections 94 (13): 1-102.

Blackwelder, R.E. 1944. Checklist of the coleopterous insects of Mexico, Central America, the West Indies, and South America. Part 1. U.S. National Museum Bulletin 185: xii + 1-188.

Blackwelder, R.E. 1952. The generic names of the beetle family Staphylinidae, with an essay on genotypy. U.S. National Museum Bulletin 200: i-iv, $1-483$.

Cameron, M. 1931. The fauna of British India including Ceylon and Burma. Coleoptera. Staphylinidae 2: viii + 1-257. London: Taylor and Francis.

Campau, E.J. 1940. The morphology of Chauliognathus pennsylvanicus (De Geer) (Coleoptera: Cantharidae). Microentomology 5 (3): 57-90.

Champion, G.C. 1898. A list of the Cicindelidae, Carabidae and Staphylinidae collected by $\mathrm{Mr}$. J.J. Walker, R.N., F.L. S., in the region of the Straits of Gibraltar. Transactions of the Entomological Society of London 1898: 65-103.

Ciceroni, A., A. Zanetti. 1995. [Genera 47-61, 79147]. In A. Ciceroni, V. Puthz, A. Zanetti 1995. Fascicolo 48. Coleoptera Polyphaga III (Staphylinidae): 10-14, 19-33, In , A. Minelli, S. Ruffo, and S. La Posta. Checklist delle specie della fauna italiana. Bologna: Edizioni Calderini.

Coiffait, H. 1978. Coléoptères staphylinides de la région paléarctique occidentale III. Sous famille Staphylininae, Tribu Quediini. Sous famille Paederinae, Tribu Pinophilini. Nouvelle Revue d'Entomologie Supplément 8 (4): 3-364.

Diamond, J.M., and J.W. Terborgh. 1967. Observations on bird distribution and feeding assemblages along the Rio Callaria, Department of Loreto, Peru. Wilson Bulletin 79 (3): 273-282.

Erichson, W.F. 1839. Genera et species Staphylinorum insectorum coleopterorum familiae (1): viii + 1-400. Berlin: F.H. Morin.

Erichson, W.F. 1840. Genera et species Staphylinorum insectorum coleopterorum familiae (2): 401-954. Berlin: F.H. Morin.

Fagel, G. 1955. Contribution à la connaissance des Staphylinidae XXXII. Notes sur le genre Oedichirus Erichson. Mémoires de la Société Royale d'Entomologie de Belgique 27: 194-206.

Fagel, G. 1958. Paederini (Coleoptera Polyphaga) fam. Staphylinidae. In Exploration du Parc National de l'Upemba, Mission G. F. de Witte ... (1946-1949) 51: 1-470. Brussels: Institut des parcs nationaux du Congo Belge. 
Fagel, G. 1961. Coleoptera (Staphylinidae): Paederinae. In B. Hanstrom, P. Brinck, G. Rudebeck., South African animal life, Results of the Lund University Expedition in 1950-1951 8: 259-295. Göteborg: Almqvist \& Wiksell.

Fagel, G. 1971. Revision des genres Procirrus Latreille, Palaminus Erichson, Oedichirus Erichson et voisins de la faune africaine (Coleoptera, Staphylinidae, Paederinae). Musée Royal de

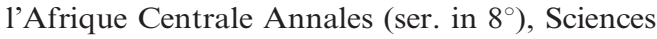
Zoologiques 186 (1970): 1-444.

Fauvel, A. 1873a. Faune gallo-rhénane ou species des insectes qui habitent la France, la Belgique, la Hollande, le Luxembourg, la Prusse rhénane, la Nassau et la Valais avec tableaux synoptiques et planches gravées 3 (liv. 4): 215-390. Caen: Le Blanc-Hardel.

Fauvel, A. 1873b. Faune gallo-rhénane ou descriptions des insectes qui habitent la France, la Belgique, la Hollande, le Luxembourg, les provinces Rhénanes et la Valais avec tableaux synoptiques et planches gravées. Bulletin de la Société Linnéenne de Normandie (2) 6: 8-136.

Fauvel, A. 1875a. Fauna gallo-rhénane ou species des insectes qui habitent la France, la Belgique, la Hollande, le Luxembourg, la Prusse rhénane, la Nassau et la Valais avec tableaux synoptiques et planches gravées. Catalogue systématique des staphylinides de la faune gallo-rhénane avec l'addition synonymique des espèces européennes, siberiénnes, caucasiques et mediterranéennes et descriptions nouvelles 3 (liv. 6): i-xxxviii. Caen: Le Blanc-Hardel.

Fauvel, A. 1875b. Faune gallo-rhénane ou species des insectes qui habitent la France, la Belgique, la Hollande, le Luxembourg, la Prusse rhénane, la Nassau et la Valais avec tableaux synoptiques et planches gravées. Catalogue systématique des staphylinides de la faune gallo-rhénane avec l'addition synonymique des espèces européennes, siberiénnes, caucasiques et mediterranéennes et descriptions nouvelles. Bulletin de la Société Linnéenne de Normandie (2) 9: 202-236.

Fauvel, A. 1878a. Les staphylinides de l'Afrique boréale. Bulletin de la Société Linnéenne de Normandie (3) 2: 83-162.

Fauvel, A. 1878b. Les staphylinides de l'Afrique boréale. Notices Entomologiques 6: 3-82.

Fauvel, A. 1886a. Les staphylinides du nord de l'Afrique. Revue d'Entomologie 5: 9-100.

Fauvel, A. 1886b. Les staphylinides du nord de l'Afrique. Notices Entomologiques 9: 1-92.

Fauvel, A. 1897. Catalogue des staphylinides de Barbarie et des îles Açores, Madères, Salvages et Canaries. 4th ed. Revue d'Entomologie 16: 237-371.
Fauvel, A. 1902. Catalogue des staphylinides de la Barbarie de la Basse-Egypte et des îles Açores, Madères, Salvages et Canaries. Revue d'Entomologie 21: 45-189.

Fernandez, L.A., N. Cabrera, M. Chani Posse, and C. Gabellone. 2007. Catalog of the types of Staphylinidae (Insecta, Coleoptera) deposited at Museo de La Plata (Argentina). Zootaxa 1611: 25-44.

Ferris, G.F. 1940a. The morphology of Plega signata (Hagen) (Neuroptera: Mantispidae). Microentomology 5 (2): 33-56.

Ferris, G.F. 1940b. The myths of the thoracic sternites of insects. Microentomology 5: 87-90.

Ferris, G.F., and B.E. Rees. 1939. The morphology of Panorpa nuptialis Gerstaecker (Mecoptera: Panorpidae). Microentomology 4 (3): 79-108.

Frisch, J., and L.H. Herman. 2008. Case 3439. Xantholinus gracilis Sperk, 1835 (Insecta, Coleoptera): proposed conservation of prevailing usage by the designation of a neotype. Bulletin of Zoological Nomenclature 65 (2): 106-109.

Gemminger, M., and E. Harold. 1868. Catalogus Coleopterorum hucusque descriptorum synonymicus et systematicus 2: 425-752 + 6. Monachii: E. H. Gummi.

Haack, H. (editor). 1925. Stielers Hand-Atlas, 254 Haupt- und Nebenkarten in Kupferstich. ... Gotha: Justus Perthes.

Hansen, D.C., and E.F. Cook. 1976. The systematics and morphology of the Nearctic species of Diamesa Meigen, 1835 (Diptera: Chironomidae). Memoirs of the American Entomological Society 30: i $+1-203$.

Hansen, M. 1997. Phylogeny and classification of the staphyliniform beetle families (Coleoptera). Biologiske Skrifter det Kongelige Danske Videnskabernes Selskab 48: 1-339.

Hayashi, Y. 1989. Two species of the genus Oedichirus (Coleoptera, Staphylinidae) from Japan and Taiwan. Kanagawa-Chûhô 90: 161-166.

Herman, L.H. 1970. The ecology, phylogeny, and taxonomy of Stilicolina (Coleoptera, Staphylinidae, Paederinae). American Museum Novitates 2412: 1-26.

Herman, L.H. 1972. Revision of Bledius and related genera. Part I. The Aequatorialis, Mandibularis and Semiferrugineus groups and two new genera (Coleoptera: Staphylinidae, Oxytelinae). Bulletin of the American Museum of Natural History 149 (2): 113-254.

Herman, L.H. 1986. Revision of Bledius. Part IV. Classification of species groups, phylogeny, natural history, and catalogue (Coleoptera, Staphylinidae, Oxytelinae). Bulletin of the American Museum of Natural History 184 (1): 1-368.

Herman, L.H. 2003. Revision of the Asian tribe Megarthropsini (Coleoptera: Staphylinidae: 
Tachyporinae). American Museum Novitates 3430: 1-72.

Herman, L.H. 2010. Generic revision of the Procirrina (Coleoptera: Staphylinidae: Paederinae: Pinophilini). Bulletin of the American Museum of Natural History 347: 1-78.

Horn, W., and I. Kahle. 1936. Über entomologische Sammlungen. Teil II: 161-296. BerlinDahlem.

ICZN (International Commission on Zoological Nomenclature). 1999. International code of zoological nomenclature. 4th ed. London: International Trust for Zoological Nomenclature, xxix + 306 pp.

Janák, J. 1995. Neue Arten und neue Funde der Gattung Oedichirus aus Madagaskar I. (Coleoptera, Staphylinidae, Paederinae, Pinophilini). Acta Coleopterologica 11 (3): 15-21.

Janák, J. 1996. Neue Arten und neue Funde der Gattung Oedichirus aus Madagascar II. (Staphylinidae, Paederinae, Pinophilini). Acta Coleopterologica 12 (3): 3-24.

Janák, J. 1998. Neue Arten und neue Funde der Gattung Oedichirus aus Madagascar III. (Coleoptera: Staphylinidae: Paederinae: Pinophilini). Klapalekiana 34: 45-60.

Janák, J. 2003. Neue Arten neue Funde der Gattung Oedichirus aus Madagaskar IV. (Coleoptera: Staphylinidae: Paederinae: Pinophilini). Klapalekiana 39: 229-255.

Jarrige, J. 1978. Contribution à l'étude des Coleoptera Brachelytra Staphylinidae du massif de l'Andringitra (Madagascar centre). Bulletin du Muséum National d'Histoire Naturelle (3) 514. Zoologie 353: 245-296.

Klaus, A.V., and V. Schawaroch. 2006. Novel methodology utilizing confocal laser scanning microscopy for systematic analysis in arthropods (Insecta). Integrative and Comparative Biology 46: 207-214.

Klaus, A.V., V.L. Kulasekera, and V. Schawaroch. 2003. Three-dimensional visualization of insect morphology using confocal laser scanning microscopy. Journal of Microscopy 212: 107-121.

Lamas, G. 1976. A gazetteer of Peruvian entomological stations (based on Lepidoptera). Revista Peruana de Entomologia 19 (1): 17-25.

Last, H.R. 1980. Records of New Guinea Staphylinidae (Coleoptera) in the Hungarian Natural History Museum. Annales Historico-Naturales Musei Nationalis Hungarici 72: 139-161.

Lawrence, J.F., et al. (2011). Phylogeny of the Coleoptera based on morphological characters of adults and larvae. Annales Zoologici (Warszawa) 61 (1): 1-217.

Lecoq, J.-C. 1986. Insectes coléoptères Staphylinidae Paederinae, I. Pinophilini. In Faune de
Madagascar 67: 1-183. Paris: Muséum National d'Histoire Naturelle.

Lecoq, J.-C. 1987. Nouveaux Oedichirus malgaches récoltés par le Professeur H. Franz. Bulletin de la Société Entomologique de France $92(1 / 2)$ : 33-38.

Lecoq, J.-C. 1990. Deux nouvelles espèces de Paederinae de Madagascar (Coleoptera, Staphylinidae). Nouvelle Revue d'Entomologie 7 (1): 75-80.

Lecoq, J.-C. 1991. Sur quelques Pinophilini de Madagascar: nouvelles espèces, nouvelles captures (Col. Staphylinidae Paederinae). Bulletin de la Société Entomologique de France 95 (1990): 229-236.

Lecoq, J.-C. 1996. Les Staphylinidae (Coleoptera) du Musée royal de l'Afrique centrale récoltés aux Comores par R. Jocqué. Journal of African Zoology 110 (2): 129-155.

Lucas, P.H. 1846. Histoire naturelle des animaux articulés. Deuxième partie. Insectes. In Exploration scientifique de l'Algérie. ... Sciences Physiques. Zoologie 2: 1-590. Paris: Gouvernement Nationale.

MacLeay, W. 1873. Notes on a collection of insects from Gayndah. Transactions of the Entomological Society of New South Wales 2: 79-205.

Matsuda, R. 1960. Morphology of the pleurosternal region of the pterothorax in insects. Annals of the Entomological Society of America 53: $712-731$.

Matsuda, R. 1963. Some evolutionary aspects of the insect thorax. Annual Review of Entomology 8: 59-76.

Matsuda, R. 1970. Morphology and evolution of the insect thorax. Memoirs of the Entomological Society of Canada 76: 1-431.

Michener, C.D. 1944. Comparative external morphology, phylogeny, and a classification of the bees (Hymenoptera). Bulletin of the American Museum of Natural History 82 (6): 151-326.

MoBot, Gazetteer of Costa Rican plant-collecting locales. Online resource (http://www.mobot.org/ mobot/research/costaricagaz.shtml), accessed December 6, 2012.

Naomi, S.-I. 1988. Comparative morphology of the Staphylinidae and the allied groups (Coleoptera, Staphylinoidea). VI. Mesothorax and metathorax. Kontyû 56 (4): 727-738.

Navarrete-Heredia, J.L., A.F. Newton, M.K. Thayer, J.S. Ashe, and D.S. Chandler. 2002. Guía ilustrada para los géneros de Staphylinidae (Coleoptera) de México. Guadalajara, Mexico: Universidad de Guadalajara y CONABIO, xii + $401 \mathrm{pp}$. 
Nevermann, F. 1931. Beitrag zur Kenntnis der Telephanus (Col. Cucujidae). Stettiner Entomologische Zeitung 92 (3): 161-187.

Normand, H. 1935. Contribution au catalogue des Coléoptères de Tunisie ( $4^{\mathrm{me}}$ fasc.). Bulletin de la Société d'Histoire Naturelle de l'Afrique du Nord 25 (9): 356-390.

Oke, C. 1933. Australian Staphylinidae. Proceedings of the Royal Society of Victoria 45: 101-136.

Oliveira, M.L. 2006. Três novas espécies de abelhas da Amazônia pertencentes ao gênero Eulaema (Hymenoptera: Apidae: Euglossini). Acta Amazonica 36: 121-127.

Outerelo, R., and P. Gamarra. 1988. Oedichirus pardoi n. sp. del norte de Africa (Coleoptera, Paederidae, Pinophilinae). Elytron 2: 69-74.

Outerelo, R., and P. Gamarra. 1989. Descripción del edeago de la especie Oedichirus unicolor Aubé, 1843, de sus caracteres sexuales secundarios y los de Oedichirus paederinus Erichson, 1839-40 (Coleoptera, Staphylinidae, Paederinae). Boletín de la Real Sociedad Española de Historia Natural (Sección Biológica) 84: 371-379.

Paynter, R.A. 1993. Ornithological gazetteer of Ecuador, xi + 247 pp. Cambridge, MA: Harvard University.

Paynter, R.A., and M.A. Traylor. 1991. Ornithological gazetteer of Brazil, iii-vii +788 pp. Cambridge, MA: Harvard University, [published in 2 volumes, pagination continuous]

Porta, A. 1926. Fauna coleopterorum italica. II. Staphylinoidea. Piacenza, Italy: Stalilimento Tipografico Piacentino, 405 pp.

Ragusa, E. 1891. Catalogo ragionato dei coleotteri di Sicilia. Il Naturalista Siciliano 10 (11): 213-231; 10 (12): 237-255.

Redtenbacher, L. 1857. Fauna austriaca. Die Käfer. ed. 2: 129-976. Wien: C. Gerold's Sohn.

Redtenbacher, L. 1874. Fauna Austriaca. Die Käfer. ed. 3: Vol. 1: cliii + 564 pp. Wien: C. Gerold's Sohn.

Rees, B.E., and G.F. Ferris. 1939. The morphology of Tipula reesi Alexander (Diptera: Tipulidae). Microentomology 4 (6): 143-178.

Reitter, E. 1906. Übersicht der mir bekannten, palaearktischen Arten der Coleopteren-Gattung Oedichirus Er. Wiener Entomologische Zeitung 25: 263-264.

Rottenberg, A.v. 1870. Beiträge zur ColeopterenFauna von Sicilien. Berliner Entomologische Zeitschrift 14: 11-40.

Saether, O.A. 1980. Glossary of chironomid morphology terminology (Diptera: Chironomidae). Entomologica Scandinavica Supplement 14: 1-51.
Sahlberg, R.F. 1844. Coleoptera diebus XVXXVII Decembris anni MDCCCXXXIX ad Rio Janeiro lecta. Acta Societatis Scientiarum Fennicae 2 (1): 499-522.

Sahlberg, R.F. 1847. Coleoptera diebus XVXXVII Decembris anni MDCCCXXXIX ad Rio Janeiro lecta. Acta Societatis Scientiarum Fennicae 2 (2): 787-805.

Schaufuss, L.W. 1888. Ein neuer Oedichirus. Entomologische Nachrichten 14 (20): 314-316.

Schawaroch, V., D. Grimaldi, and A.V. Klaus. 2005. Focusing on morphology: applications and implications of confocal laser scanning microscopy (Diptera: Campichoetidae, Camillidae, Drosophilidae). Proceedings of the Entomological Society of Washington 107 (2): 323-335.

Scheerpeltz, O. 1933. Staphylinidae VII. In S. Schenkling (editor), Coleopterorum catalogus 6 (129): 989-1500. Berlin: Junk.

Sharp, D.S. 1876. Contribution to an insect fauna of the Amazon Valley. Coleoptera-Staphylinidae. Transactions of the Entomological Society of London 1876: 27-424.

Silfverberg, H. 1988. List of the insects types in the Zoological Museum, University of Helsinki. 8. Coleoptera: Staphylinidae. Acta Entomologica Fennica 52: 15-40.

Smetana, A. 2004. Staphylinidae (in New nomenclatural and taxonomic acts, and comments), Omaliinae, Proteininae, Micropeplinae, Dasycerinae, Phloeocharinae, Olisthaerinae, Tachyporinae, Trichophyinae, Habrocerinae, Aleocharinae, Trigonurinae, Apaticinae, Piestinae, Osoriinae, Oxytelinae, Oxyporinae, Megalopsiinae, Steninae, Euaesthetinae, Leptotyphlinae, Pseudopsinae, Paederinae, Staphylininae. In I. Löbl and A. Smetana (editors), Catalog of Palaearctic Coleoptera 2: 29-35; 237-272; 329 495; 504-698. Stenstrup, Denmark: Apollo Books, 942 pp.

Snodgrass, R.E. 1935. Principles of insect morphology. New York: McGraw-Hill, ix + 667 pp.

Sparacio, I. 1995. Coleotteri di Sicilia. [Palermo, Italy]: L'Epos Società Editrice, 238 pp.

Thayer, M.K. 2005. Chapter 11.7. Staphylinidae Latreille, 1802. In R. Beutel, and R.A.B. Leschen (volume editors). 2005. Coleoptera, Beetles, vol. 1: morphology and systematics (Archostemata, Adephaga, Myxophaga, Polyphaga partim), 296-344, In N.P. Kristensen and R. Beutel (editors), Handbook of zoology. A natural history of the phyla of the animal kingdom. Vol. 4 (Part 38): Arthropoda: Insecta. New York: Walter de Gruyter, Inc.

Times Books. 1999. The Times atlas of the world. 10th ed. New York: Crown Publishers, $67+\mathrm{v}+$ 220 pp, 124 pls. 
Tuxen, S.L. (editor). 1956. Taxonomist's glossary of genitalia in insects. Copenhagen: Ejnar Munksgaard.

Weber, H. 1928. Die Gliederung der Sternopleuralregion des Lepidopterenthorax. Eine vergleichend morphologische Studie zur Subcoxaltheorie. Zeitschrift für Wissenschaftliche Zoologie 131: 181-254.
Wendeler, H. 1930. Neue exotische Staphyliniden. Neue Beiträge zur systematischen Insektenkunde 4: 181-192.

Wollaston, T.V. 1867. Coleoptera Hesperidum, being an enumeration of the coleopterous insects of the Cape Verde Archipelago. London: John van Voorst, xxxix + 285 pp.

\section{ERRATUM}

\section{Matrix for the Phylogeny of the Procirrina}

(see Herman, 2010)

The matrix for the Procirrina was inadvertently omitted by the printer from my "Generic Revision of the Procirrina...." The omission was overlooked by me and the editor of the Museum's scientific publications and is herewith presented.

\section{CHARACTER/TAXON MATRIX} for the Procirrina

\begin{tabular}{|c|c|c|c|c|}
\hline & $\begin{array}{l}0000000000 \\
0123456789\end{array}$ & $\begin{array}{l}1111111111 \\
0123456789\end{array}$ & $\begin{array}{l}2222222222 \\
0123456789\end{array}$ & $\begin{array}{l}3333333 \\
0123456\end{array}$ \\
\hline Pseudopsis & 0100000000 & 2000000000 & 0000010000 & 0000000 \\
\hline Ochthephilus & 1001001001 & 0000000010 & 0000001000 & 0000100 \\
\hline Pinophilus & 1100003111 & 1011111012 & 0011001000 & $01000 ? 1$ \\
\hline Procirrus & 1210002112 & 0211111021 & 2011022201 & 0101100 \\
\hline Neoprocirrus & 1300012112 & 0211111020 & 2011022201 & 0101100 \\
\hline Oedodactylus & 1100003113 & 1111111021 & 1011012201 & 0101110 \\
\hline Palaminus & 1100003111 & 2011111120 & 2111122211 & 2110100 \\
\hline Paraprocirrus & 1200012011 & 0211111021 & $20110222 ? 1$ & 0101100 \\
\hline Oedichirus & 1100103112 & 0211111020 & 2111022211 & 1101100 \\
\hline Pseudoprocirrus & 1100003113 & 0211111021 & 1011012201 & 0101000 \\
\hline Stylokyrtus & 1100003113 & $0 ? 11111020$ & $2 ? 110222 ? 1$ & $01 ? 11 ? 0$ \\
\hline
\end{tabular}

